\title{
HIDING IN
}

\section{PLAIN SIGHT}

DESIGNING MEDICAL DEVICES FOR ADOLESCENTS WITH TYPE 1 DIABETES TO MATCH THEIR PREFERENCES FOR CONSPICUITY. 
Hiding in plain sight:

Designing medical devices for

adolescents with type 1 diabetes to match

their preferences for conspicuity

90 point thesis submitted to Victoria

University of Wellington in fulfilment

of the requirements for the degree of

Master of Design Innovation

Madeleine Hazelton

2019 


\section{ABSTRACT}

Adolescents with type 1 diabetes use medical devices that attract attention in public settings. While adolescents have varying experiences with this attention, current medical devices do not allow them control over the conspicuousness of self-management. Accordingly, this research used a participatory design methodology to investigate adolescents' self-management experiences and preferences regarding conspicuity, and to develop semantic strategies to inform the design of medical devices.

Adolescent participants had varied experiences using their medical devices to manage type 1 diabetes in public. Some adolescents were comfortable managing their diabetes in public and disclosing their condition to new people. However, other adolescents preferred to manage their type 1 diabetes in private and feel embarrassed disclosing their diabetes.

Four semantic strategies were used to design devices that could appeal to the different preferences of adolescents: to enhance traditional medical devices to make them more beautiful, to personalise the medical device for the user, to disguise the medical device as a non-medical item, and to conceal the medical device from the public. Adolescents displayed different preferences towards these strategies and associated design concepts.

As adolescents have a range of experiences and preferences, but little control over the conspicuousness of their medical devices, the study found that these medical devices could be better designed to facilitate adolescents' agency through catering to their nuanced and differing preferences for conspicuity. 


\section{ACKNOWLEDGEMENTS}

I would like to thank my supervisors. Gillian, thank you for the guidance and advice at our many coffee meetings. I appreciate your constant reassurance and support. Edgar, thank you for your confidence in me.

Thank you to the Smart Interactions group for providing me with a great group of designers to ask for help and advice.

Thank you to all the staff and administrators at the school of design and to my proof reader Jean McDowall. I would like to thank MedTech CoRE for assisting me with a scholarship

I would like to thank and acknowledge all the participants who gave their time to take part in this research; I greatly appreciate your desire to share your knowledge and experiences of type 1 diabetes. Thank you to the volunteers and nurses at the camp, your insights have been invaluable.

To the MDI cohort, thank you for the ping-pong balls, pegs and nerf guns. There is not a better group of people to have gone through the last year with. Thank you Will, Max, Christy, Rose, Jess and Steve you kept me sane throughout the year,

Finally, to my family, thank you for the endless love and support. I could not have done it without you, and I hope this makes you proud. 


\section{MOTIVATION}

During my undergraduate study, the area of design I was most interested in was interaction design, and specifically designing with people. Type 1 diabetes in adolescents is frequently written about from a medical perspective. I want to use my knowledge of design to empower adolescents with type 1 diabetes. This project is a continuation of my supervisor Gillian McCarthy's research.

I cannot cure this disease, but through this research I can hopefully start a conversation about designing either a more conspicuous or inconspicuous device to help young people cope with their diabetes. 


\section{CONTENTS}

LIST OF FIGURES

LIST OF TABLES 12

$\begin{array}{ll}\text { INTRODUCTION } & 14\end{array}$

$\begin{array}{ll}1.1 \text { Research portfolio overview } & 17\end{array}$

BACKGROUND RESEARCH 19

2.1 Managing life and type 1 diabetes $\quad 20$

2.2 Conspicuity of medical devices 23

2.3 Semantics 25

2.5 Summary 36

METHODOLOGY $\quad 39$

3.1 Aims and objectives $\quad 40$

3.2 Research paradigm $\quad 42$

3.3 Ethics and recruitment 44

3.4 Data collection methods $\quad 47$

3.6 Project timeline $\quad 48$

3.5 Data analysis methods $\quad 48$

THEMATIC ANALYSIS OF

ADOLESCENT INTERVIEWS 51

4.1 Methods $\quad 52$

4.2 Participants $\quad 52$

4.3 Procedure $\quad 53$

4.4 Findings $\quad 53$

4.5 Summary 61

COLLAGING AND SKETCHING

WITH INDIVIDUAL PARTICIPANTS 63

5.1 Methods 64

5.2 Findings 65

$\begin{array}{ll}5.3 \text { Summary } & 75\end{array}$

CREATIVE METHODS WITH FOCUS GROUP 77

$\begin{array}{ll}6.1 \text { Methods } & 78\end{array}$

6.2 Findings $\quad 82$

6.3 Summary $\quad 86$ 
DESIGN EXPLORATION

7.1 Methods 90

7.2 Findings $\quad 91$

USER FEEDBACK 117

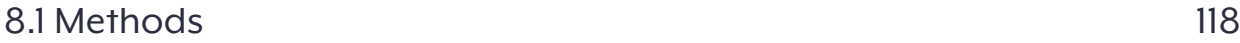

8.2 Participants $\quad 118$

$\begin{array}{ll}8.3 \text { Procedure } & 119\end{array}$

$\begin{array}{ll}8.4 \text { Findings } & 120\end{array}$

DISCUSSION 127

9.1 Findings in relation to previous literature $\quad 128$

9.2 Strengths and limitations 131

9.3 Future research 133

9.4 Implications and applications 133

CONCLUSION 134

REFERENCES $\quad 136$ 


\section{LIST OF FIGURES}

Figure 1. Examples of a blood glucose meter, insulin pen and syringe available for adolescents in New

Zealand

Figure 2. Blood glucose meter in use.

Figure 3. Adolescent using an insulin pump

Figure 4. Adolescent using an insulin pen

Figure 5. Medical devices and tools

Figure 6. Diagram showing the conspicuity relationship between a consumer and medical product.

Figure 7. Epipi Epipen. Reprinted from Epipi , H. Moorman. Retrieved from https://www.behance.net/ gallery/54936019/Epipi. Copyright [2017] Harry Moorman. Reprinted with permission.

Figure 8. Hue inhaler colour options. Reprinted from Hue Inhaler, T. Zarki, 2017. Retrieved from https://www. zarki.net/work/huin Copyright [2018] Tim Zarki. Reprinted with permission

Figure 9. Close up of hue inhaler. Reprinted from Hue Inhaler, T. Zarki, 2017. Retrieved from https://www. zarki.net/work/huin Copyright [2018] Tim Zarki. Reprinted with permission

Figure 10. Type 1 diabetes medical device CareSensN with a personalised sticker.

Figure 11. Blood glucose monitoring jewellery. Reprinted from "Design Experiments. Identifying areas for intervention and designing medical technology for adolescents and young adults with type 1 diabetes," by G. McCarthy, 2017, The Design Journal, 20(1), p. S2051. Copyright [2017] by Gillian McCarthy. Reprinted with permission.

Figure 13. Charging station for Dab ECG sensor. Reprinted from Behance, by A. Miklosi, 2018, Retrieved from https://www.behance.net/gallery/64353807/Dab-ECG-sensor?tracking_source=search-all\%7CDab

Figure 12. Dab ECG sensor. Reprinted from Behance, by A. Miklosi, 2018. Retrieved from https://www. behance.net/gallery/64353807/Dab-ECG-sensor?tracking_source=search-all\%7CDab. Reprinted with permission.

Figure 14. Blood glucose temporary tattoo sensor. Reprinted from Flickr, by J. Wang, 2015. Retrieved from https://www.flickr.com/photos/jsoe/16054780789/in/album-72157649793949249/jsoe/16054780789/in/ album-72157649793949249/. 
Figure 20. Epilepsy sensor. Reprinted from Artefact Group, Designing a wearable for chronic conditions, 2014. 68 Retrieved from https://www.artefactgroup.com/case-studies/dialog/. Copyright [2014] by the Artefact Group. Reprinted with permission

Figure 21. Epipi interaction. Reprinted from Epipi, H. Moorman. Retrieved https://www.behance.net/ gallery/54936019/Epipi. Copyright [2017] Harry Moorman. Reprinted with permission.

Figure 22. Pink and purple hue inhaler. Reprinted from Hue Inhaler, T. Zarki, 2017. Retrieved from https:// www.zarki.net/work/huin Copyright [2018] Tim Zarki. Reprinted with permission

Figure 23. Biomimicry pin. Reprinted from Yanko Design, by T. Fukaya, 2012, Retrieved from https://www. yankodesign.com/2012/03/28/biomimicry-pin/. Copyright [2012] Toshi Fukaya. Reprinted with permission.

Figure 24. Participant 1 sketch of an all-in-one insulin pump and flash blood glucose meter dorcarmon.com/\#/tweet/. Copyright [2018] by Dor Carmon. Reprinted with permission. 


\section{LIST OF TABLES}

Table 1. Research portfolio overview

Table 2. Strategies that applied to the design of a tangible object grouped into relevant themes.

Table 3. Research aims, objectives and methods

Table 4. Participants involved in the participatory methods of the research.

Table 5. Participants involved in the individual session and female group discussion. 
(2) 


\section{INTRODUCTION}

Type 1 diabetes is an invisible chronic autoimmune disease. The immune system attacks and destroys insulin-producing cells within the pancreas (Atkinson, Eisenbarth, \& Michels, 2014; Thrower \& BiWngley, 2014). This results in the production of no or too little insulin, a hormone that unlocks the glucose from carbohydrates in the food we eat to be used as energy or to store for future use (Oberleitner \& Malzone, 2018). Although type 1 diabetes can be diagnosed at any age, it is most frequently diagnosed in children between 5 and 7 years old and diagnosis rates peak again at 14 years old (Atkinson et al., 2014). This research focuses on adolescents aged 13 to 18 years old.

Adolescence is a developmental and transitional time when youths experience hormonal changes, pubertal physiology, family dynamics, perceived social pressures, increased risk-taking, and reduced ability to consider long-term effects (Borus \& Laffel, 2010; Chaney, 2012). These factors can result in poorer management of type 1 diabetes in adolescents (Borus \& Laffel, 2010; Cameron, 2006; KyngÄs, Kroll, \& Duffy, 2000). Accordingly, approximately $50 \%$ of adolescents with long-term health conditions do not manage them effectively (Feldman \& Elliott, 1990; KyngÄs et al., 2000).
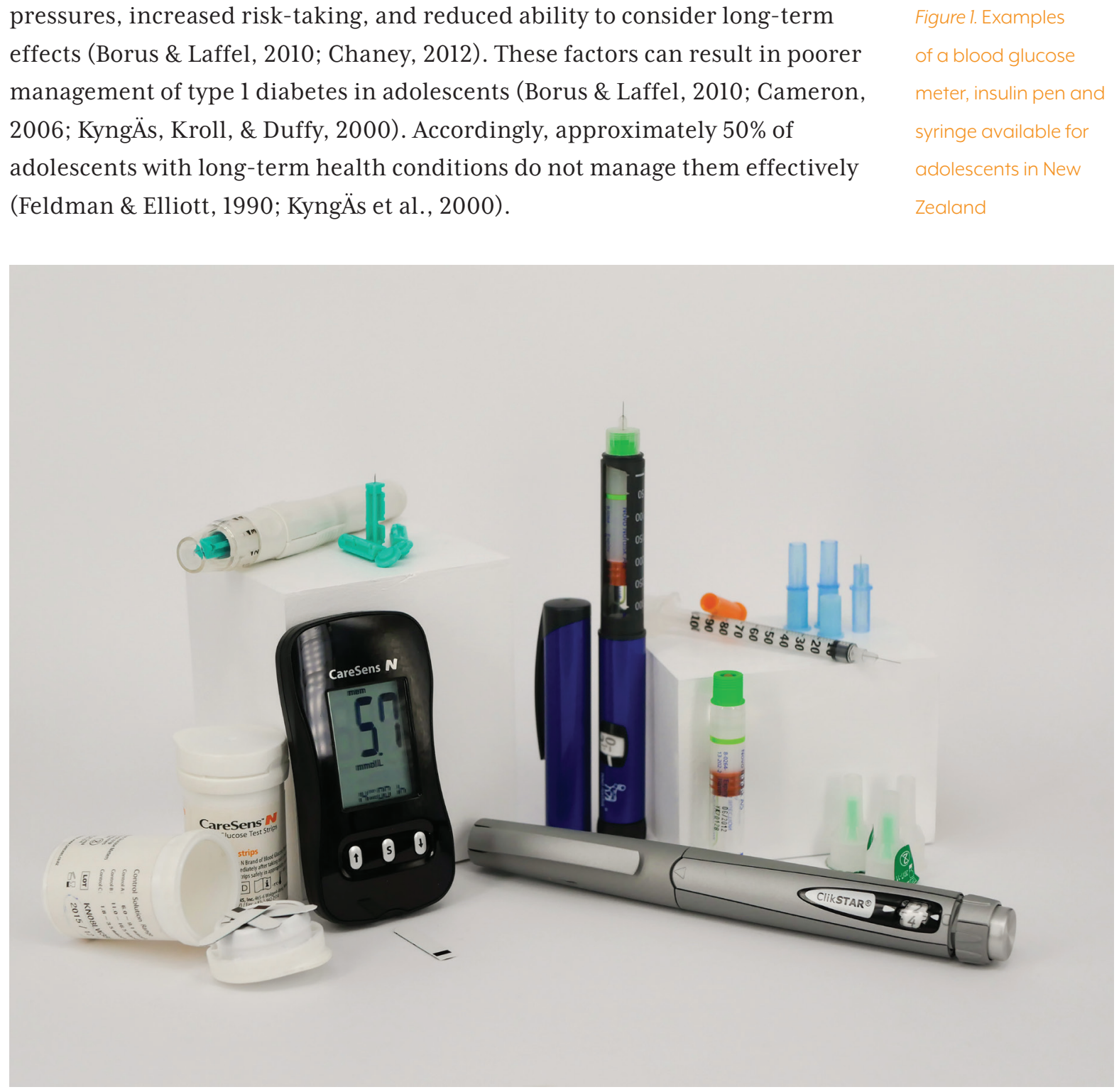


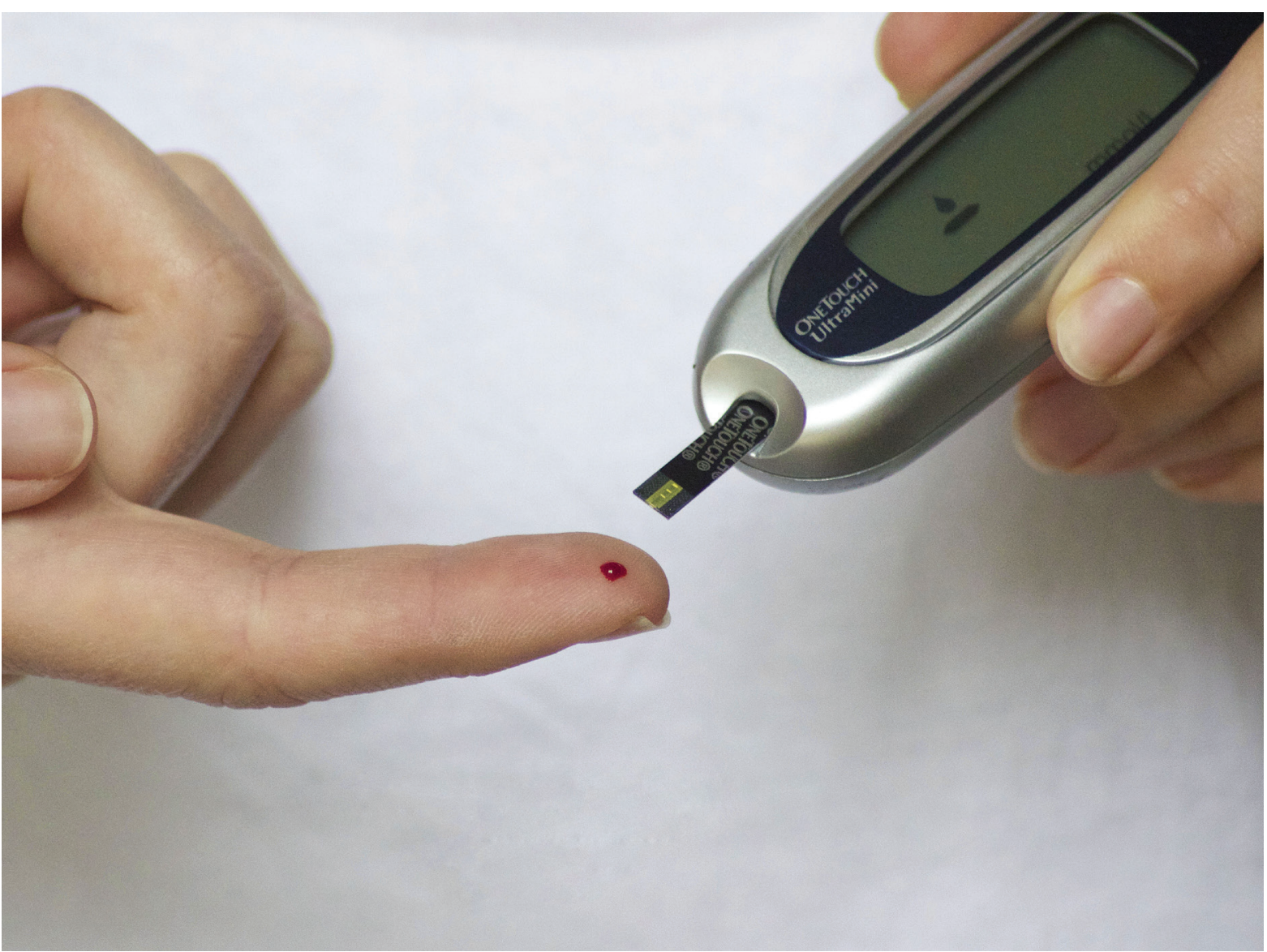

Effective management of type 1 diabetes is demanding (Babler \& Strickland, 2015; Chao et al., 2016). Adolescents are required to test blood glucose levels regularly, monitor their diet, factor in daily exercise and then calculate the required amount of insulin to lower their blood glucose levels (Main et al., 2015; Oberleitner \& Malzone, 2018). Adolescents are also required to treat the events of hypoglycaemia (low blood glucose) and hyperglycaemia (high blood glucose) (Oberleitner \& Malzone, 2018). Intensive self-management is necessary to prevent or delay complications such as seizures, nephropathy, diabetic ketoacidosis, neuropathy, and retinopathy (Oberleitner \& Malzone, 2018). While some symptoms of diabetes may be felt acutely, other complications may present years later, obscuring the relationship between current selfmanagement behaviours and medical outcomes. Therefore, it can be difficult for some adolescents to self-manage to the recommended standards every day, although by maintaining regular blood glucose levels adolescents can live a healthy and active life.

Adolescents use several medical devices (Figure 1) to enable them to live a healthy life, such as a blood glucose meter or a continuous glucose monitor (CGM). A blood glucose meter requires the adolescent to prick their finger and to apply a drop of blood onto a test strip (Figure 2). The test strip is inserted into a blood glucose meter, and a blood glucose reading is displayed on the 
screen. Alternatively, CGMs are constantly attached invasively to the body, and periodically measure glucose from interstitial fluids. Several devices can administer insulin, such as an insulin pen, syringe, or pump (Figure 1). Insulin pens and syringes allow insulin to be injected, whereas insulin pumps periodically drip feed small amounts of insulin into the body through a cannula.

Diabetes self-management is intensive, complex, and visible, contributing to feelings of stress and social awkwardness in some adolescents (Chao et al., 2016). Successful management of type 1 diabetes for adolescents includes regulating not only themselves, but also their social relationships (Wiebe, Berg, Mello, \& Kelly, 2018). Social regulation includes both how perceived social pressures affect the individual's emotions, thoughts, and behaviours towards diabetes management, and how adolescents regulate the involvement of friends, family, clinicians, and others to help manage type 1 diabetes (Wiebe et al., 2018). Regulation may involve disclosing their condition to friends, seeking out helpful involvement, and preventing unhelpful involvement from others.

Some adolescents feel embarrassed managing their type 1 diabetes in public spaces, and try to avoid unwanted attention by withdrawing themselves, avoiding activities, or not adhering to the management of their diabetes (Brazeau et al., 2016). This can have a severe impact on the health of adolescents who feel embarrassed by their medical devices. One aspect of being able to test and maintain regular blood glucose levels is having the ability to test in public spaces. This inspired the research question:

How might semantic strategies be used to inform the design of medical devices for adolescents with type 1 diabetes that match users' preferences for conspicuousness? 


\subsection{RESEARCH PORTFOLIO OVERVIEW}

Table 1 shows the research portfolio overview for each chapter.

Table 1. Research portfolio overview

\begin{tabular}{|c|c|c|}
\hline Chapter & Section & Description \\
\hline 2 & Background research & $\begin{array}{l}\text { This section provides an overview of recent literature about managing } \\
\text { type } 1 \text { diabetes and social interactions, conspicuity, and semantics. } \\
\text { It also describes the development of five semantic strategies and } \\
\text { explores design precedents to highlight the possibilities of the } \\
\text { strategies within the context of the research. }\end{array}$ \\
\hline 3 & Methodology & $\begin{array}{l}\text { Aims and objectives are outlined in this chapter, as well as the } \\
\text { participatory design methodology and methods used to answer the } \\
\text { research question. }\end{array}$ \\
\hline 4 & $\begin{array}{l}\text { Thematic analysis of } \\
\text { interviews }\end{array}$ & $\begin{array}{l}\text { Adolescent experiences and preferences, discovered through semi- } \\
\text { structured interviews, are analysed through thematic analysis. }\end{array}$ \\
\hline 5 & $\begin{array}{l}\text { Collaging and Sketching } \\
\text { with Individual } \\
\text { Participants }\end{array}$ & $\begin{array}{l}\text { This section describes collages and sketches completed with } \\
\text { individual participants. }\end{array}$ \\
\hline 6 & $\begin{array}{l}\text { Creative methods with } \\
\text { focus group participants }\end{array}$ & $\begin{array}{l}\text { This section describes post-it-note vignettes and sketches completed } \\
\text { with focus group participants. }\end{array}$ \\
\hline 7 & Design exploration & $\begin{array}{l}\text { Based on the creative methods and interviews, four designs were } \\
\text { explored in this section. }\end{array}$ \\
\hline 8 & User feedback & $\begin{array}{l}\text { This section describes the final user feedback session completed with } \\
\text { the individual participants. }\end{array}$ \\
\hline 9 & Discussion & $\begin{array}{l}\text { This section discusses findings in relation to previous research and } \\
\text { explores avenues for future research. }\end{array}$ \\
\hline
\end{tabular}




\section{BACKGROUND RESEARCH}

The purpose of the background research was to understand the existing research into adolescents with type 1 diabetes and the development of medical devices based on their preferences. Firstly, previous qualitative research conducted with adolescents is examined and compared to understand their experiences managing, integrating, and disclosing their type 1 diabetes. Secondly, the current conspicuity of medical devices and the opinions adolescents have towards their medical devices is evaluated. Finally, the term 'semantics' is defined as a way to explore new opportunities to design medical devices for adolescents with type 1 diabetes. 


\subsection{MANAGING LIFE AND TYPE 1 DIABETES}

Adolescents with type 1 diabetes are already navigating a challenging time in their life, but have the added stress of managing a chronic disease; this can be described as a "life with layers" (Rechenberg, Grey, \& Sadler, 2018, p. 547). Adolescents must overcome the typical stressors, but their lives are complicated by an additional 'layer' of managing diabetes. Adolescents have differing ways of integrating medical and rest-of-life activities, and varying opinions regarding disclosure, managing symptoms in public, and medical devicerelated attention (Commissariat, Kenowitz, Trast, Heptulla, \& Gonzalez, 2016; McCarthy, 2018; Rechenberg et al., 2018; Shinohara \& Wobbrock, 2011).

\subsubsection{Integrating type 1 diabetes management into daily life}

Adolescents who have integrated managing type 1 diabetes into their daily life are often more comfortable disclosing their condition to others, managing their symptoms in public spaces, and dealing with medical device-related attention (Figure 3)(Commissariat et al., 2016; Rechenberg et al., 2018). Rechenberg et al. (2018), found that these adolescents did not hide from their peers for fear of judgement "it's not something I put upon myself. It's something that happened, you know ... to me it's normal and I'm ok with being open about it to other

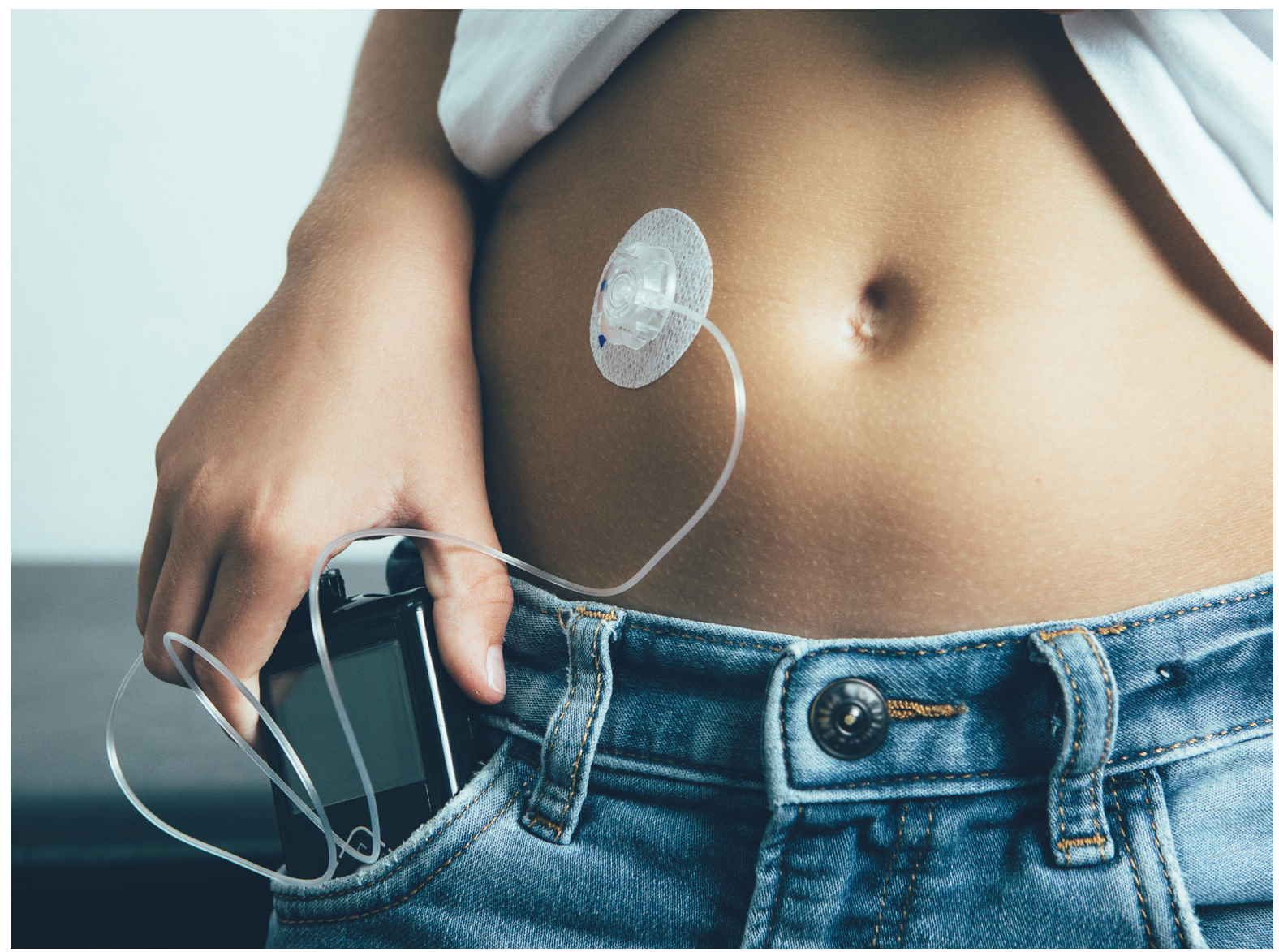


people." (p. 548). Some adolescents who have integrated their management enjoy the opportunity to educate others about type 1 diabetes (Shinohara \& Wobbrock, 2011). Adolescents who have integrated their management often find it easier to cope with the extra layers of their life.

Conversely, adolescents who have not yet integrated management into their daily life often find it difficult disclosing diabetes to their friends, managing type 1 diabetes in public, and dealing with medical device-related attention (Commissariat et al., 2016; Rechenberg et al., 2018). They often do not want others to know about their condition, for fear their peers will treat them as "sick" (Rechenberg et al., 2018, p. 548). Some adolescents will avoid managing their diabetes in public spaces, "when I'm in a very crowded place, I make sure that I'll go somewhere like a bathroom and go into a small stall and do it myself, but if not, I will just ignore it for a few minutes." (Rechenberg et al., 2018 , p. 548). These behaviours separating diabetes management from restof-life activities can stem from social discomfort; they can also be a strategy for adolescents to concentrate on challenging self-management tasks and to prevent diabetes from becoming an all-encompassing aspect of their identity

I have to go the bathroom first, sort it all out, push all my buttons then come and sit down and have lunch... I find it more comfortable ... it is sometimes good to keep separate decision-making time versus just living your life time, so that it doesn't become all consuming. (McCarthy, 2018, p. 207).

Accordingly, adolescents have varying strategies for integrating diabetes management into their lives. These differences are also evident in the way they disclose their type 1 diabetes.

\subsubsection{Disclosing diabetes}

One of the decisions adolescents are met with when meeting new people is the choice to disclose their diabetes. Some adolescents feel apprehensive when disclosing their condition for fear of being judged. "I find it hard to express to people that I have diabetes, and I try to keep hidden, so that most people don't find out, because I feel like they will judge me." (Rechenberg et al., 2018, p. 547). However, other researchers (Commissariat et al., 2016; McCarthy, 2018) have found that some adolescents will openly disclose their diabetes to new acquaintances, explaining medical equipment and self-management behaviours the acquaintance might encounter them undertaking.

If I've never met a person, [who] doesn't know I have diabetes then I lift up my shirt, and they see the catheter for the first time and they don't know what it is. . . they freak out. They think it's something crazy. I just go through and explain it to them. (Commissariat et al., 2016, p. 676) 
Commissariat et al. (2016) found that adolescents who had disclosed their diabetes to their friends were happy they had made the decision to tell them. Their friends would often encourage their treatment by reminding them to check their blood glucose levels or administer insulin.

\subsubsection{Managing diabetes in public}

For adolescents who are comfortable using medical devices in public spaces, not testing could make them feel they are hiding a part of themselves, "I do it in restaurants cafés, clubs wherever I need to eat . . . If I start hiding it, I hide myself and I would feel ashamed and that's not who I am.” (McCarthy, 2018, p. 160).

On the other hand, McCarthy(2018) also found that some adolescents can feel embarrassed testing and managing in public, "It's kind of embarrassing having to inject myself in front of other people. Injecting yourself is gross for some people and that's weird.” (p. 206)(Figure 4). In addition, Rechenberg et al. (2018) found the most common source of diabetes-related anxiety was treating diabetes in public. This feeling is most common when managing in front of untrusted peers, or acquaintances that adolescents have not disclosed their diabetes to (McCarthy, 2018; Rechenberg et al., 2018).

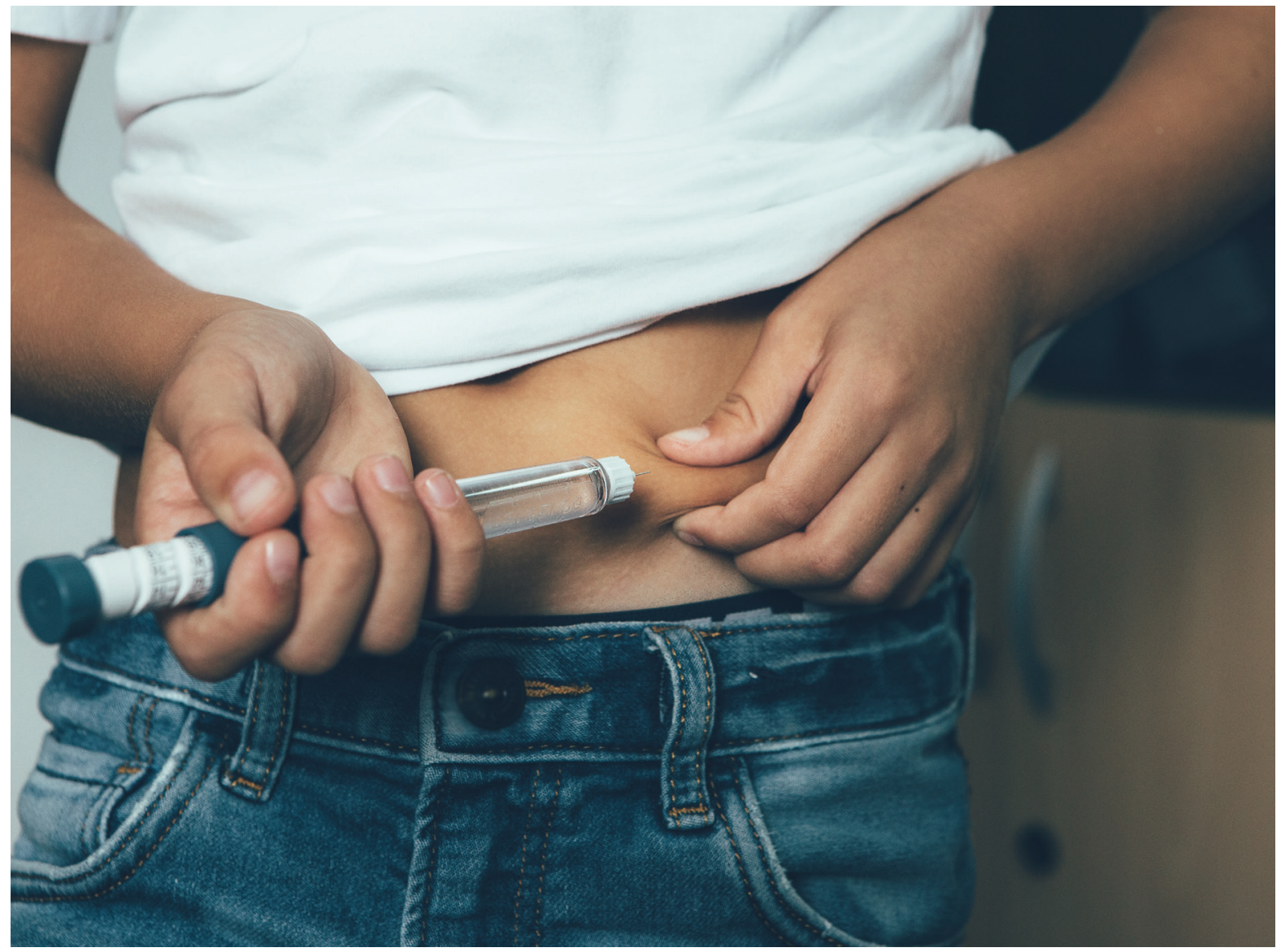




\subsection{CONSPICUITY OF MEDICAL DEVICES}

\subsubsection{Stigma and type 1 diabetes}

Researchers often refer to the negative attention that adolescents with type 1 diabetes receive in public spaces as stigmatising (Brazeau et al., 2018, 2016; Schabert, Browne, Mosely, \& Speight, 2013). Stigma is the social response people receive if they have a different or discreditable attribute. Goffman (1963) describes two types of stigmatised people: the discredited and the discreditable. Adolescents with type 1 diabetes are classified as discreditable, as their medical condition is largely invisible; however, stigma can occur when medical devices or symptoms are visible. Medical devices can cause stigma rather than help a person feel better and do so in a way that forces the disclosure of an illness, (Schabert et al., 2013). However, not all adolescents feel stigmatised by their devices, and some see their devices as an empowerment tool (McCarthy, 2018).

\subsubsection{Medical device-related attention}

Adolescents can experience a range of medical device-related attention. Some of it can be negative, for instance, adolescents feeling uncomfortable using syringes to administer insulin as they are reminiscent of illicit drug paraphernalia, which can cause negative connotations for onlookers (McCarthy, 2018). Rechenberg et al.(2018, p. 549), found that one participant disliked the sounds their devices made, "I don't need, like, something beeping during the day, like, drawing all attention to me." Some adolescents were wary of medical devices such as insulin pumps, which are unable to be hidden away as they are constantly attached to the body.

I didn't want the pump for three or four years because it was quite visible, quite intrusive and it's, always connected to you. It makes you feel less normal. . I I keep my pump in my bra so you can't see it... I met this old lady last week and she always wears it on her hip so everyone can see the cords and everything. I don't know if I'd ever have the confidence to do that. I'm not sure whether it's just my personality. I guess the initial feelings I had haven't left. (McCarthy, 2018, pp. 161-162)

Adolescents have different perspectives about which device they prefer to use, and also which device creates attention. Furthermore, these perspectives can shift over time.

I've got a robotic pancreas and that's friggen awesome... In Year 8 I would be like, 'I can't wear this because it shows my site', but now it's like, 'So what?'. I suppose it draws more attention; if you walk down the corridor people are going to go, 'She's got something on her stomach,' but then at the moment it's like, 'Yeah look at me, damn right I look good'. (McCarthy, 2018, pp. 207-208) 
As the experiences and preferences of adolescents with type 1 diabetes vary regarding the attention they receive in public, terms other than stigma could be more appropriate to describe medical-device related attention. The term I am using for this research is conspicuity. Conspicuity refers to how well an object visually stands out from its environment. Hence, conspicuity describes a relationship; the scale of which the object is visually embedded in its surrounding scene (Wertheim, 2010). For example, an insulin pen looks more conspicuous when an adolescent is using the device at school compared to when using that device in a hospital setting. The environment the object is in can determine how conspicuous or inconspicuous the object is.

Adolescents have different requirements; some require devices that are inconspicuous and discrete in design so that they do not draw attention to themselves. Others require devices that are conspicuous and more beautiful in design to facilitate positive conversation. Occasionally a conspicuous device is better in an emergency as it is more recognisable than an inconspicuous device.

\subsubsection{Conspicuity of current medical devices}

Current devices have minimal variation in the conspicuity of the design. As pictured in Figure 5, the current devices appear typically medical and dated.
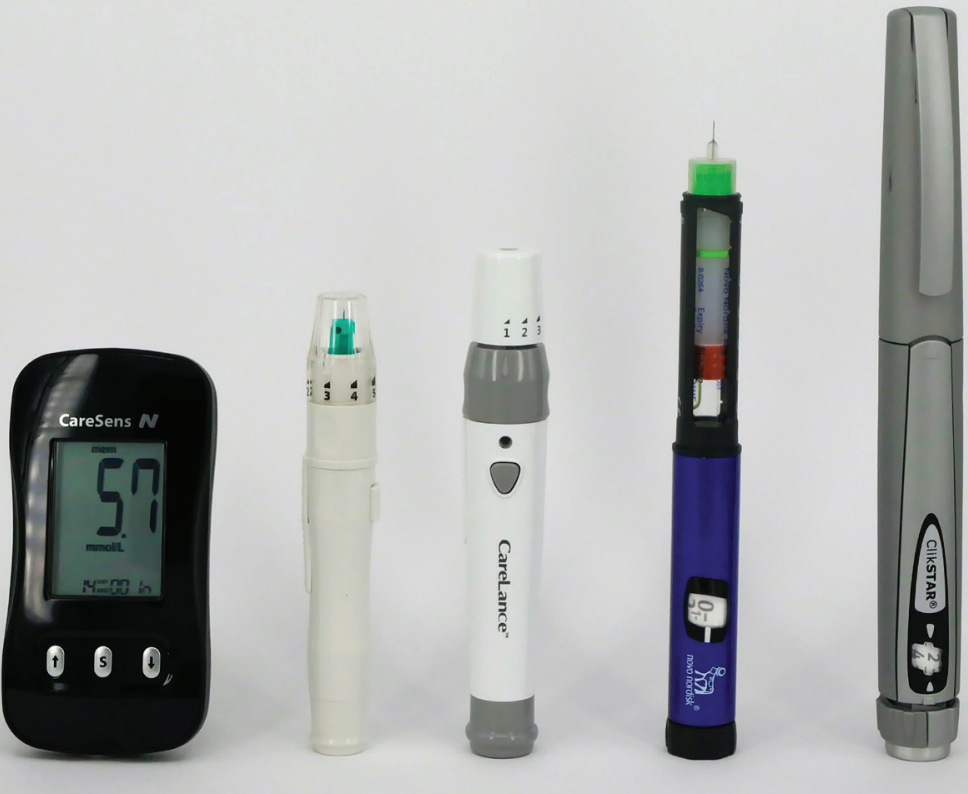


\subsection{SEMANTICS}

To better understand the dynamics of conspicuity, product semantics can be considered. Product semantics have been defined as:

The study of the symbolic qualities of man-made forms in the context of their use and the application of this knowledge to industrial design. It considers not only the physical and physiological functions but the psychological, social and cultural context, which we call the symbolic environment. (Krippendorff \& Butter, 1984 , p. 4)

Semantics gives a product a set of identifiable clues, that creates a simple communication loop; a message, a sender, and a receiver (Rodríguez Ramírez \& Chan, 2016). The communication of the product determines how it will function in a social context (Demirbilek \& Sener, 2003). The message that the product sends out can be interpreted as acceptance or rejection (Demirbilek \& Sener, 2003). The acceptance or rejection can create either positive or negative perceptions, emotions, and values associated with the product and the person. Devices designed with semantics taken into consideration might be able to provide adolescents with an opportunity to manage their type 1 diabetes in public spaces.

\subsubsection{Development of semantic strategies to address conspicuity}

Literature describing semantic strategies was identified by searching databases with terms including conspicuity, stigma, medical device, design, stigma design, and attention. Strategies were excluded if they did not apply to the design of a tangible product; for example, Vaes (2014) proposed a strategy labelled "design intervention". The aim of the strategy is to change the mindset of groups of people so they change their attitudes and beliefs towards a stigmatising product. Although this is a viable strategy to consider, it does not pertain to the design of a physical object; therefore, the strategy was disregarded for this research. Several strategies discussed similar ideas to change the perspective of the public; these strategies are outlined in Table 2.

This left 16 individual strategies for the design of tangible products that address stigma; however, the strategies are easily applied to the design of conspicuous or inconspicuous products. These existing strategies are outlined below and grouped into five overarching strategies developed using Braun and Clarke's (2012) thematic analysis method of coding and developing themes. The final themes developed through the thematic analysis determined the names of the overarching strategies. The term 'strategies' will be used throughout this research instead of 'themes'. 


\begin{tabular}{|c|c|c|c|c|}
\hline Source & Strategy & Aim of strategy & Code & Theme \\
\hline (Vaes et al., 2012) & $\begin{array}{l}\text { Camouflage - } \\
\text { disguise }\end{array}$ & $\begin{array}{l}\text { This strategy aims to } \\
\text { camouflage or hide the } \\
\text { medical aspects of the device. }\end{array}$ & $\begin{array}{l}\text { Hide } \\
\text { stigmatising } \\
\text { features }\end{array}$ & $\begin{array}{l}\text { Disguise as a } \\
\text { non-medical } \\
\text { device }\end{array}$ \\
\hline (Vaes et al., 2012) & Extra ability & $\begin{array}{l}\text { The device also provides } \\
\text { another function or ability. }\end{array}$ & $\begin{array}{l}\text { Dual } \\
\text { functionality }\end{array}$ & $\begin{array}{l}\text { Disguise as a } \\
\text { non-medical } \\
\text { device }\end{array}$ \\
\hline (Vaes et al., 2012) & $\begin{array}{l}\text { Reshaping product } \\
\text { meaning through } \\
\text { meaningful } \\
\text { interaction with other } \\
\text { products }\end{array}$ & $\begin{array}{l}\text { The interaction of products } \\
\text { can be cooperative, } \\
\text { competitive, or independent. } \\
\text { Products that copy or } \\
\text { complement each other can } \\
\text { provide positive feelings. }\end{array}$ & $\begin{array}{l}\text { Distraction } \\
\text { accessory }\end{array}$ & $\begin{array}{l}\text { Disguise as a } \\
\text { non-medical } \\
\text { device }\end{array}$ \\
\hline (McCarthy,2018) & $\begin{array}{l}\text { Downplay stigma } \\
\text { sensitive features } \\
\text { by disguising the } \\
\text { product as an } \\
\text { accepted non- } \\
\text { medical item }\end{array}$ & $\begin{array}{l}\text { Participants thought this } \\
\text { strategy would make the } \\
\text { device less noticeable and } \\
\text { allow them to hide their type } \\
1 \text { diabetes. However, it would } \\
\text { not be useful in an emergency }\end{array}$ & $\begin{array}{l}\text { Disguise as a } \\
\text { non-medical } \\
\text { device }\end{array}$ & $\begin{array}{l}\text { Disguise as a } \\
\text { non-medical } \\
\text { device }\end{array}$ \\
\hline (Jacobson, 2014) & $\begin{array}{l}\text { Fading out and } \\
\text { disguising }\end{array}$ & $\begin{array}{l}\text { It involves not only hiding } \\
\text { unpleasant features but also } \\
\text { replacing them with more } \\
\text { pleasant ones, which fit the } \\
\text { overall design of the context } \\
\text { of use. The aim is not solely to } \\
\text { manage stigma, but also to } \\
\text { express something about a } \\
\text { user's identity and that of their } \\
\text { home. }\end{array}$ & $\begin{array}{l}\text { Enhance the } \\
\text { product }\end{array}$ & $\begin{array}{l}\text { Aesthetically } \\
\text { enhanced } \\
\text { medical devices }\end{array}$ \\
\hline (Jacobson, 2014) & $\begin{array}{l}\text { Drawing positive } \\
\text { attention }\end{array}$ & $\begin{array}{l}\text { This strategy aims to design } \\
\text { devices that create positive } \\
\text { attention for assistive } \\
\text { technologies }\end{array}$ & $\begin{array}{l}\text { Beautiful and } \\
\text { positive devices }\end{array}$ & $\begin{array}{l}\text { Aesthetically } \\
\text { enhanced } \\
\text { medical devices }\end{array}$ \\
\hline
\end{tabular}




\begin{tabular}{|c|c|c|c|c|}
\hline Source & Strategy & Aim of strategy & Code & Theme \\
\hline (McCarthy, 2018) & $\begin{array}{l}\text { Strengthen } \\
\text { the product's } \\
\text { institutional identity } \\
\text { by reinforcing the } \\
\text { medical role played } \\
\text { by the device }\end{array}$ & $\begin{array}{l}\text { Participants felt that this } \\
\text { strategy had associations } \\
\text { of disability or a scary and } \\
\text { serious medical condition. } \\
\text { However, it would be useful in } \\
\text { an emergency }\end{array}$ & Medical Design & $\begin{array}{l}\text { Aesthetically } \\
\text { enhanced } \\
\text { medical devices }\end{array}$ \\
\hline (Vaes et al., 2012) & Diversion of attention & $\begin{array}{l}\text { This strategy asks for the } \\
\text { designer to create a diversion } \\
\text { of attention away from the } \\
\text { medical aspects of the device. }\end{array}$ & $\begin{array}{l}\text { Distraction from } \\
\text { stigmatising } \\
\text { features }\end{array}$ & $\begin{array}{l}\text { Aesthetically } \\
\text { enhanced } \\
\text { medical devices }\end{array}$ \\
\hline $\begin{array}{l}\text { (Bispo \& Branco, } \\
\text { 2011) }\end{array}$ & $\begin{array}{l}\text { Covering the } \\
\text { stigmatising object }\end{array}$ & $\begin{array}{l}\text { This strategy aims to conceal } \\
\text { the disabling or stigmatising } \\
\text { part of the product }\end{array}$ & $\begin{array}{l}\text { Hide the } \\
\text { stigmatising } \\
\text { part of the } \\
\text { device }\end{array}$ & $\begin{array}{l}\text { Conceal the } \\
\text { medical device } \\
\text { from the public }\end{array}$ \\
\hline (McCarthy, 2018) & $\begin{array}{l}\text { Minimise stigma- } \\
\text { sensitive aspects } \\
\text { of the device by } \\
\text { making it invisible or } \\
\text { less confronting and } \\
\text { minimise its presence } \\
\text { when not in use }\end{array}$ & $\begin{array}{l}\text { Participants thought it } \\
\text { would make the device } \\
\text { less noticeable and less } \\
\text { embarrassing in public. } \\
\text { However, they thought it } \\
\text { felt robotic and ought to be } \\
\text { hidden. }\end{array}$ & $\begin{array}{l}\text { Camouflaging } \\
\text { the medical } \\
\text { device }\end{array}$ & $\begin{array}{l}\text { Conceal the } \\
\text { medical device } \\
\text { from the public }\end{array}$ \\
\hline (Jacobson, 2014) & Hiding and covering & $\begin{array}{l}\text { Hiding is probably the most } \\
\text { common means of managing } \\
\text { both visible and non-visible } \\
\text { stigma. }\end{array}$ & $\begin{array}{l}\text { Hiding the } \\
\text { device }\end{array}$ & $\begin{array}{l}\text { Conceal the } \\
\text { medical device } \\
\text { from the public }\end{array}$ \\
\hline (Jacobson, 2014) & Personalisation & $\begin{array}{l}\text { Personalised products feel } \\
\text { more tailored to the user }\end{array}$ & Personalisation & Personalisation \\
\hline (Vaes et al., 2012) & Individual identity & $\begin{array}{l}\text { Allowing the user to } \\
\text { personalise their device, either } \\
\text { through mass customisation } \\
\text { or by enabling the user to } \\
\text { incorporate their own identity. }\end{array}$ & Personalisation & Personalisation \\
\hline
\end{tabular}




\begin{tabular}{|c|c|c|c|c|}
\hline Source & Strategy & Aim of strategy & Code & Theme \\
\hline (McCarthy, 2018) & $\begin{array}{l}\text { Strengthen the } \\
\text { individual identity } \\
\text { of the device by } \\
\text { providing more } \\
\text { choice and } \\
\text { opportunities for } \\
\text { personalisation so } \\
\text { users value it as an } \\
\text { extension of their } \\
\text { personality }\end{array}$ & $\begin{array}{l}\text { This strategy provides } \\
\text { participants with a sense of } \\
\text { control and ownership over } \\
\text { their device. It reflects the } \\
\text { user's style and allows them } \\
\text { to feel proud of their device. } \\
\text { Others were worried the device } \\
\text { would draw attention, and } \\
\text { onlookers would not know it } \\
\text { was medical. }\end{array}$ & Personalisation & Personalisation \\
\hline (Jacobson, 2014) & Designing stigma out & $\begin{array}{l}\text { Technology can be used for } \\
\text { reshaping and presenting the } \\
\text { user. Assistive products can } \\
\text { become more varied, tailored } \\
\text { and personalised }\end{array}$ & $\begin{array}{l}\text { New } \\
\text { technology can } \\
\text { be used in the } \\
\text { design }\end{array}$ & $\begin{array}{l}\text { Technological } \\
\text { advancements }\end{array}$ \\
\hline (Vaes et al., 2012) & $\begin{array}{l}\text { Reshaping product } \\
\text { meaning through } \\
\text { advances in material } \\
\text { technology }\end{array}$ & $\begin{array}{l}\text { Integrating new technology } \\
\text { into an existing product } \\
\text { provides the designer with a } \\
\text { way to reshape a product }\end{array}$ & $\begin{array}{l}\text { Technological } \\
\text { advancements }\end{array}$ & $\begin{array}{l}\text { Technological } \\
\text { advancements }\end{array}$ \\
\hline
\end{tabular}

\subsubsection{Semantic Strategies to design conspicuous medical devices}

The existing strategies were combined, resulting in five overarching semantic strategies described below. These strategies will be used and developed throughout the research to inform the design of medical devices for adolescents with diabetes based on their preferences for conspicuity. The five strategies are:

1. Enhance the aesthetics of the traditional medical device

2. Personalise the medical device to the user

3. Disguise the medical device as a non-medical item

4. Conceal the medical device from the public

5. Use technology to advance the medical device

As pictured in Figure 6, each of the strategies provides a different level of conspicuity. Each strategy can also be seen on a consumer and medical scale. Adolescents will have different preferences, and these strategies aim to match their needs. Each of the strategies are explained in the following sections. 


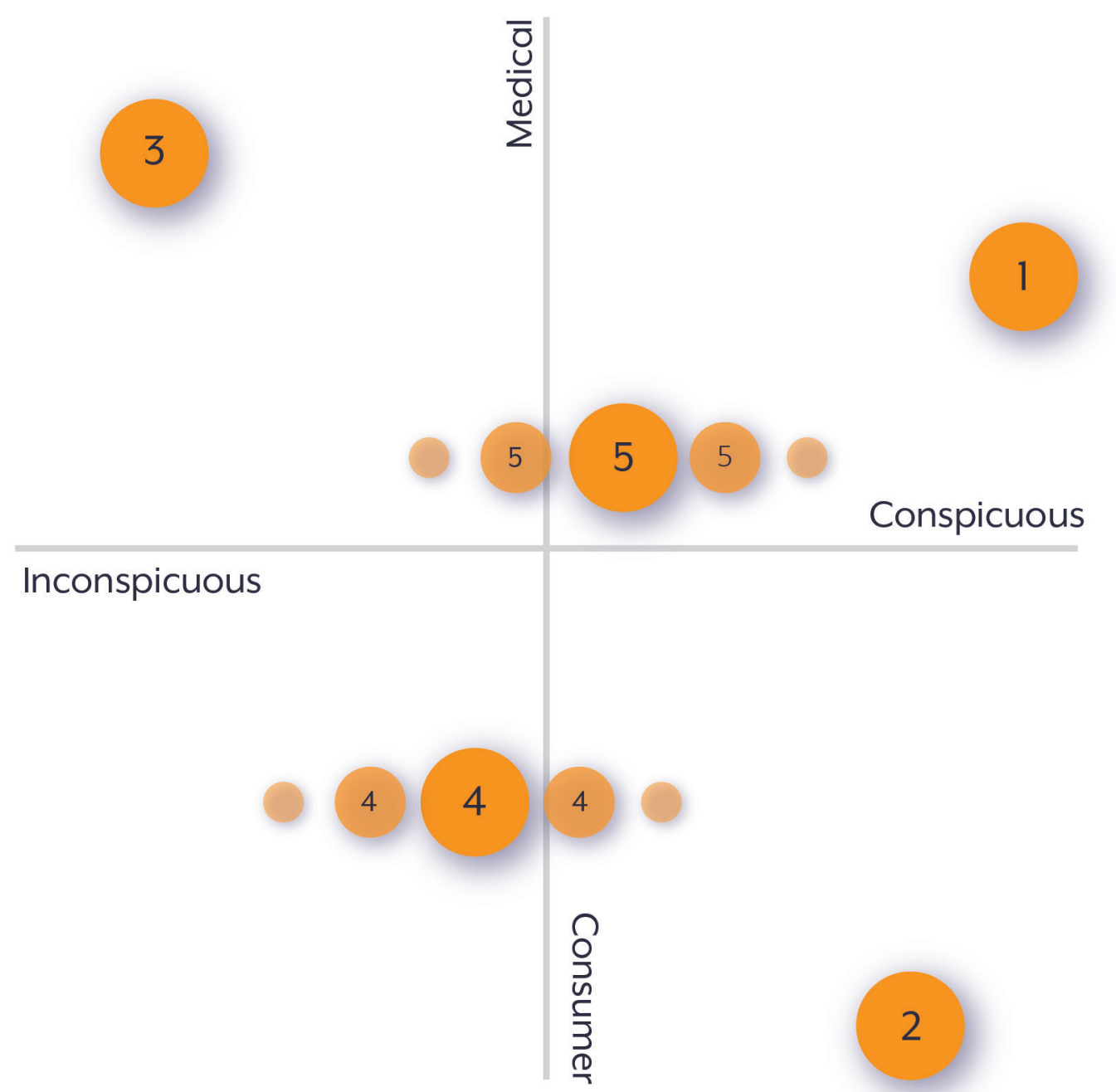

1 Enhance the aesthetics of the traditional medical device

2 Disguise the medical device as a non-medical item

3 Conceal the medical devicefrom the public

$4 \quad$ Personalise the medical device for the user

$5 \quad$ Use technology to advance the medical device 


\subsubsection{Enhance the aesthetics of traditional medical devices}

The advantages of enhancing the aesthetics of a medical device are that it allows the device to appear less 'medical', making it more innovative, stylish, and modern. This can be achieved through colour, texture, pattern, material, or form.

Medical devices are often associated with specific colours, materials, and textures that make them identifiable. Examples include white and grey colours, smooth plastic surfaces, exposed needles, medical wording and symbols, and basic shapes (McCarthy, 2018). A previous strategy from McCarthy (2018) suggested strengthening the product's institutional identity by reinforcing the medical role played by the device. Adolescents who previously gave feedback on this strategy did not favour it, as it had associations of disability or a serious medical condition. The only benefit of this strategy is that it would be useful in an emergency.

The Epipi EpiPen (Figure 7) Hue Inhaler (Figure 8-9) are examples of traditional medical devices that have been aesthetically enhanced. The designers have used colour, texture, and patterning to create a unique medical device. Exploring similar methods with type 1 diabetes devices could be a way to enable adolescents to manage their in public.
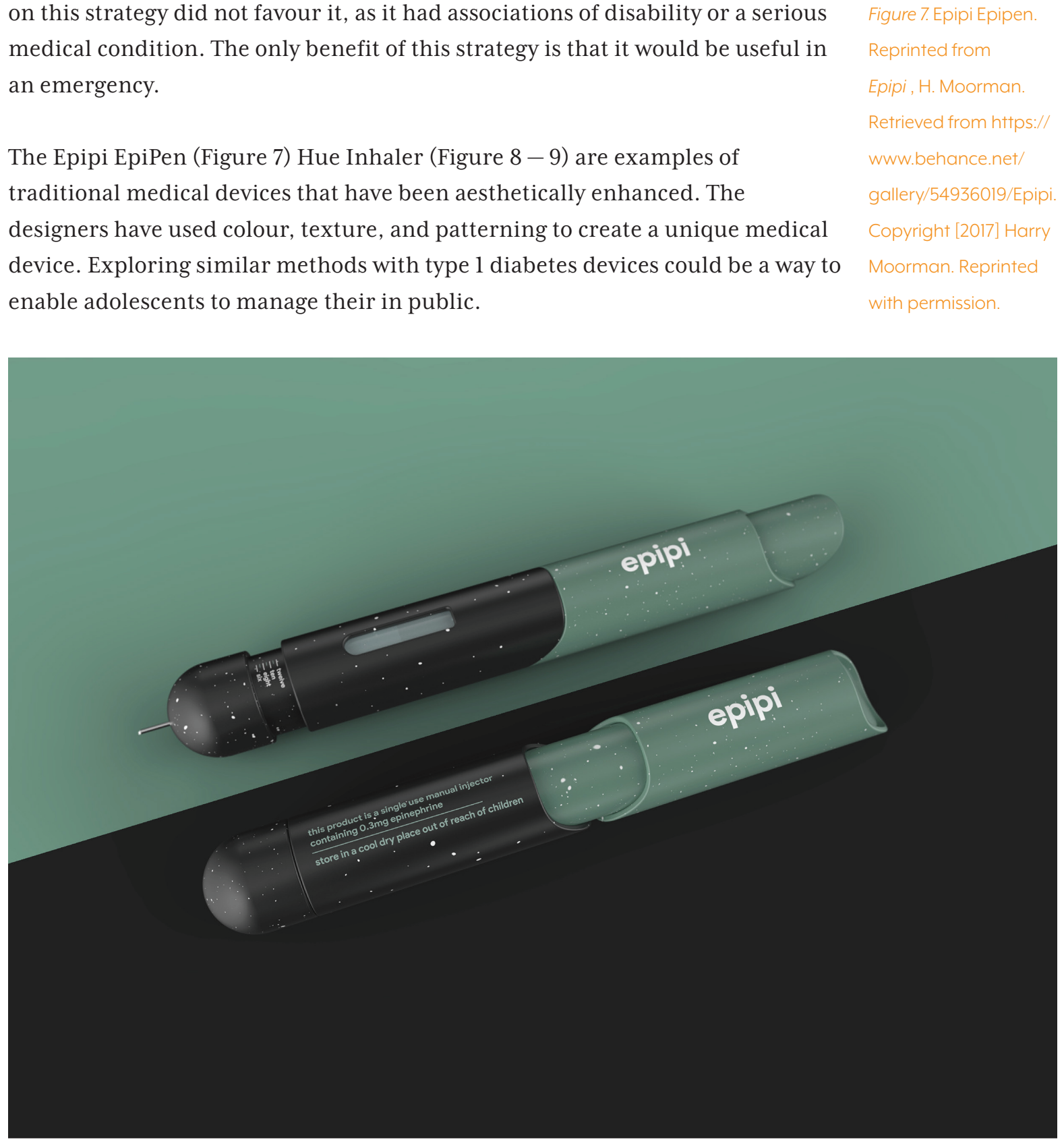


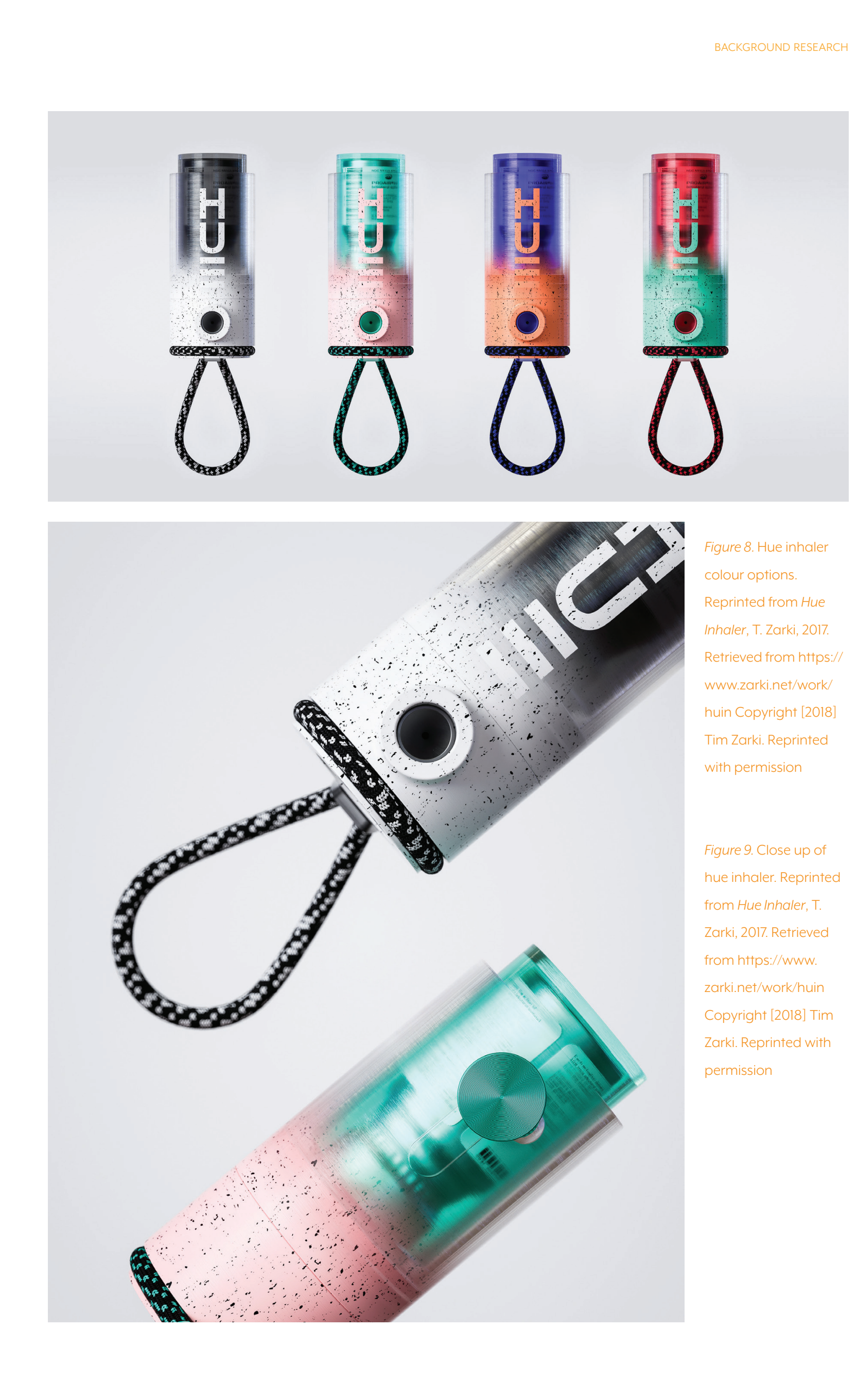




\subsubsection{Personalise the medical device to the user}

This strategy aims to provide the medical device with personalised qualities. This makes the device unique to the user, and less like a traditional medical device. While aspects of this strategy can be like the one in section 2.3.3, personalised elements such as engraving, and providing colour and pattern options, make this approach unique.

Adolescents have previously shown a preference for this approach and described it as being able to create a sense of control, see the device as an extension of themselves, reflect their style, and foster feelings of pride in ownership (McCarthy, 2018) For example, the Hue Inhaler (Figure 8-9) comes in four different colours, providing users with a choice of a personalised device.

Although some elements of personalisation are already available for current medical devices, such as stickers (Figure 10), they are often seen as childish and "ugly" (McCarthy, 2018, p. 268). However, this strategy could be used more in alignment with the tastes and preferences of adolescents.

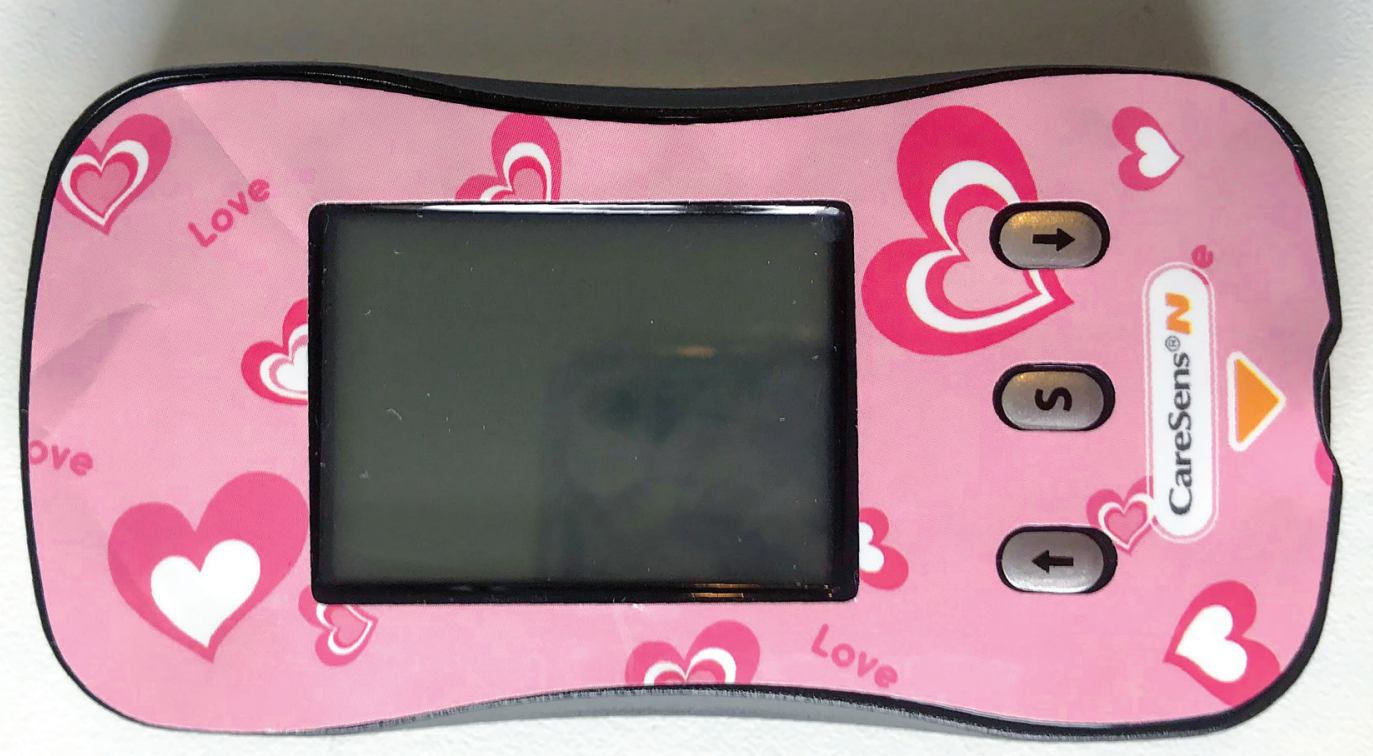




\subsubsection{Disguise the medical device as a non-medical item}

This strategy aims to disguise a type 1 diabetes medical device, by hiding the identifiable and stigmatising features such as a finger pricker or needle, and pretending that this product is a consumer item. This type of device could be shown to the public and onlookers would not know it was a medical device. In McCarthy's (2018) research participants thought this strategy would make the device less noticeable and allows them to hide their type 1 diabetes. However, they thought devices designed for this strategy would not be easily identifiable in an emergency.

The blood glucose necklace (Figure 11) is an example of disguising the medical device(McCarthy, Ramírez, \& Robinson, 2017). Unless the device is being used, onlookers would not immediately know that it is a medical device for adolescents with type 1 diabetes.

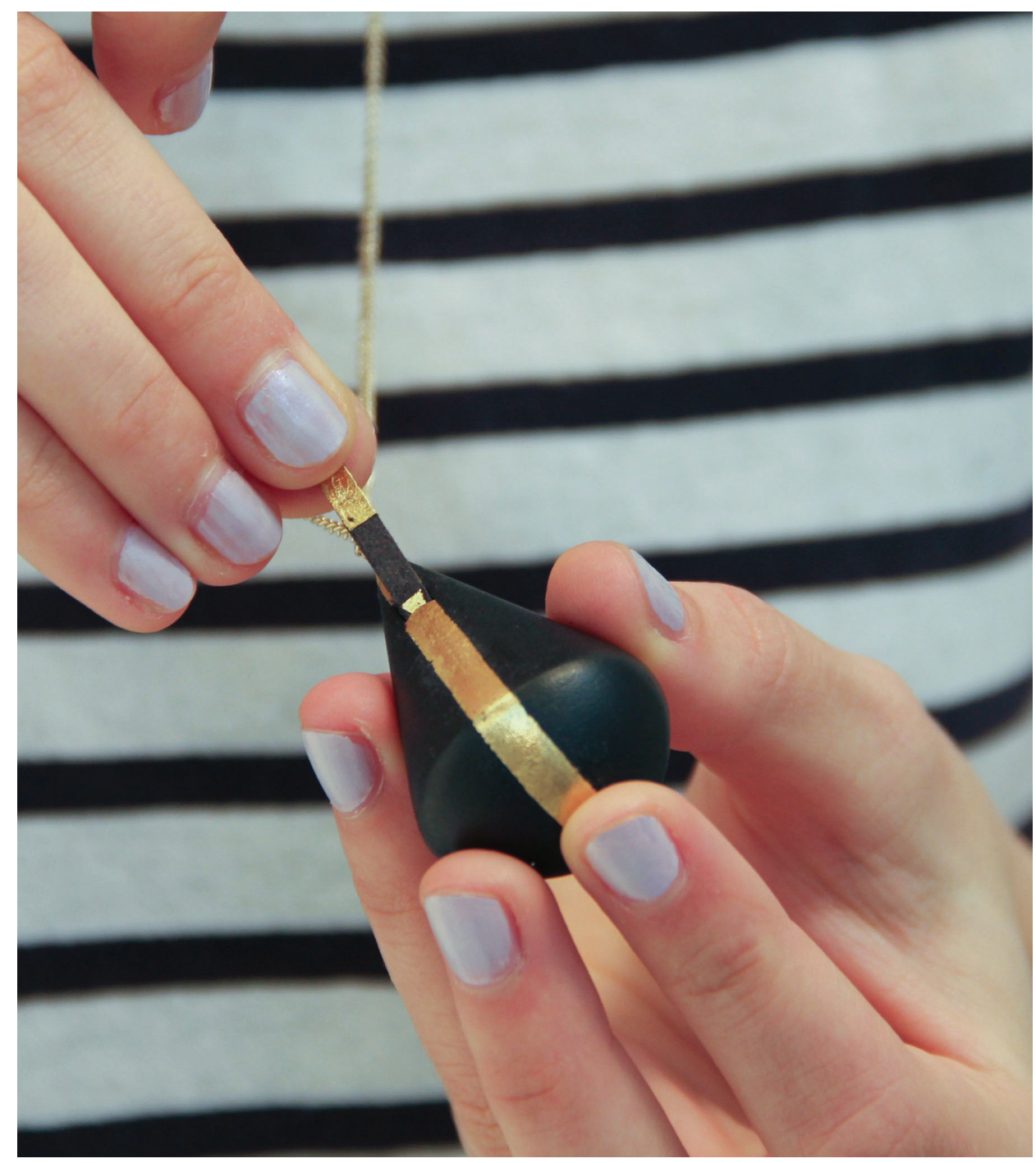

Figure 11. Blood glucose monitoring jewellery. Reprinted from "Design Experiments. Identifying areas for intervention and designing medical technology for adolescents and young adults with type 1 diabetes," by G. McCarthy, 2017, The Design Journal, 20(1), p. S2051. Copyright [2017] by Gillian McCarthy. Reprinted with permission. 


\subsubsection{Conceal the medical device from the public}

Adolescents who are embarrassed by their type 1 diabetes or their medical devices might gravitate towards concealing their medical device from the public. This strategy is different from disguising as an accepted non-medical device, as it asks the designer to remove the object from the public view altogether. Often medical devices designed with this strategy are on the body so they can be covered by clothing. For example, the Dab ECG (Figure $12-$ 13) is very inconspicuous and would hardly be noticed by the public. This is the most common strategy used when trying to reduce stigma and make the medical device less noticeable (Jacobson, 2014). Additionally, McCarthy (2018, p. 283) noted that participants thought this strategy would make the device less noticeable and less embarrassing in public. However, some participants also thought the devices felt robotic and that they ought to be hidden.

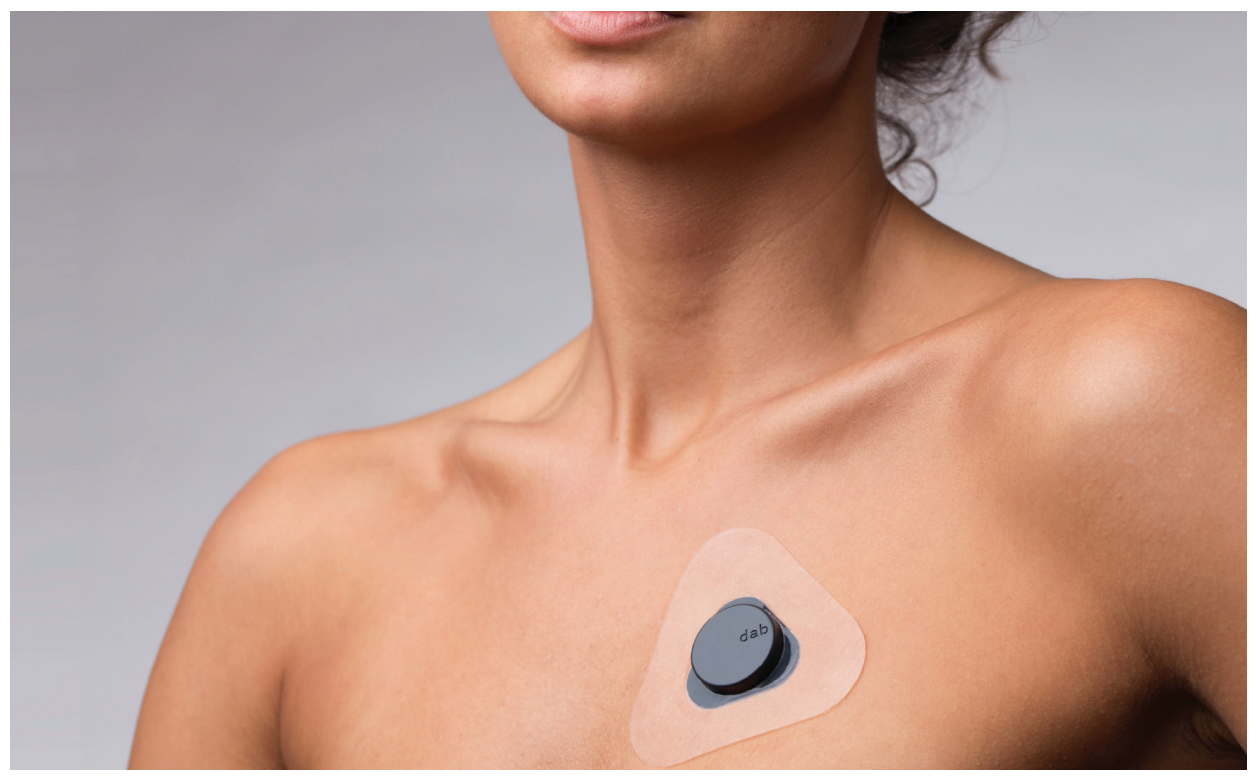

Figure 12. Dab ECG

sensor. Reprinted

from Behance, by

A. Miklosi, 2018

Retrieved from https://

www.behance.net/

gallery/64353807/Dab

ECG-sensor?tracking_

source=search

all\%7CDab. Reprinted

with permission

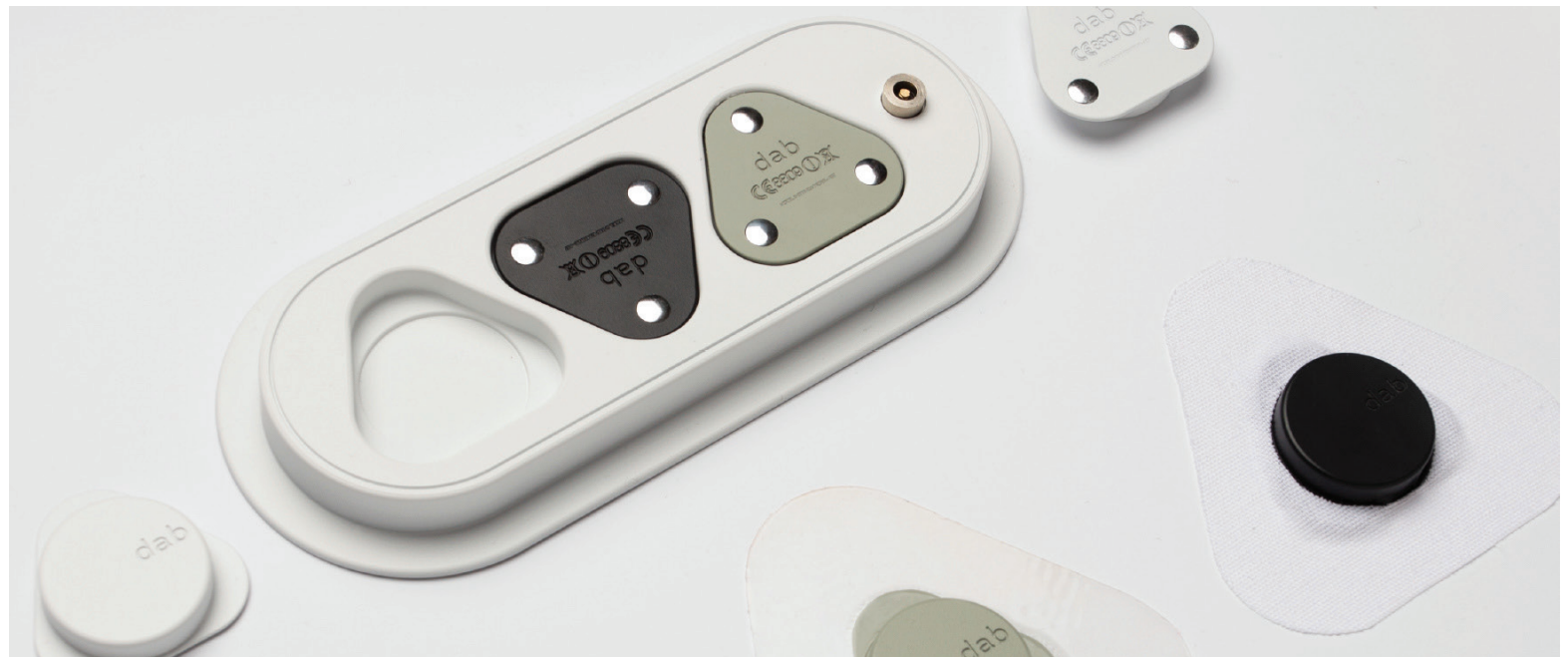

Figure 13. Charging station for Dab ECG sensor. Reprinted from Behance, by A. Miklosi, 2018, Retrieved from https://www.behance. net/gallery/64353807/Dab-ECG-sensor?tracking_source=search-all\%7CDab 


\subsubsection{Use Technology to advance the medical device}

Using technology to advance the medical device looks at new technology and materials to create devices that are exciting and interesting. It is also very similar to concealing the product, as when the product is in an 'off' state it is not recognised as a medical device. However, when the device is 'on' it could be recognised as a medical device. The temporary tattoo blood glucose meter (Figure 14) is an example of how technology could make a device more inconspicuous. Technology allows the interaction to be simplified. Currently no literature provides an adolescent's preference towards this strategy.

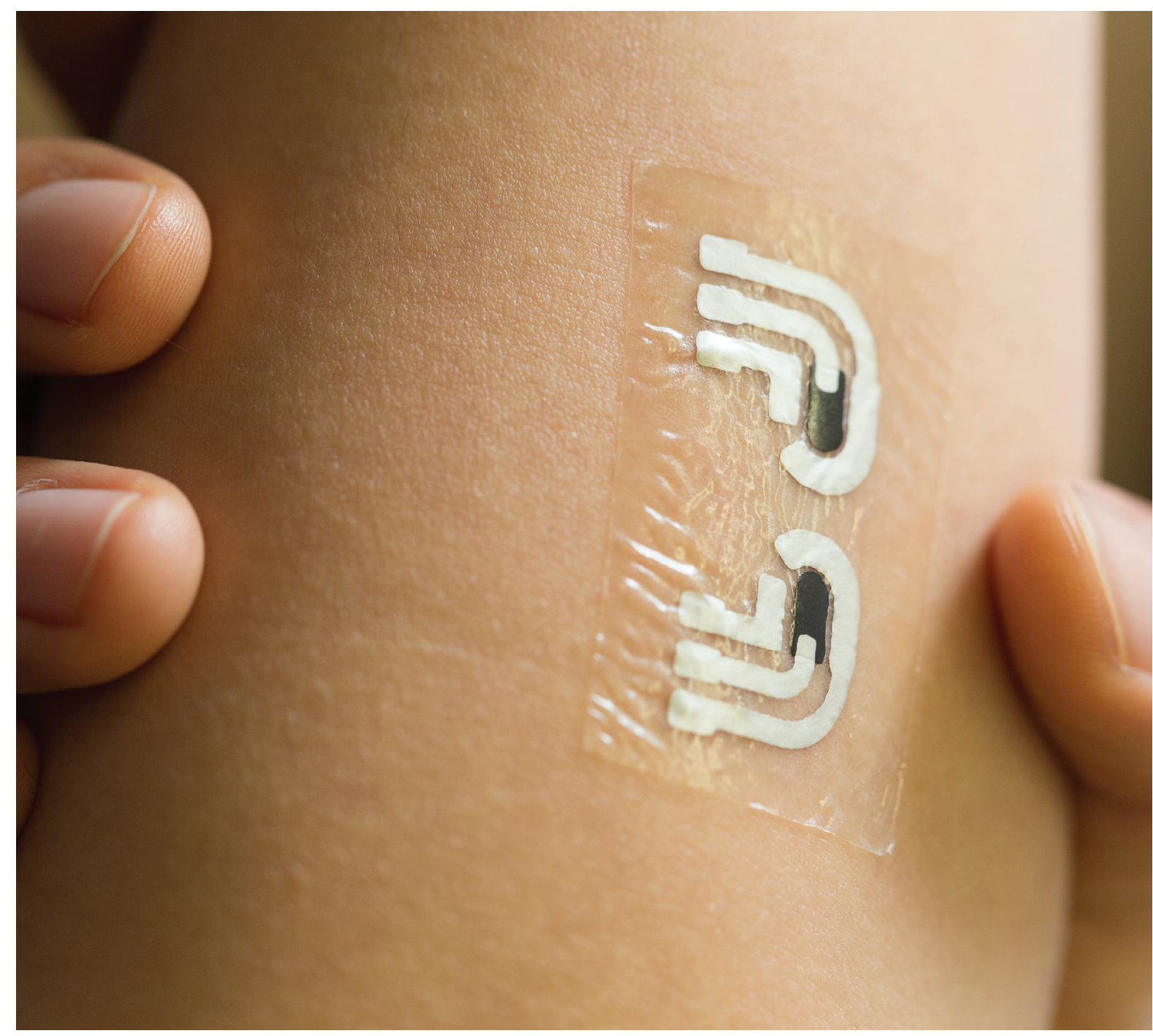

Figure 14. Blood glucose temporary tattoo sensor. Reprinted from Flickr, by J. Wang, 2015. Retrieved from https://www.flickr.com/ photos/jsoe/16054780789/in/album-72157649793949249/jsoe/16054780789/in/album-72157649793949249/. 


\subsection{SUMMARY}

Adolescents with type 1 diabetes are forced to not only manage their symptoms, but also their daily lives. This can create added stress for adolescents as they are not just managing a developmental phase in their life, but also a demanding medical condition. Some adolescents have learnt how to integrate managing their type 1 diabetes into their daily lives, and some have yet to learn. Similarly, some adolescents are more comfortable disclosing their type 1 diabetes to new people and managing their symptoms in public spaces. Other adolescents do not feel as comfortable testing in public or disclosing their diabetes for fear of being judged.

Moving forward, conspicuity will be used instead of the word 'stigma', to accommodate adolescents who do not feel stigmatised by their medical devices. To my knowledge there is no literature about the conspicuity of type 1 diabetes medical devices.

Most type 1 diabetes medical devices in New Zealand are designed to meet functionality requirements, yet globally there is very little literature about the semantic considerations of medical devices. Available devices are often clunky and unattractive, resulting in some adolescents feeling embarrassed. This presents a unique opportunity to explore adolescent preferences towards conspicuity, and design informed medical device prototypes.

The semantic strategies developed from this preliminary research are a starting point to discuss semantics and conspicuity with adolescent research participants. These strategies will be refined further throughout the research, based on adolescent preferences and discoveries, through designing. The strategies will also direct the design phase of this research to explore a range of conspicuous and inconspicuous designs that might better match the preferences of the adolescents. A device that achieves this would ideally provide an adolescent with the autonomy to choose to discuss their type 1 diabetes in public and give them the confidence to manage their diabetes throughout the day, without feeling judged.

As type 1 diabetes is a condition that adolescents will manage their entire life, it is important to provide them with devices that they feel comfortable to use and enable them in their daily life. Through talking with adolescents and designing alongside them, this research aims to highlight the importance of designing medical devices for adolescents with type 1 diabetes that match their preferences for conspicuity. 
(2) 
Chapter 3

\section{METHODOLOGY}

The qualitative methodologies and ideologies applied in this research were chosen based on their ability to support the overall aims and objectives to answer the question:

'How might semantic strategies be used to inform the design medical devices that match the preferences for conspicuousness of adolescents with type 1?' 


\subsection{AIMS AND OBJECTIVES}

Table 3 shows the structure of the aims, objectives, methods, analysis, and the research outputs. The first aim is to understand adolescents' preferences for conspicuity when designing type 1 diabetes medical devices. I will conduct semi-structured interviews, create collages and sketch concepts with adolescent participants. This will help me to discover their preferences for medical devices, and if they should be conspicuous or inconspicuous. I will also be able to determine which semantic strategies I have developed in aim two will be better suited to design medical devices. The second aim is to use a range of semantic strategies to develop and test conceptual medical device designs that provide adolescents with type 1 diabetes the opportunity to match users' preferences for conspicuousness. From the information found during aim one, I will be able to validate the semantic strategies, I have developed through thematic analysis. From this information I will design conceptual medical devices that will be evaluated in a focus group and with the original interview participants. 
How might semantic strategies be used to inform the design of medical devices that match the preferences for conspicuousness of adolescents with type 1 diabetes?

Aim 1: Understand adolescents' preferences for conspicuity of type 1 diabetes medical devices.
Aim 2: Use a range of semantic strategies to develop and test conceptual medical device designs that provide adolescents with type 1 diabetes the opportunity to match their preferences for conspicuity.

Objective 2: Identify and explore a range of semantic strategies that address the conspicuity of medical devices for adolescents with type 1 diabetes.

Objective 1: Investigate through qualitative and creative methods adolescents' experiences and preferences of medical-device related conspicuity in public settings.

Objective 3: Design medical device concepts and evaluate their alignment with adolescents requirements towards facilitating conspicuity in public settings

\section{Method:}

High fidelity prototyping

Adolescent feedback

Sketching, collaging and vignettes with adolescents (Lang, 2012; Martin \& Hanington, 2012; O'Brien, 2003; Sanders \& Stappers, 2014)

Thematic Analysis (Braun \& Clarke, 2012)

Output:

Themes of adolescent conspicuity experiences A collage of the participants preferences Sketches of initial ideas of medical devices Post-it note vignettes of participant ideas and preferences
Output:

A set of high-fidelity 3D printed prototypes 


\subsection{RESEARCH PARADIGM}

\subsubsection{Constructivism}

I conduct the research from a constructivist research paradigm because this research focuses on the detailed and varied experiences of individuals and how products shape these experiences. Accordingly, Constructivists assume that absolute realities are unknowable, and researchers should investigate an individual's perspective or view of reality (Hatch, 2002). Constructivists believe that multiple realities exist that are each unique because they are constructed by individuals who experience the world from their own point of view (Hatch, 2002). I agree with Corbin (2008), who believes that concepts and theories are constructed by the researchers out of stories that are told by the participants who are trying to explain and make sense out of their experiences. This results in knowledge being something the researcher constructs from the viewpoints and experiences of the participants. Therefore, I have researched the experiences and opinions of adolescents with type 1 diabetes to construct new knowledge, that can aide me in the design process of conspicuous medical devices.

When conducting qualitative research, it is important to consider the rigor of the methods. The four criteria considered; credibility, transferability, dependability, and confirmability (Lincoln \& Guba, 1985).

The credibility criteria involved establishing that the results of qualitative research are credible or believable from the perspective of the participant in the research. Since qualitative research is used to describe and understand the perspectives and opinions of adolescents with type 1 diabetes, the participants involved in this research are the only people who can judge the credibility of the results. Therefore, I will be talking to two participants in the individual interviews that will be involved different phases of the research to make sure the results are reliable. I will also be using several different methods with the two participants, as well as talking to other participants in a different session to triangulate the data.

Transferability refers to how the research can be generalised or transferred to other contexts. As a research I can enhance the transferability by thoroughly describing the research context and the findings that are central to the research. Therefore, my findings are not a generalisation about all adolescents with type 1 diabetes, instead I have studied the participants involved in this research in great detail. Other researchers can choose how they want to transfer this information. 
The dependability criteria emphasises the need to for the researcher to account for the changing context within which the research occurs. As a researcher I am responsible for describing any changes that occur in the setting or to the participants and how these changes might affect the way I approach the study. For example within the type 1 diabetes context the participant's medical devices might change over time due to access or changes in funding. Adolescents might also feel differently in the sessions that occur on different days, hence why I have spoken to the same participants multiple times.

The final criteria confirmability refers to the degree to which the results could be verified by others. As a researcher I will describe when the participants contradict or agree with each other, or previous research. I will write reflectively and reflexively discussing how I have done the research throughout the research to report on a rich and detailed account of a small number of people experiences.

\subsubsection{Participatory design}

A methodology that aligns with a constructivist outlook is participatory design; both prioritise the participant's perspectives and opinions. The methodology originated in Scandinavia in the 1970's (Spinuzzi, 2005) and is a process of investigating, understanding, reflecting, establishing and developing ideas with participants (Simonsen and Robertson, 2013). It requires the researcher to prioritise the opinions of the participants (Simonsen \& Robertson, 2013).

Researchers must use methods that facilitate open conversation and create trust between the researcher and the participant (Sanoff, 1990). Research methods such as interviews, focus groups, sketching, or creating low fidelity prototypes can be used to inform and iterate the developing design in alignment with participants' preferences (Martin \& Hanington, 2012; Spinuzzi, 2005).

Previous research conducted by McCarthy (2018) used a participatory design methodology which was successful in creating an open dialogue with adolescents about their experiences with type 1 diabetes and their thoughts on their current medical devices. Building from that research, the same methodology was applied however, the individual methods used were adjusted so that the design of conspicuous medical devices will be the primary focus. 


\subsection{ETHICS AND RECRUITMENT}

\subsubsection{Ethics application}

This research is considered high-risk because the participants, being aged under 16 and having a health condition, are considered vulnerable. A scoping form was submitted to the Health and Disability Ethics Committee (HDEC) to determine which ethics body had oversight of this research. As the research is observational and not interventional, the research was considered "Out of Scope" of the HDEC (Appendix A). As such, an ethics application \#0000026751 was submitted and subsequently granted by Victoria University of Wellington's Human Ethics Committee on the 26th of September 2018.

\subsubsection{Recruitment Process}

This research sought to develop a rich understanding of the experiences and preferences of individual adolescents with type 1 diabetes. As such, two participants were recruited for the semi-structured interviews, collaging, sketching and user-feedback sessions. However, I had repeated contact with them throughout the research process, to establish rapport and creditable qualitative research. The participants involved in this study were recruited through a local diabetes nurse who emailed patients aged 13-18 a recruitment poster (Figure 15). The exclusion criteria for participants included; if they had been diagnosed with type 1 diabetes less than one year ago or if they had another significant health condition. All ethics documentation can be found in Appendix B.

Participant 1 was diagnosed with type 1 diabetes at around three years old, whereas participant 2 had diagnosed two years prior when she was 13.

Before initiating data collection, I met with both participants individually in a café. During the first meeting with participant 1, his parents were also present. This allowed me to create a rapport with the participants and their parents, and to ask more fundamental questions about their diagnosis age and their current devices. This was also an opportunity for the participants and their parents to ask me any questions or bring up any concerns they had about the research.

Both participants have used a flash blood glucose monitor for eight months. Participant 1 had already been innovative and customised their flash blood glucose meter, by 3D printing an armband to hold the sensor over flash blood glucose meter so that he could turn his flash blood-glucose meter into a continuous blood glucose meter. These readings were then sent directly to his watch and his parents' phones. Participant 2 used insulin pens to administer insulin, whereas participant 1 used an insulin pump. 


\section{DESIGNING MEDICAL DEVICES FOR TYPE 1 DIABETES}

At Victoria University of Wellington, we're researching how type 1 diabetes medical devices could be better in the future. How can we design cooler more inviting medical devices that fit your lifestyle?

We want to work with young people, by chatting about your current medical devices and designing ideas for future medical devices together by sketching and collaging. We'd love to hear from you if:

- You're 13-18 years old

- You were diagnosed with type 1 diabetes at least one year ago

If you choose to take part, we will get in touch with you 2 times over the coming year, but you can stop taking part at any time. To take part or find out more, contact Maddy Hazelton at:

-madeleine.hazelton@gmail.com

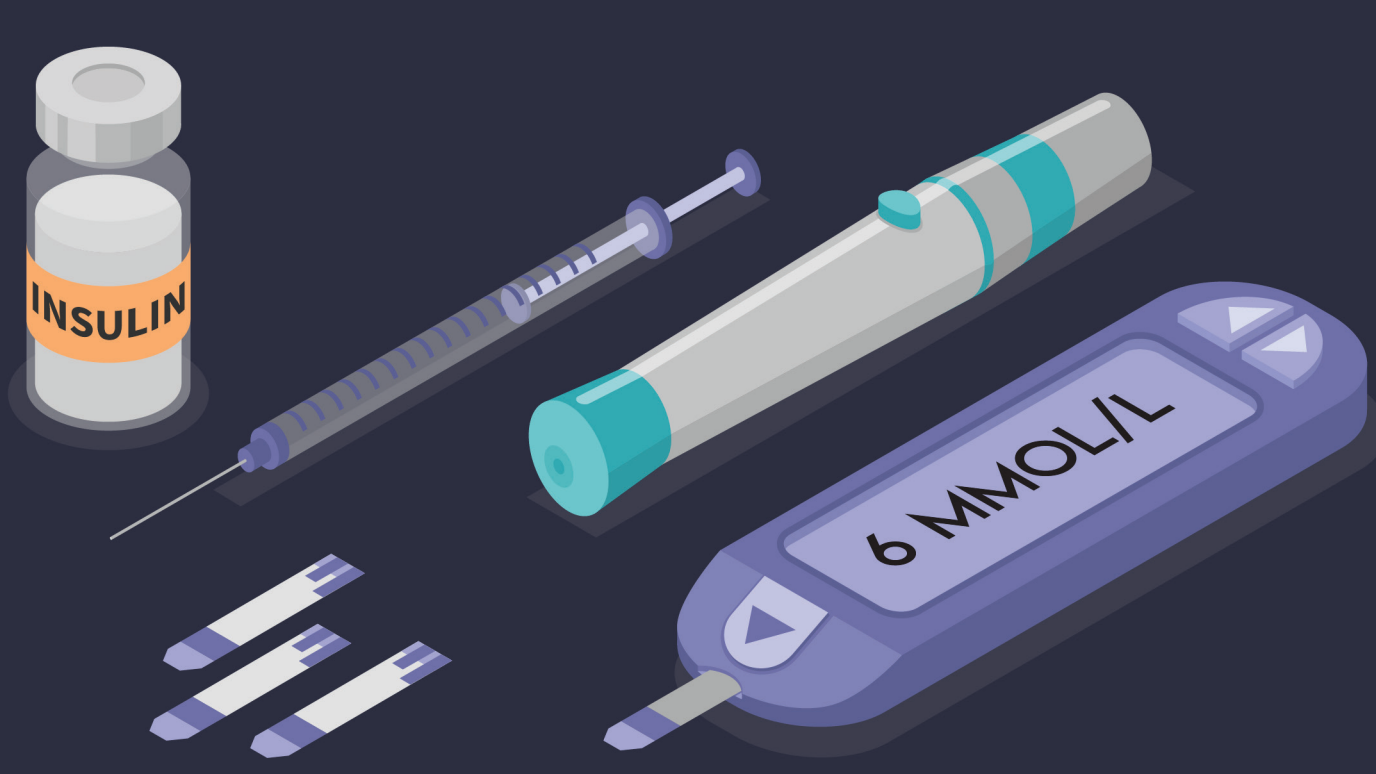


A focus group was also held in March 2019 at a family diabetes camp with 8 participants, from different areas of New Zealand. I was approached by the organiser of the camp to take part. Attending families were emailed the information sheet before the camp and were given the option to take part in the research or not. I worked as a volunteer during the camp, so I met with each of the participants and their parents prior to the focus group.

Participants recruited through these two approaches who took part in the research are listed in Table 4. In each of the chapters following it will be stated which participants' involvement is reported on.

\begin{tabular}{|c|c|c|c|c|c|}
\hline Code & Name & Gender & Age & Medical Device & Session \\
\hline Pl & Participant 1 & Male & 15 & Pump and Libre & Individual \\
\hline P2 & Participant 2 & Female & 15 & Pen and Libre & Individual \\
\hline FGl & Focus Group 1 & Female & 14 & Pen and Libre & Focus Group \\
\hline FG2 & Focus Group 2 & Female & 14 & Pump and Libre & Focus Group \\
\hline FG3 & Focus Group 3 & Female & 15 & Pen and BGM & Focus Group \\
\hline FG4 & Focus Group 4 & Female & 13 & Pen and CGM & Focus Group \\
\hline FG5 & Focus Group 5 & Male & 15 & Pump, pen and BGM & Focus Group \\
\hline FG6 & Focus Group 6 & Male & 15 & Pen and Libre & Focus Group \\
\hline FG7 & Focus Group 7 & Male & 13 & Pump and Libre & Focus Group \\
\hline FG8 & Focus Group 8 & Male & 13 & Pump, BGM & Focus Group \\
\hline
\end{tabular}




\subsection{DATA COLLECTION METHODS}

This research used a combination of conversation-based and creative research methods as creative approaches can be used to help participants express their ideas for new designs in different visual ways. The timeline of methods are seen in Figure 17.

The first session with the two individual participants involved a semistructured interview to guide conversation and facilitate discussion while maintaining a relaxed atmosphere and building rapport (Adams, 2015; Galletta \& Cross, 2013). This was followed by a collaging activity to discuss ideas. Collaging provides adolescents an opportunity to project personal information onto visual artefacts (Martin \& Hanington, 2012). Sanders, Brandt \& Binder (2010) use collage as a tool to probe, prime, understand and generate ideas. It is a tool that can be used in an individual setting, with a group, online or face-toface (Sanders et al., 2010). The collage images used are all products that can be categorised into one or more of the semantic strategies defined in the following chapter. Adolescents were presented with the images, and other tools to annotate and create a collage of their ideal semantics for future type 1 diabetes medical devices. Following this participants were invited to sketch future concepts and ideas. This was to start develop ideas talked about in the collaging activity into ideas to be tailored towards type 1 diabetes medical devices, and the possibilities of new more conspicuous or inconspicuous designs.

In the second participatory session of the research I conducted a focus group. Focus groups are often used to gage the opinions, feelings and attitudes from a group of carefully recruited participants about a product (Martin \& Hanington, 2012). During the focus group, a visual vignette task (Lang, 2012) was used to help participants explore design ideas that pertain to a semantic strategy. This was done with post it notes, so that adolescents can quickly write ideas and stick them under a corresponding category or question. Participants in this workshop were also asked to sketch future concepts and ideas for medical deivces.

Following these sessions, four prototypes (Martin \& Hanington, 2012; Sanders \& Stappers, 2014) will be created using 3D printing methods. Each of the prototypes will pertain to one of the semantic strategies developed in the background research.

Finally in the third participatory session, the initial two participants were contacted again to take part in a user feedback session (Martin \& Hanington, 2012). Semi-structured interviews (Adams, 2015) were used again to gage the adolescents opinions about the prototypes and the semantic strategies. A questionnaire (Martin \& Hanington, 2012) will also be conducted in this final 
phase of the research, to gain a quick understanding of adolescents thoughts towards the appearance of the device and the conspicuity.

\subsection{DATA ANALYSIS METHODS}

The primary analysis method was thematic analysis. Thematic analysis is useful when trying to find meaning from a set of qualitative data (Braun \& Clarke,

2012; Guest, MacQueen, \& Namey, 2019). Braun and Clarke (2012) defined thematic analysis as a systematic method for identifying patterns of meaning across a data set. The method "allows the researcher to see and make sense of collective or shared meanings and experiences." (Braun \& Clarke, 2012, p. 57). Braun and Clarke (2012) break thematic analysis down into six phases as shown in Figure 16. Thematic analysis is a good method for analysing not only interview transcripts, but a range of data, such as the collages, sketches and vignette tasks. By following these six phases, research was analysed thoroughly and consistently throughout the course of the research.
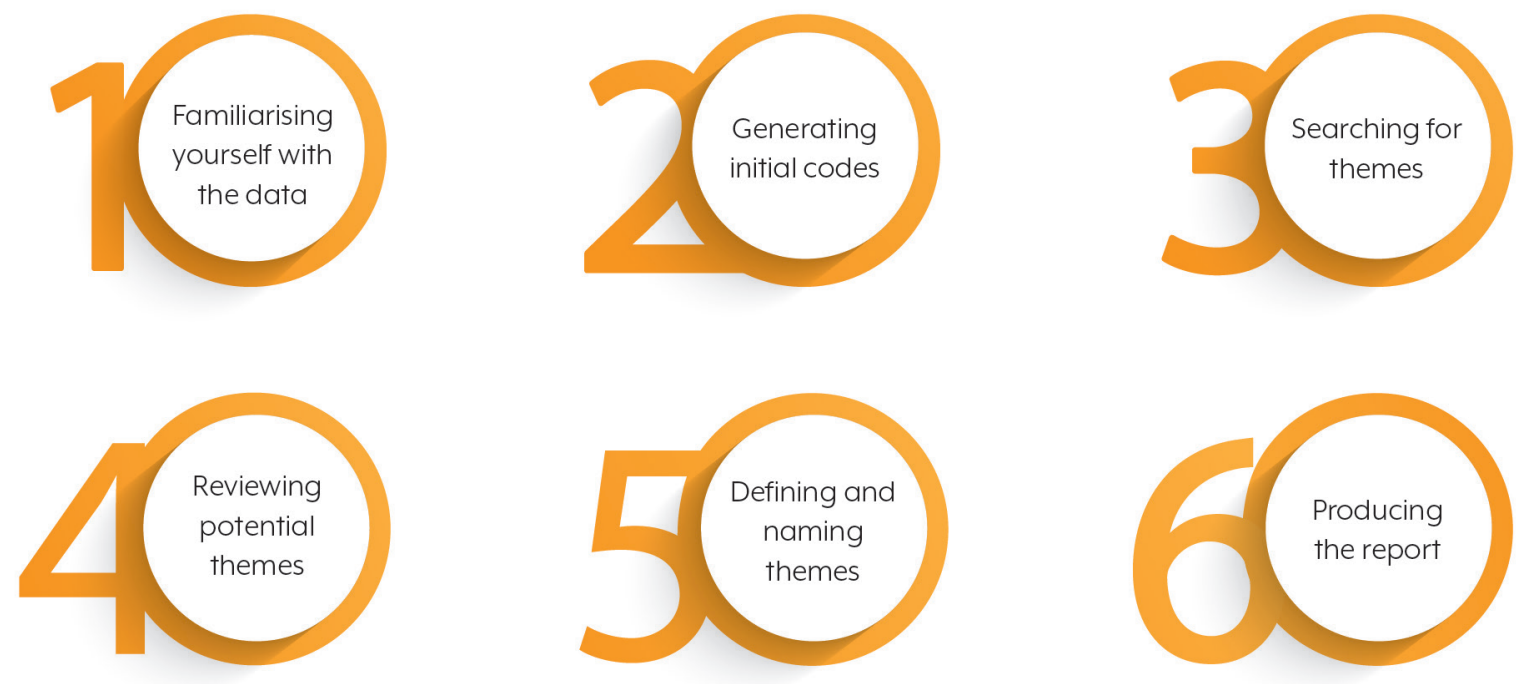

\subsection{PROJECT TIMELINE}

Figure 17 shows the timeline of this project. As there are multiple sessions with participants, it is useful to understand when each event takes place. 


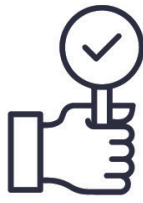

ETHICS APPROVED

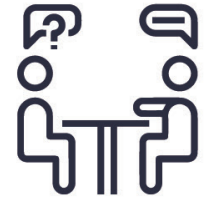

FIRST MEETING WITH INDIVIDUAL PARTICIPANTS

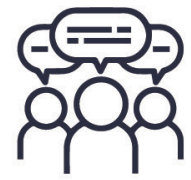

FOCUS

GROUP

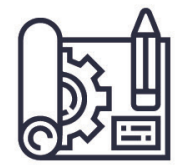

CREATIVE METHODS WITH

INDIVIDUAL

PARTICIPANTS

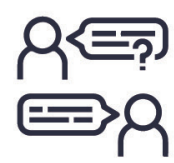

INTERVIEWS WITH

INDIVIDUAL

PARTICIPANTS
1. CREATIVE VIGNETTES

2. GROUP DISCUSSION

3. THEMATIC ANALYSIS

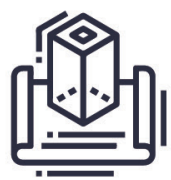

PROTOTYPING
1. COLLAGE

2. SKETCHING

1. SEMI-STRUCTURED

INTERVIEWS

2. THEMATIC ANALYSIS

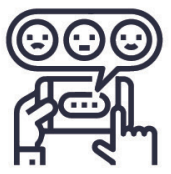

USER FEEDBACK

WITH INDIVIDUAL

PARTICIPANTS 


\section{THEMATIC ANALYSIS OF ADOLESCENT INTERVIEWS}

This chapter describes the thematic analysis of findings from the semistructured interview conducted with the two participants, and the group discussion with female participants from the focus group. The findings were analysed together so similar ideas and experiences could be grouped together under common themes. This phase of the research fulfills the first aim: understand adolescents' preferences for conspicuity when designing type 1 diabetes medical devices, and specifically answers the first objective: Investigate through qualitative and creative methods adolescents' experiences and preferences of medical-device related conspicuity in public settings. 


\subsection{METHODS}

The methods used to fulfil this objective include: semi-structured interviews with the two individual participants (Adams, 2015; Galletta \& Cross, 2013), and discussion (O'Brien, 2003) with the female focus group participants. Only the female participants from the focus group were involved in the discussion because they were interested in discussing their ideas more in depth compared to the male participants. I analysed the results using six-step thematic analysis (Braun \& Clarke, 2012) as described in the methodology chapter.

\subsection{PARTICIPANTS}

This chapter describes the opinions and experiences of several participants from the individual semi-structured interview and focus group session. Table 5 displays the participants mentioned in this chapter.

Table 5. Participants involved in the individual session and female group discussion

\begin{tabular}{|c|c|c|c|c|c|}
\hline Code & Name & Gender & Age & Medical Device & Session \\
\hline $\mathrm{Pl}$ & Participant 1 & Male & 15 & Pump and Libre & Individual \\
\hline P2 & Participant 2 & Female & 15 & Pen and Libre & Individual \\
\hline FG1 & Focus Group 1 & Female & 14 & Pen and Libre & Focus Group \\
\hline FG2 & Focus Group 2 & Female & 14 & Pump and Libre & Focus Group \\
\hline FG3 & Focus Group 3 & Female & 15 & Pen and BGM & Focus Group \\
\hline FG4 & Focus Group 4 & Female & 13 & Pen and Dexcom & Focus Group \\
\hline
\end{tabular}




\subsection{PROCEDURE}

\subsubsection{Individual Interview}

In a private room at Victoria University of Wellington, I asked questions to understand participants' preferences and experiences about conspicuity in public spaces while using their medical devices to manage their type 1 diabetes. Through semi-structured interviews a more relaxed approach could be taken, therefore further questions and prompts were asked to expand on positive and negative experiences, as well as ideas they had for future medical devices.

The semi-structured interviews were designed to identify areas of need for current devices, but also to understand the social impact of type 1 diabetes. I conducted a pre-interview test with a young adult who has type 1 diabetes, to gauge how relevant the questions were and to make sure they were not too intrusive or confusing. I edited the questions, based on some recommendations from the young adult, to allow the questions to be understood by an adolescent.

\subsubsection{Focus Group Discussion}

During the focus group I had the opportunity to talk to the female participants in a group setting. Similar questions to the interviews were asked in the discussion; however, there was more opportunity for the participants to discuss their preferences and experiences with each other.

\section{4 FINDINGS}

Through thematic analysis (Braun \& Clarke, 2012; Guest et al., 2019) five themes were developed and are described below. The final themes are:

1. Adolescent experiences of diabetes-related interactions

2. $\quad$ Adolescent preferences towards current medical devices

3. Behavioural strategies for testing in public

4. Adolescent theory of conspicuity

5. Adolescent preferences and ideas for new medical devices 


\subsubsection{Adolescent experiences of diabetes-related interactions}

Frequently, onlookers will ask adolescents questions or make comments about their medical devices. Often these questions will be asked out of curiosity as the person may not have seen the device before or are confused about type 1 diabetes. Several different experiences were identified by the participants. The sub-themes include positive type 1 diabetes conversations and uncomfortable type 1 diabetes related attention.

\subsubsection{Positive type 1 diabetes conversations}

Participant 1 described situations where people have been knowledgeable about type 1 diabetes and the devices used and how exciting it is to talk to someone who understands, even if they do not have type 1 diabetes themselves.

P1: When I tell someone about it, and they're like ... 'Oh yeah is that ...?' and they list the exact product, because someone, or their friend or sibling has got it. That's pretty cool because they know exactly what I've got and they understand it all. But for some people they don't actually know what it is, it's really confusing.

Participant 2 had a similar experience discussing type 1 diabetes with people that had noticed her sensor.

P2: I was wearing a t-shirt and you could see my sensor, and this boy came up to me and was like oh my god my flatmate's diabetic ... and we just talked about it for like five minutes and it was nice that he was aware.

Although the onlookers sometimes don't have type 1 diabetes, it can be nice for an adolescent to talk to people who are aware of their condition, or who know about the medical devices they use. The same can also be said when two type 1 diabetics run into each other. Participant 1 mentioned that while she was on holiday in Fiji, someone noticed her flash blood glucose meter and stopped to talk to her parents, P2: "I like walked over and it turns out that she also has diabetes and the Libre [flash blood glucose meter], and she had seen it on my arm and I was like weird.”

\subsubsection{Uncomfortable type 1 diabetes related attention}

In contrast to the participants I interviewed initially, some of the female focus group participants did not feel comfortable testing in public. One adolescent, FGl, said,: "I hate it [testing]. Yeah everyone is like ewww." Another participant was shocked by this as she had different experiences.

FG3: Do your friends actually say it's gross and stuff? I must be really lucky, because some of my friends are surf lifesavers, and so they had to go through the training and one of them knows my ratios. So on Friday I was 28 at lunch, because I had a frozen coke and she was like "ok get a shot now, do this much." 
and then an hour later she came up to me and was like ok have you done a test, do a test now. She was like being my mum.

Another participant also tried to be inconspicuous with their flash blood glucose scanner, as they were scared that a teacher or authority figure who was not aware of its purpose might confiscate it FG2:"I always get told off in class for it, like having my phone out for scanning and stuff and like I nearly get it confiscated." Two of the participants who went to school together described how they do not test at school because they are worried about what their friends will say. The participants recognised that they should be testing more regularly.

FG1: Yeah, I don't [test], I used to like always not [test] at school.

FG2: Yeah, I never [test] at school, it's really naughty, but I just don't want to [test]. I go sit on the backfield so I walk there and then just sit down and like forget, and I just start eating, and your like 'oh I was supposed to do that aye?'

Following this, I asked the female participants if there were occasions when they were too tired to answer questions from friends or onlookers. All the female participants promptly and unanimously responded yes, and it was evident there are occasions when they are not in the mood or right mindset to answer questions.

\subsubsection{Adolescent preferences towards current medical devices}

Type 1 diabetes is a hidden disease; it is recognised once medical devices are visible or in use. Adolescents will often use differing medical devices because of preferences, access to technology and currently funded ${ }^{1}$ devices. Adolescents could identify several occasions when their medical devices had been noticed. Subthemes include: medical device recognition, mistaking the identity of the medical device, the conspicuity of convenient medical devices, and the sterile aesthetics of current medical devices.

\subsubsection{Medical device recognition}

As the flash blood glucose meter is always worn, Participant 2 regarded the device as more noticeable than an insulin pen, P2: "The Libre [flash blood glucose meter] it's definitely more noticeable, not that it's a bad thing but everyone can see cause it's on your arm.” Onlookers have often asked Participant 2 questions at tennis matches, because she is wearing t-shirts or sleeveless tops and her sensor is more visible.

${ }^{1}$ PHARMAC is a New Zealand government organisation that funds select medical devices and medications, making them significantly cheaper than alternatives. 
P2: I have had a lot of people come and ask me 'are you ok?' at tennis. On Sundays, I normally have two in, so they are both on the same arm, so it looks a bit weird like 'oh my god is your arm ok?' and I'm like 'yeah it's just a sensor.'

On the other hand, Participant 1 uses an insulin pump and regards that device as being more noticeable than the flash blood glucose meter,

P1: Definitely the pump. The only reason is that, it's the one, people can actually see. Because it's the only one I really have out, yeah because this Iflash blood glucose meter] is covered by my shirt and jersey and stuff, so no-one really sees that.

\subsubsection{Mistaking identity of the medical device}

Due to a wide variety of devices, some type 1 diabetes medical devices can be mistaken as familiar consumer objects. For instance, Participant 2's flash blood glucose has been compared to a large Band-Aid, and Participant l's flash blood glucose meter has an elastic armband wrapped around it, so has been mistaken as a school garter; P2: "When I am doing P.E. or something people always ask, 'oh what is that wrapped around your arm? It looks like a school garter?' They always ask, 'why are you wearing a garter around your arm?'” Insulin pens can also be mistaken for other objects.

P2: A lot of people think the pen is a writing pen as well, they are like 'oh my gosh this is such a cool pen like where did you get this from, I want to go buy it' and I was like, ah that's not what it is.

\subsubsection{The conspicuity of convenient medical devices}

Both participants praised the flash blood glucose meter as being more convenient than a blood glucose meter and finger pricker. P1: "You have to get less out of your bag than pricking and it requires less effort and less time." Using a blood glucose meter and a finger pricker requires a more manual approach to tracking and managing type 1 diabetes. P1: "When we had the pricker and stuff, we would have this book and every time you would write each $\log$ and then we moved to a phone-based data system." The flash blood glucose meter allows the data the adolescents receive to be tracked automatically on their phone or the scanner.

The participants had different experiences when administering insulin. Participant 1 used a pump and thought it was more convenient and required less time to use than an insulin pen.

P1: With insulin you have to like put it in every time you eat, and so that is a lot of effort each time having to get it out. With the pump you just have to put in some numbers, it's so much easier. 
Participant 2 uses an insulin pen, and found "It's quite annoying, obviously there is not a time when you wouldn't need your insulin pen. That's the thing with anything that isn't attached to you that you can take off. You're more likely to lose it."

The flash blood glucose meter and insulin pump are constantly attached to those who use them, which can be both convenient and inconvenient. By constantly wearing a pump and flash blood glucose meter, adolescents do not forget their devices or have the inconvenience of carrying an extra bag with insulin pens and a blood glucose meter.

\subsubsection{Sterile aesthetics of current medical devices}

Currently medical devices for adolescents are limited in their aesthetic appeal and options. Both participants highlighted that their medical devices only come in basic colours such as blues, blacks, and greys. Pl: "There is like six colours for the pump, but it's very basic navy, blue, green, black, and grey." Participant 2 called the blue theme "clean" and "sterile" and thought that not all adolescents want a blue device. P2: "Well you know how diabetes is like blue, I know there is a blue theme going through it, because it's clean, but it doesn't need to be because people don't want all blue.”

Participant 2 was also in favour of the shape of the flash blood glucose meter. P2: "The libre [flash blood glucose meter] is good, it's quite slim, I like it being circular I guess, it would be weird if it was pointy I think, or like, it could be like a rounded square, it's quite flat which I appreciate." As the devices are worn on the adolescent's arm, they must be comfortable. Rounded edges are an important aspect of the design of a flash blood glucose meter, and a shape with pointy edges would be uncomfortable to wear.

\subsubsection{Behavioural strategies for testing in public}

Both the two individually interviewed participants had similar views about testing in public spaces. Participant 2 explained that they don't mind testing in public because it is something that helps to keep them healthy and alive: P2: "I don't mind testing in public, because I feel it's something you need to do." Participant 1 had similar feelings; however, they had been diagnosed at the age of three, so their knowledge of type 1 diabetes management developed from a young age.

P1: It's not like I can really hide it, but I do not actively try to hide it, I just use it like I would at home. It's quite different, I have had it for 11 years, but if someone had it for 3 months or something, it might become more awkward for them, and they might want to go off and do it privately.

Both participants felt similarly that testing is something that has to be done; 
however, Participant 2 described how they will purposefully turn away from people to test and inject as they are unsure who might feel squeamish looking at needles

P2: At lunch time I wouldn't do it that way [motioning to test towards people] to scare everyone off, I would turn away, so that people wouldn't be like "oh my god." Because you never know who is needle phobic, also my locker is right buy the cafeteria, so I get a lot of foot traffic past me.

FG3 had a similar opinion to Participant 2. Both felt comfortable testing in public; however, they were aware that other people might feel uncomfortable around needles or blood.

FG3: No I don't mind it, obviously if everyone is eating or something I won't do it in front of everyone, because it might be gross for them, like seeing the blood, because I have like a pencil case, I will just do it inside the pencil case, not just for me but because other people don't like it.

Testing in public spaces is something that both the interview participants felt confident and comfortable doing, and they felt it was their right to test in public; however, they did not make others uncomfortable.

\subsubsection{Adolescent theory of conspicuity}

Participant 1 had confident views on what makes a medical device appear medical, and the reasoning behind why people ask questions.

P1: I think the main thing is that there is something where people it's so obvious it's not medical - where people don't ask about it and then there is a period where it shows that it's medical so people don't ask about it; and then there's that middle zone, where people are unsure whether it's medical or not, so people ask you about it. But if you make it really discreet or really obvious people won't.

Devices that are clearly medical typically draw more attention; however, the public can also see that the device is medical, therefore they will not ask questions about what the device does, or what is wrong. Such objects are devices such as a wheelchair, glasses, crutches, and walkers

Alternatively, the 'middle zone' could involve medical devices such as type 1 diabetes medical devices, leg splints or prosthesis, Epipens, asthma inhalers, and hearing aids. These devices are less well known by the public, so onlookers are typically more curious about the function of the device, and why the person has to use it. The public cannot see inconspicuous medical devices, so there is no opportunity for them to ask questions about their function or the medical condition that they treat. 
When designing inconspicuous or conspicuous medical devices, Participant 1 said: "I think the whole thing of this is trying to make sure people do not look at it and immediately think 'oh it's medical, what's wrong?" This aligns with the requirements found in McCarthy's (2018) participatory design workshop.

\subsubsection{Adolescent preferences and ideas for new medical devices}

Adolescents had different opinions and ideas for new medical devices. The ideas discussed in this theme were important influencers for the design phase of the research. Sub themes include: creating a convenient device, using technology to improve current systems, and adolescent ideas for the aesthetic appearance of new medical devices.

\subsubsection{Creating a convenient device}

Having a convenient device would reduce the time a medical device is on show, making it more inconspicuous. Participant 2 regarded themselves as lazy, and so having an all-in-one connected system would address that.

P2: It would be cool if the insulin pen somehow linked up to the CGM. Because on the thing you can add your card and units. I am lazy and I do not do that ... and everyone tells me to, but I don't.

Participant 1 wanted a system that was all made by the same company. This would allow all their devices and applications to work together in a more seamless way. P1: "But having the possibility all made by one company, where they work together. Designing a system and standard over just one product. Creating convenient devices, that can integrate together".

\subsubsection{Using technology to improve the current systems}

Both individual participants wore flash blood glucose meters, and appreciated the constant information the devices provided them, as it made management easier. Participant 1 also wears an insulin pump. Participant 1 was more concerned about improving the insulin pump's interface, appearance, and size. "Well with the pump make it faster. Right now, you have to go through so many menus and buttons, and the size, maybe make it a bit smaller? Sometimes when I'm running and stuff, it gets a little bulky."

Participant 1 was particularly excited that they were getting a new pump soon that they considered more modern. P1: "It's the pump, it's straight out of 2007. I am getting a new pump on Monday. It's more modern." A more modern pump was exciting, as the participant had used the current one for 10 years.

One of the participants had a few ideas to suggest. The first idea was a watch that acted as a scanner so that it is easier to use a flash blood glucose meter. G2: "What if your watch was the scanner, so you just went [motioned towards 
scanning]. That would be smart, some can do that, and then you can pretend you are scratching your arm."

\subsubsection{Adolescent ideas for the aesthetic appearance of new medical devices}

Adolescents had different opinions about the aesthetic appearance of medical devices. During the group discussion I asked the female participants "Is there anything that you think would make it easier for you to test at school? For example, if it was smaller or more hidden?" FG2 used a pump and was wanting a pump that was slimmer and came in a lot more pattern options.

FG2: If the pump was a lot skinner cause the one I have is really big, and heavy, and if you have the case to clip on it's like double the size as well. You can only get different colours, black, green, blue, pink and purple. But you could have a design on them, I've always wanted a marble one. You can get stickers to go over the top of your pump.

In contrast FGl said that they did not care what it looked like, so long as it was as small as possible. FG1: "I just want it as small as possible so you can't see it. I don't care how it looks. Yeah, I just want it small, and less heavy.” don't care how it looks. Yeah I just want it small, and less heavy." 


\subsection{SUMMARY}

Although the individual participants were diagnosed at different ages, both felt comfortable testing in public spaces. This was something that I was not expecting, as other research had reported, that adolescents can have varying opinions when it comes to testing in public. Nevertheless, during the focus group, the females had different preferences to testing in public. Some adolescents felt comfortable, compared to others that felt uncomfortable managing in front of friends. It was interesting to discuss this during the focus group, as the participants were able to talk to each other and ask each other questions.

Convenience is a major factor that adolescents consider when deciding which medical device is best for them. Both of the individual participants use a flash blood glucose meter as it is smaller, more convenient and provides better information than a standard blood glucose meter. Convenience was also factor when it came to portability and playing sport. Participant 2 played more sport so used an insulin pen, whereas participant 1 did not play as much sport so an insulin pump was more suitable. Convenience also plays a role in the conspicuity of a device. Participants that used a flash blood glucose meter liked the device as it means that they do not have to carry as many bulky items with them.

When discussing ideas for new medical devices with participants, some participants were more concerned over the aesthetic appearance. Some participants were not concerned with the appearance of the devices, but just wanted the devices to be small and hidden. Other adolescents wanted devices that would match their personality or preferences for materials, colours and patterns. Moving forward these preferences will be important to consider in the design phase of the research. 
Chapter 5

\section{COLLAGING AND SKETCHING WITH INDIVIDUAL PARTICIPANTS}

The second stage of the session with the individual participants included exploring creative methods with the participants. The intention was to fulfill aim 1: understand adolescent's preferences when designing type 1 diabetes medical devices, and specifically objective 1: Investigate through qualitative and creative methods adolescents' experiences and preferences of medical-device related conspicuity in public settings. 


\subsection{METHODS}

\subsubsection{Participants}

Two participants were involved in the collaging and sketching tasks, as seen in Table 6.

Table 6. Participants involved in the collaging and sketching activities.

\begin{tabular}{|c|c|c|c|c|c|}
\hline Code & Name & Gender & Age & Medical Device & Session \\
\hline $\mathrm{Pl}$ & Participant 1 & Male & 15 & Pump and Libre & Individual \\
\hline P2 & Participant 2 & Female & 15 & Pen and Libre & Individual \\
\hline
\end{tabular}

\subsubsection{Procedure}

The first creative method explored with the participants was a collage (Martin \& Hanington, 2012; Sanders et al., 2010; Sanders \& Stappers, 2014) using images of products that explore the semantic-strategies developed in the literature review.

1. Enhance the traditional medical device to make it more beautiful.

2. Disguise the medical device as a non-medical item.

3. Conceal the medical device from the public.

4. Personalise the medical device for the user.

5. Use technology to advance medical device.

I selected approximately ten images for each strategy, allowing for a variety to be available for the participants to select. Some images of products were applicable for more than one strategy. The images did not contain any type 1 diabetes devices, instead they were of other medical and consumer devices that conformed to the strategies, allowing the discussion to be more about the strategy than the particular design implementation.

The other benefit of completing a collage also provided some visual representations and starting points for the adolescents to start sketching. Sketching (Martin \& Hanington, 2012) was the second method used this session. Sketching was used as it is quick, easy and less daunting than prototyping. Adolescents were asked to sketch ideas based off their favourite images from the collage, and what their ideal medical device would entail. 


\subsection{FINDINGS}

\subsubsection{Collage}

Pictured in Figures 18 and 19 are the annotated collages created by participants.

Both participants engaged well with the collage, using tactile images allowed them to make relationships and connections between the images. The participants placed sticky dots on the images and annotated the collages to indicate their likes and dislikes and identify aspects of the products might translate into a medical device. 


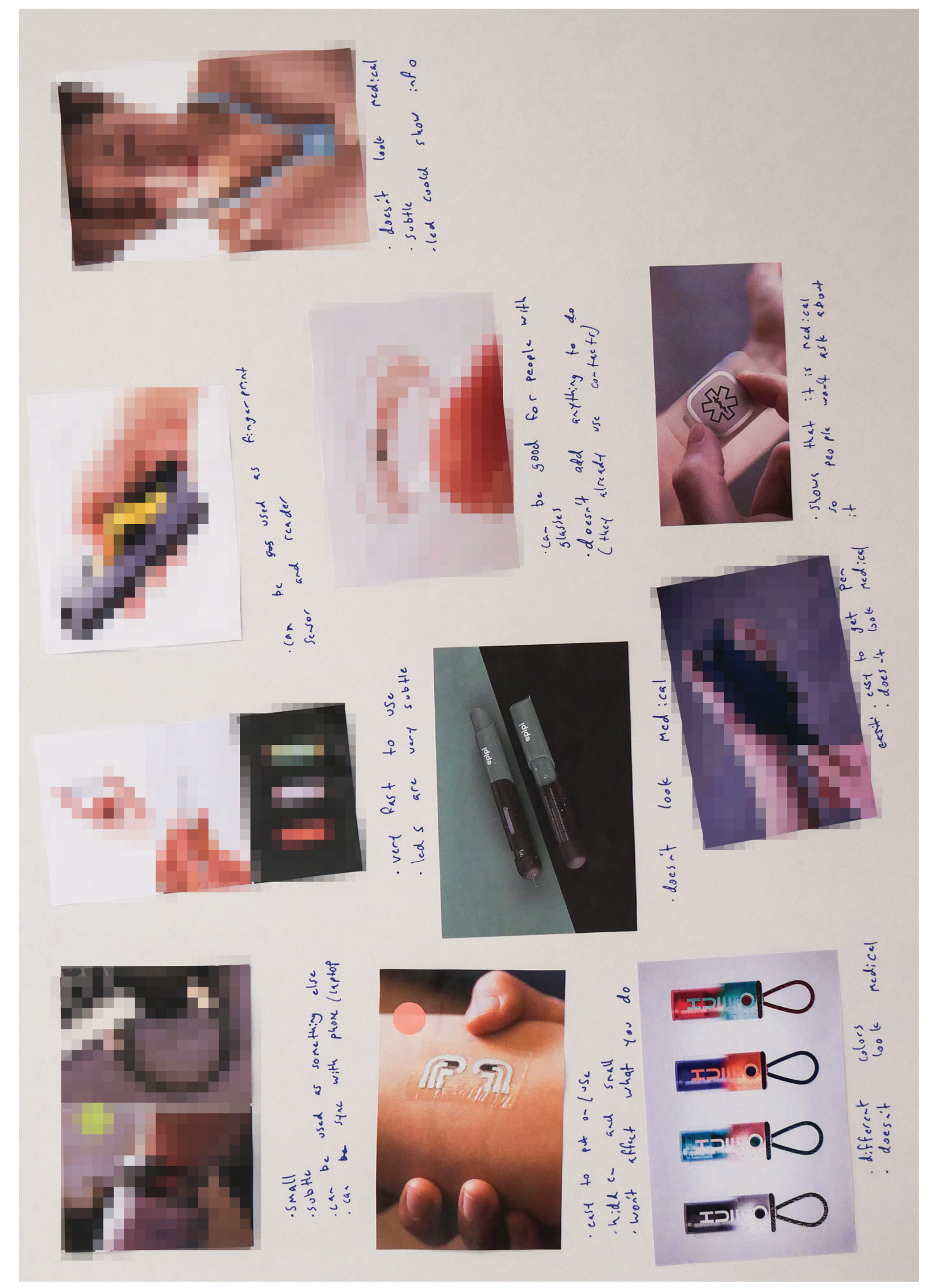

Figure 18. Participant 1 collage 


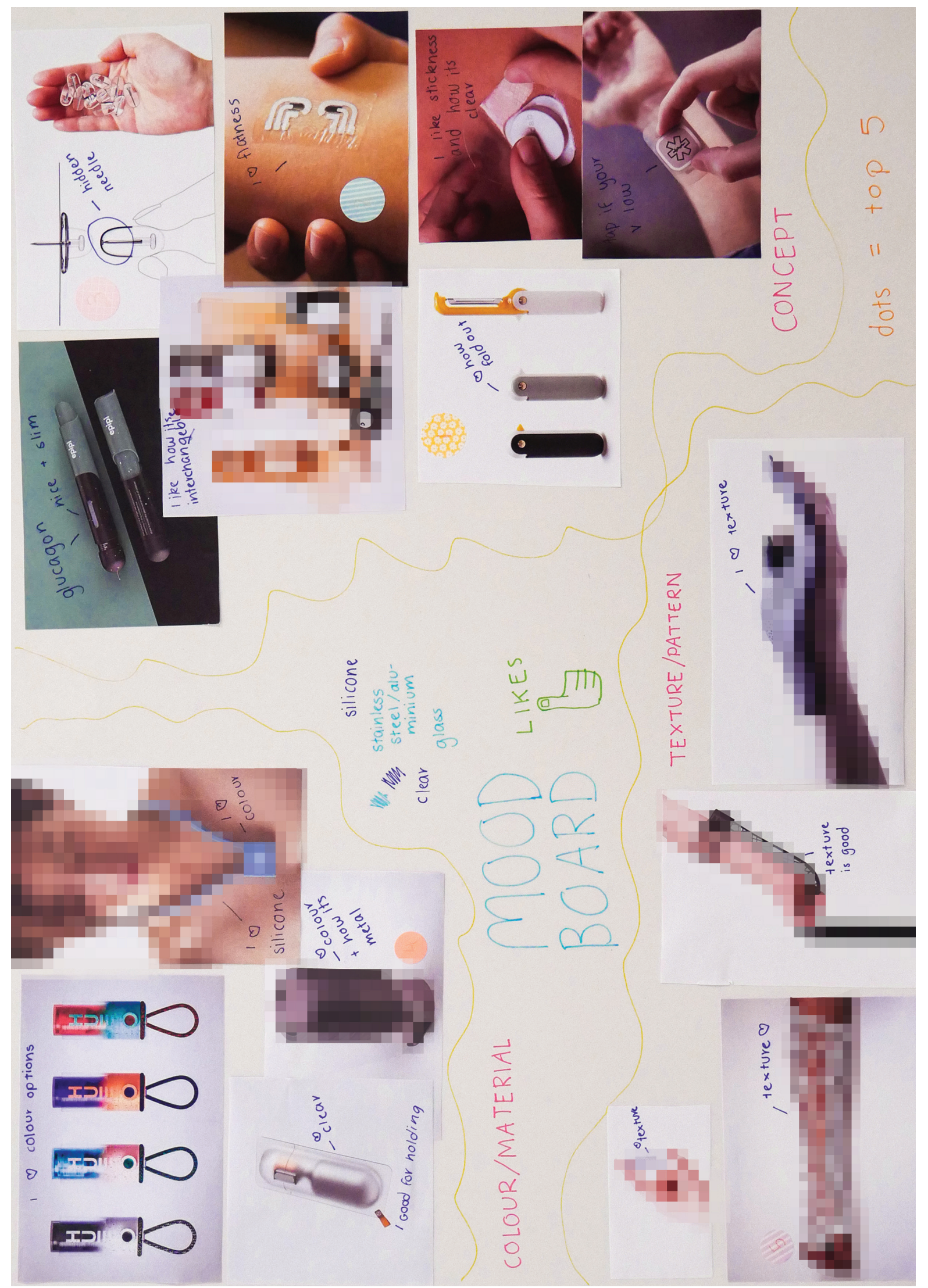

Figure 19. Participant 2 collage. 
Most of the images were chosen by participants because of their aesthetic appeal; they were interested in the products that did not appear immediately 'medical'. Participant 1 was in-terested in concepts that were more inconspicuous and subtle, such as the epilepsy sensor (Figure*), or products that were disguised as something else, such as cell phone cases or bracelets.

Participant 2 also placed the epilepsy sensor (Figure 20) on her collage, alongside the tattoo sensor (Figure 14), and the Dab sensor (Figure 12-13). sensor. Reprinted Some of these sensors are very similar to the current Freestyle Libre; however, they are a way of showing adolescents different shapes and concepts for a sensor or insulin pump.

Both participants placed the Epipen model (Figure 21) on their collages because it does not appear 'medical'. P1: "The Epipen, that model will be good for an insulin pen. You look at it and you don't think anything medical, it looks cool. It gives a different vibe." A similar concept that was on both participants' collages was the Hue Inhaler (Figure 22). Both participants liked the colour options. P1: "A lot of these are quite subtle I think this one [Hue inhaler] with all the colours, it doesn't make it look medical. It provides that personalisation.”

from Artefact Group, Designing a wearable for chronic conditions, 2014. Retrieved

from https://www. artefactgroup.com case-studies/dialog/ Copyright [2014] by the Artefact Group. Reprinted with permission.

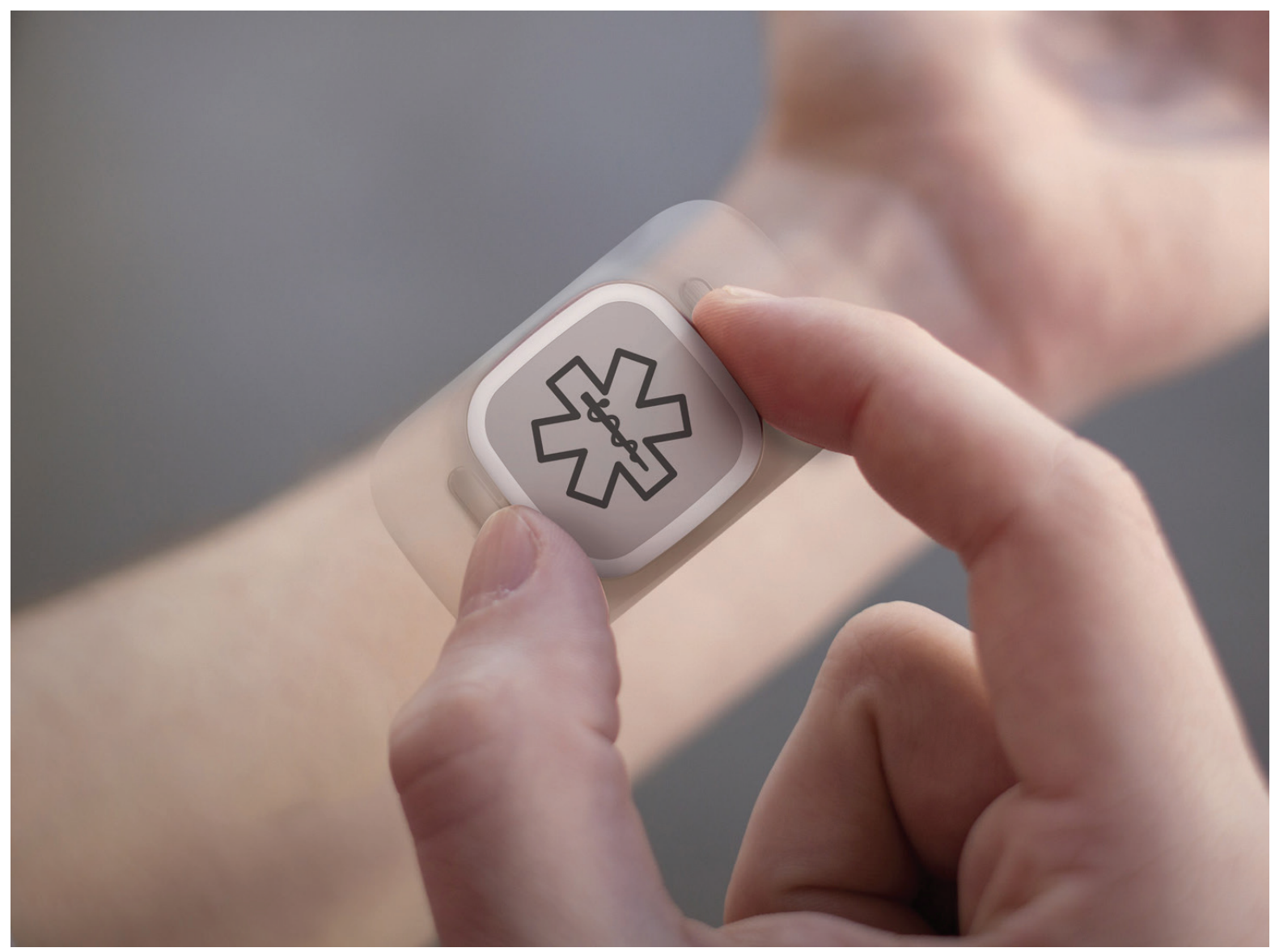




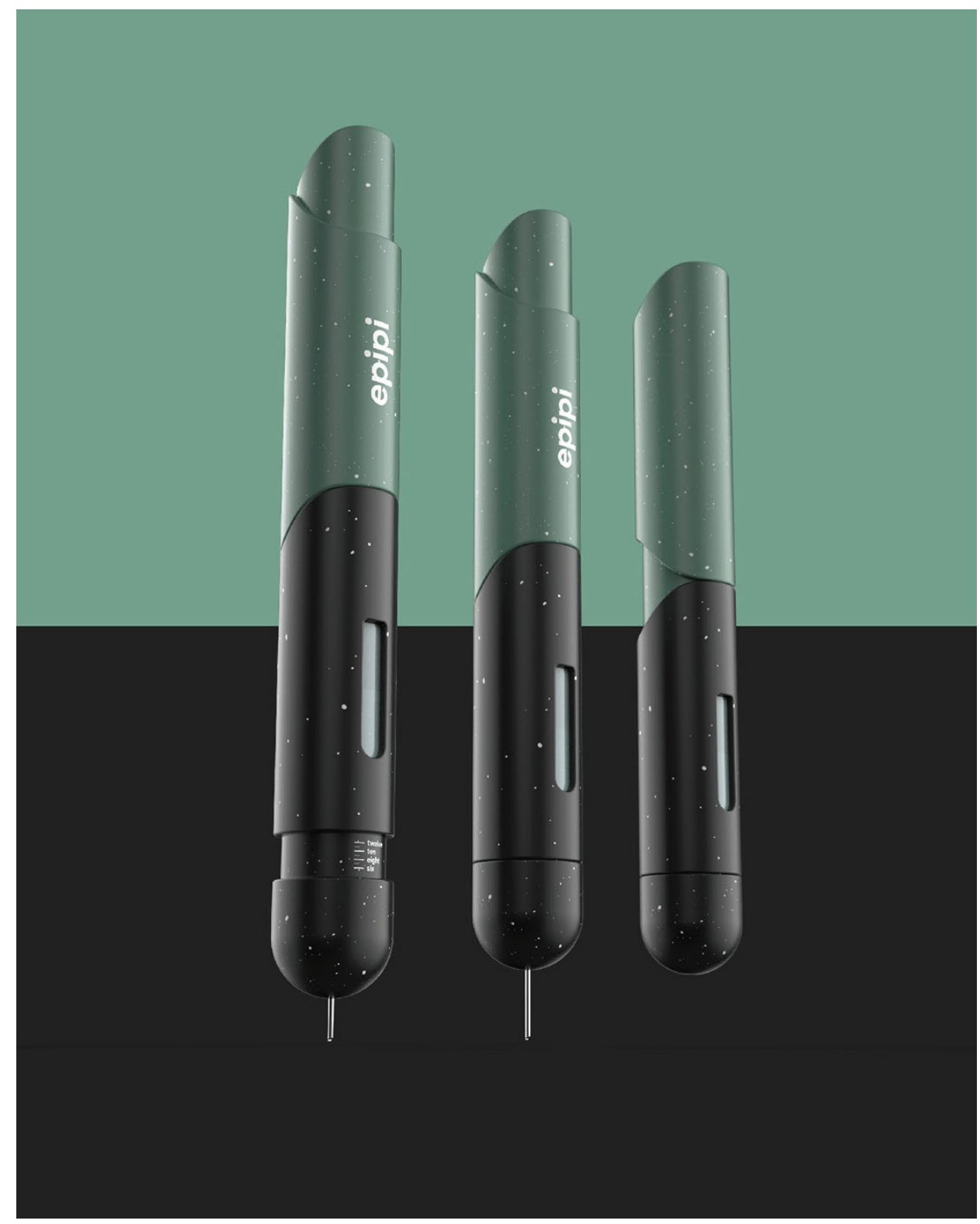

Figure 21. Epipi

interaction. Reprinted

from Epipi, H.

Moorman. Retrieved

https://www.behance.

net/gallery/54936019/

Epipi. Copyright [2017]

Harry Moorman.

Reprinted with

permission

Figure 22. Pink and

purple hue inhaler.

Reprinted from Hue

Inhaler, T. Zarki, 2017.

Retrieved from https://

www.zarki.net/work

huin Copyright [2018]

Tim Zarki. Reprinted

with permission

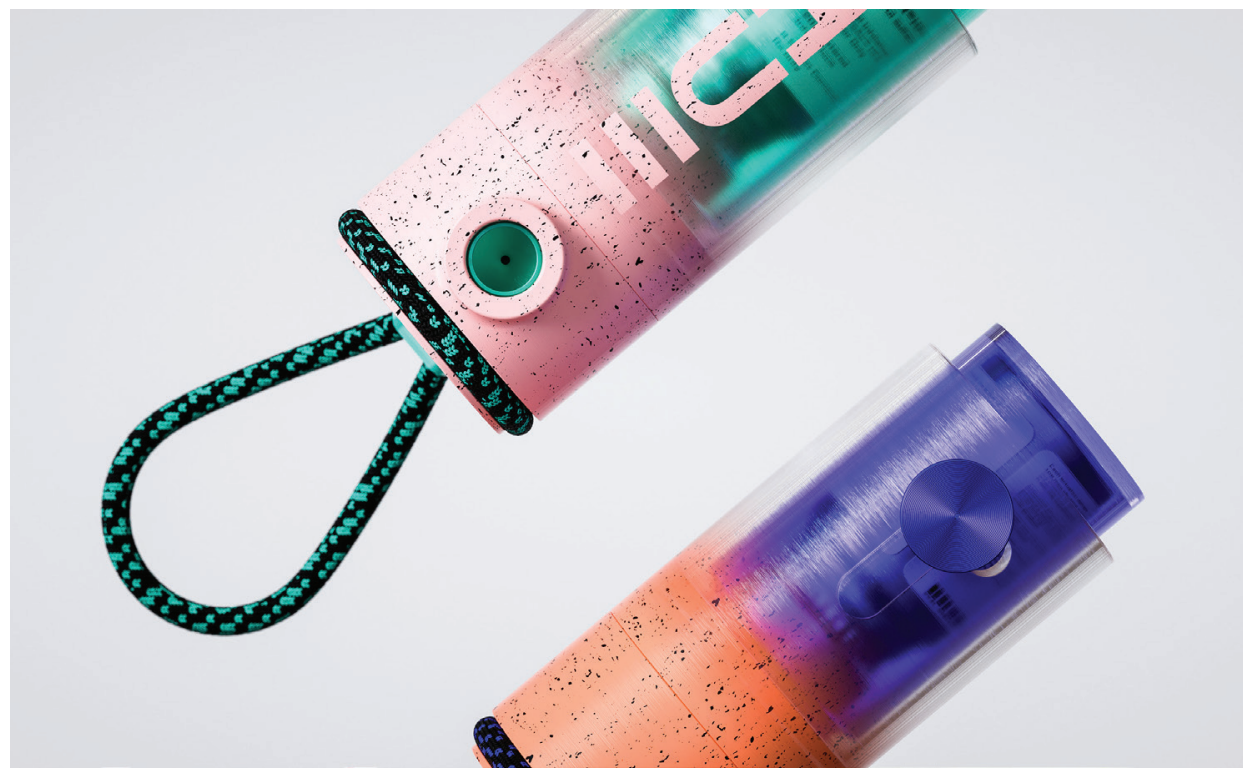


Participant 2 was interested in creating a design that other people would also be interested in. She was aware that not everyone might be confident when diabetes testing, or that they might fear needles. When talking about the needle head, the silicone casing on the biomimicry pin (Figure 23) was discussed as a way to conceal the needle.

P2: This [biomimicry pin] would look good on the Freestyle Libre [flash blood glucose meter], there's this massive needle sticking out, when you're about to insert it. It's this massive needle just there, and you're like 'aaahhh.' that would be clear. But not clear for some people because they might get scared.

The images the participants selected for their collages helped them start thinking about creative ways to improve their medical devices. Following on from the collages, the participants sketched ideas for new medical devices.
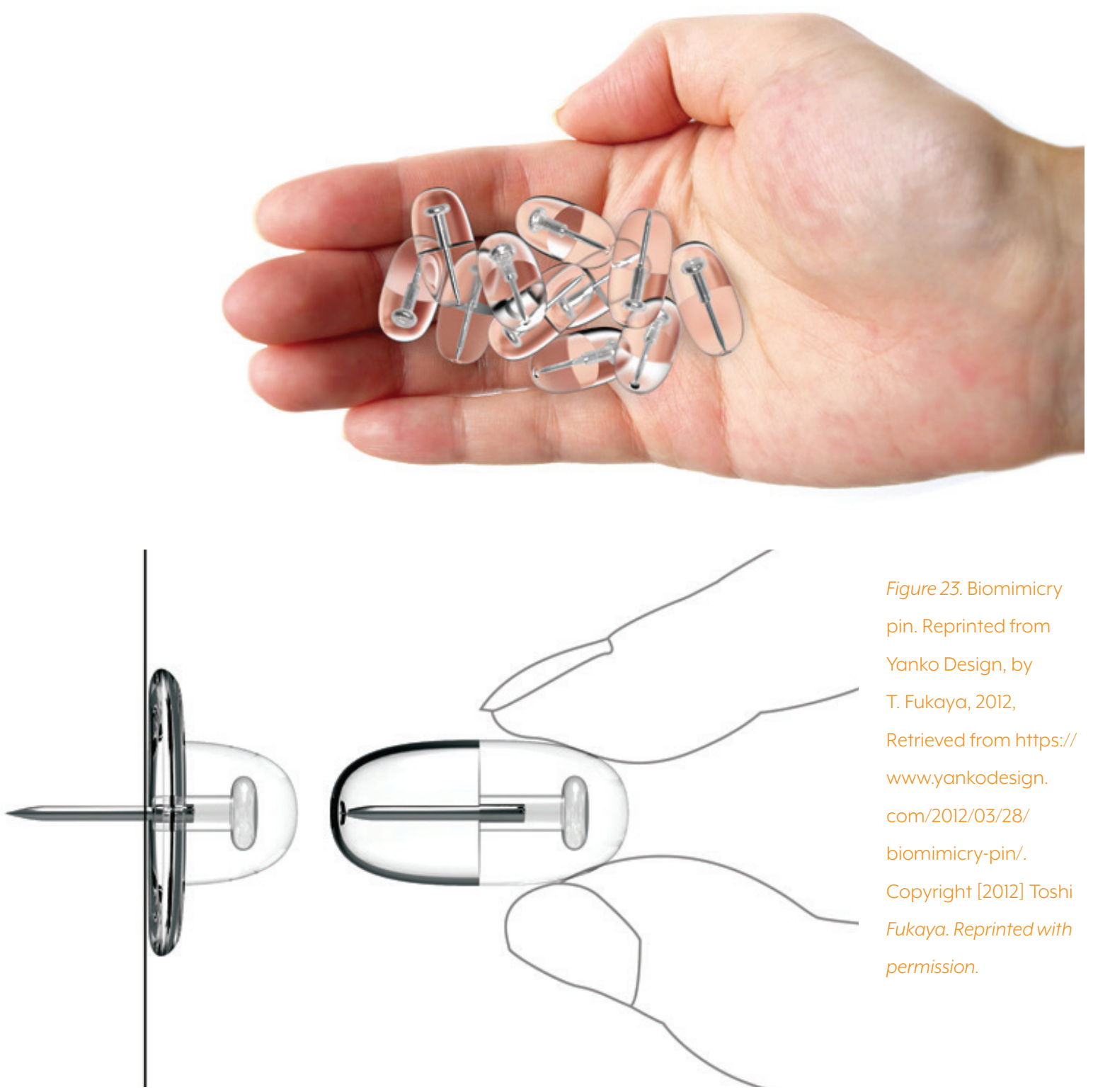

Figure 23. Biomimicry pin. Reprinted from Yanko Design, by T. Fukaya, 2012 Retrieved from https:/ www.yankodesign com/2012/03/28 biomimicry-pin/ Copyright [2012] Toshi Fukaya. Reprinted with permission 


\subsubsection{Sketches}

Both participants were interested in creating a device that was an all-in-one tool. They both found their current systems inconvenient, and Participant 2 regarded carrying everything with them as "annoying.” Participant 2's 'all-inone' device (Figure 25) is a portable testing and administering device. "You could have a three-in-one tool! So, it would be like your injection, finger pricker and blood glucose meter.” This device would not only be convenient but also a more beautiful device that would not be recognised as easily by the public because of its casing.

Like Participant 2, Participant 1 wanted a device that was convenient and linked all his current devices together. They wanted the opportunity to create an all-in-one modular device (Figure 24). The device would be worn on the arm, like the flash blood glucose meter. P1: "Yeah you could have lots of pieces! One's got the insulin, one's got the battery, and one's got the Libre [flash blood glucose meter].” The participant liked the idea of technology developing in the not-too-distant future whereby all their devices could be in one spot on the body and all linked to a phone app to control blood glucose levels, and insulin administration.

Fiqure 24. Participant 1 sketch of an all-in-one insulin pump and flash blood glucose meter
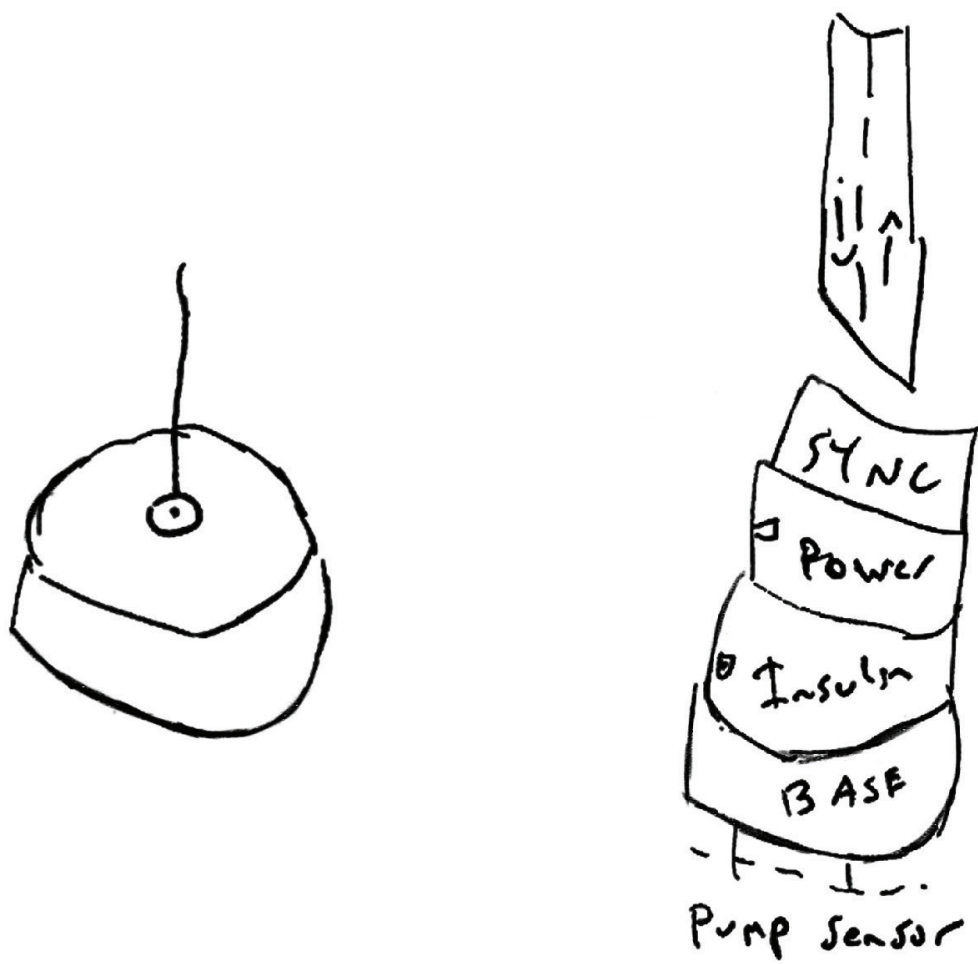
COLLATING AND SKETCHING WITH INDIVIDUAL PARTICIPANTS

CASING - MESH -STAINLESS STEEL

OPENING

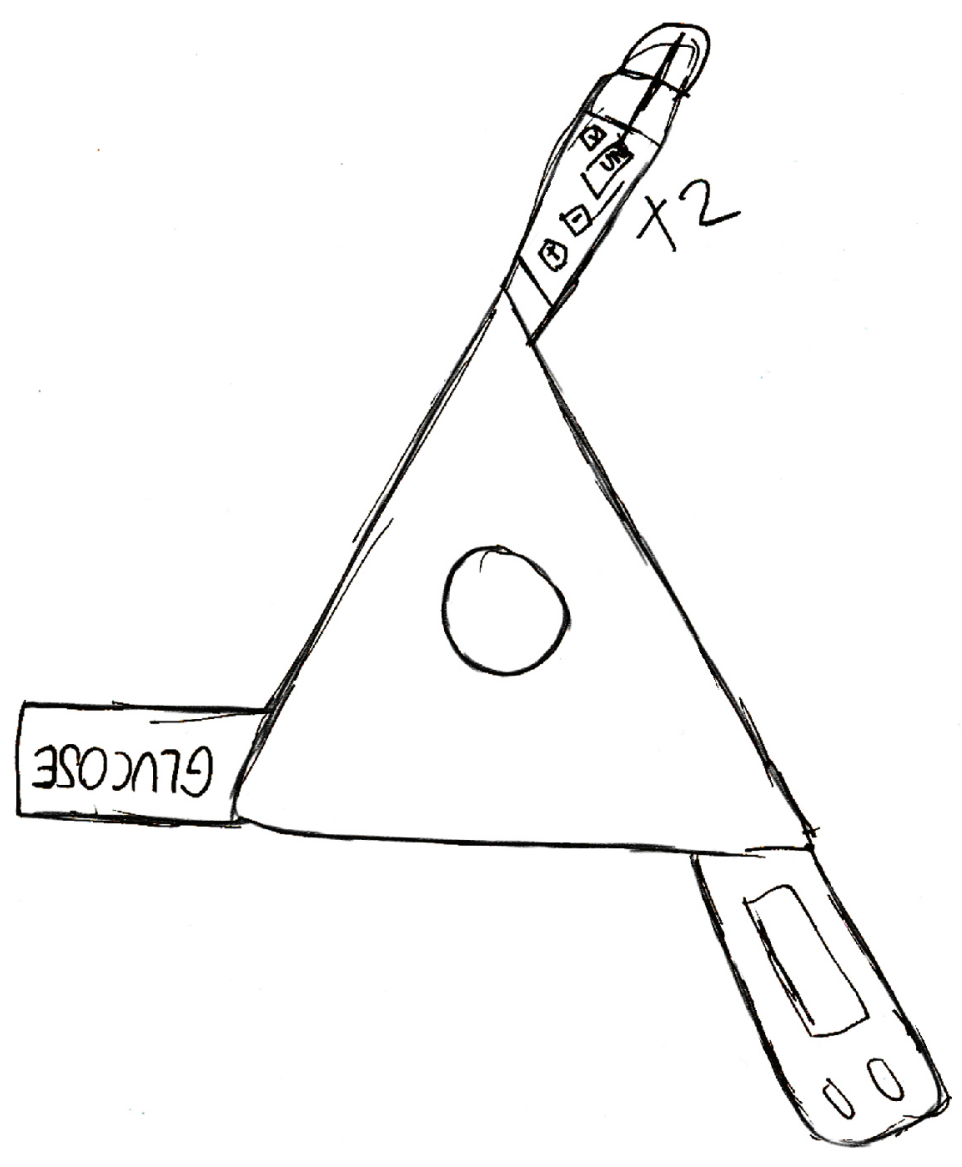

Figure 25. Participant 2 sketch of an all-in-one medical device.

| 72 


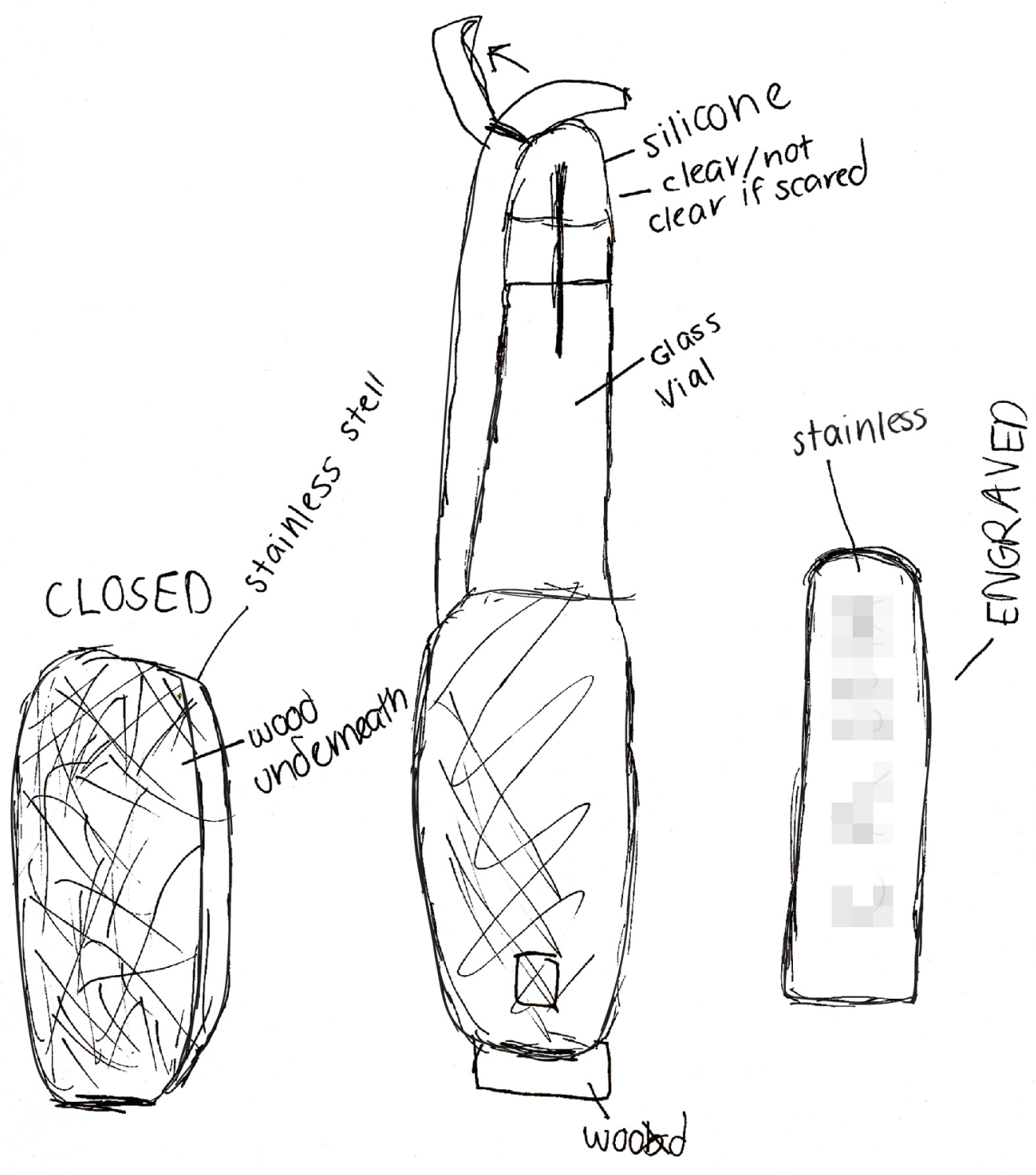


Participant 2's second sketch was of an insulin pen that is encased in metal. The object would have a similar texture to the Cortex cast by Jake Evill. The top of the model would have a silicone cap covering the needle, similar to the biomimicry pin pictured in Figure 23.

Participant 2 also drew inspiration from other objects that were chosen for their collage, such as the tweet peeler (Figure 27).

P2: I don't think the penguin will work for everyone, so I am going to avoid the penguin part. I like how it's circular and rounded but then it might not stand up so it needs a flat bottom, a very flat one so it can stand, with a rounded edge.

The Tweet peeler inspired the functionality and interaction of the final form sketched by Participant 2 (Figure 26).

The final sketches from the participants helped inform the designs later in the design phase - forming an idea that is like the all-in-one devices that both participants sketched, and also the insulin pen sketched by Participant 2 .
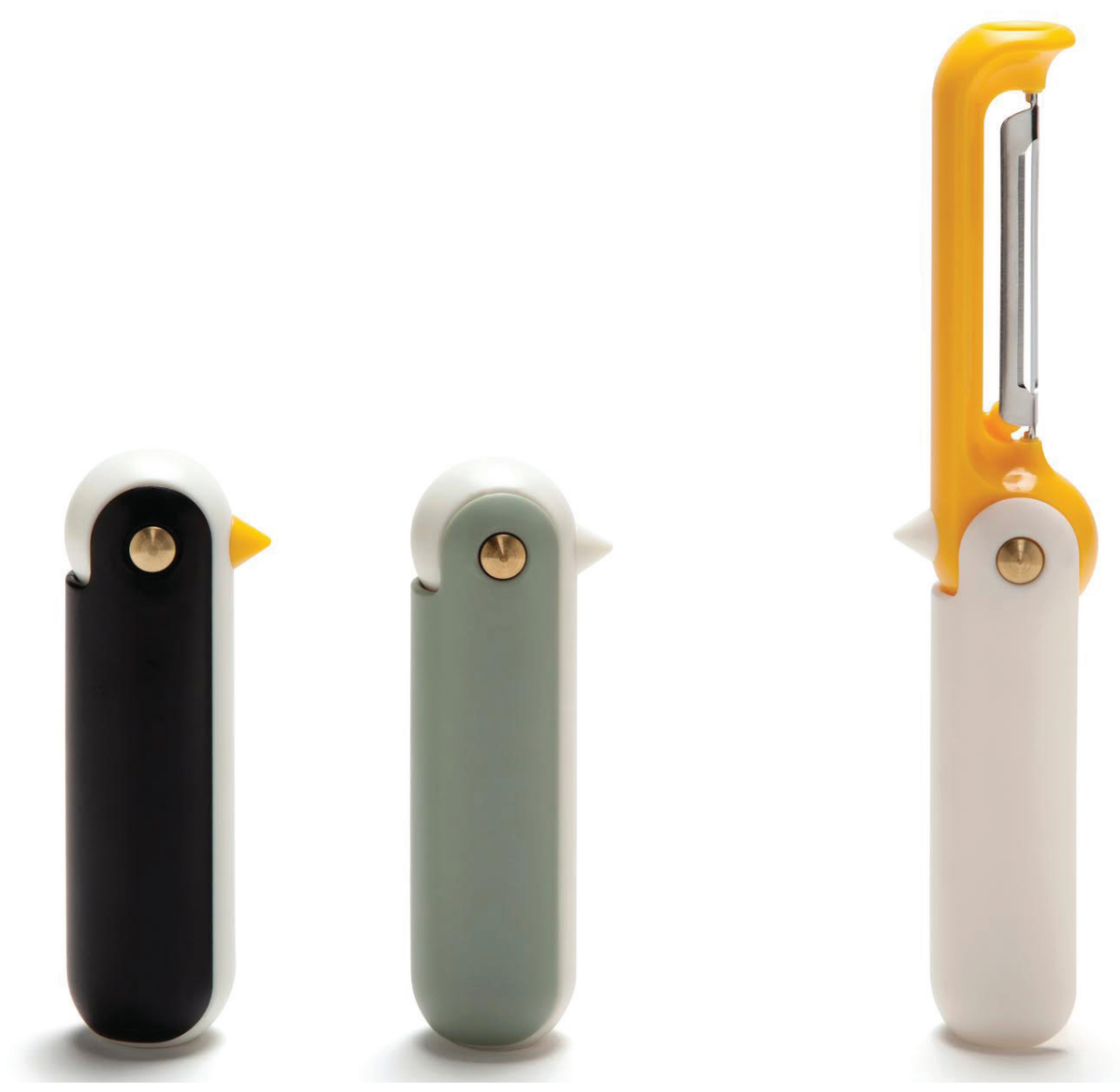


\subsection{SUMMARY}

Both participants drew an all-in-one device, combining the blood glucose meter, insulin pen, and another aspect such as a finger pricker or glucose source. An all-in-one medical device is something that can be explored alongside one of the semantic strategies, such as enhancing the aesthetics of the medical device, or personalising the medical device.

Something both participants mentioned during the collage was to have a blood glucose meter in their veins, or as an implant of some description. This is an idea that could be realised in future, with developments under way including the Google blood glucose meter contact lens, tattoo ink that measures blood glucose levels, and blood powered micro-chips.

Although technology was used to achieve all of these products, moving forward with this research the strategy Advancing the technology of the medical device was removed. This was because technology was understood to be an enabler of other semantic strategies, but not a semantic strategy in itself. For instance, the use of technological advancements to create a microchip-based glucose meter could also be understood as concealing the medical device. 
Chapter 6

\section{CREATIVE METHODS WITH FOCUS GROUP}

While the previous chapter involved individual interviews and tasks, the second meeting with adolescents with type 1 diabetes was in a focus group at a family diabetes camp. The focus group aimed to fulfil Objective 1: Investigate through qualitative and creative methods adolescents' experiences and preferences of medical device-related conspicuity in public settings. 


\subsection{METHODS}

The methods intended to be used during the focus group included poster vignettes (Lang, 2012; O’Brien, 2003), brainstorming (O’Brien, 2003), and sketching (Martin \& Hanington, 2012). I analysed the results with six-step thematic analysis (Braun \& Clarke, 2012) as described in the methodology section. The full focus group plan is in Appendix D.

\subsubsection{Participants}

Participants were four females and four males with type 1 diabetes aged 13 to 18, involved in the focus as seen in Table 7.

\begin{tabular}{|l|l|l|l|l|l|}
\hline Code & Name & Female & 14 & Pen and Libre & Focus Group \\
\hline FG1 & Focus Group 1 & & Age Medical Device & Focus Group \\
\hline FG2 & Focus Group 2 & Female & 14 & Pump and Libre & Focus Group \\
\hline FG3 & Focus Group 3 & Female & 15 & Pen and BGM & \\
\hline FG4 & Focus Group 4 & Female & 13 & Pen and Dexcom & \\
\hline FG5 & Focus Group 5 & Male & 15 & Pump, pen and BGM & Focus Group \\
\hline FG6 & Focus Group 6 & Male & 15 & Pen and Libre & \\
\hline FG7 & Focus Group 7 & Male & 13 & Pump and Libre & Focus Group \\
\hline FG8 & Focus Group 8 & Male & 13 & Pump, BGM & Focus Group \\
\hline
\end{tabular}

\subsubsection{Procedure}

I facilitated the workshop on the final day of the family camp, so all the participants had met each other earlier in the weekend. The first workshop activity was the worksheet pictured in Figure 28. The worksheet showed the focus group rules, and also had a few questions regarding the medical devices participants currently used, and any initial thoughts about how their medical devices could be improved. Secondly, participants were asked draw blind portraits in pairs as pictured in Figure 29 so they would become comfortable with one another and the drawing activities. 


\section{Hi Welcome! Please find your own space, and read the following rules for the focus group. Then fill out the small task below}

- The information shared in this meeting is confidential. You should not discuss the opinions and comments made by other focus group participants with anybody outside this room. We would like you and others to feel comfortable when sharing information.

- You do not need to agree with others, but you should listen respectfully as others share their views.

- We would like to hear a wide range of opinions: please speak up on whether you agree or disagree.

- There are no right or wrong answers, every person's experiences and opinions are important.

- The meeting is audio recorded, therefore, please one person speak at a time.

- Please turn off your phones.

Name:

Age:

Around what age were you diagnosed with type 1 diabetes?

What type 1 diabetes medical devices do you currently use? (for example, blood glucose meter, insulin pen, insulin pump, continuos blood glucose meter, etc.)

Do you have any ideas for how we can make your medical device better?

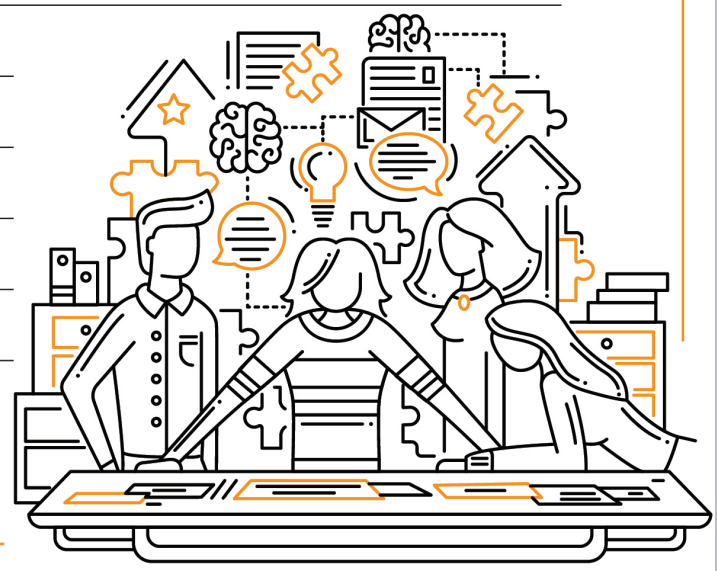




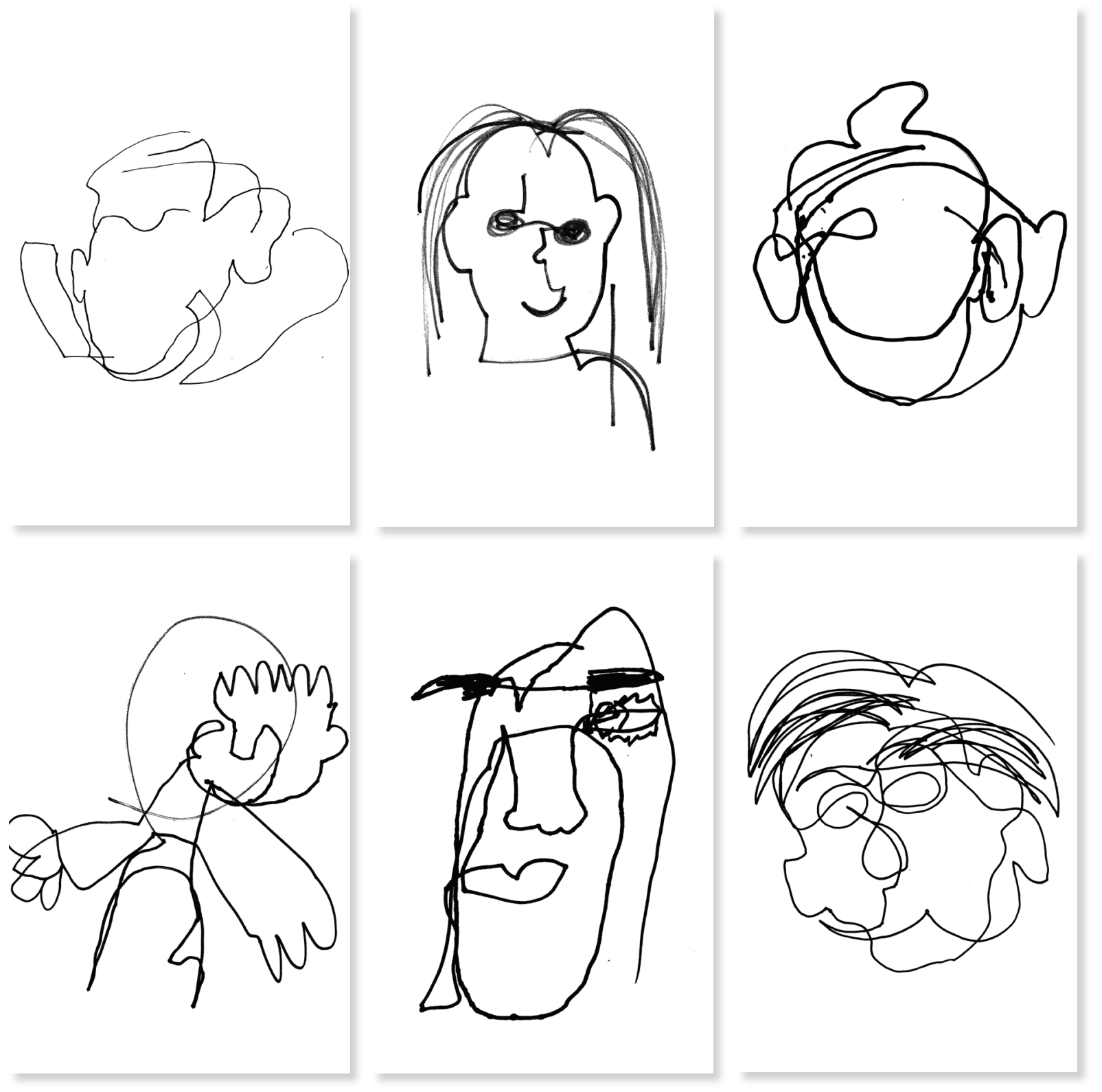

Figure 29. Participant blind portraits of each other.

Staying in their pairs, the participants were instructed to approach a vignette station. Each station had a question written in simple language and corresponding sketches of ideas that were produced based on the interviews with the adolescents (Figure 30). Each of the questions pictured in Figure 30 corresponded with a semantic strategy:

1. Enhance the aesthetics of traditional medical devices

2. Personalise the medical device to the user

3. Disguise the medical device as a non-medical item

4. Conceal the medical device from the public 
How might we design your medical devices to make their appearance more beautiful, modern or cool?

How might we design your medical devices so it's disguised as another everyday object?
How might we design your medical devices so they are personalised to you?

How might we design your medical devices so you can't see it while you are using it in public?

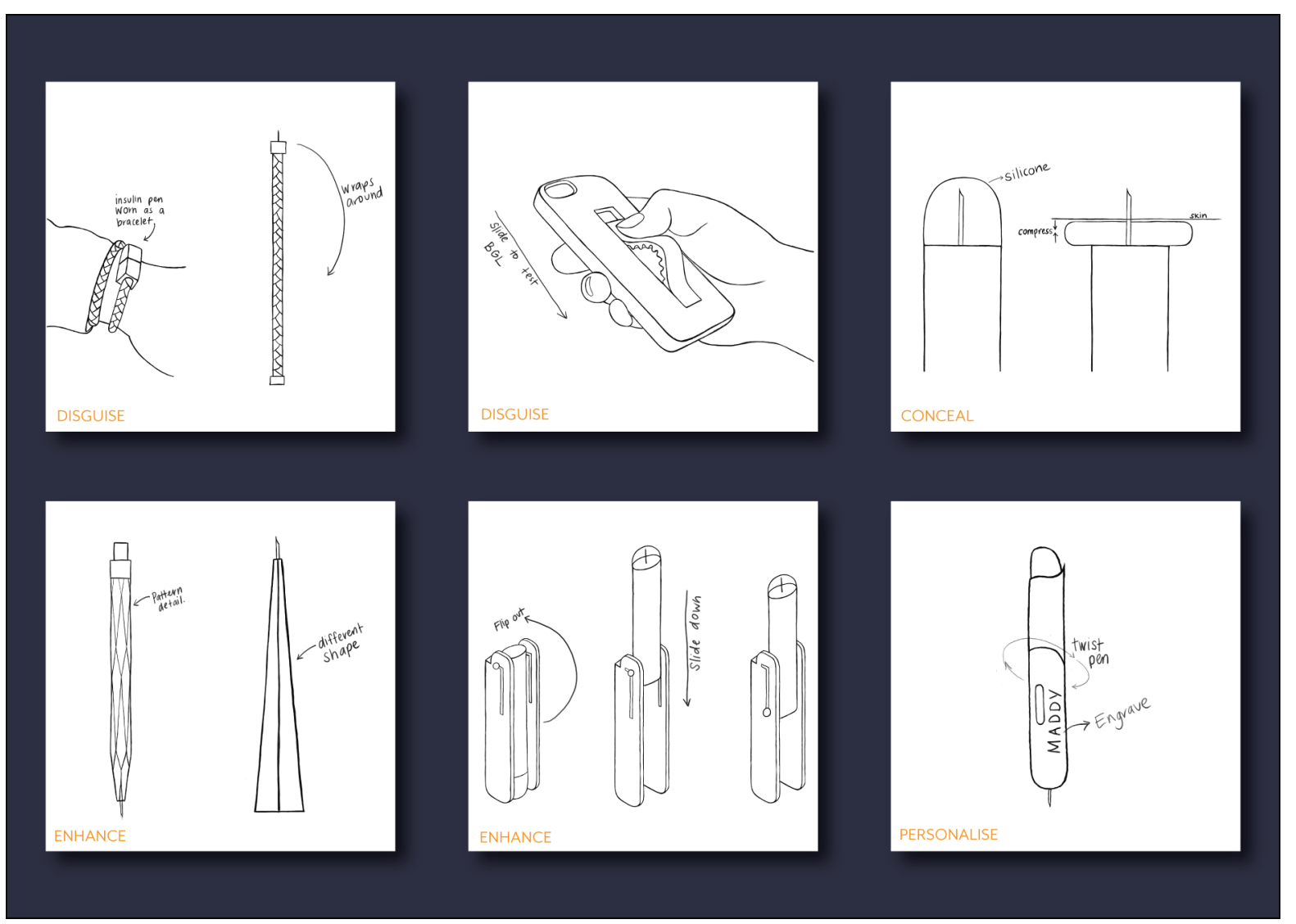




\subsection{FINDINGS}

The results below are organised based on the four semantic strategies.

\subsubsection{Participant ideas to make the medical device more beautiful}

One of the ideas that related to the strategy to enhance the aesthetics of the medical device was written by FG3. As seen in Figure 32, she asked for "different shaped pens with more grip, like a geometric shape." She said that her current pen did not have enough grip, so a geometric shape would provide more stability (Figure 31). Most of the ideas participants wrote down for this question could also fit into one of the other strategies. For example, one participant wrote down an idea that could also fit into the strategy to personalise their medical device; "Be able to design your own pens, so we can make it more to your liking." One of the other ideas was to make the medical device "look like a phone" which also fits into the disguise strategy. Some of the other ideas did not pertain to the design of medical devices, but accessories for current devices such as a bag, or special tape for their flash blood glucose meter.
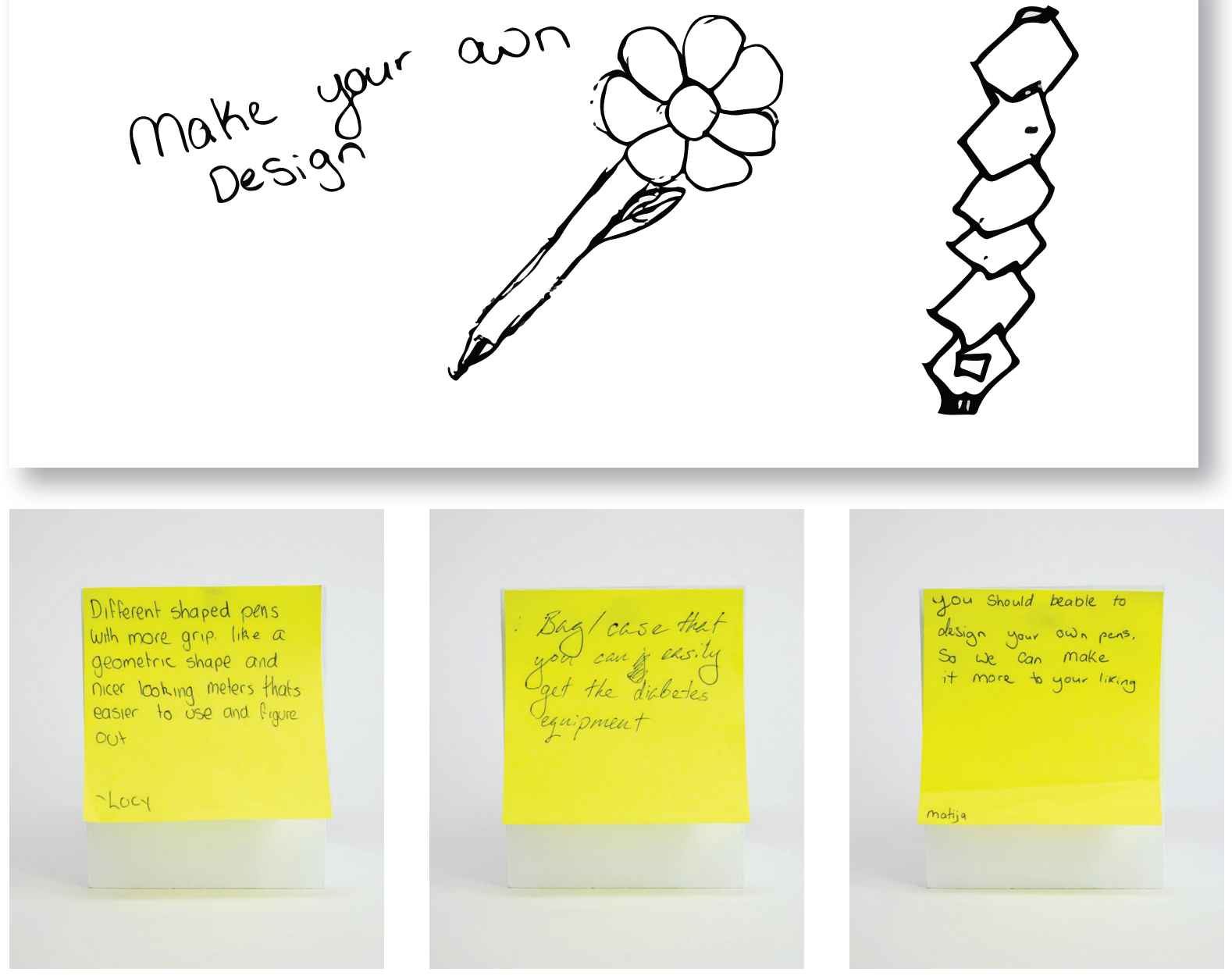


\subsubsection{Participant ideas to make the medical device more}

\section{personalised}

Participants responded to this question most enthusiastically, as they were able to think about their personal preferences and the changes they wished to make to their medical devices. Although other questions also asked them to do this, including the word 'personalised' was an effective prompt for creativity. Many of the ideas involved using technology to personalise devices. For example, one participant wanted to have personalised ringtones to let them know when their blood sugars were low. Others wanted to have customisable settings, or the opportunity to design stickers for the exterior of their devices (Figure 34). This could be something similar to the Nike-iD website, allowing adolescents to upload images, patterns, or colours to a base design of a blood glucose meter. Some of the answers were very broad, such as "different design features" which made analysis challenging.

As seen in Figure 33, participants sketched a personalised pump that would be smaller and lighter. The pump would provide choices for music and images.
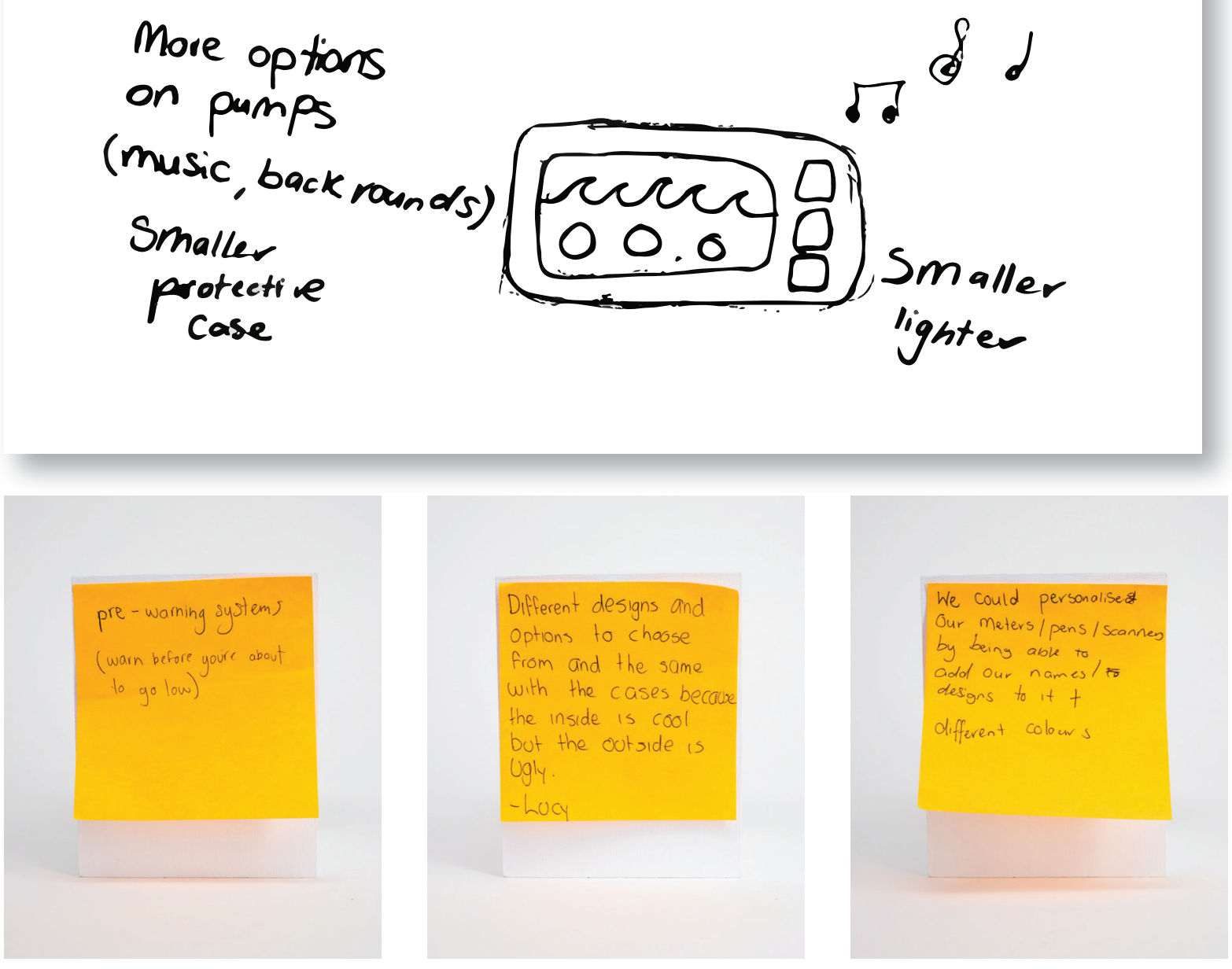


\subsubsection{Participant ideas to better disguise the medical device}

This idea generated the most detailed sticky notes, and the adolescents enjoyed thinking of products they could disguise their medical devices as. One of the most common items they thought they could disguise their medical devices as was jewellery (Figure 36). The participants explained ideas for a blood glucose meter ring and necklace. This could have been influenced by the idea I drew that was included in the vignette of the bracelet (Figure 30). Other adolescents wanted their devices to be incorporated with their phone in some way or to be disguised as stationery (Figure 36).

As seen in Figure 35, FG5 drew an idea for a watch or bracelet accessory that could scan a flash blood glucose meter, for a more inconspicuous way of testing blood glucose levels.
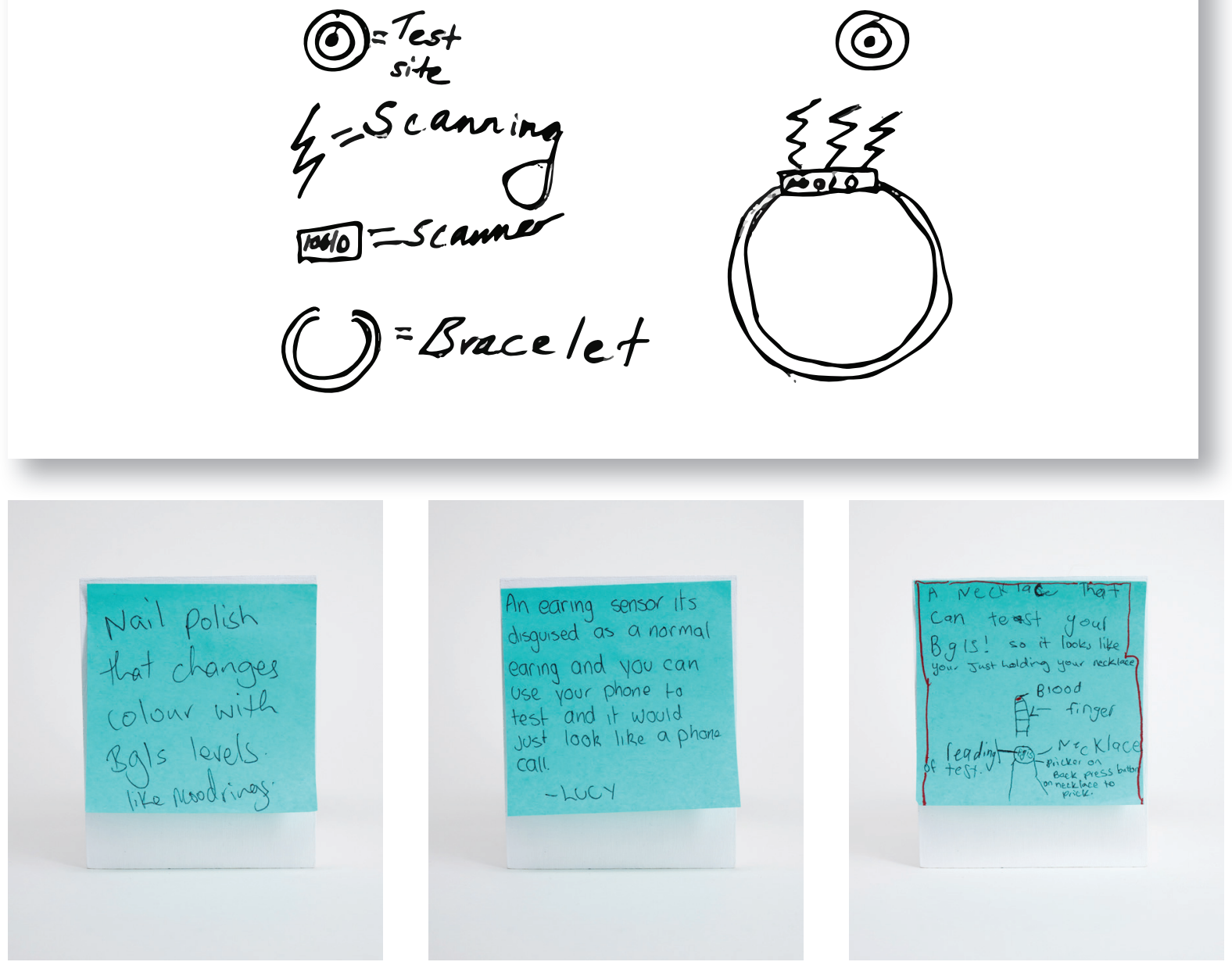


\subsubsection{Participant ideas to make the medical device concealed}

Participants struggled with this strategy the most; most ideas involved finding a cure, making a slimmer pump, or creating a micro-chip that sits under the skin (Figure 38). The idea of producing a microchip that tests blood glucose levels was also mentioned in the interviews with individual participants; again, this is a way that technology can be used to conceal medical devices from the public. Figure 37 also shows a sketch FG3 drew of the microchip that would sit underneath the skin. Most participants liked the sketch I had produced of the silicone cap that covered the needle. Many of the participants noted that they did not like needles, and this would mean that they would not have to see the needles when they were injecting insulin. Participants in the individual interviews also liked the idea of covering the needle, so perhaps adolescents would like the idea of concealing the aspects of the medical device that make it more recognisable.
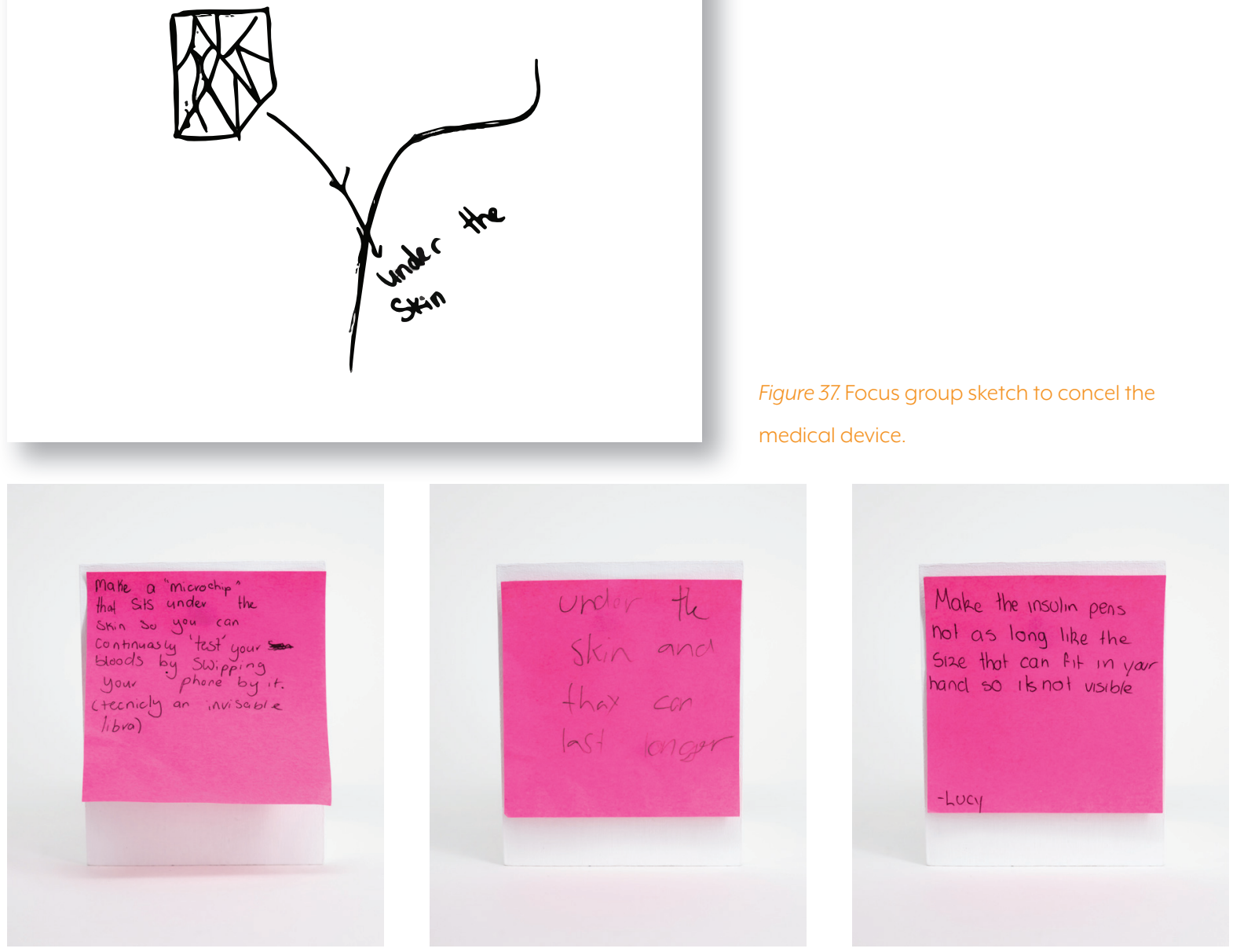

Figure 38. Personalised strategy ideas from the focus group 


\subsection{SUMMARY}

Although there were some interesting discoveries and findings during the focus group, it did not follow the initial plan. From the start of the workshop, it was evident that the male participants were not very interested in the tasks. Other camp activities were available that these participants seemed to prefer. However, it is possible that their parents had advised them to attend the focus group.

The vignettes produced mixed results. While some of the adolescents enjoyed being able to write their ideas on the sticky-notes, others struggled to produce ideas, were embarrassed to write ideas down for the fear of them being 'uncool' or 'stupid', or thought a cure was the only possible way to fix things. The other difficulty they faced was distinguishing between the strategies, and as such there was often cross-over, particularly with ideas that embodied personalisation.

As many of the participants became distracted during the vignette task, I thought that the sketching activity might be more engaging. Originally participants were going to be asked to draw a device in pairs based off their favourite idea. Since many of them had not thought of many ideas, I asked them to draw what they would like their medical devices to do, or if they could expand on a post-it-note idea.

Although this focus group did not follow the intended plan, some notable ideas and experiences were explored through the vignette task and sketching. The visual vignettes created an opportunity for participants to write down ideas rapidly, and to be inspired by sketches that I had already created. Sketching was also successful in allowing expansion of the quick ideas from the vignettes. 
C.

87 


\section{DESIGN EXPLORATION}

The interviews and focus group results were highly informative regarding exploring the possibilities for new devices and the experiences adolescents had that might shape their opinions of new devices. This chapter describes the design phase of the research, which intends to fulfil Aim 2: Use a range of semantic strategies to develop and test conceptual medical device designs that provide adolescents with type 1 diabetes the opportunity to match users' preferences for conspicuousness - particularly Objective 3: Design and evaluate the conceptual designs of medical devices' alignment with adolescents' requirements towards facilitating conspicuity in public settings. Four prototypes, each pertaining to one of the strategies, are explored in this chapter. 


\subsection{METHODS}

High fidelity models were created during design exploration. The models were made to demonstrate interaction and materiality. The models do not include other aspects such as electronic interfaces or medical components. All the models were produced through varying forms of additive manufacturing, depending on what materials they needed to be made from, and the fidelity of the print. 3D printing is effective for creating one-off prototypes. The final 3D printing processes used can be seen in Table 8 . The findings from the previous primary research influenced the final designs. A prototype was created for each of the four final semantic strategies.

\begin{tabular}{|l|l|l|l|l|}
\hline 3D printer & Material & Source & Process \\
\hline $\begin{array}{l}\text { Fused deposition } \\
\text { modelling (FDM) }\end{array}$ & $\begin{array}{l}\text { PLA and ABS } \\
\text { Plastic }\end{array}$ & In-house & $\begin{array}{l}\text { Most common form of 3D } \\
\text { printing. Heats and extrudes } \\
\text { plastic in layers. }\end{array}$ & $\begin{array}{l}\text { Disguise, } \\
\text { personalise, aesthetic } \\
\text { and conceal }\end{array}$ \\
\hline $\begin{array}{l}\text { J750 } \\
\text { Ink jet } \\
\text { photopolymer 3D } \\
\text { printer }\end{array}$ & Resin & In-house & $\begin{array}{l}\text { Layers resin and cures it with } \\
\text { light. }\end{array}$ & Conceal and aesthetic \\
\hline $\begin{array}{l}\text { Shapeways } \\
\text { ExOne metal 3D }\end{array}$ & $\begin{array}{l}\text { Stainless } \\
\text { steel }\end{array}$ & Outsourced & Layers steel powder & Aesthetic \\
\hline $\begin{array}{l}\text { Shapeways Projet } \\
\text { 3500 CPX Max }\end{array}$ & Silver & Outsourced & $\begin{array}{l}\text { A 3D printed wax model is cast } \\
\text { using traditional techniques to } \\
\text { make a silver model. }\end{array}$ & Aesthetic \\
\hline $\begin{array}{l}\text { Shapeways Mutli- } \\
\text { Frosted }\end{array}$ & Outsourced & $\begin{array}{l}\text { Layers of nylon powder are } \\
\text { cured with heat }\end{array}$ & Aesthetic \\
\hline
\end{tabular}




\subsection{FINDINGS}

The final prototypes (Figure 39) were not designed to be functioning medical devices for two reasons. Firstly, it would be unethical to test functioning prototypes without meeting safety standards, and secondly, the primary purpose for the prototypes was to discover adolescents' preferences for conspicuity and to inform designs that meet those requirements. Product semantics is an important factor within this, and so focus was placed on the appearance, materiality, and finish of the models.

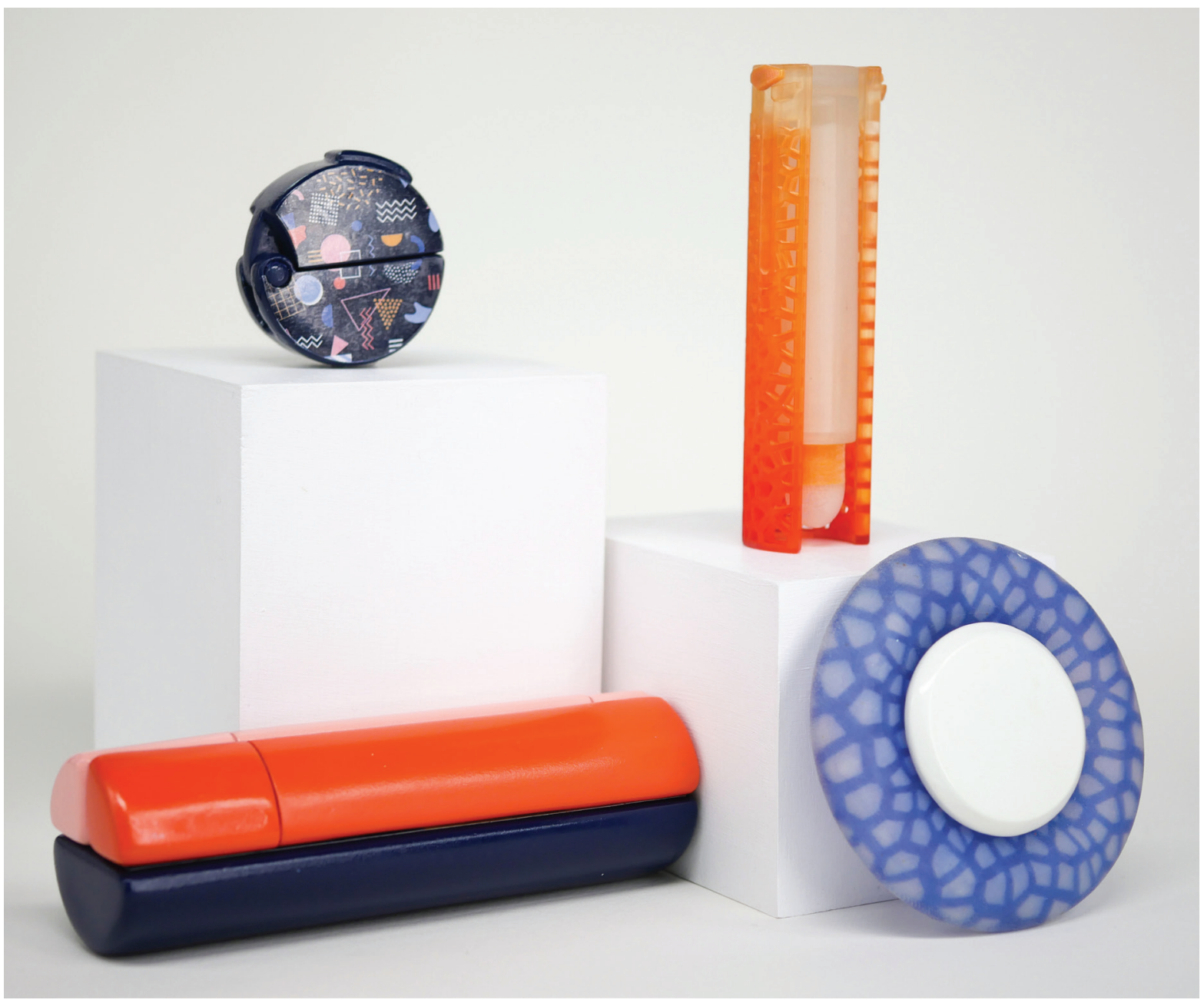

Figure 39. Final four prototypes pertaining to each strategy 


\subsubsection{Enhance the aesthetics of the traditional medical device}

\subsubsection{Adolescent input into concept}

When discussing ideas with participants in the individual interviews,

Participant 2 was primarily interested in enhancing the aesthetics of the medical device. Her drawing of the insulin pen as pictured in Figure 26 was the primary precedent for this model.

The main points that the participant highlighted in this model include a textured metal case, like the cortex cast designed by Jake Evill that was placed on her collage (Figure 18. Page 64). The top of the drawing shows a silicone casing covering the needle, which was inspired by the biomimicry pin, also on the participant's collage (Figure 18. Page 64).

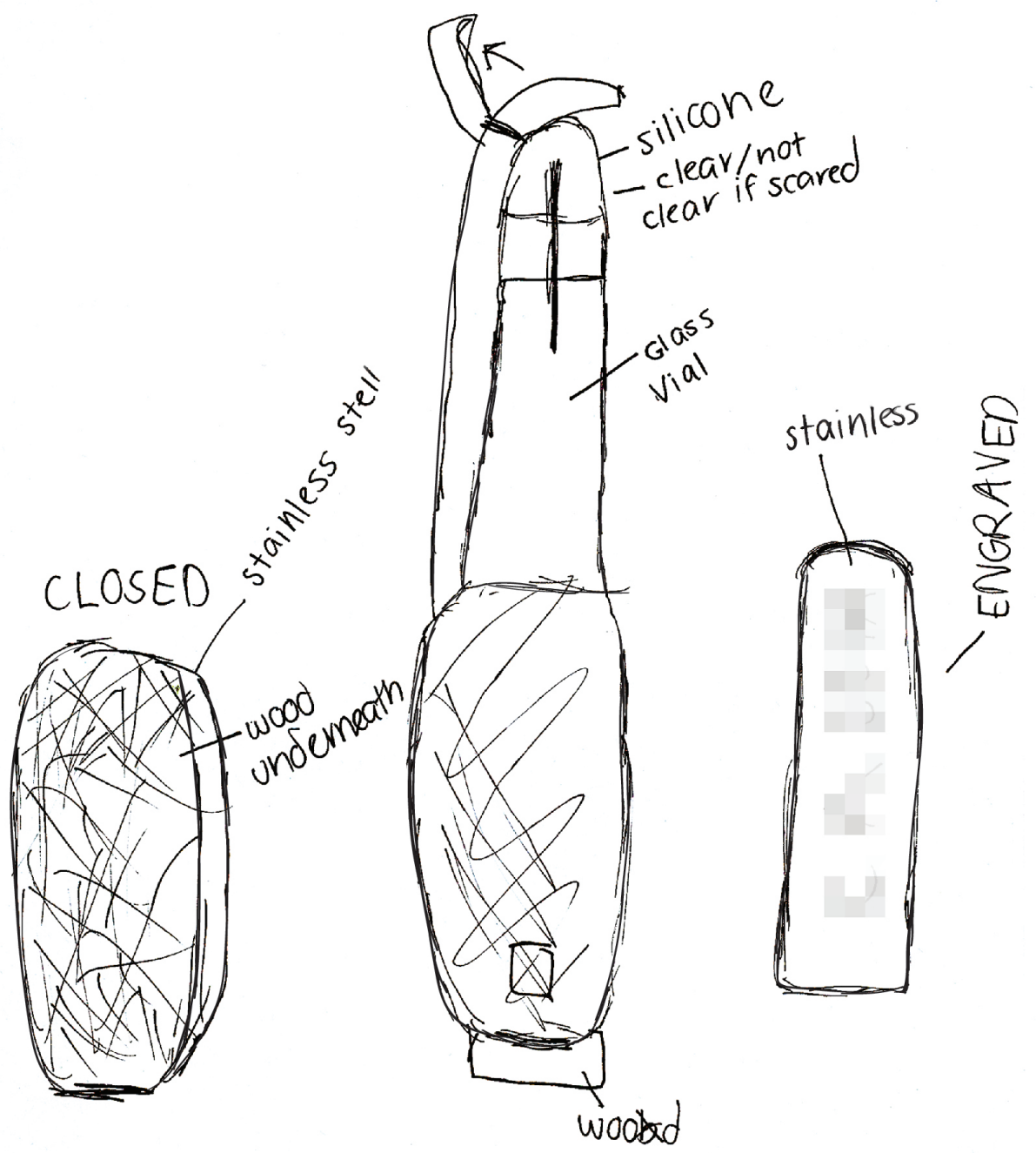




\subsubsection{Concept development}

Several iterations were created in the development of this design; not all of them have been included in this section of the review. They are included in Appendix D. The main factors to consider when designing with this strategy were details such as materiality, patterns, colour, and form.

The voronoi patterning (Figure 42) was created through a grasshopper script on rhino, which resulted in the pattern being parametric. Therefore, it could be changed and made bigger or smaller depending on the 3D printing capabilities and the level of conspicuity the patterning could provide. These models were printed in a fine detail frosted plastic and stainless steel (Figure 40). The fine detail plastic model was hand-dyed to create the gradient colour effect. The top piece of the model was printed from a malleable material (Figure 41).
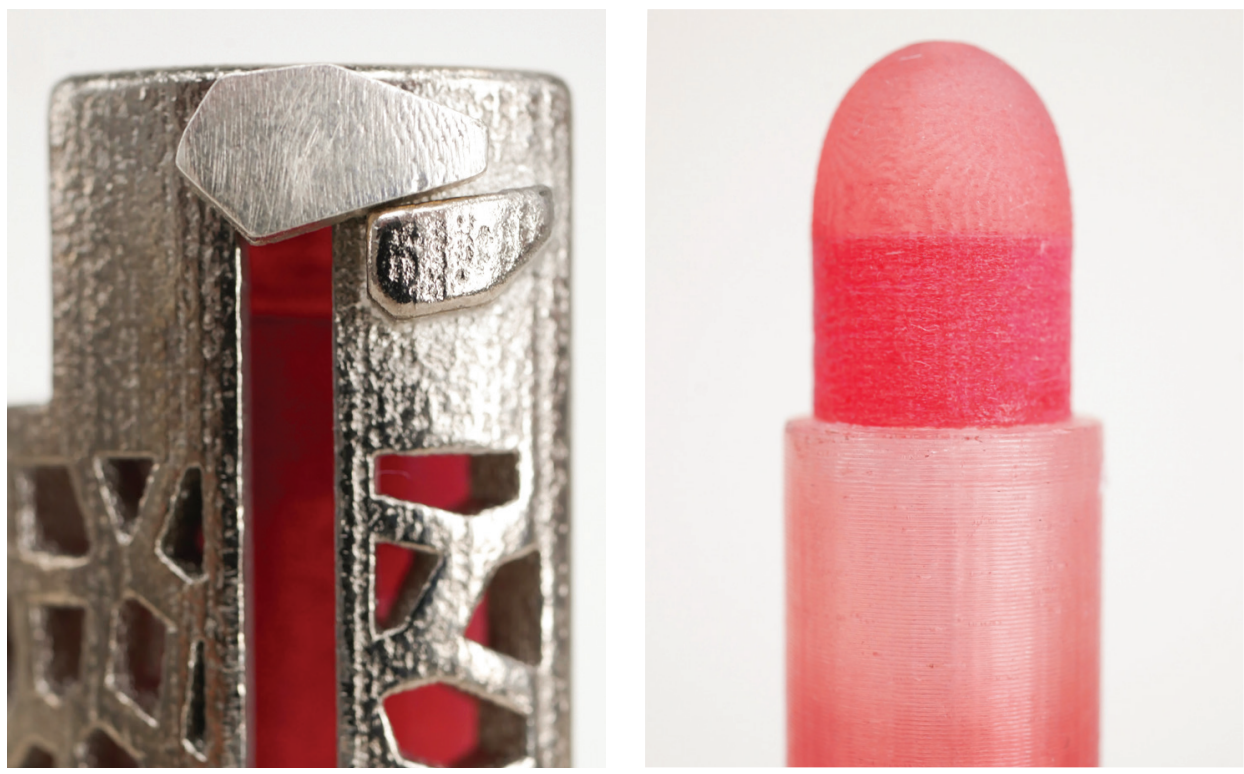

Figure 40. Prototype Locking interaction.

Figure 41. Cap of the enhanced prototype.

Figure 42. Full metal prototype

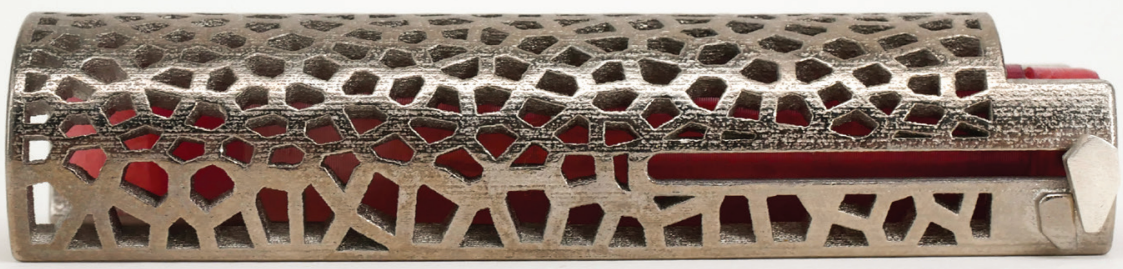




\subsubsection{Final prototype}

The final prototype (Figure $43-46$ ) involved four versions that differed in colour or materiality. Blue, orange, and purple designs were created as well as a metal one to fulfil the original design created by Participant 2 .
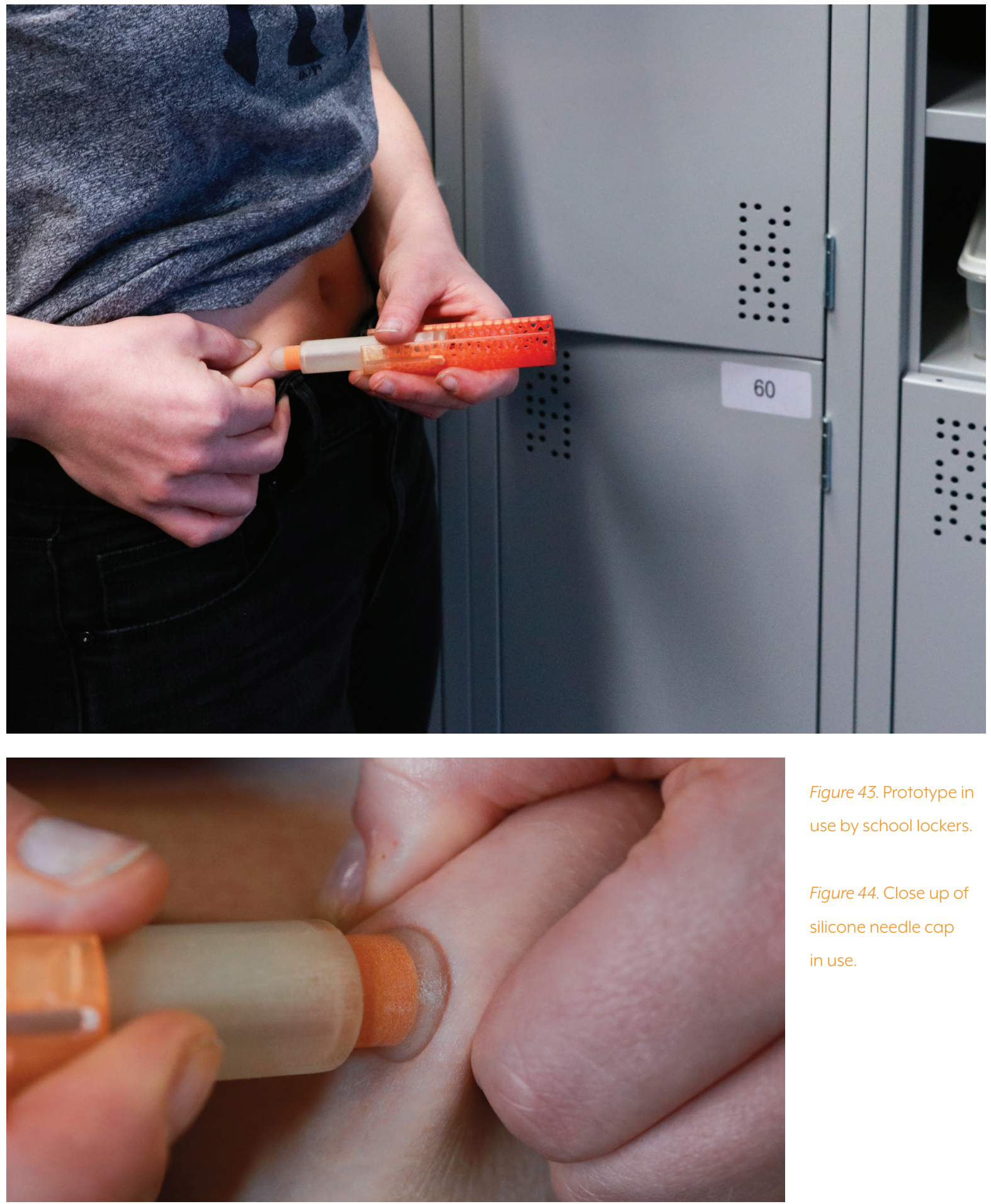

Figure 43. Prototype in use by school lockers.

Figure 44. Close up of silicone needle cap in use. 


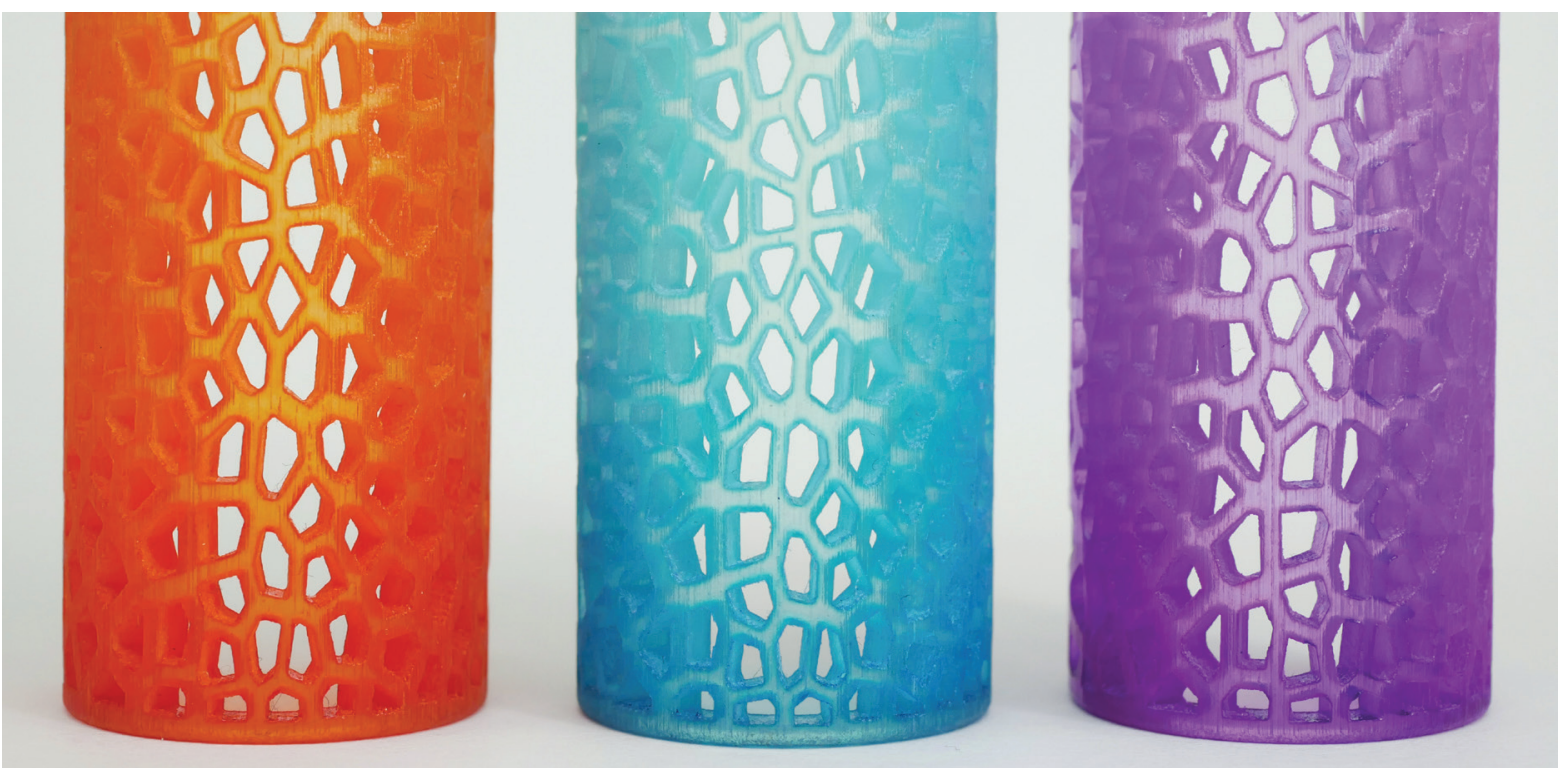

Figure 45. Close up of voronoi patter

Figure 46. Final

models to enhance the aesthetics of the medical device.

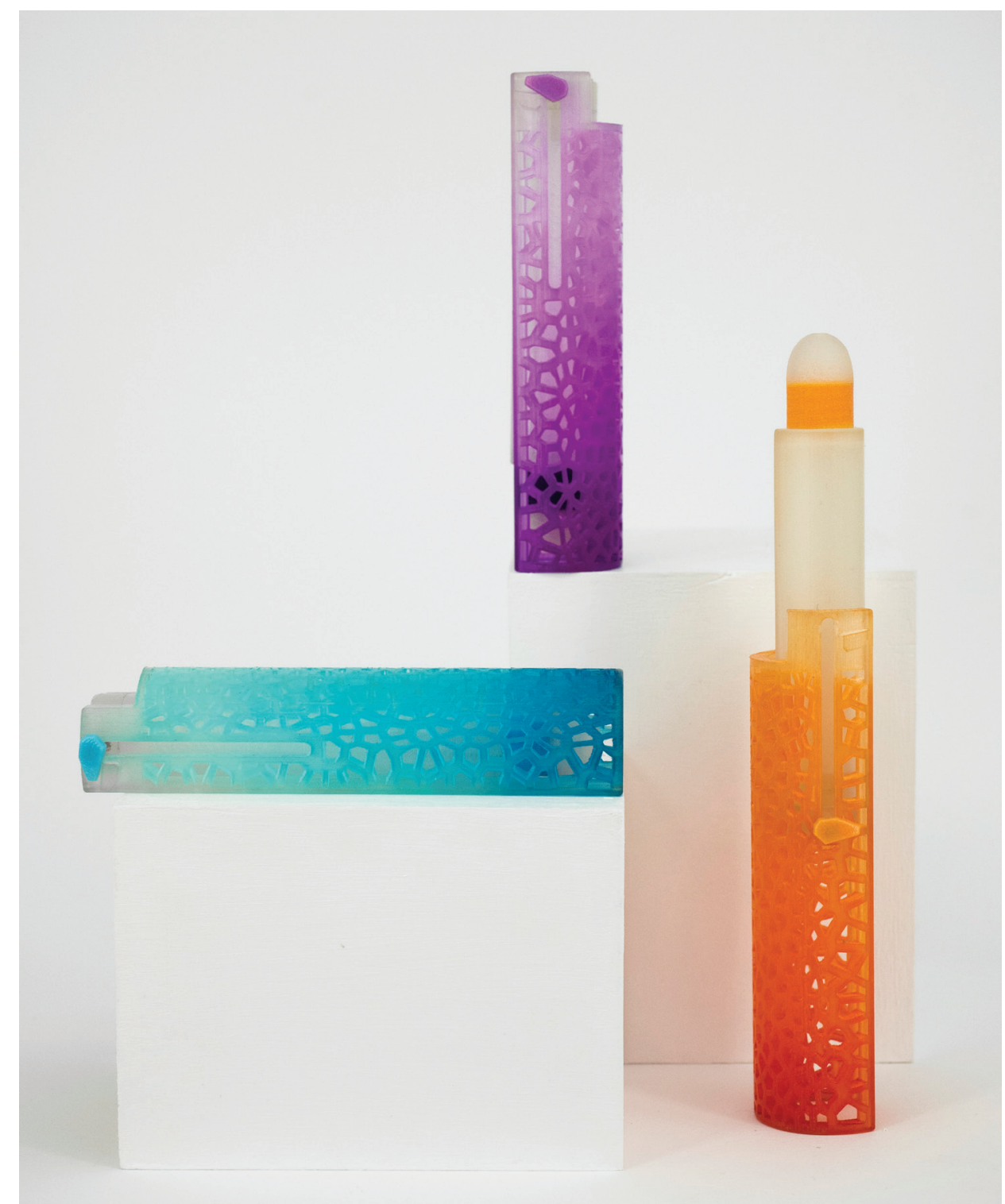




\subsubsection{Measuring the conspicuity of the prototype throughout the interaction}

It is important to assess the conspicuity of these medical devices not only as static objects, but throughout the interactions people may have with them. For example, while an insulin pen may be less conspicuous than a syringe, when it is uncapped and used to complete an injection its conspicuity increases as its disguise breaks down. For each prototype the diagram illustrates how the conspicuity of the designed prototypes might change over the duration of a

Figure 47. Timeline of the aesthetic medical device in use. user's interaction with them. The strategy 'Enhance the aesthetic appearance of the medical device' can be seen across the interaction (Figure 47), until the device is directly in contact with the skin. Due to the soft material used to cover the needle, this typically conspicuous aspect of the medical device is hidden, and therefore it is not recognisable until the device is injecting insulin into the adolescent using the medical device.
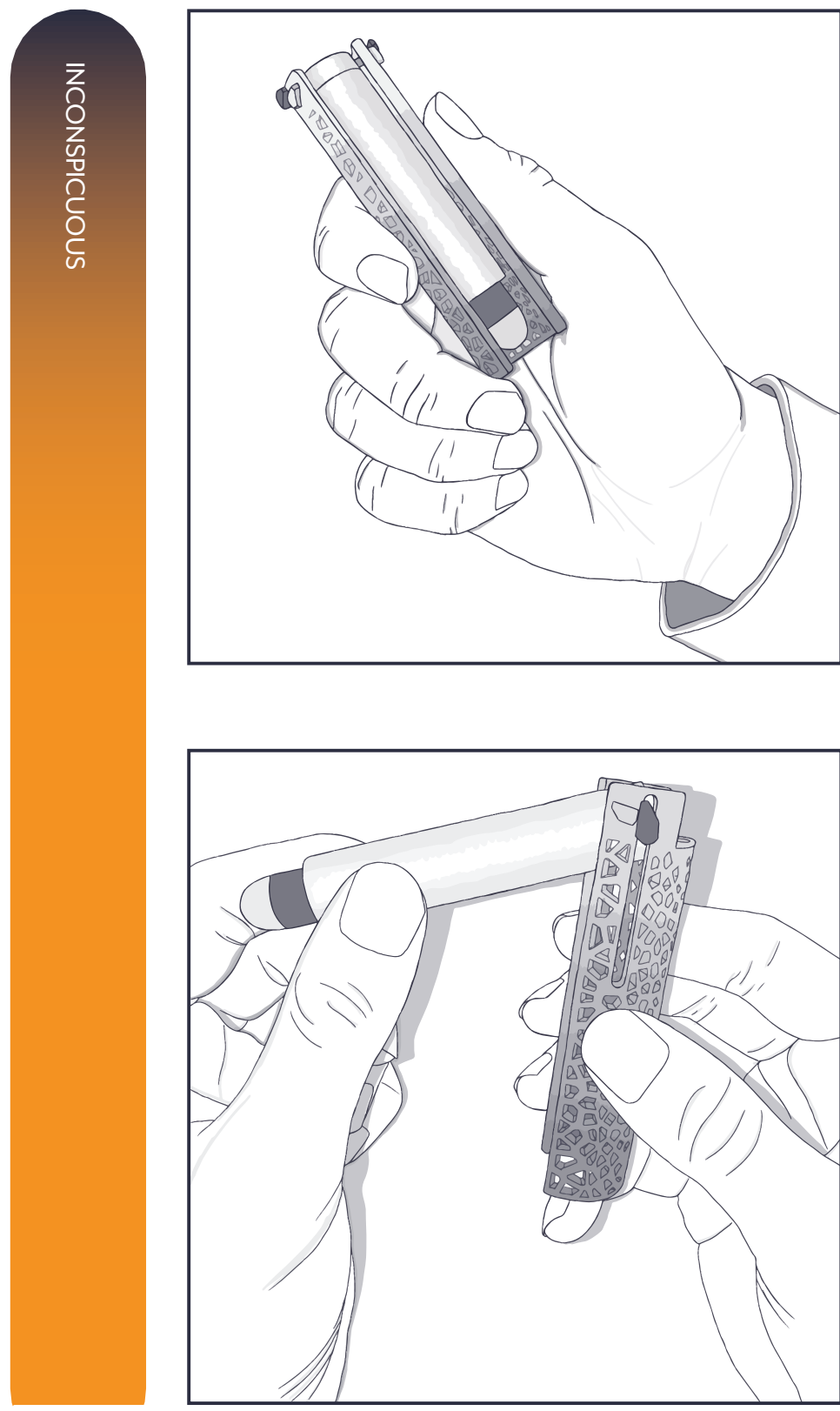

The medical device appears conspicuous as the colour and patterns are more eye-catching. The needle is covered however, so there is an element of inconspicuous.

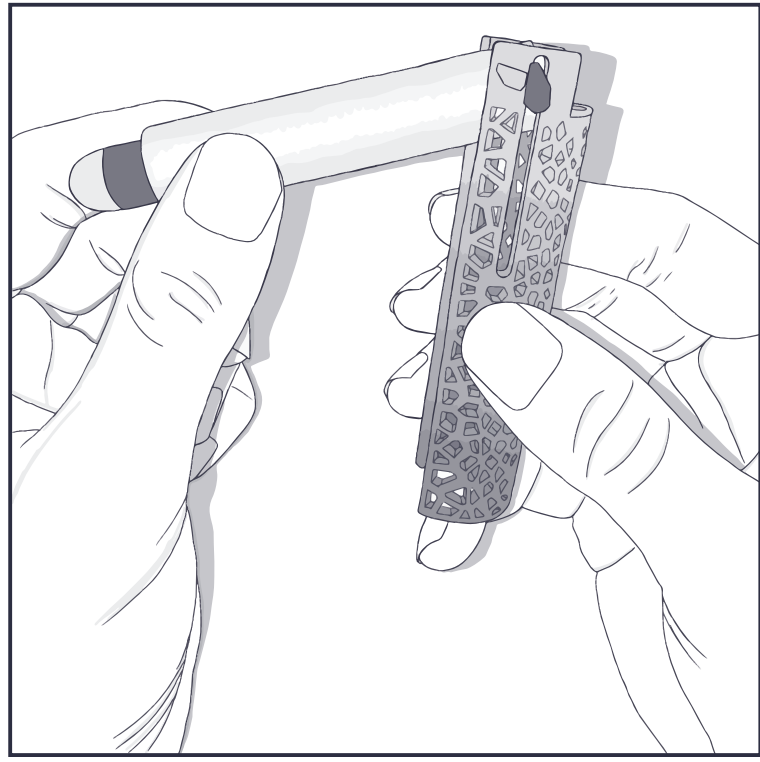

When the medical device is being opened the interaction is more conspicuous 


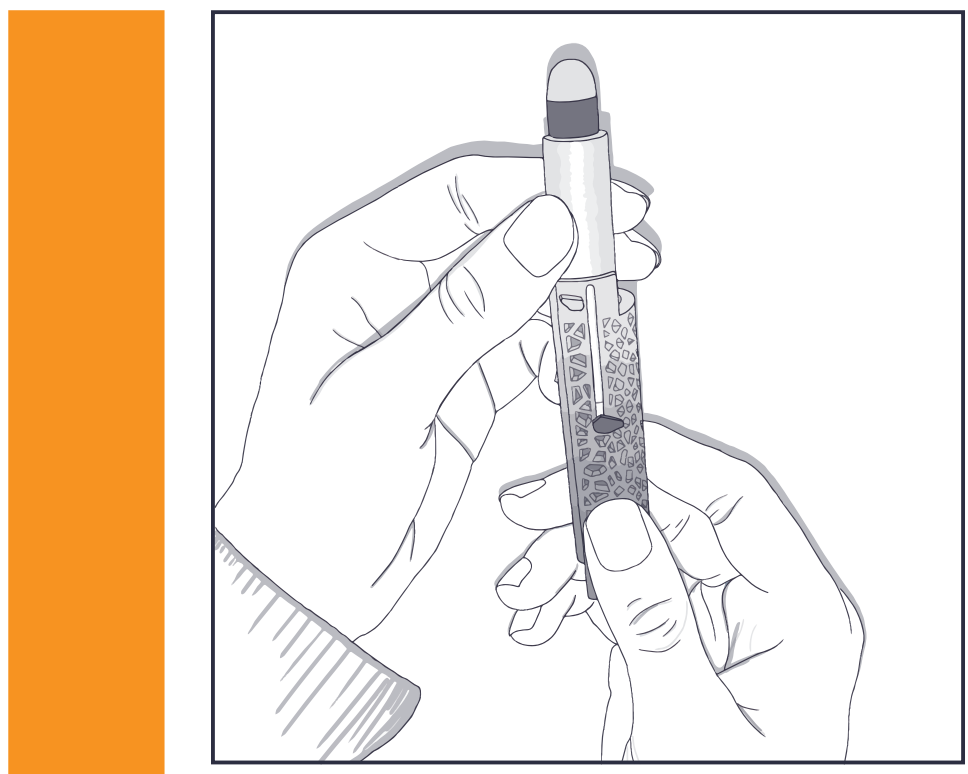

The final opened device is more conspicuous.

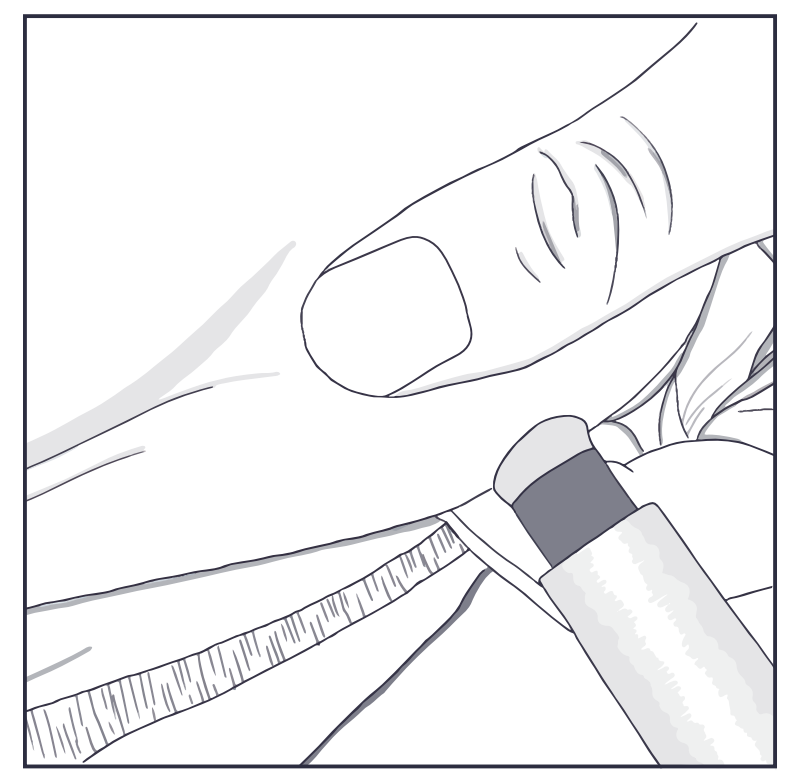

When the adolescent is injecting

themself, the interaction is conspicuous. 


\subsubsection{Personalise the medical device for the user}

\subsubsection{Adolescent input into concept}

During the individual interviews, both adolescents sketched ideas for a personalised medical device that involved combining several devices to create an all-in-one item (Figure $24-25$ ). The benefits of having an all-in-one device include being able to incorporate functions that are useful and tailored to the user, and improving convenience, as adolescents would only have to carry one device with them, making it more inconspicuous in public.

CASING - MESH-STAINLESS STEEL
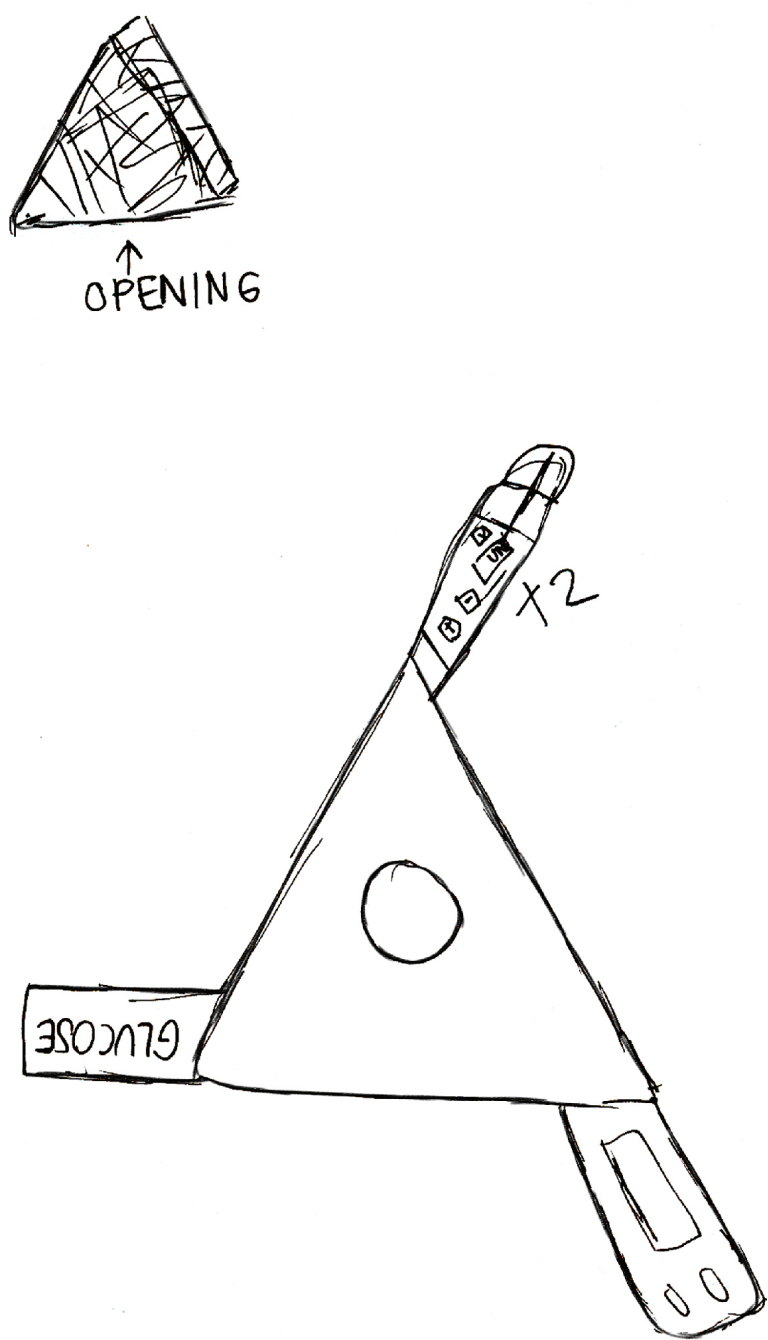

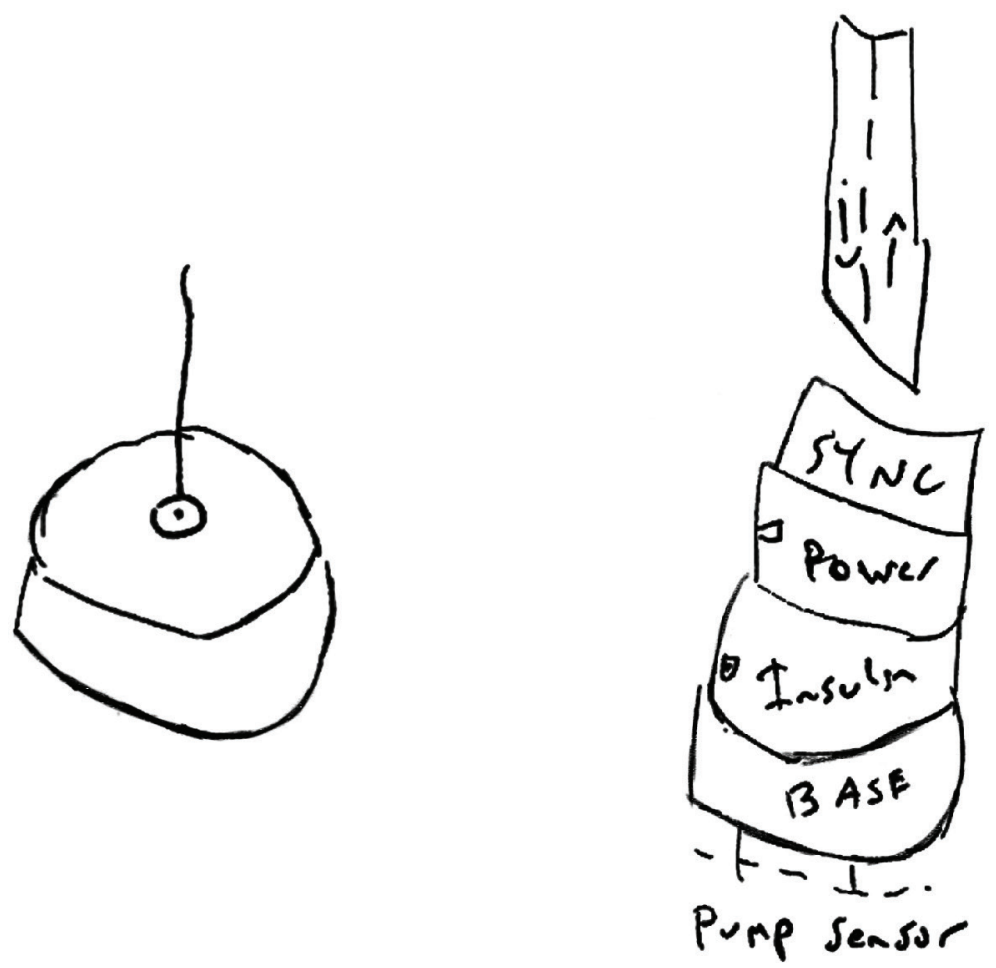

Figure 24. Participant 1 sketch of an all-in-one insulin pump and flash blood glucose meter

\subsubsection{Concept development}

The sketches produced by the participants were a great starting point for developing this prototype. An important aspect to consider when designing an all-in-one device is having the option of splitting the device up into its original components. Magnets are an effective way to connect components, while retaining the individual components. The device has been designed as a cylinder, as rounded edges were mentioned by the participants in the individual interviews. Iterations of this device can be found in Appendix D. 


\subsubsection{Final prototype}

The final prototype (Figure $48-51$ )consists of three segments, each painted a different colour so the functions can be easily identified. The face of the blood glucose meter has a decal on it to further enhance the personalised strategy.
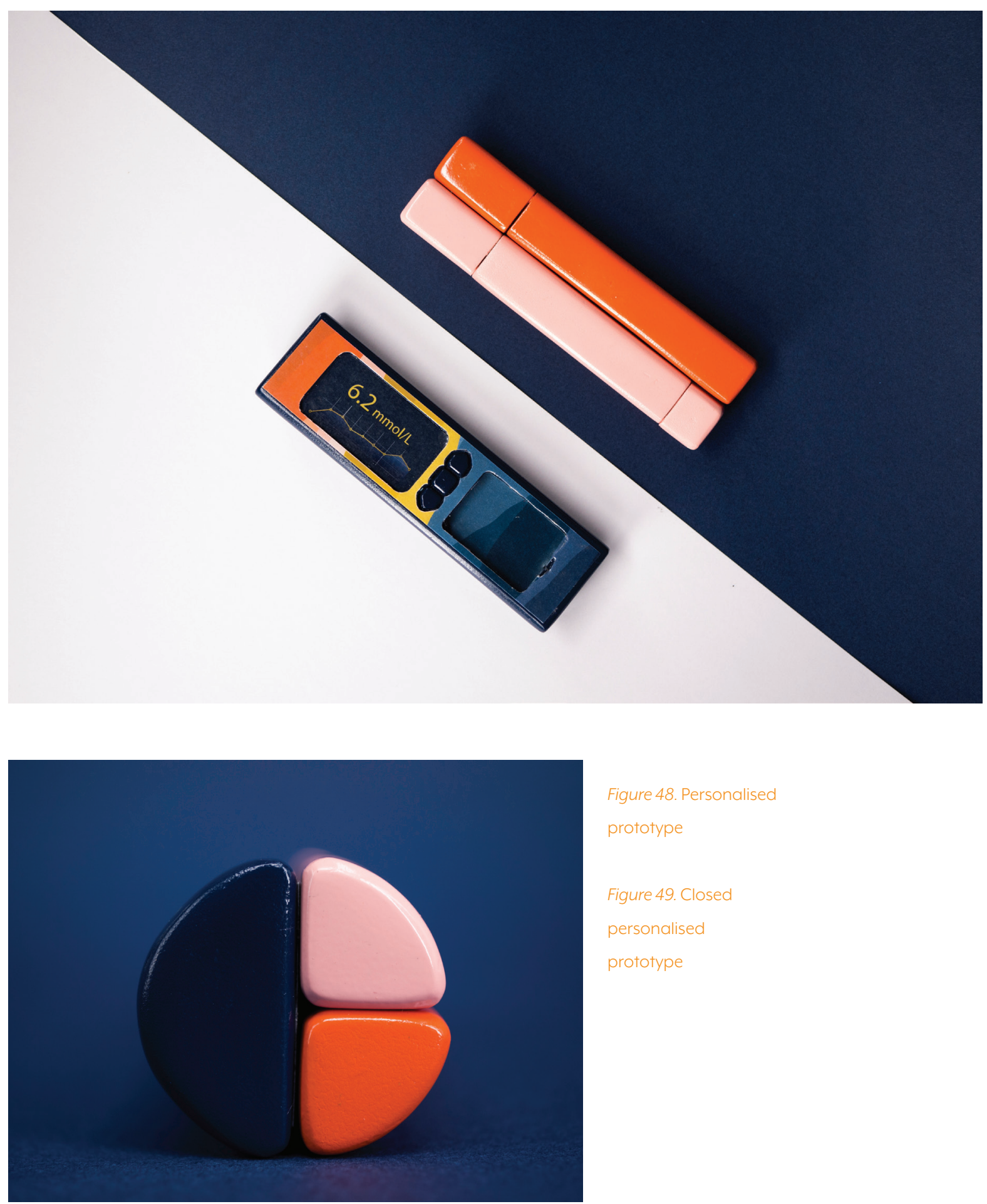

Fiqure 48. Personalised

prototype

Figure 49. Closed

personalised

prototype 


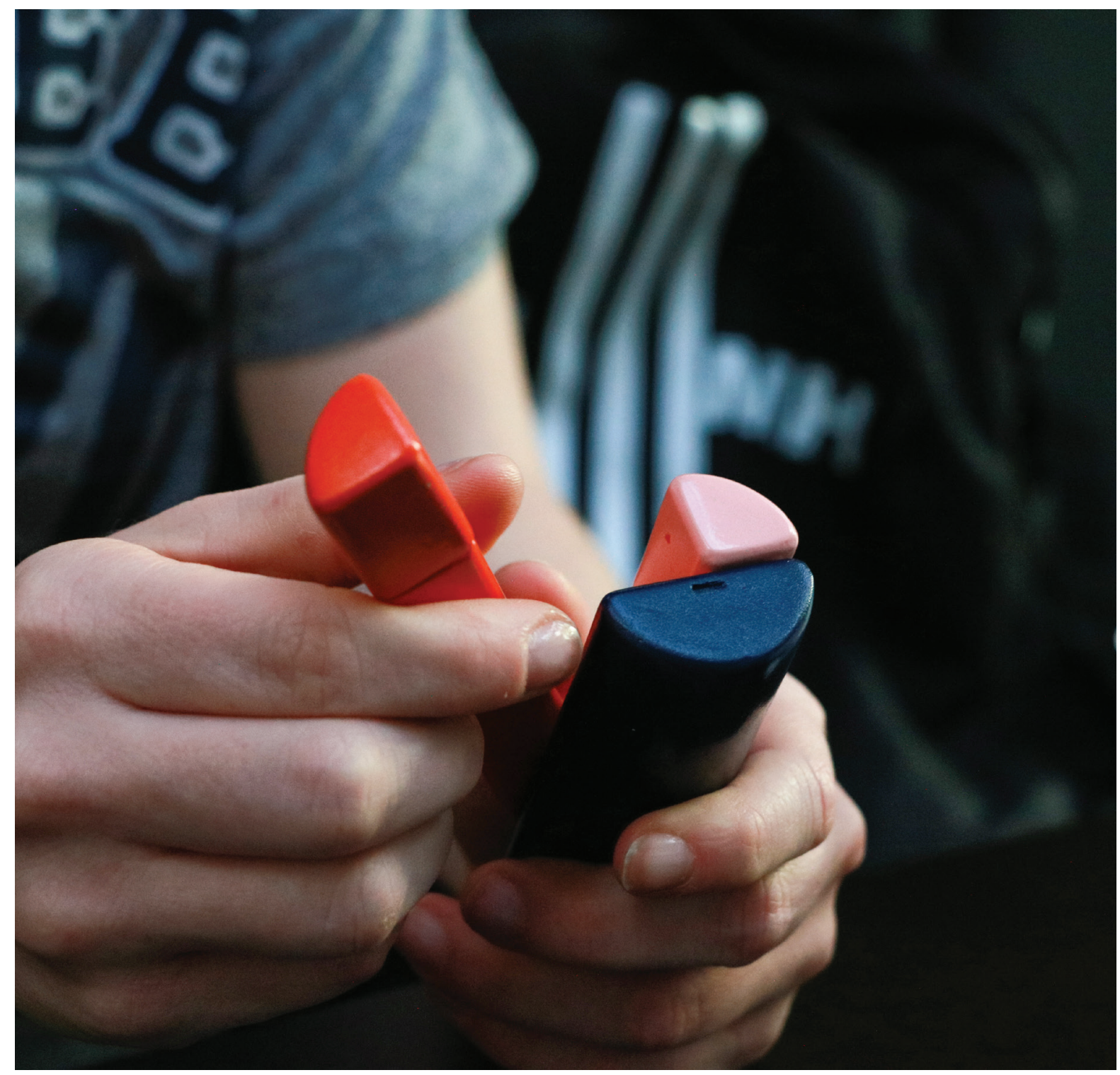

Figure 50. Opening personalised prototype

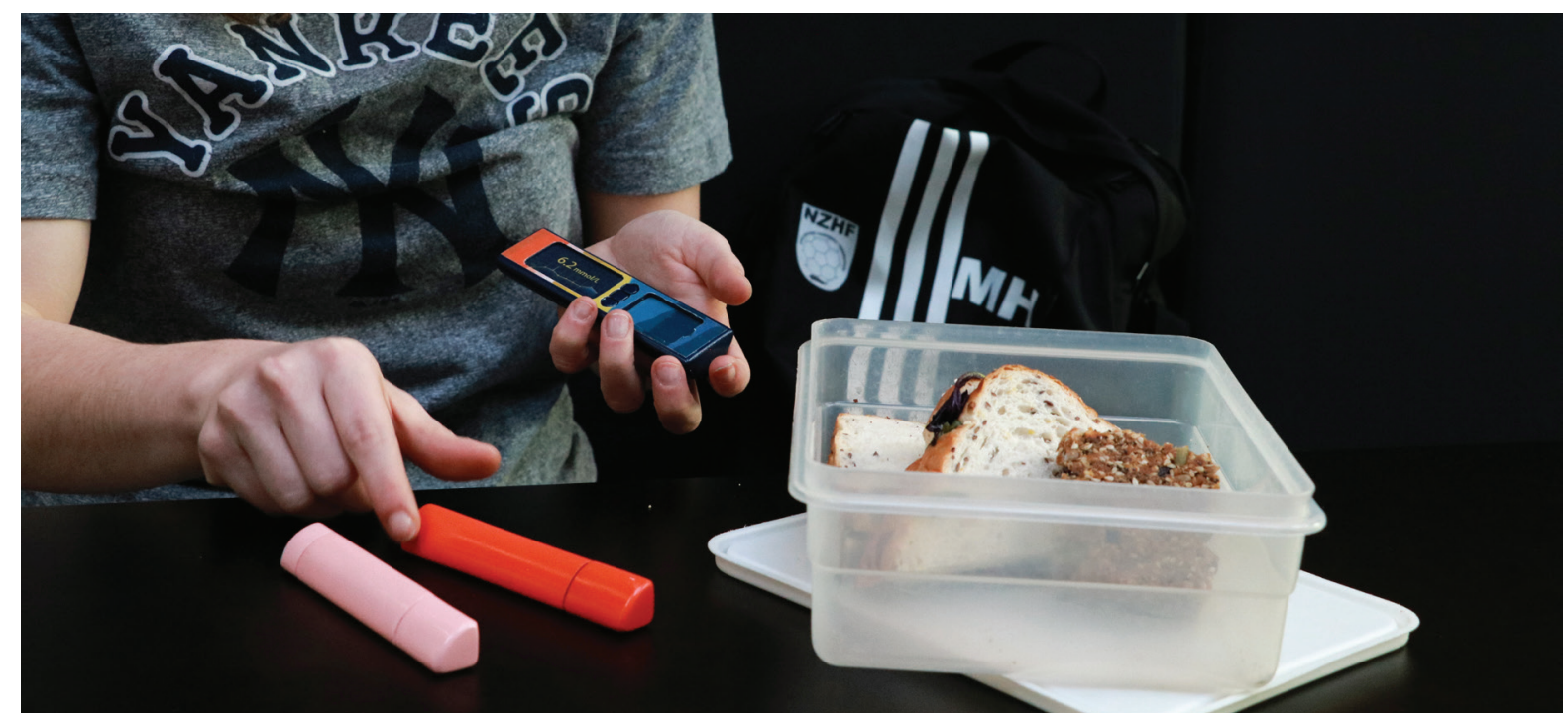

Figure 51. Personalised prototype being used at lunch 


\subsubsection{Measuring the conspicuity of the prototype throughout the interaction}

This prototype is the most medical-looking; however, it only appears medical once opened and in its 'on' state. When the device is closed and in an 'off' state it appears more like a consumer object. The strategy used to design this device can be seen throughout the entirety of the interaction (Figure 52).

Figure 52. Timeline

of the personalised

medical device in use
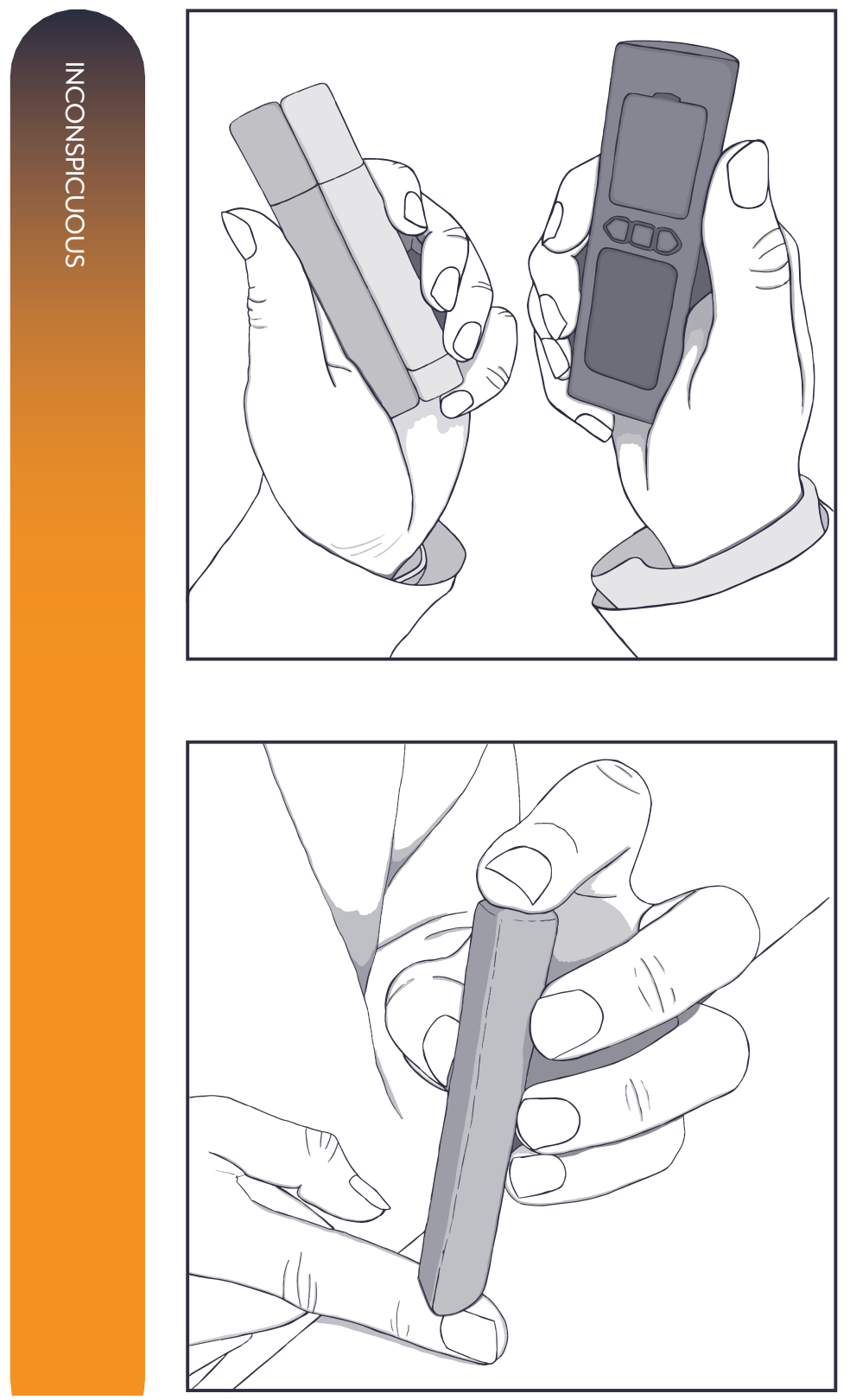

When the device is opened it appears more conspicuous and medical.

The lancet is used first to draw blood. This interaction appears medical and conspicuous 

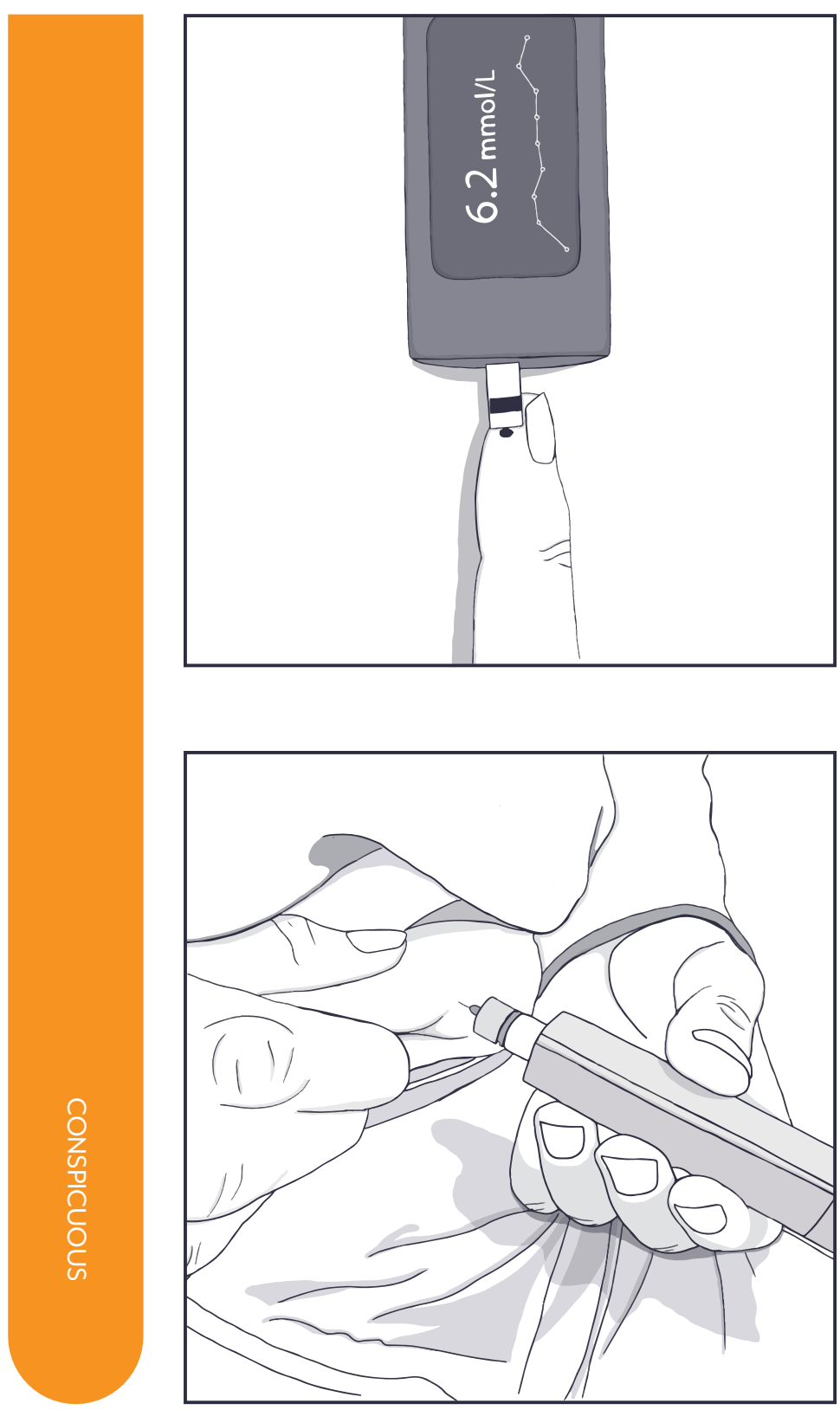

Secondly the blood is tested using the blood glucose meter. This interaction also appears medical and conspicuous

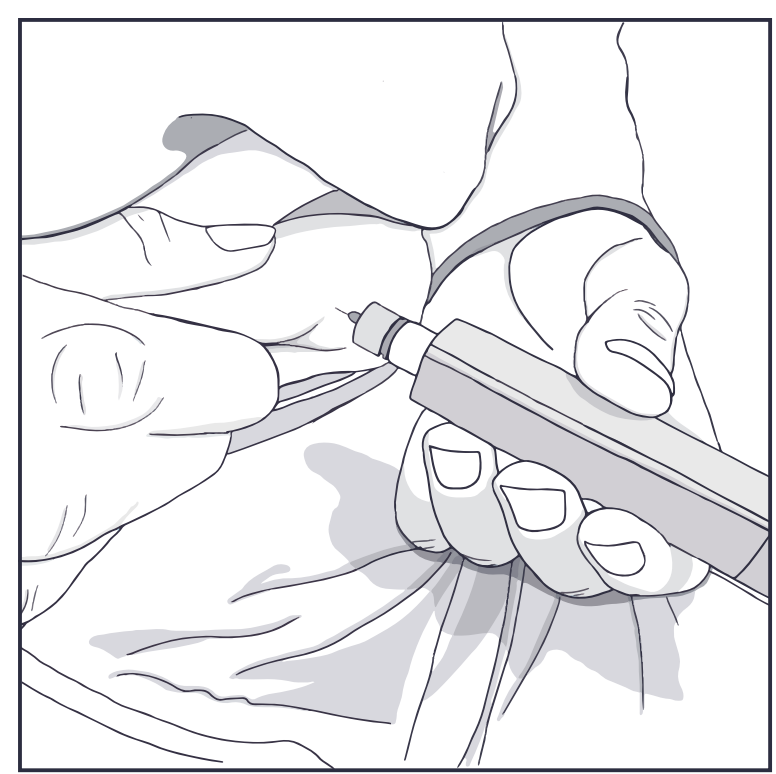

Finally the adolescent administers insulin, and the interaction remains conspicuous. 


\subsubsection{Disguise the medical device as a non-medical item \\ 7.2.3.1 Adolescent input into concept}

Several adolescents in the focus group and individual interviews mentioned combining their medical devices with a cell phone. Participant 1 from the individual interviews mentioned the idea of putting "a sensor on your phone, but you can also use it to see your readings, so you would unlock your phone and see the readings." Participants from the focus group also had ideas relating to integrating their phone and medical devices (Figure 53).

Another design feature that adolescents were interested in was updating the current pattern or sticker options. As mentioned in the individual interviews, many of the stickers are currently designed for children. P2: "But the decals look like they were designed for children. They would bring them out at camp and there were loads that had bears." One participant at the focus group wanted a marble decal for her current pump. FG2: "But you could have I don't know a design on them, I've always wanted a marble one.” These ideas discussed with the participants influenced the final outcome for the design.
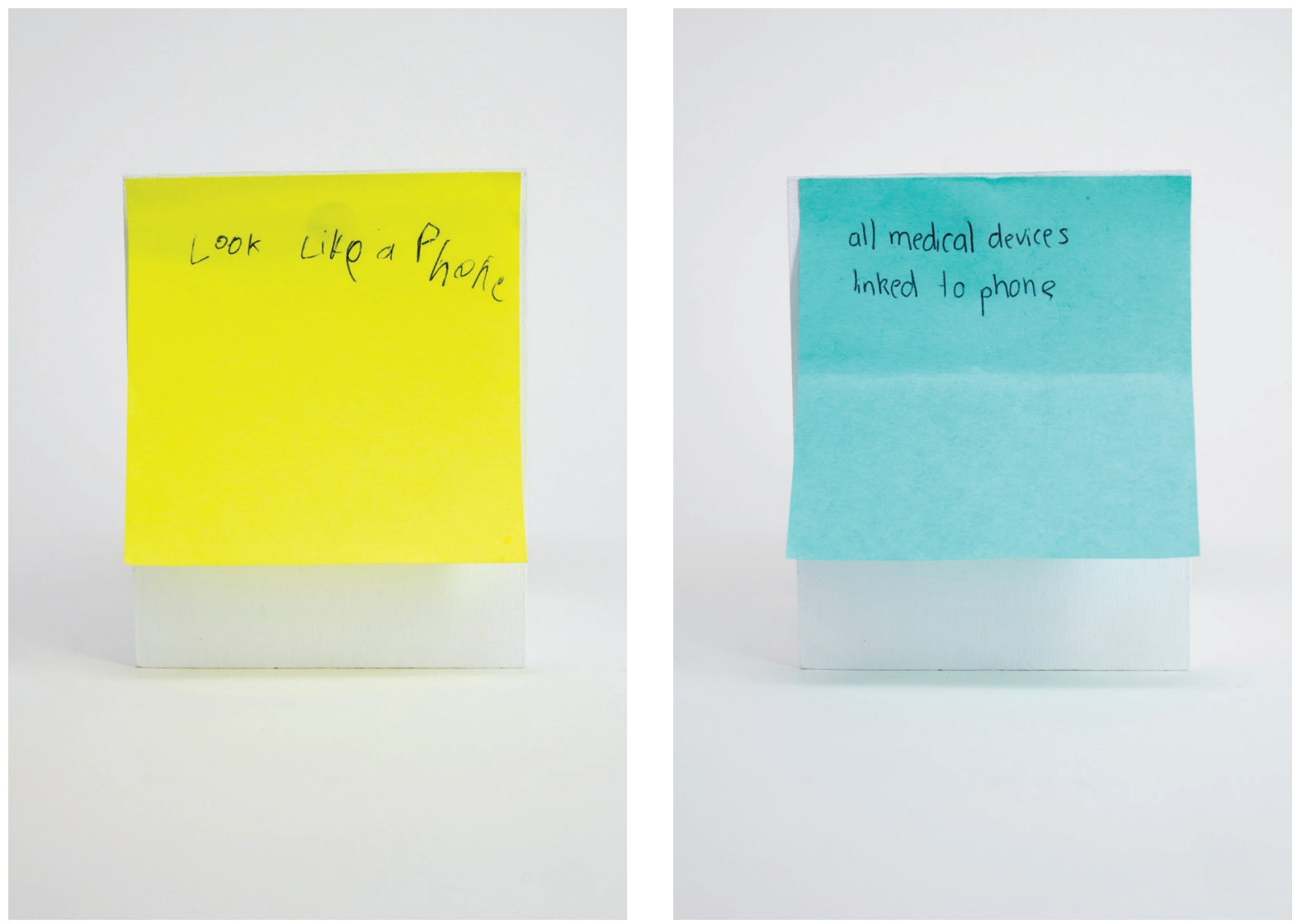


\subsubsection{Concept development}

Although none of the participants mentioned designing a medical device to be like a PopSocket (Figure 54), which are frequently used by adolescents. A PopSocket is an attachment added to the back of a cellphone that can allow the phone to stand up, or to be gripped more easily. PopSockets come in a range of patterns and are easily personalised. The benefit of disguising an insulin pen as a PopSocket is that it would allow the device to be portable and easily removed from the phone if necessary. 


\subsubsection{Final prototype}

The final prototypes (Figure 55 - 58) created for this theme include three insulin syringes, all with different patterned decals. The decal patterns were chosen to match the preferences voiced by the participants in the focus group, as well as to provide options to match different preferences.
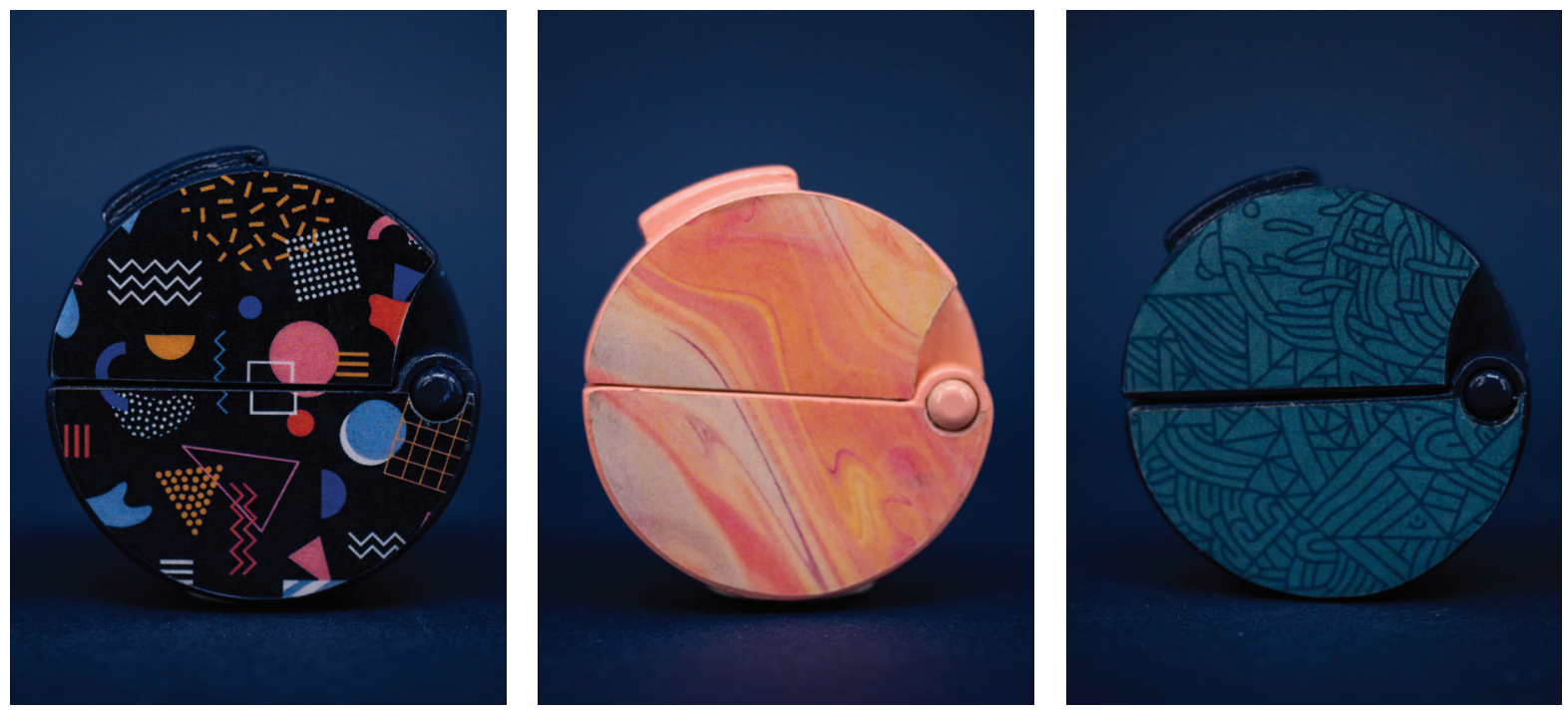

Figure 55. Disguise colour and pattern options

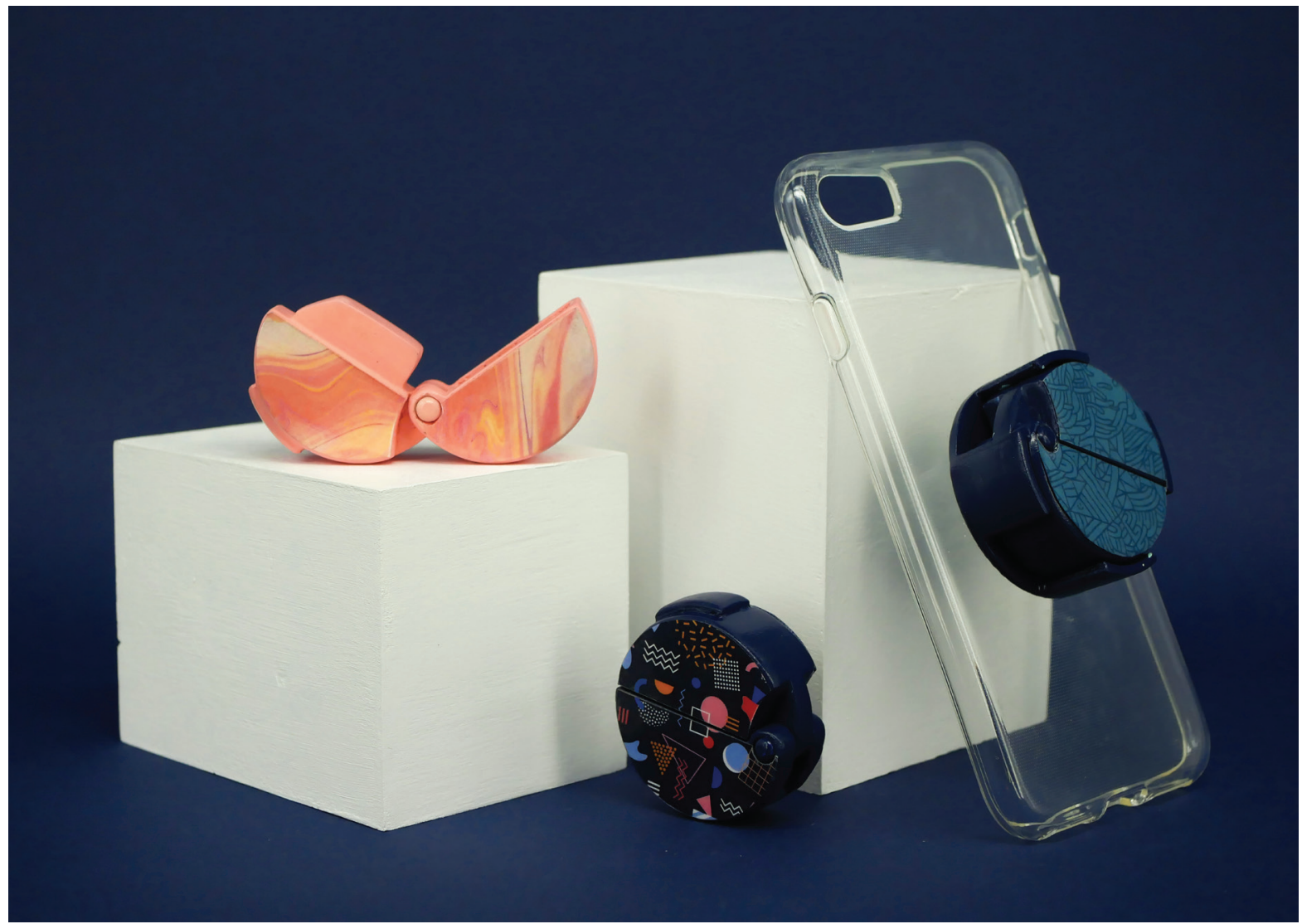

Figure 56. Prototype to disguise the medical device as a non-medical item 


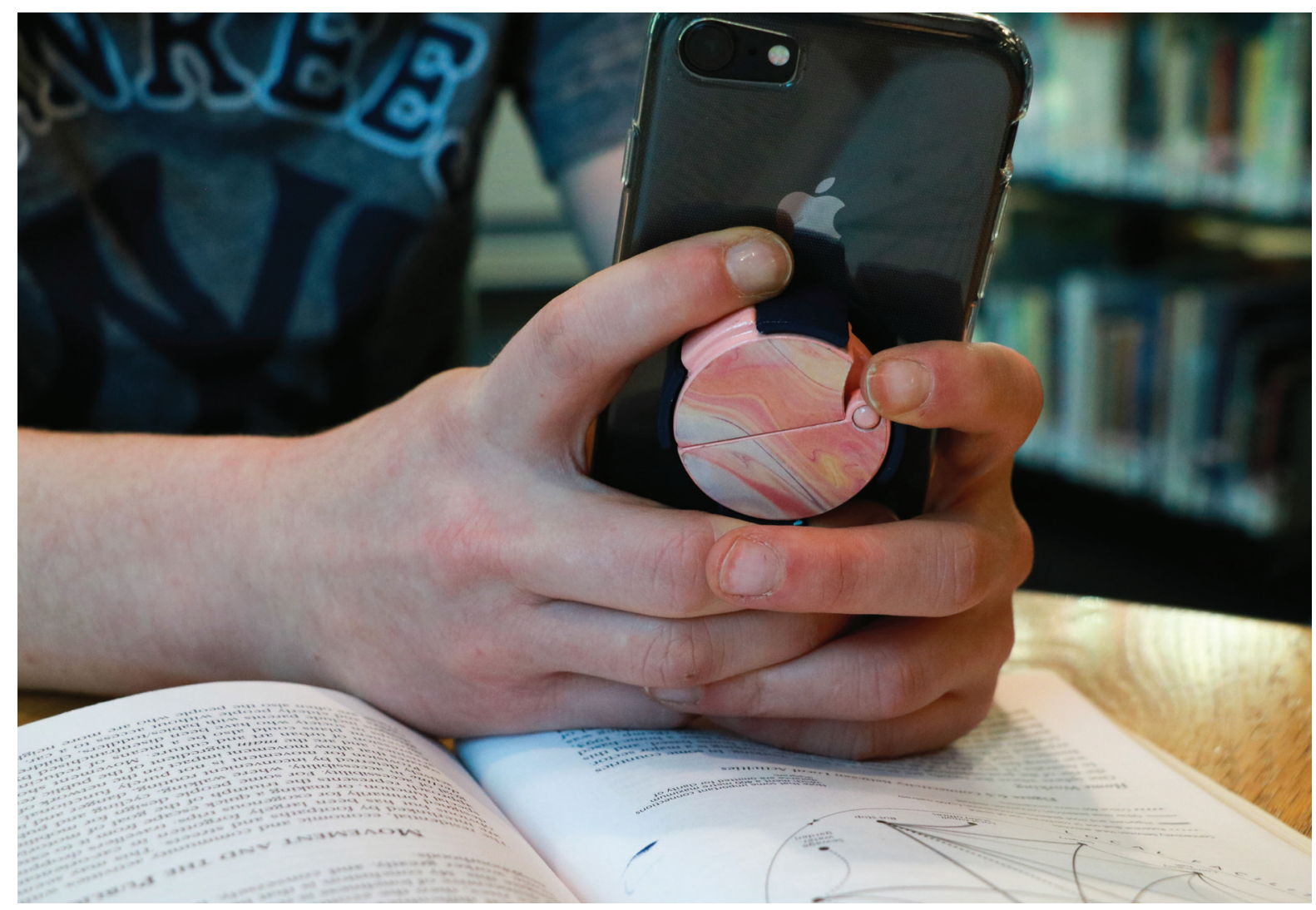

Figure 57. Disguise prototype on the back of a phone case

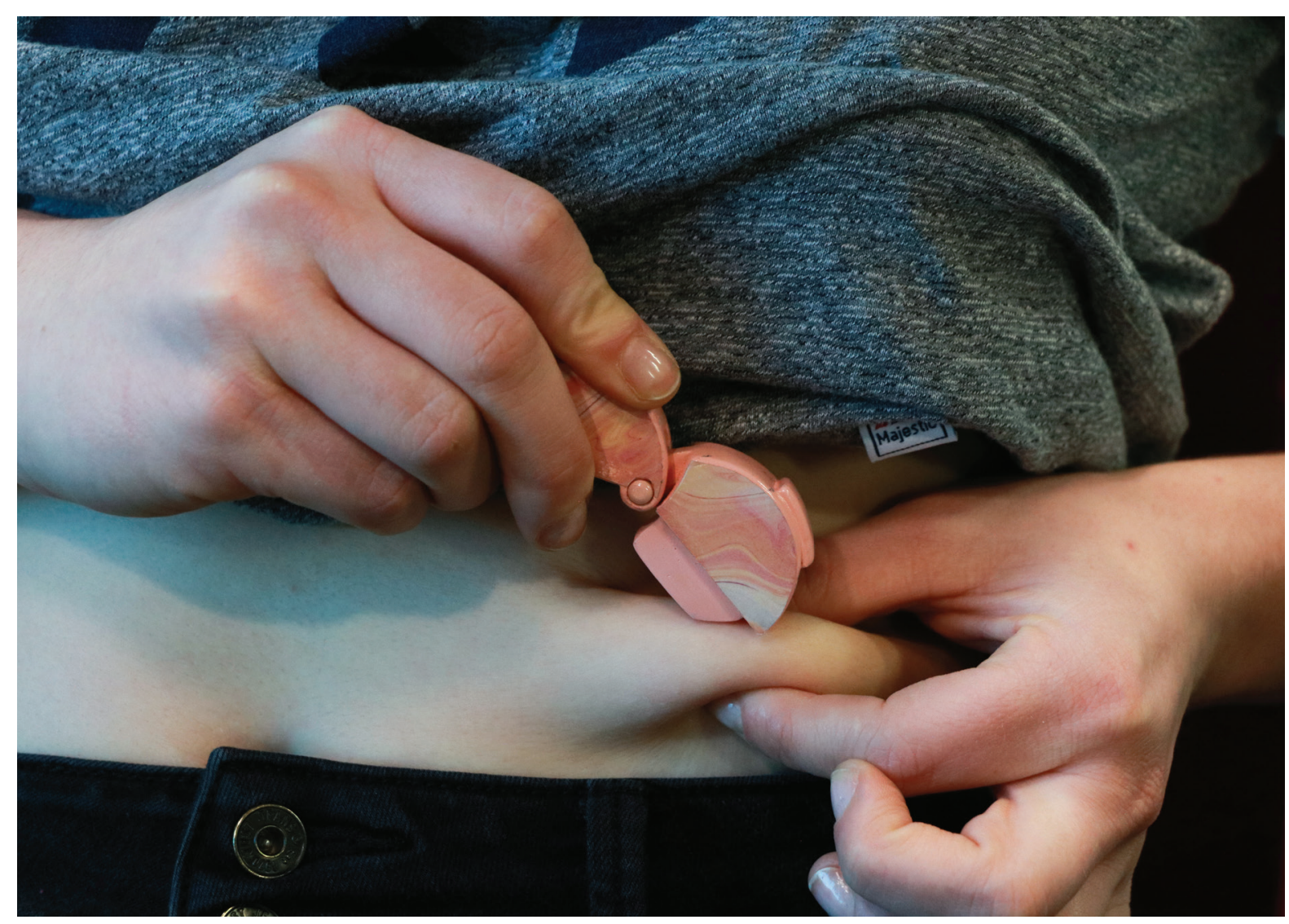

Figure 58. Using the disguise device to inject insulin 


\subsubsection{Measuring the conspicuity of the prototype throughout the interaction}

The final prototypes designed for this strategy are disguised and inconspicuous until the device is opened and the needle is revealed (Figure 59). This timeline of inconspicuity could be extended if a silicone cap was applied over the needle, similar to the one used in the 'Enhanced the aesthetics' model of the insulin pen.
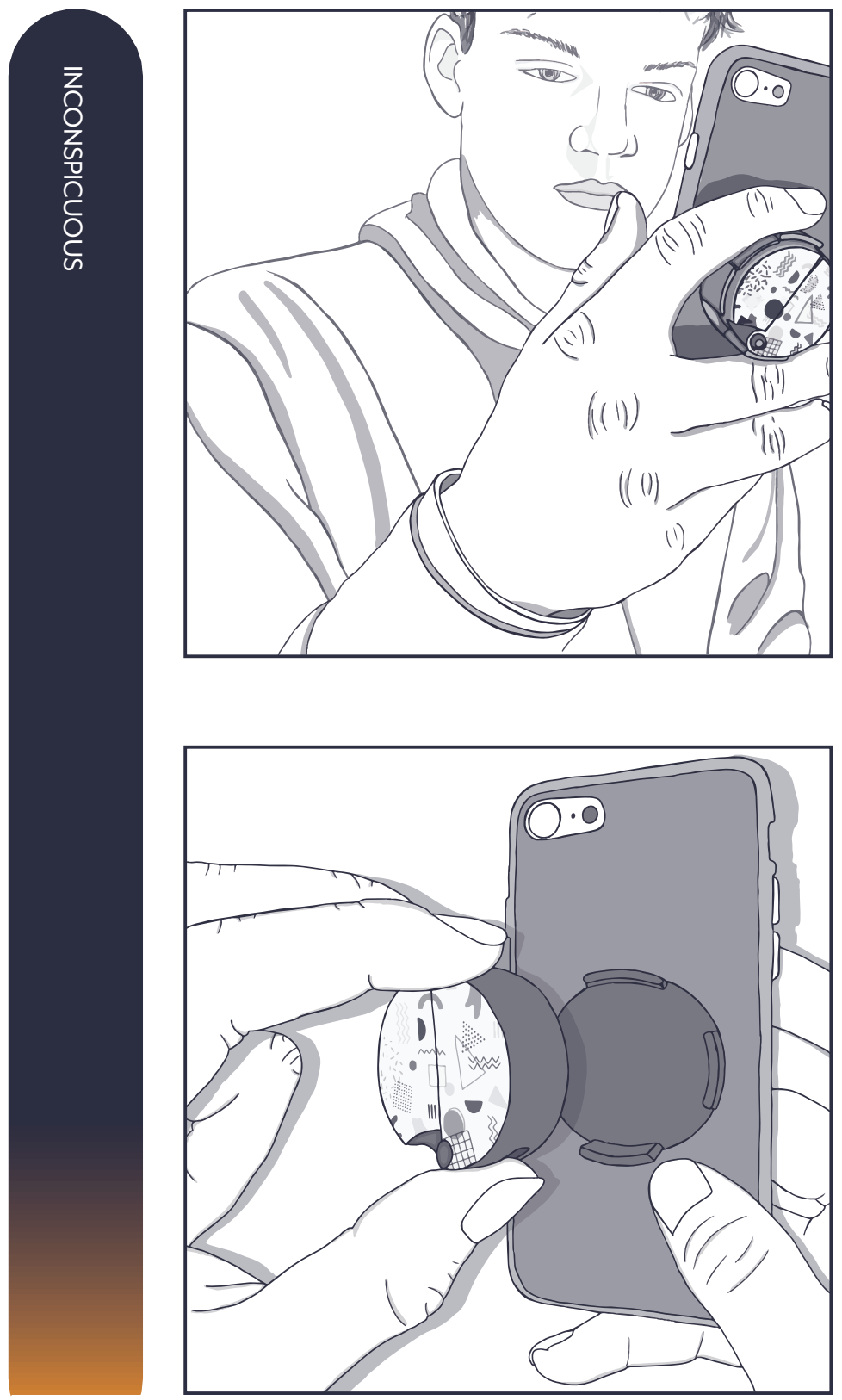

The medical device sits on the back of the phone, so it is disguised and inconspicuous

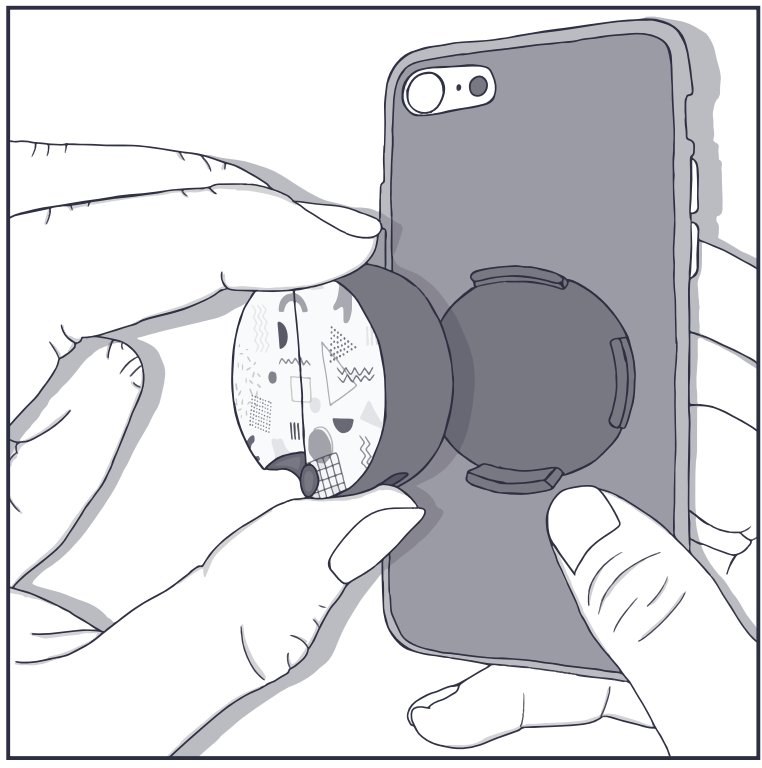

Once the medical device has been removed from the phone, it is no longer disguised, however it is still inconspicuous. 

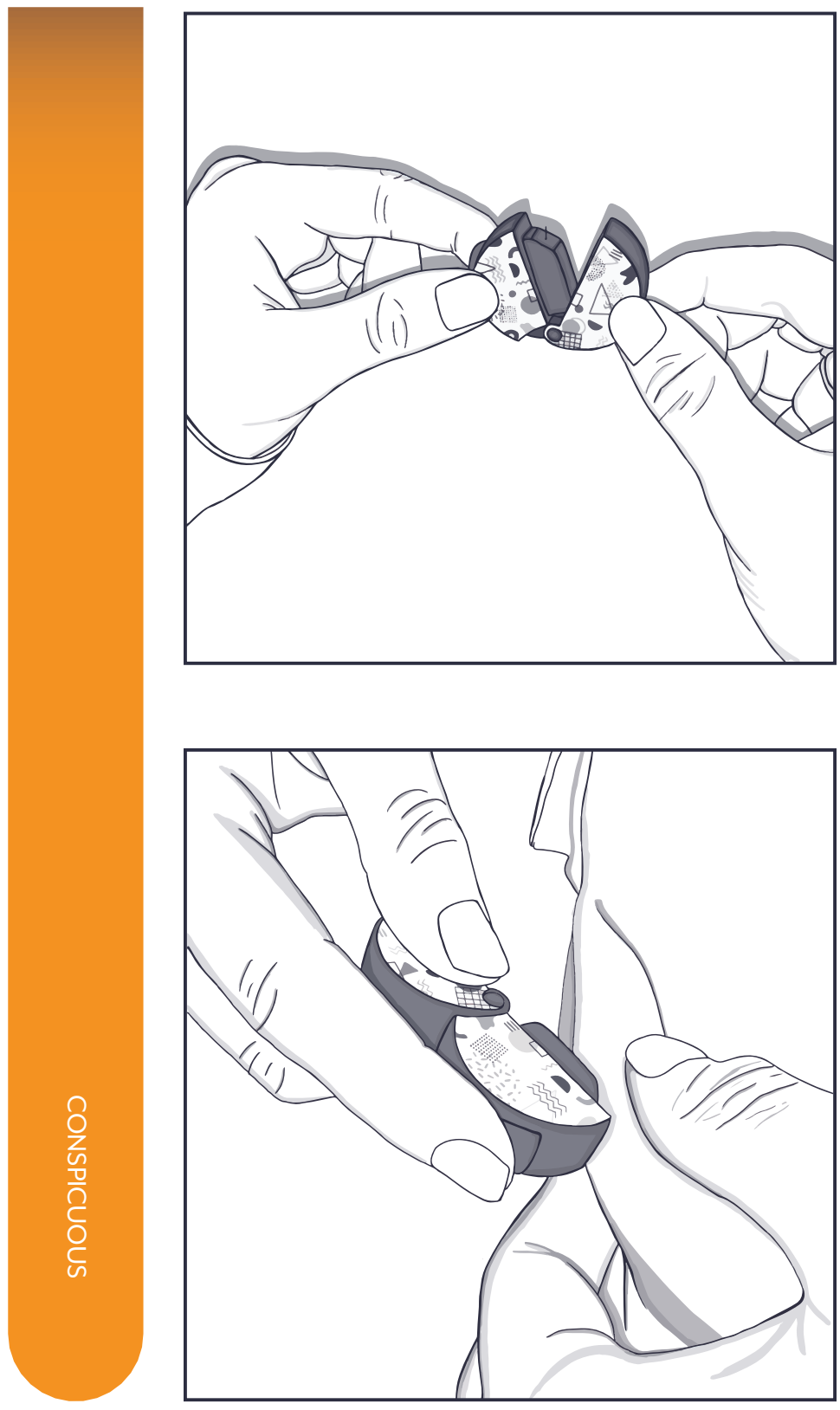

When the medical device is open, the needle is exposed, and the device is no longer disguised.

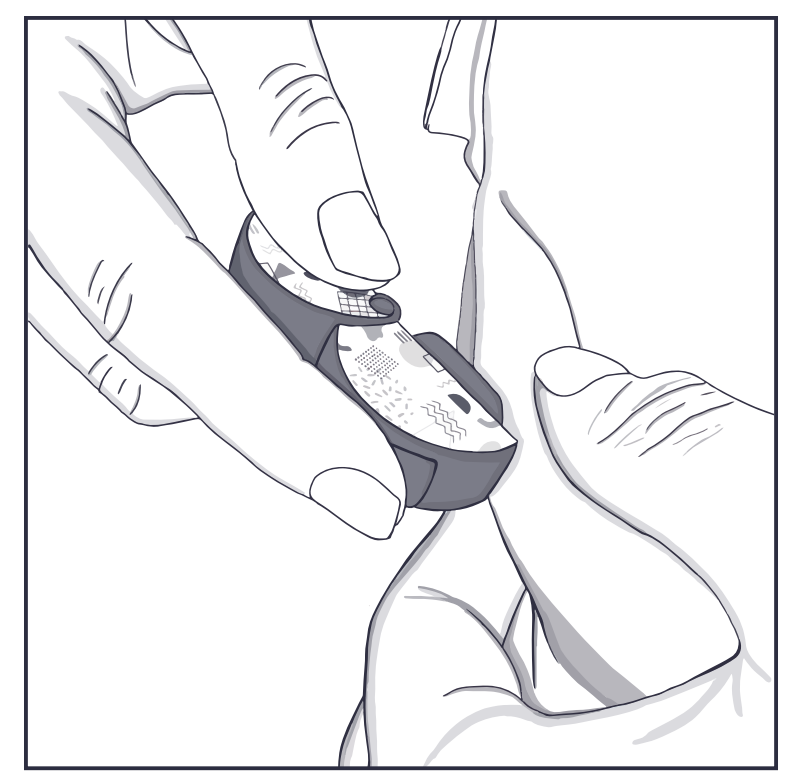

As the adolescent is injecting themself, the strategy does not apply, and the device appears more medical. 


\subsubsection{Conceal the medical device from the public}

\subsubsection{Adolescent input into concept}

Adolescents use several different devices based on their preferences; however, the current device that is best at fulfilling this strategy is the Freestyle Libre. During the focus group and individual interview, adolescents described their pump as "bulky" and "heavy".

FG2: If the pump was a lot skinnier cause it's really, well the one I have is really big, and it's like really heavy, and if you have the case to clip it on its like double the size as well.

One participant at the focus group wanted their pump to be "as small as possible so you can't see it. I don't care how it looks.” (Figure 33)

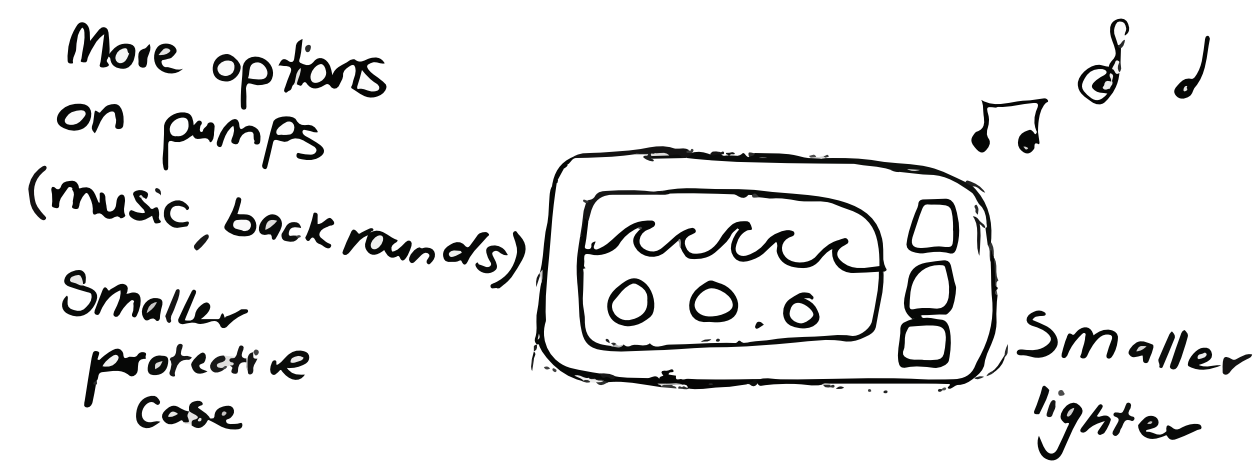

Figure 33. Focus group sketch to personalise the medical device

\subsubsection{Concept development}

One idea that I have not seen explored is the idea of an insulin pump made from a flexible material (Figure $60-61$ ) so that it could be moulded around the body, resulting in a slimmer profile, making it less detectable under clothing. Another aspect to include into this design is a way to combine the interaction of the Freestyle Libre, allowing adolescents to use a phone or watch to scan the de-vice and measure glucose levels. Furthermore, adolescents would not have to lift their shirts to administer insulin and could input the insulin amount and then swipe the pump to administer the dosage. 


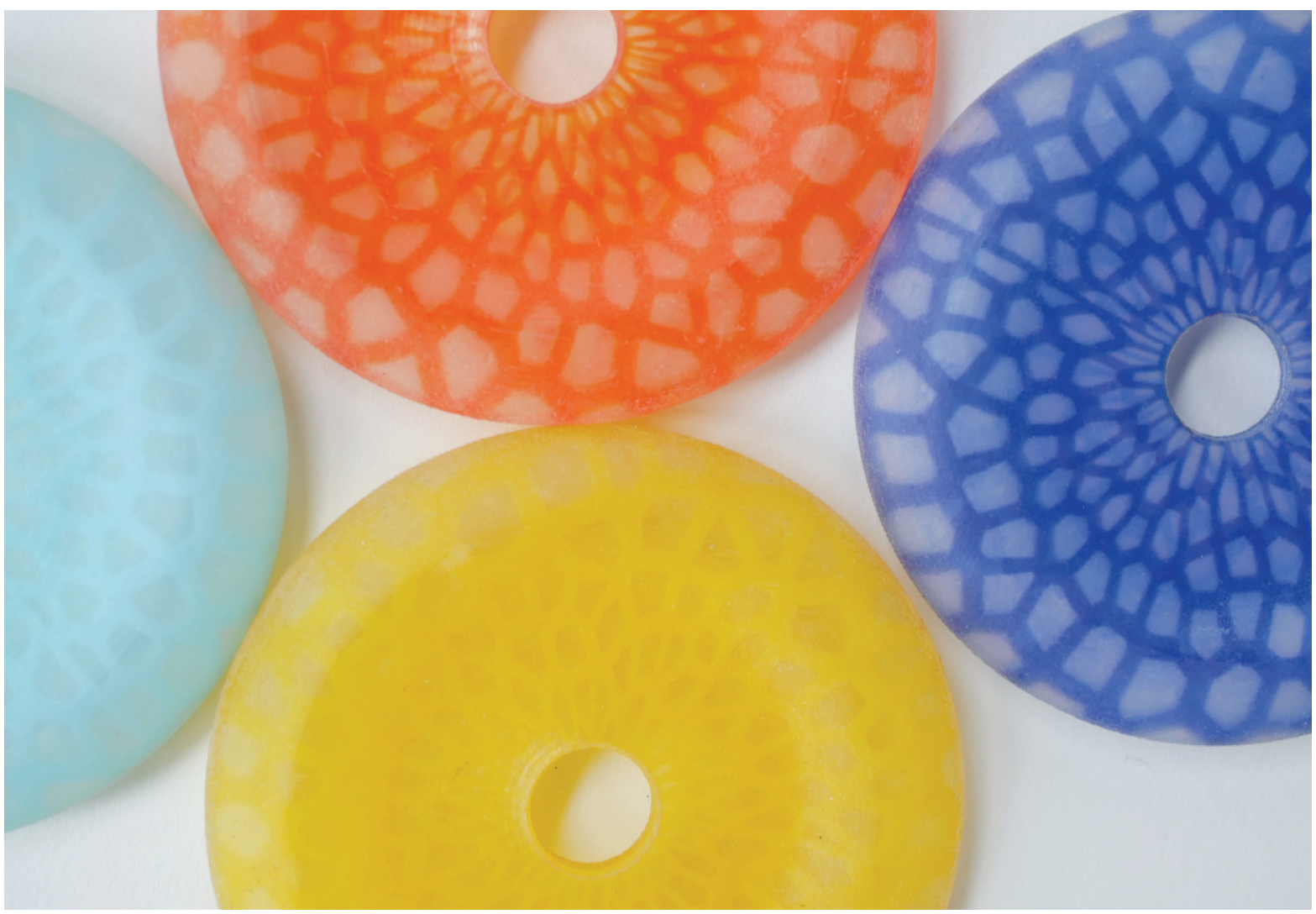

Figure 60. 3D printed pump colours

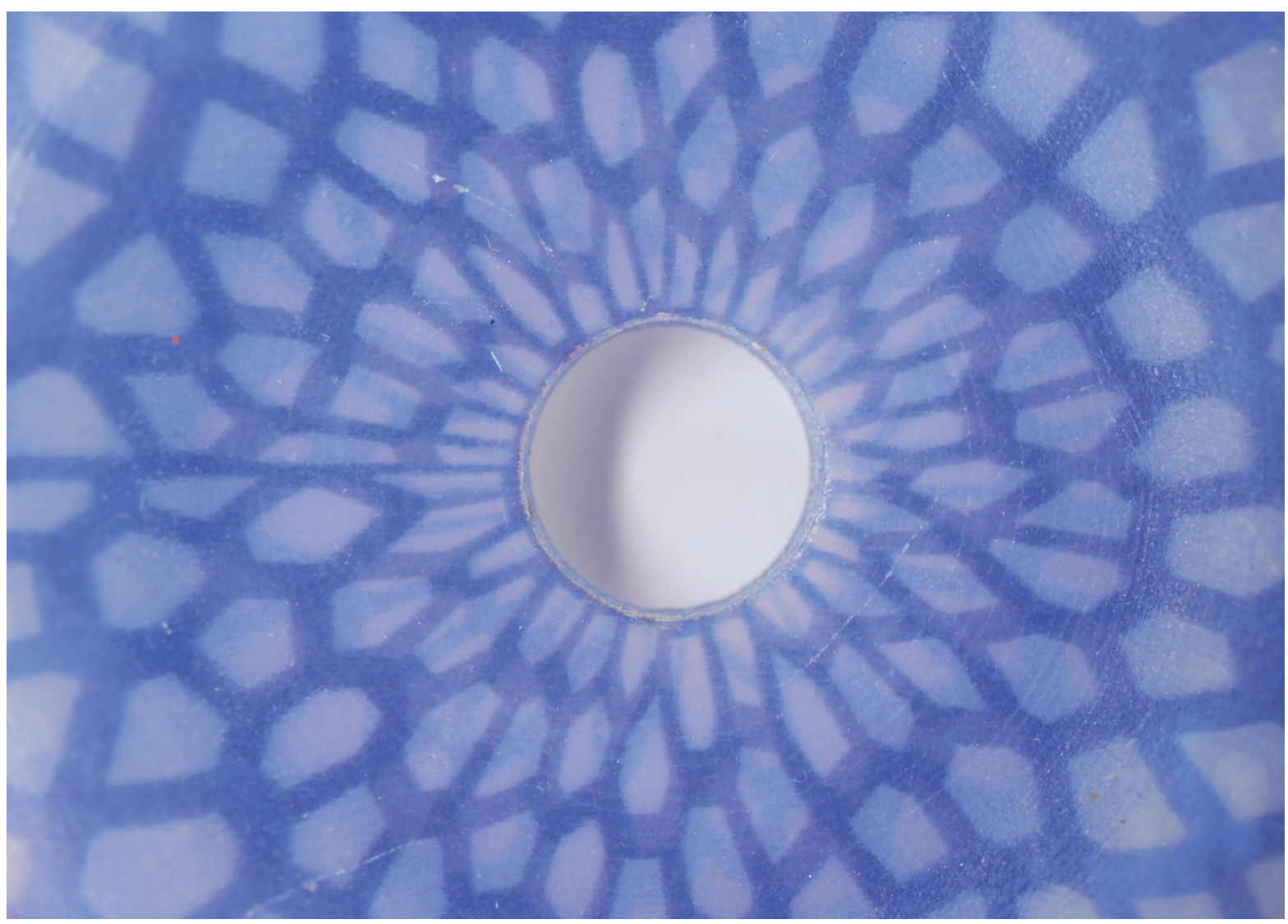

Figure 61. Close up of pump pattern 


\subsubsection{Final Prototype}

Four final prototypes were made for this strategy (Figure 63). To make these prototypes even more inconspicuous, other iterations of different colour options could have been explored.
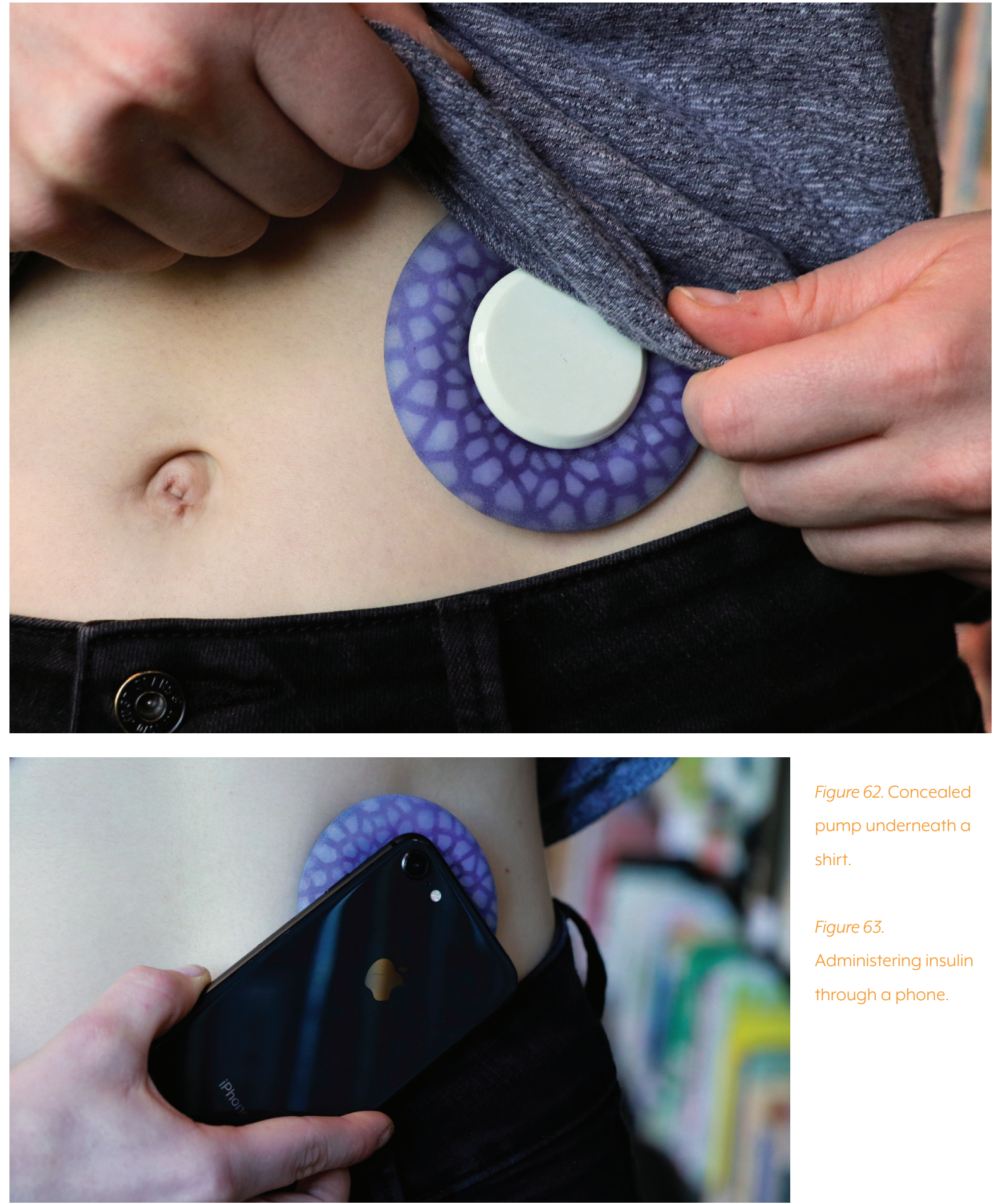

Figure 62. Concealed pump underneath a shirt.

Figure 63 .

Administering insulin through a phone. 


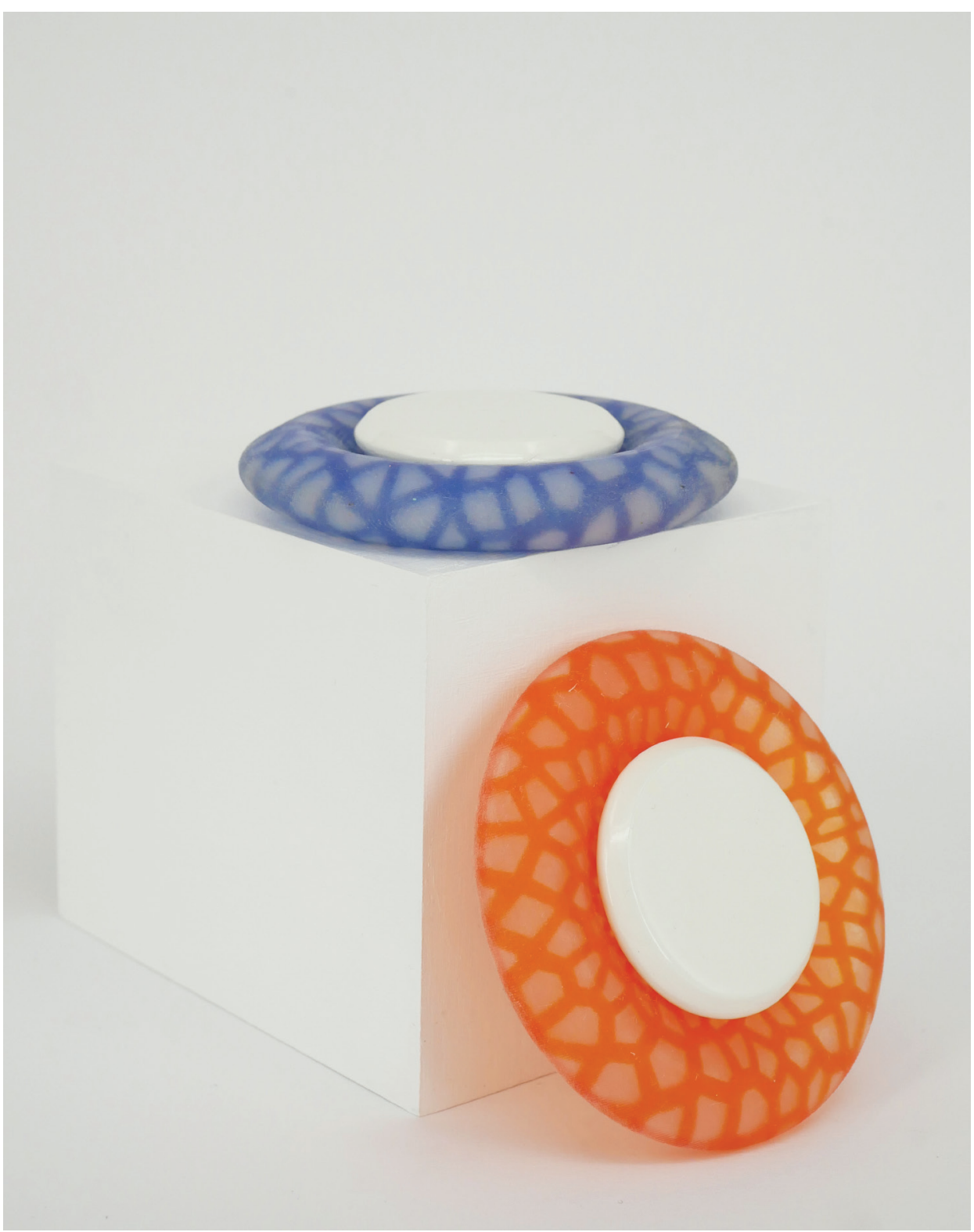

Figure 64. Final

concealed prototypes

Figure 65. Close up of

pump details.

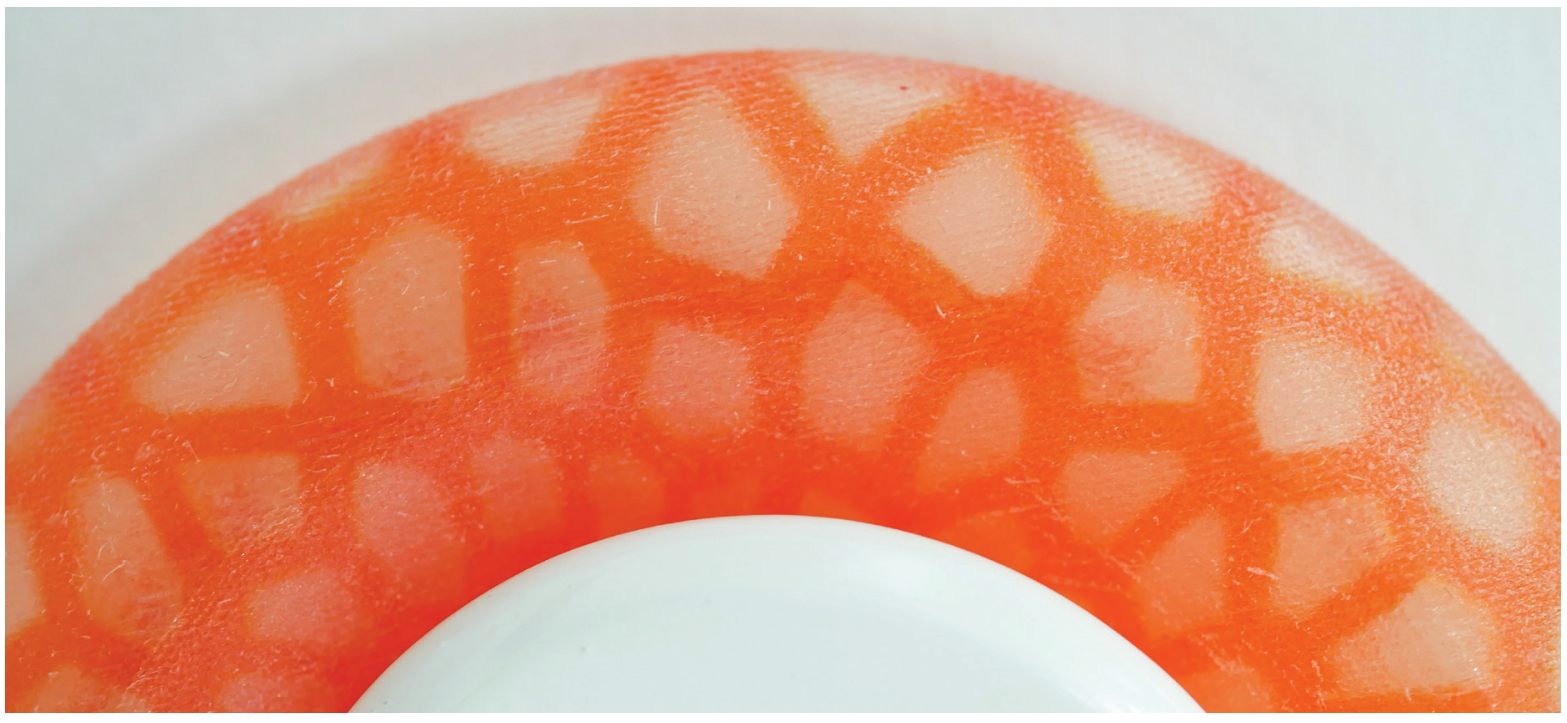




\subsubsection{Measuring the conspicuity of the prototype throughout the}

\section{interaction}

As this prototype can remain under clothing, it is the only prototype that is completely inconspicuous throughout the interaction. The strategy to conceal the concealed medica the medical device also remains throughout the entirety of the interaction device in use.

(Figure 66)
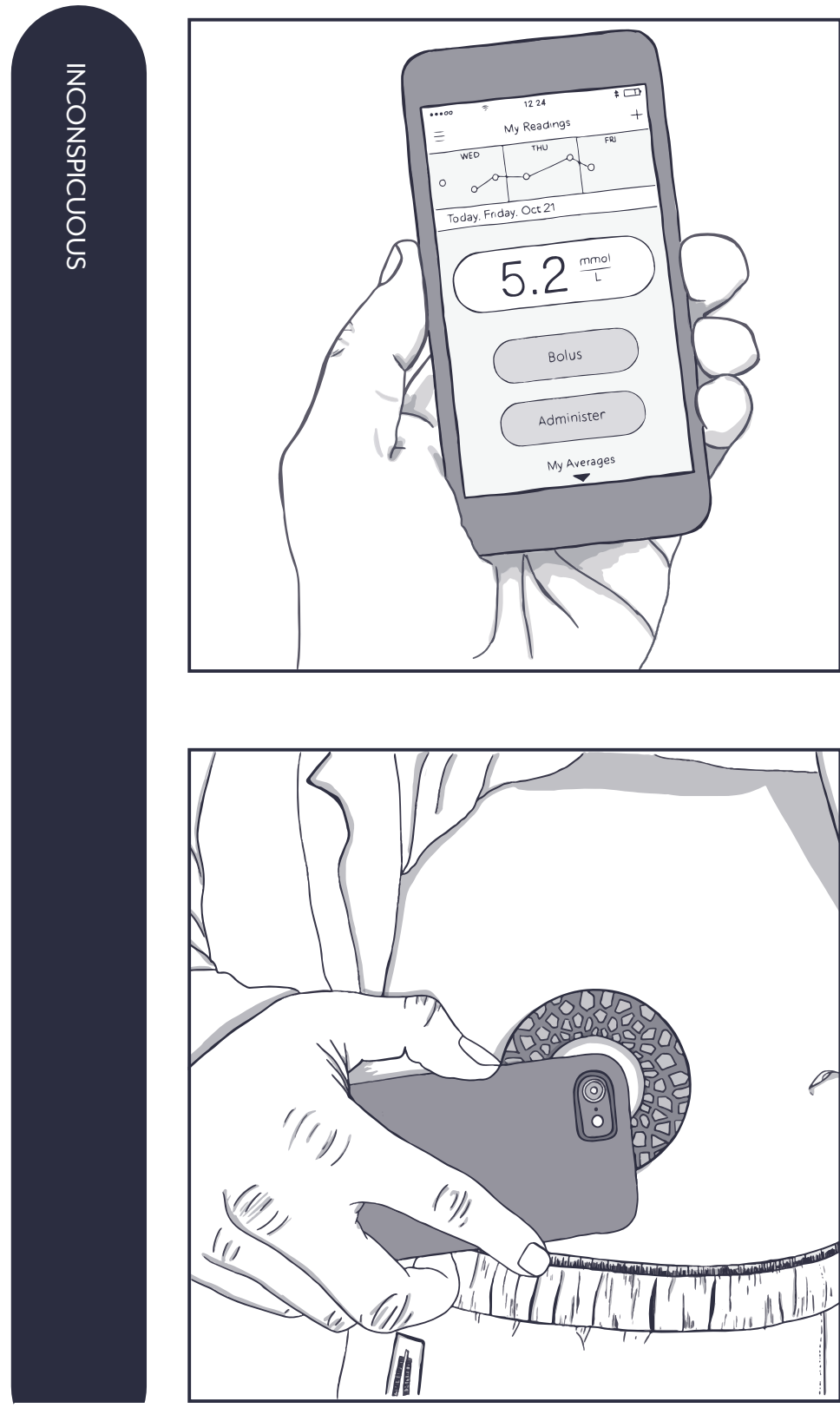

When an adolescent is using their phone to input their glucose levels, the device is inconspicuous and concealed.

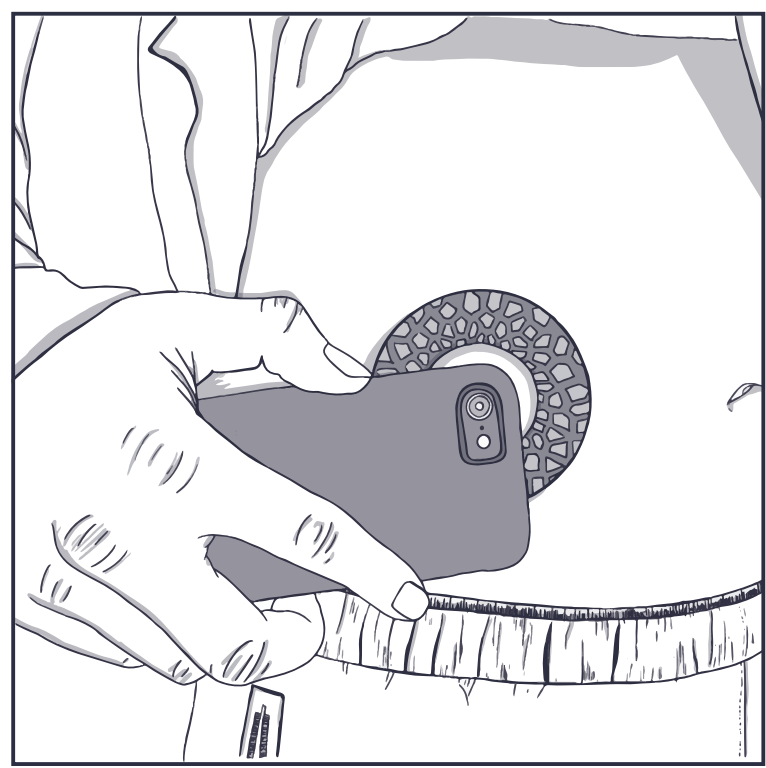

When the adolescent uses their phone to administer insulin, the device can remain hidden under clothing and so remains concealed. 

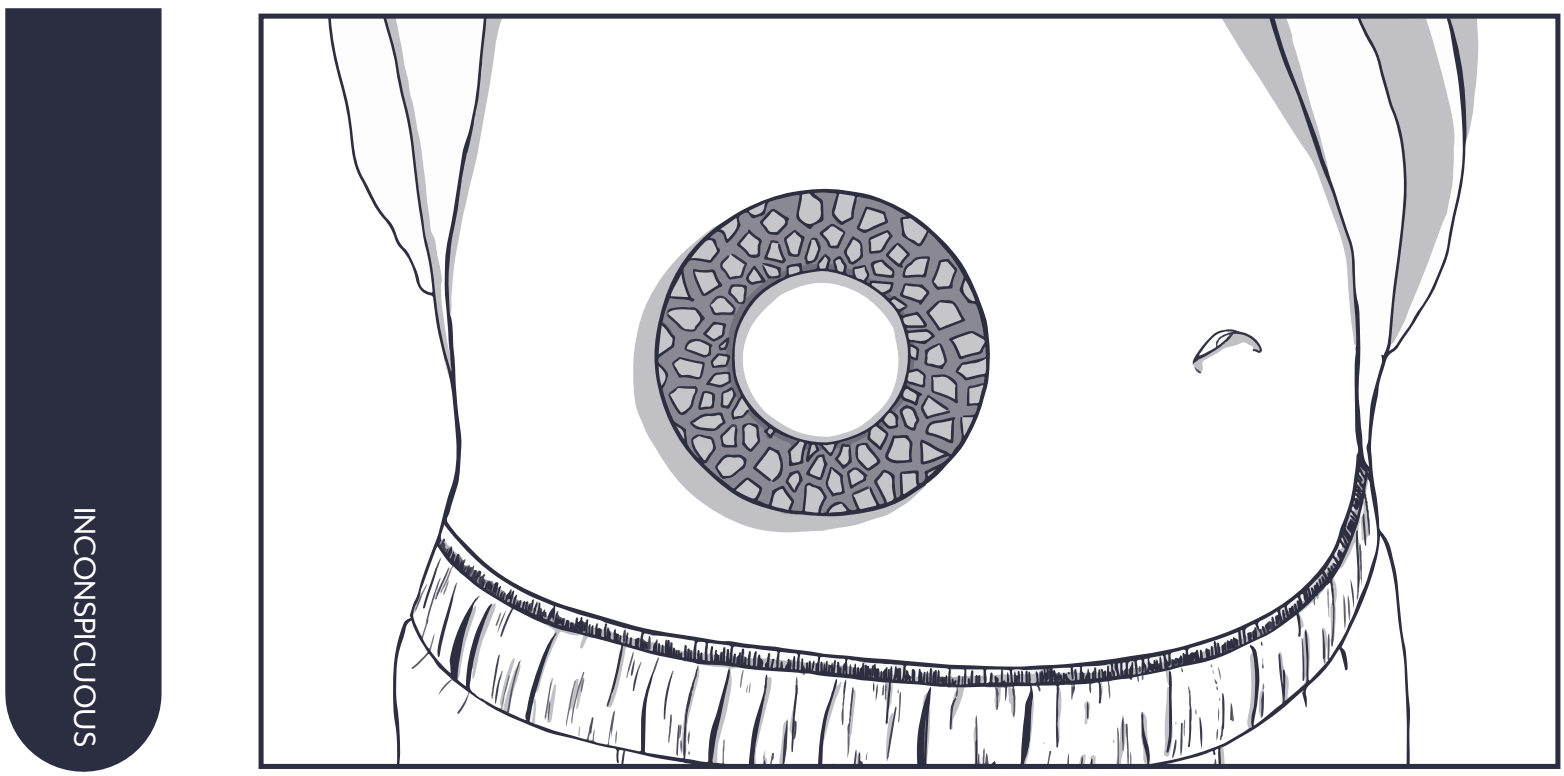

The final medical device can remain concealed and inconspicuous throughout the interaction. 


\section{Chapter 8}

\section{USER FEEDBACK}

The final user feedback session allowed the initial individual participants to provide feedback on the prototypes created during the design phase. This final phase of the research fulfils the second aim: Use a range of semantic strategies to develop and test conceptual medical device designs that provide adolescents with type 1 diabetes the opportunity to match users' preferences for conspicuousness. It also specifically addresses Objective 2: Identify and explore a range of semantic strategies that address the conspicuity of medical devices for adolescents with type 1 diabetes, and Objective 3: Design and evaluate the conceptual designs of medical devices' alignment with adolescents' requirements towards facilitating conspicuity in public settings. 


\subsection{METHODS}

The methods used during this user feedback session included semi-structured interviews (Adams, 2015) and a short questionnaire (Martin \& Hanington, 2012). Both these methods were used to try and facilitate a range of feedback from the participants.

\subsection{PARTICIPANTS}

Participant 1 and Participant 2 were involved in the feedback session to sustain their engagement throughout the research (Table \#). This allows for the participants to reflect on their initial interviews, and to make the research creditable. Both participants were eager to take part in a second session. During the interview it was also noted that Participant 1 had a new pump, which can be seen in Table 9.

\begin{tabular}{|c|c|c|c|c|c|}
\hline Code & Name & Gender & Age & Medical Device & Session \\
\hline $\mathrm{Pl}$ & Participant 1 & Male & 15 & Pump and Libre & Individual \\
\hline P2 & Participant 2 & Female & 15 & Pen and Libre & Individual \\
\hline
\end{tabular}




\subsection{PROCEDURE}

As the aim of discovering semantic preferences at the focus group was not achieved, the aim at the user feedback session was to understand adolescent preferences for semantic strategies, and to understand their preferences towards the prototypes.

The prototypes were kept in boxes, both so they could be revealed one at a time and to provide an opportunity to discuss the strategy first without being influenced by the prototype. Participants were asked about each of the strategies to receive their feedback and to explore their perspectives and understanding of the strategy. Each prototype was then revealed and explained to the adolescent, and they had an opportunity to hold the prototype and ask questions. For each of the prototypes the participants were given a simple questionnaire (Figure 67) to gain understanding of how the they perceived the product and its conspicuity, as well as how 'medical' or 'consumer' the product was. The terms on the sheet were explained to participants. Finally,

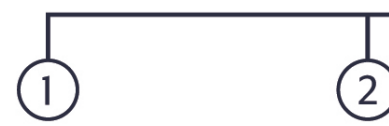

(2)

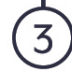

$(4)$
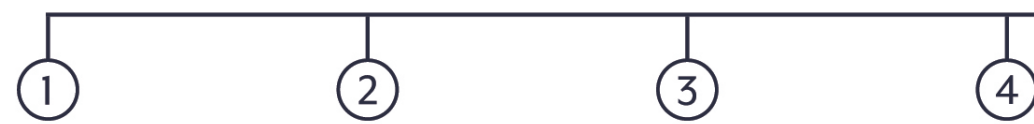


\subsection{FINDINGS}

\subsubsection{Participant feedback about the prototypes}

8.4.1.1 Enhance the aesthetics of the medical device

The participants liked the prototype that was designed to enhance the aesthetics of the medical device. Participant 2's initial reaction to the prototype was "I love this it's so cool, I thought this was like a lip gloss."

Both liked the colour options, and the outer casing that covers most of the 'medical' identifiers. P1: "You've got the colours and that blocks the insulin, which blocks all the medical stuff so it's not that obvious." Participant 2 also liked that the casing concealed part of the medical object.

P2: Yes, I would feel confident using this. I feel like it's concealed, not that that's an issue for me, and also the needle is concealed. Part of the public . . people don't like it. And it's just that is very good at hiding it.

When I asked the participants if there was anything I needed to change about the design, both participants couldn't think anything, P1: "I don't think there's much to add. If this was a functional syringe and it works.” Both participants gave similar responses on the questionnaire (Figure 68), saying that the medical device appears like a consumer object, and it is inconspicuous.

MEDICAL CONSUMER

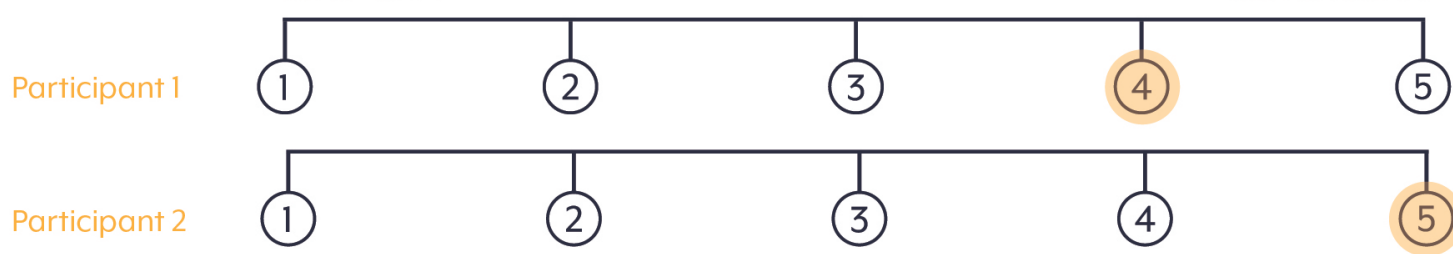
INCONSPICUOUS CONSPICUOUS Participant 1<smiles>CCc1ccccc1</smiles> 


\subsubsection{Personalise the medical device to the user}

Both participants reacted similarly to the prototypes by saying "Oh, that's really cool." Immediately Participant 2 liked the colour combination "I like the colour coordination as well." Both the participants liked that everything was in one place, and there would be no need to carry multiple devices. P1: "You could carry around just this." Participant 1 liked that this device would provide personalisation and the possibility of one company manufacturing the device.

P1: With this you give people choice on what they want. Right now people have to choose what they want off completely different companies, so if you had one person doing it and you had multiple options and they all could work together and all the combinations and stuff, everyone would have a slightly different device so it would feel more personal I guess.

When I asked the participants if there was anything I could add to the device, both thought it would be great to have the option to add other pieces onto the device, at the base or even onto the existing form.

Both participants thought that the medical device had an 'on' state and an 'off' state. Participant 2 thought that the device was inconspicuous when it was closed (Figure 69). P2: "I feel like you can definitely not tell what that is when it's closed up because it's all sealed on the inside, I feel like it's definitely very inconspicuous, like there's nothing indicating what it could be." Participant 1 also said that the device was inconspicuous (Figure *); however, thought the device appeared more medical once it was in its 'on' state. Pl:"It's very hidden, you don't even know but also when you open it and you've got all these pieces separated it does look quite obvious I guess. It still looks more medical than that [enhanced device]."

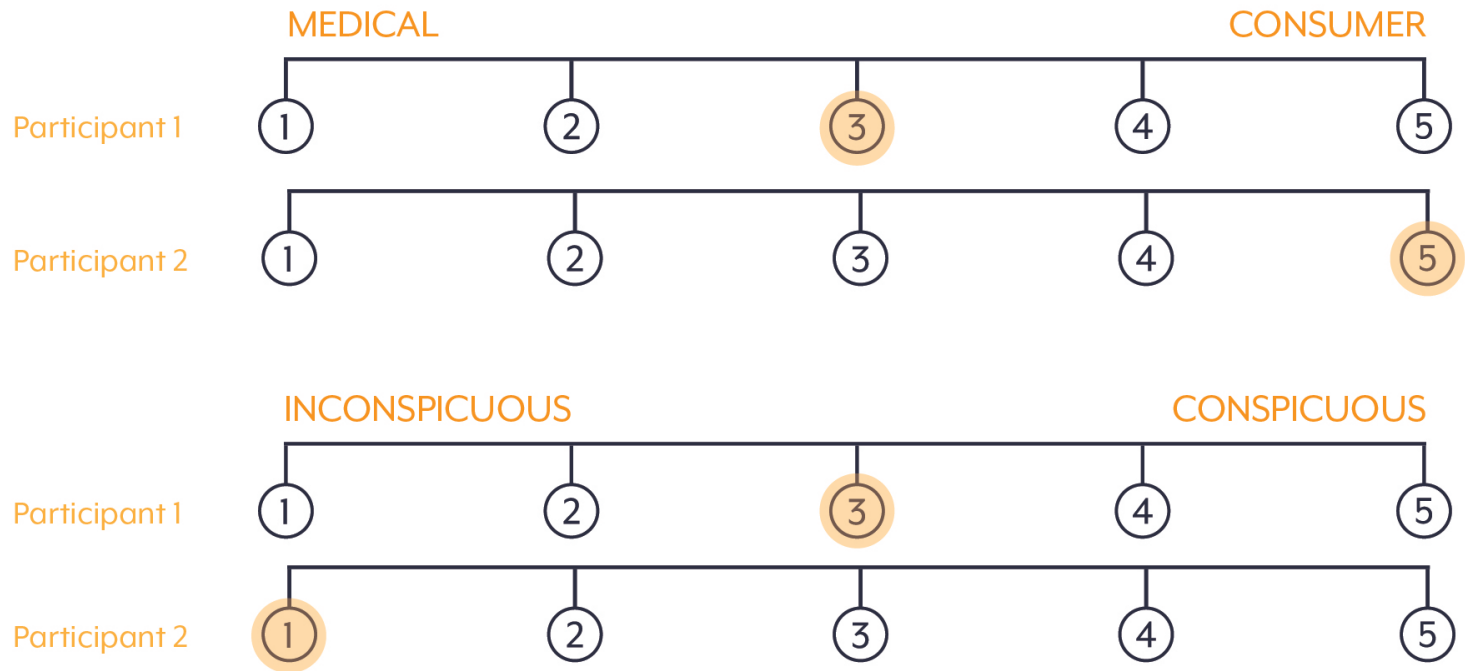




\subsubsection{Disguise the medical device as a non-medical item}

The participants liked the device for disguising the medical device as a nonmedical item, and both participants immediately thought the device looked like a PopSocket. P2: "No, but I genuinely would not know that that was, like out of context, I'd just think this a new type of PopSocket."

Participant 2 highlighted the fact that adolescents constantly have their phones with them "Yeah, because people always bring their phone. Like obviously you're not going to go anywhere without your phone these days." Which would also make this device more convenient. She also mentioned that the patterns help to disguise it further. P2: "And these patterns are cool, they also add the extra little bit of disguise." Participant 1 also said that this device achieved the goal of disguise effectively.

P1: People look at it and they think, 'Okay what is it?' so they try and think of the first thing that they think of for it. For those, I don't know a pen or something. For my kit everyone asks, 'why do you have two pencil cases?'. Well it's a PopSocket that's what everyone holds their phone with it and nobody would really ask questions about that. If people look closer, they might, then you know, it's fine. For the goal of disguising it, it does work well, and you also allow for the personalisation as well.

Both participants scored this device a 5 on the questionnaire for consumer; however, Participant 2 scored it 5 for conspicuous, whereas Participant 2 scored it 2 for inconspicuous (Figure 70.

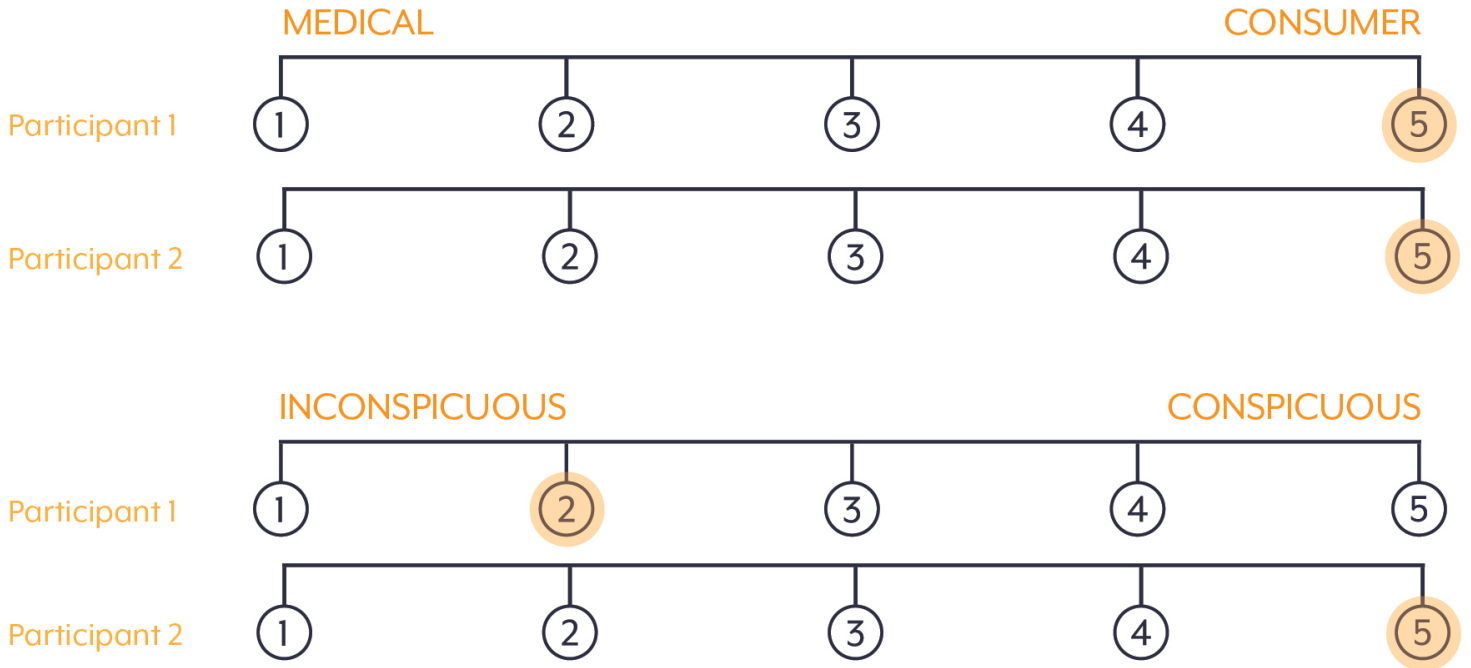




\subsubsection{Conceal the medical device from the public}

The final device to show participants was the insulin pump. Both participants liked this idea, as there had not been a pump design shown to them yet. They liked the colours the pump could provide, and the softer material the outside was made from. P2: "So, when I sleep or stuff like that, I can just feel like, it's quite uncomfortable, so I feel like with the silicone it would just be better." Both participants thought this device was more medical than the rest. However, they still marked it 4, being more Consumer than Medical. P2: "I think this one is slightly more medical than the rest, and I'm saying that because of the white circle." Participant 1, however, thought this device appeared more medical because it is worn on the body.

P1: If something's on your body it's already not fully consumer because you know, nothing fully consumer is on your body, but for things that are on your body, this is not really that medical but even with the pen and stuff it would . . you've got the cool colours and you've got not many, I don't know, symbols and stuff that would give it away. Not that many buttons or anything. It doesn't really look like a device if that's what you want.

Participant 1 scored this device 1 , very inconspicuous, because they would wear it on their stomach underneath clothing, whereas Participant 2 scored it 5, very conspicuous, because they discussed wearing the device on the back of the arm and the colours being very eye catching (Figure 71).

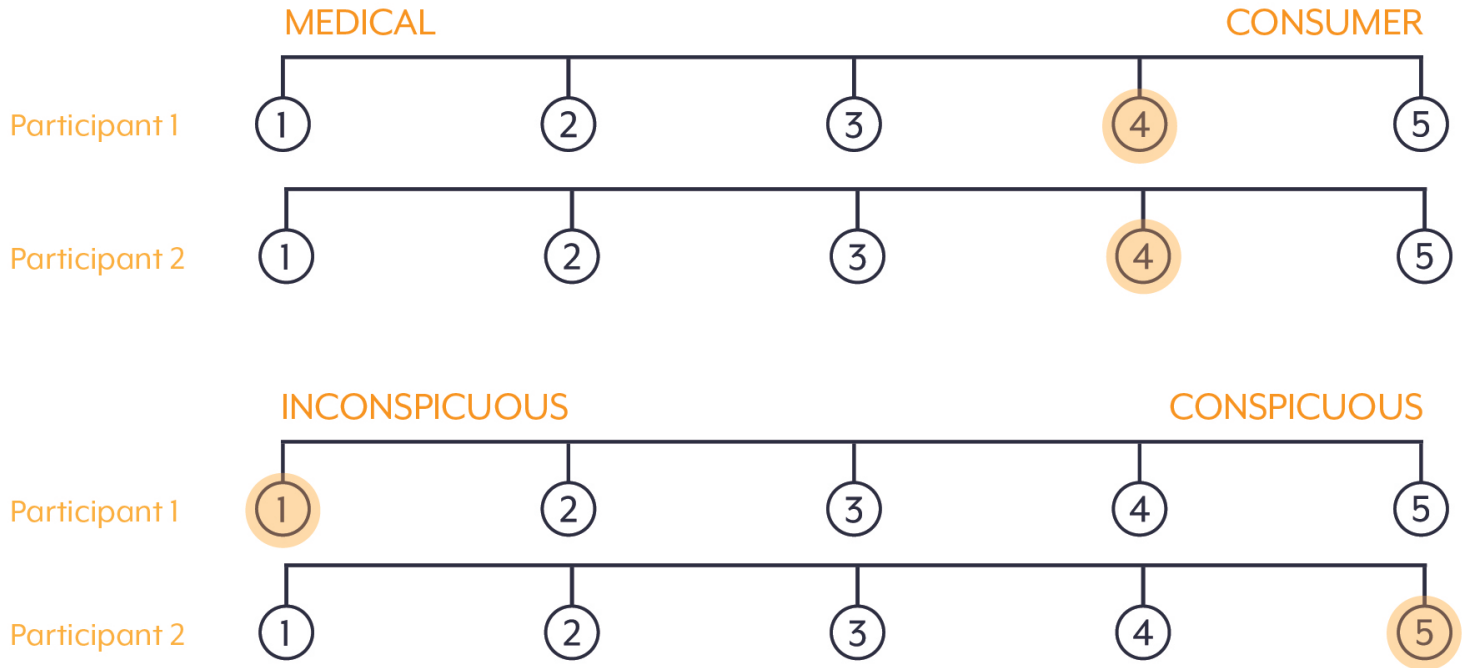




\subsubsection{Participant preferences for strategies and prototypes}

Finally, participants ranked the prototypes and the strategies from 1 to 4 , with 1 being the best (Figures $72-73$ ). The orange numbers are rankings for the strategies, and the blue numbers are for the prototypes.

The participants had different opinions about which of the devices they preferred. However, they both placed the personalised and concealed devices in their top two, and aesthetic and disguised devices in their bottom two. Participant 1 favoured the concealed insulin pump device, whereas Participant 2 favoured the all-in-one personalised device. Participant 2 was conflicted when deciding which device she preferred, since the insulin pen designed to enhance the aesthetics of the device was based off her sketch "I think this is crazy, because I designed this one [enhanced aesthetics], but I like that one more."

Both participants favoured the strategy to disguise the medical device as a nonmedical item. They also both placed Enhance the aesthetics of the traditional medical device as their third favourite strategy. Participant 1 placed Conceal the medical device as their second strategy, whereas Participant 2, placed Personalise the medical device as their second favourite strategy. Although there was some similarity in their preferences, there were many differences in what they favoured. Their different opinions, and the devices they currently used, could have influenced these decisions. 


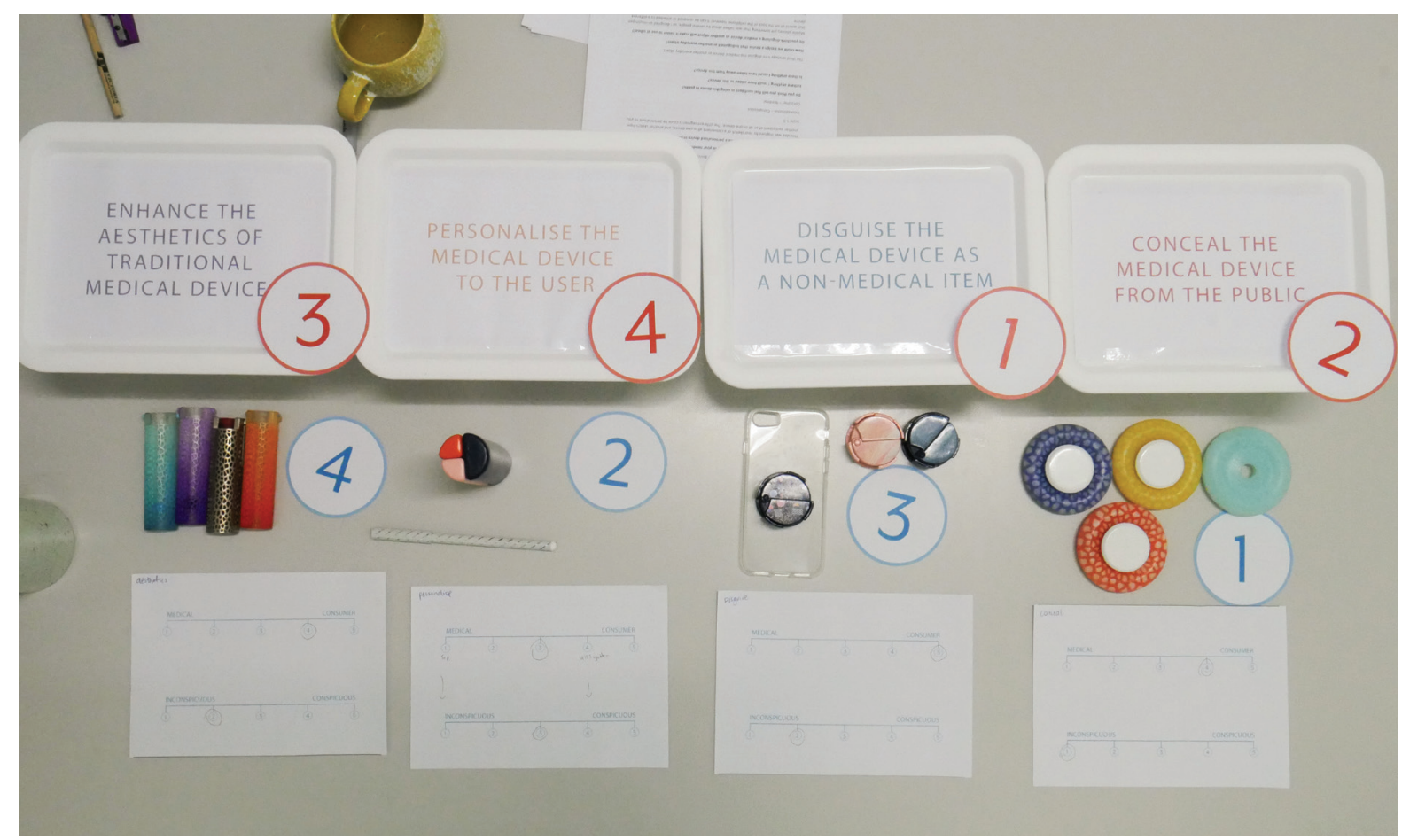

Figure 72. Participant l's final ranking of the strategies and prototypes

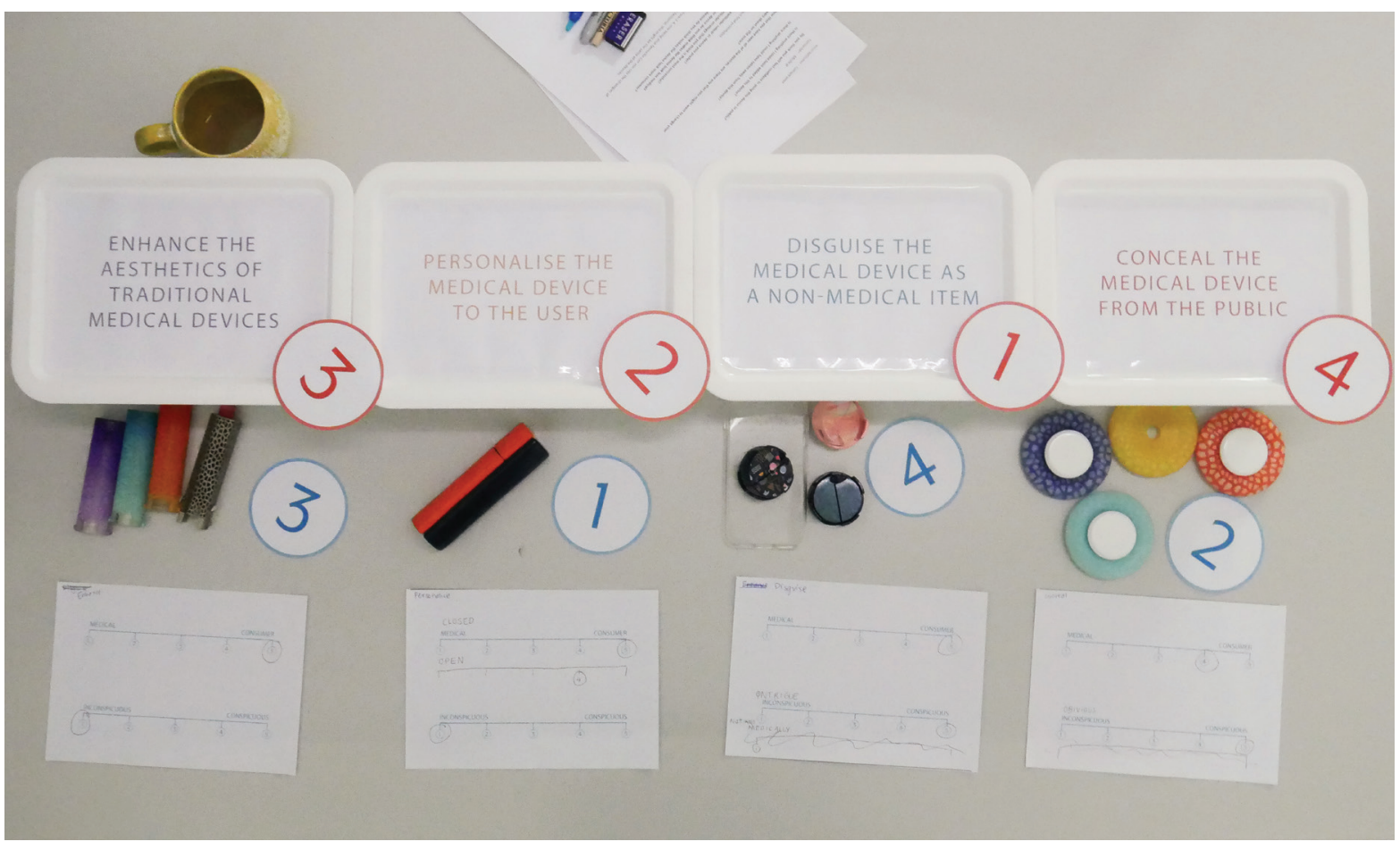

Figure 73. Participant 2's final ranking of the strategies and prototypes 
Chapter 9

\section{DISCUSSION}

This research sought to answer the question:

\footnotetext{
How might semantic strategies be used to inform the design of medical devices for adolescents with type 1 diabetes that match users' preferences for conspicuousness?
}

As outlined in previous chapters, a constructivist, participatory design approach was used to investigate adolescents' experiences and preferences for medical device conspicuity and to design and gather feedback on medical device designs that embodied a range of sematic strategies. This chapter begins by addressing each of the research objectives and comparing the findings from this research to previous work. Next, strengths, limitations, improvements, and future research are examined. Finally, implications and applications of the research are contextualised and discussed. 


\subsection{FINDINGS IN RELATION TO PREVIOUS LITERATURE}

\subsubsection{Objective 1: Investigate through qualitative and creative methods adolescents' experiences and preferences of medical- device related conspicuity in public settings.}

In order to achieve this objective, participatory sessions were conducted so that the research could be credible and triangulated. These sessions included conducting semi-structured interviews, collaging and sketching with individual participants, and using vignettes, sketching and discussion with a focus group.

Participants had mixed experiences managing type 1 diabetes. Some adolescents do not like managing their type 1 diabetes in public spaces. They fear being judged by their peers who are not understanding or supportive of their intensive management routine. Therefore, they choose not to test in order to avoid awkward social interactions, judgement from peers and feeling embarrassed. To a degree, these views align with previous literature which primarily discusses experiences of adolescents who feel uncomfortable testing in public spaces and disclosing their diabetes (Borus \& Laffel, 2010; Brazeau et al., 2018; Chao et al., 2016; Shinohara \& Wobbrock, 2011). However, some of the existing research is unsuccessful at exploring the more nuanced perspectives and opinions of adolescents that feel more comfortable managing and disclosing their type 1 diabetes.

As made evident through this research, adolescents have different experiences and preferences towards self-management, disclosure and medical devices. This research contributes to a more recent body of literature that has started to report on adolescents having varied and nuanced experiences whilst managing type 1 diabetes in public spaces (Commissariat et al., 2016; McCarthy, 2018; Rechenberg et al., 2018). For instance, some adolescents, described friends that are supportive and encourage them to regularly test their blood glucose levels. Supportive friends are more aware of the importance of maintaining steady blood glucose levels, and the implications that type 1 diabetes could have in the future. Consequently, adolescents with supportive friends felt more comfortable managing their type 1 diabetes in public and social settings.

Regardless of adolescents' opinions and preferences towards managing in public spaces, all of the participants agreed that there are occasions when they do not want to answer questions about their type 1 diabetes. This can be due to feeling tired, stressed, or experiencing low blood sugars.

In addition to having different experiences, adolescents also had different preferences towards medical devices. Convenience was a major factor in 
determining how adolescents manage their type 1 diabetes. If a medical device is convenient, an adolescent is more inclined to use it. Inconvenient medical devices are more conspicuous, because adolescents have to carry multiple bulky items, or feel required to remove themselves from social environments to use their devices.

The majority of participants in this research paid for and used a flash blood glucose meter, as the device is considered more convenient as it is constantly worn. At the time of the interviews with individual participants the Freestyle Libre had been introduced to New Zealand eight months prior. This usage is vastly different to McCarthy's (2018) research whereby the majority of participants used subsidised blood glucose meters. This willingness to pay for an unsubsidised device demonstrates the importance of its convenient characteristics for adolescent users. Currently subsidised devices in New Zealand accomplish neither convenience or conspicuity. Only one brand of blood glucose meter is now subsidised in New Zealand. As such, the funding of a variety of medical devices would allow for both affordability and choice. Similarly to how we can go to a shop to pick out a mobile phone that is best suited to our needs, adolescents should have the opportunity to choose a medical device that meets their preferences.

\subsubsection{Objective 2: Identify and explore a range of semantic strategies that address the conspicuity of medical devices for adolescents with type 1 diabetes.}

This research developed and explored four semantic strategies to address conspicuity through participatory design methods. The four semantic strategies are to Enhance the traditional medical device to make it more beautiful; Personalise the medical device for the user; Disguise the medical device as a non-medical item; and Conceal the medical device from the public.

These strategies are a useful framework to enable designers to create conspicuous medical devices for adolescents. The final strategies are similar to those that have been used to reduce stigma (Jacobson, 2014; McCarthy, 2018; Vaes, 2014). However, the strategies used to reduce stigma fail to recognise that not all adolescents with type 1 diabetes feel stigmatised by their medical devices. Therefore, these strategies have been modified to allow adolescents to feel confident managing their type 1 diabetes by both reducing and increasing conspicuity in a variety of ways.

The strategy to disguise a medical device as a non-medical item was favoured amongst adolescents. This strategy allows for medical devices to blend into their environment becoming inconspicuous. Previous research has described that adolescents feel ashamed of their medical devices when they have to hide them 
(McCarthy, 2018). By disguising the medical device, adolescents are provided a device that is aesthetically enhanced and more personalised. Therefore, this strategy has an opportunity to encompass elements of the other three strategies.

\subsubsection{Objective 3: Design medical device concepts and evaluate their alignment with adolescents' requirements towards facilitating conspicuity in public settings.}

Four prototypes were created to match each of the semantic strategies that addressed conspicuity. They were heavily influenced by the adolescents' sketches, collages, vignettes, interviews and group discussions. The prototypes were then evaluated with the two participants who took part in the individual interviews and creative methods.

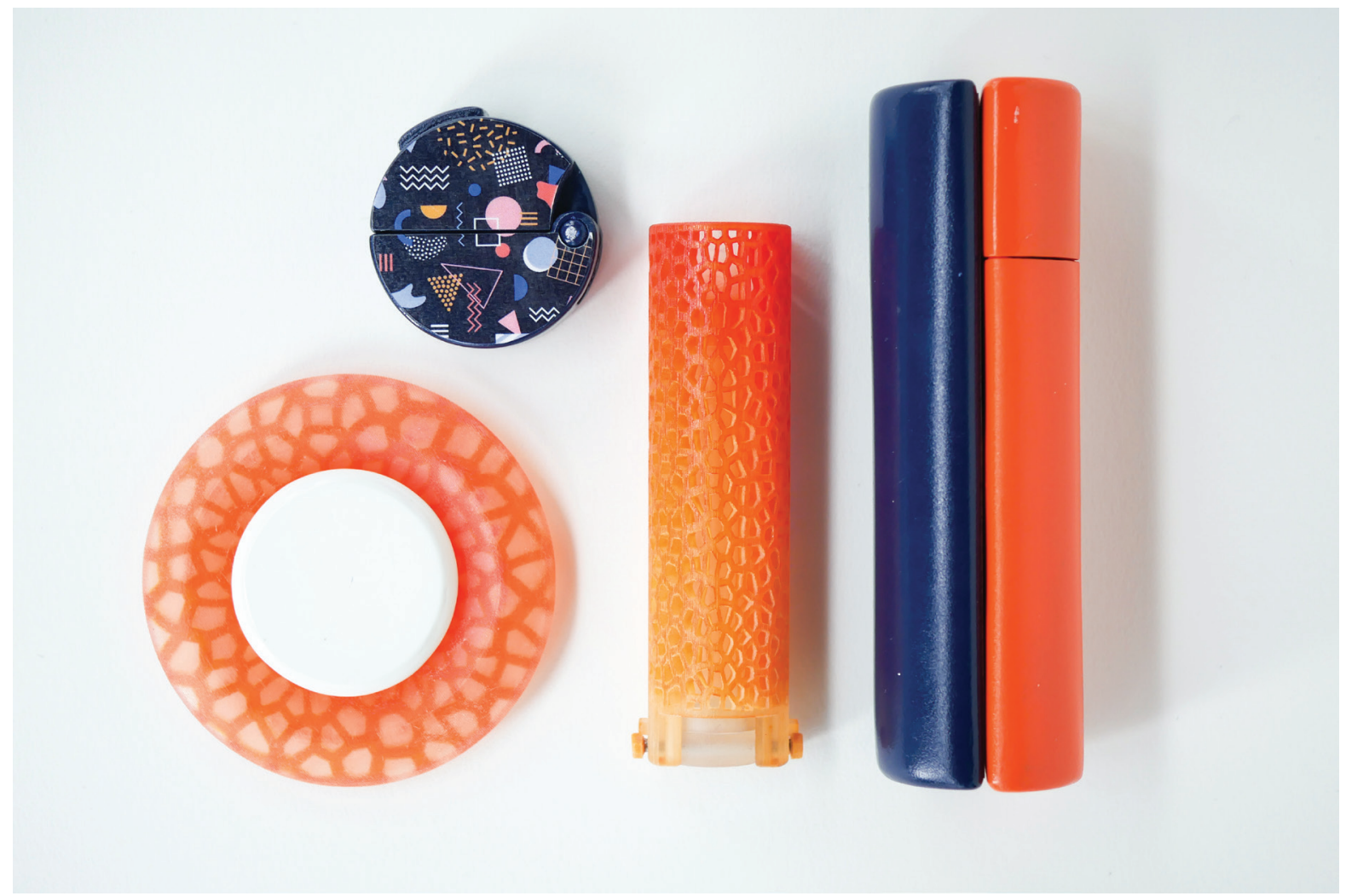

The final prototypes are vastly different from medical devices currently available in New Zealand. Therefore, adolescents did not have any other medical devices similar to the prototypes we designed to compare them to. As a result adolescents thought the final prototypes appeared inconspicuous because they did not appear 'medical'. The prototypes would not draw the same 'medical' related attention as their current devices, hence why the adolescents thought the prototypes appeared inconspicuous. I was not expecting this result, as some of the prototypes were designed to be conspicuous and facilitate positive attention due to their colours, materials and patterns. 
Participants preferred the magnetic personalised device, and the concealed insulin pump. The personalised device provides users options to match their preferences, through the different segments, colour choices and stickers. A further advancement of this device would be to provide adolescents the opportunity to customise the device by adding or removing segments, and choosing their colour options and stickers. Currently there are no all-in-one type 1 diabetes medical devices in New Zealand. Most adolescents carry around a second pencil case or small bag containing their medical equipment, which is inconvenient and conspicuous (McCarthy, 2018). The personalised device provides adolescents with ownership over their devices, and might make them more proud.

Adolescents also preferred the insulin pump that is concealed from the public. The pump is hidden and convenient, something that the participants described during the interviews as being important. Interacting with the device similar to a flash blood glucose meter would enable the adolescents to integrate the device into their daily lives.

Participants gave a mixed response to the level of conspicuity the concealed device projected. One participant discussed wearing the device on the back of her arm, therefore the bright colours of the device would be conspicuous and easily recognised. However, if the device is worn on the stomach it would be more inconspicuous because it would be covered by clothing. The patterns and colours of the concealed device lead to adolescents thinking this devices appeared more like a consumer item. I was not expecting this result, since the device is attached to the body, which typically makes a device more noticeably medical.

\subsection{STRENGTHS AND LIMITATIONS}

This research has several strengths and limitations that need to be considered. While previous research has explored stigma and attention, to my knowledge there has been no previous research that has linked the conspicuity to type 1 diabetes medical devices. This research highlights the importance of providing adolescents with opportunities to match their nuanced preferences for conspicuity, and therefore fills an unexplored area of current literature.

The strengths of this research stem from its participatory approach. As this research was conducted from a constructivist viewpoint, it was essential to consider what the adolescent wanted, especially as I do not have type 1 diabetes. Through semi-structured interviews and group discussion, the participants' experiences of type 1 diabetes were described in richer detail than might 
have been achieved through a questionnaire or survey. The creative methods allowed for adolescent opinions to be the primary inspiration for the designing phase of the research. Furthermore, the adolescents engaged well with creative methods, providing them with interesting tasks to complete rather than just answering questions. It allowed participants to tell their stories through different forms of media and to be proud of the work they were producing. The interviews and focus groups were able to specifically focus on and prompt responses about conspicuity, which has not previously been examined with adolescents and addresses a crucial gap in current literature.

This research also highlights the importance of providing several medical device options for adolescents. As there is only one brand of medical devices funded in New Zealand, this research calls attention to conspicuity as an important factor the funding committee should consider when selecting which devices they subsidise.

The research was limited due to only two adolescents taking part in the individual interviews, collaging, sketching, and feedback session. This was due to time constraints, the recruitment processes, and access to participants. More participants would have been helpful to clarify the semantic strategies and provide further opinions and preferences around conspicuity. Although only two adolescents participated in the interviews, sketching, collaging and user feedback session, it allowed for the final prototypes to be tailor-made to their specific preferences.

During the focus group, the timing and location of the event limited some of the results that could have occurred if the participants had not been distracted by other activities. At the focus group, male participants were only interested in some aspects, as some of the activities that were occurring outside were more interesting for them. If the focus group had been a standalone event, and the participants had volunteered to come without input from their parents, they might have been more engaged with the activities.

Finally, with fewer time constraints, it would have been helpful to explore more than one design prototype for each strategy. With more time, I could have developed the current prototypes further and incorporated more of the technical aspects of the medical device to allow for more realistic prototypes. 


\subsection{FUTURE RESEARCH}

The findings from this study have created several possible avenues to continue the research. Continuing the development of the design phase would provide some new options for medical devices that could be presented to medical technology companies. The devices I have designed in this research are just a starting point to open up further exploration into designing for conspicuity. Further, work could be undertaken with Pharmac to better inform their criteria used to determine which medical devices are subsidised. While this research has demonstrated a range of experiences and preferences around conspicuity, future research could explore the quantifiable size of these elements on health outcomes.

Further exploration into the semantic strategies would also be valuable to explore how designers could operationalise the strategies. Additionally, medical devices may not be the only area where a conspicuous product is preferred; other areas of design such as safety products, assistive products, and wearable technology might be areas in which to explore how the semantic strategies could address the conspicuity of products.

\subsection{IMPLICATIONS AND APPLICATIONS}

Qualitative research about adolescents with type 1 diabetes has only recently examined different experiences adolescents' have using medical devices in public. This research supports and extends existing literature. It was found that adolescents had mixed experiences towards managing in public and disclosing their condition. Therefore, adolescents also had mixed preferences towards using a conspicuous or inconspicuous medical device.

There are several ways to address the conspicuity of medical devices. The four strategies developed in this research are new ways of designing for conspicuity. The semantic strategies approach contributes new research to literature, and proposes a different approach compared to the strategies that address stigma.

Adolescents have different preferences for these strategies, as they have experienced device-related attention that has influenced their opinions. By creating several devices that match the strategies, adolescents could choose a device that suits their needs. In future, adolescent opinions need to be incorporated more thoroughly into both product development and selection for subsidisation. 
Chapter 10

CONCLUSION 
Creating medical devices that achieve the conspicuity preferences for adolescents is an important design feature medical companies need to start considering. This process has revealed that adolescents have different experiences managing type 1 diabetes in public spaces, and different preferences for the four semantic strategies and four medical devices developed and explored in this research.

The four strategies explored were: enhancing the traditional medical device to make it more beautiful, personalising the medical device for the user, disguising the medical device as a non-medical item, and concealing the medical device from the public. These strategies aim to produce either conspicuous or inconspicuous medical devices for adolescents with type 1 diabetes that do not attract negative attention.

The results from this research have shown how a more conscious effort needs to take place when designing medical devices for adolescents with type 1 diabetes. The prototypes designed are a stepping stone towards creating devices that achieve the desired conspicuity for the adolescent and facilitate positive conversations about type 1 diabetes. 


\section{REFERENCES}

Adams, W. C. (2015). Conducting semi-structured interviews. In K. E.

Newcomer, H. P. Hatry, \& J. S. Wholey (Eds.), Handbook of practical program evaluation (pp. 492-505). doi:10.1002/9781119171386

Artefact Group. (2014). Dialog epilepsy smart watch [Photograph]. Retrieved March 27, 2019, From https://www.artefactgroup.com/case-studies/dialog/

Atkinson, M. A., Eisenbarth, G. S., \& Michels, A. W. (2014). Type 1 diabetes. The Lancet, 383(9911), 69-82. doi:10.1016/S0140-6736(13)60591-7

Babler, E., \& Strickland, C. J. (2015). Normalizing: Adolescent experiences living with type 1 diabetes. The Diabetes Educator, 41(3), 351-360. doi:10.1177/0145721715579108

Borus, J. S., \& Laffel, L. (2010). Adherence challenges in the management of type 1 diabetes in adolescents: Prevention and intervention. Current Opinion in Pediatrics, 22(4), 405-411. doi:10.1097/MOP.0b013e32833a46a7

Braun, V., \& Clarke, V. (2012). Thematic analysis. In APA handbook of research methods in psychology, Vol 2: Research designs: Quantitative, qualitative, neuropsychological, and biological. (pp. 57-71). doi:10.1037/13620-004

Brazeau, A. S., Nakhla, M., Wright, M., Henderson, M., Panagiotopoulos, C., Pacaud, D., ... Dasgupta, K. (2018). Stigma and its association with glycemic control and hypoglycemia in adolescents and young adults with type 1 diabetes: Cross-sectional study. Journal of Medical Internet Research, 20(4), 151. doi:10.2196/jmir.9432

Brazeau, A. S., Nakhla, M., Wright, M., Panagiotopoulos, C., Pacaud, D., Henderson, M., ... Dasgupta, K. (2016). Stigma and Its Impact on Glucose Control Among Youth With Diabetes: Protocol for a Canada-Wide Study. JMIR Research Protocols, 5(4), e242. doi:10.2196/resprot.6629

Cameron, F. (2006). Teenagers with diabetes - management challenges. Australian Family Physician; Melbourne, 35(6), 386-390.

Carmon, D. (2018). Tweet [Photograph]. Retrieved May 23, 2019, From https:// www.dorcarmon.com/\#/tweet/ 
Chaney, D. (2012). Structured diabetes education for children and adolescents. Nursing Standard: Official Newspaper of the Royal College of Nursing, 27, 41-47. doi: 10.7748/ns2012.10.27.6.41.c9350

Chao, A. M., Minges, K. E., Park, C., Dumser, S., Murphy, K. M., Grey, M., \& Whittemore, R. (2016). General life and diabetes-related stressors in early adolescents with type 1 diabetes. Journal of Pediatric Health Care, 30(2), 133-142. doi:10.1016/j.pedhc.2015.06.005

Chung, A. (2017). Emergency Beacon [Photograph\}. Retrieved April 9, 2019, From https://www.behance.net/gallery/53148289/Emergency-beacon

Commissariat, P. V., Kenowitz, J. R., Trast, J., Heptulla, R. A., \& Gonzalez, J. S. (2016). Developing a personal and social identity with type 1 diabetes during adolescence: A hypothesis generative study. Qualitative Health Research, 26(5), 672-684. doi:10.1177/1049732316628835WW

Corbin, J. M. (2008). Basics of qualitative research: Techniques and procedures for developing grounded theory (3rd ed.). Retrieved from http://methods. sagepub.com/book/basics-of-qualitative-research

Demirbilek, O., \& Sener, B. (2003). Product design, semantics and emotional response. Ergonomics, 46(13-14), 1346-1360. doi:10.1080/00140130310001 610874

Feldman, S. S., \& Elliott, G. R. (1990). At the threshold: The developing adolescent. Cambridge, Mass.: Harvard University Press.

Fukaya, T. (2012). Biomimicry pin [Photograph]. Retrieved May 29, 2019, From https://www.yankodesign.com/2012/03/28/biomimicry-pin/

Galletta, A., \& Cross, W. E. (2013). The semi-structured interview as a repertoire of possibilities. In From research design to analysis and publication. Mastering the semi-structured interview and beyond (pp. 45-72). Retrieved from https:// www.jstor.org/stable/j.ctt9qgh5x.7

Goffman, E. (1963). Stigma: notes on the management of spoiled identity. Englewood Cliffs: Prentice-Hall, Inc.

Guest, G., MacQueen, K., \& Namey, E. (2019). Applied Thematic Analysis. doi:10.4135/9781483384436

Hatch, J. A. (2002). Doing Qualitative Research in Education Settings. Retrieved from http://ebookcentral.proquest.com/lib/vuw/detail.action?docID=3408084 
Jacobson, S. (2014). Personalised Assistive Products: Managing Stigma and Expressing the Self (Ph.D., Aalto University School of Arts).

Krippendorff, K., \& Butter, R. (1984). Product Semantics: Exploring the Symbolic Qualities of Form. Innovation, 3(2), 4-9.

KyngÄs, H. A., Kroll, T., \& Duffy, M. E. (2000). Compliance in adolescents with chronic diseases. Journal of Adolescent Health, 26(6), 379-388. doi:10.1016/ S1054-139X(99)00042-7

Lang, A. R. (2012). Medical device design for adolescents (Ph.D., University of Nottingham). Retrieved from http://eprints.nottingham.ac.uk/12501/

Lincoln, Y. S., \& Guba, E. G. (1985). Naturalistic inquiry. Beverly Hills, Calif.: Sage Publications.

Main, A., Wiebe, D. J., Van Bogart, K., Turner, S. L., Tucker, C., Butner, J. E., \& Berg, C. A. (2015). Secrecy From Parents and Type 1 Diabetes Management in Late Adolescence. Journal of Pediatric Psychology, 40(10), 1075-1084. doi:10.1093/jpepsy/jsv060

Martin, B., \& Hanington, B. (2012). Universal Methods of Design. United States of America: Rockport Publishers.

McCarthy, G. M., Ramírez, E. R. R., \& Robinson, B. J. (2017). Design Experiments. Identifying areas for intervention and designing medical technology for adolescents and young adults with type 1 diabetes. The Design Journal, 20(1), S2044-S2056. doi:10.1080/14606925.2017.1352723

McCarthy, G. (2018). Dear my very problematic blood glucose meter: adolescents' experiences self-managing type 1 diabetes and their psychosocial user requirements of medical technologies. Retrieved from http://researcharchive.vuw.ac.nz/ handle/10063/6975

Miklosi, A. (2018). Dab ECG sensor [Photograph]. Retrieved March 28, 2019, From https://www.behance.net/gallery/64353807/Dab-ECG-sensor?tracking_ source=search - all $\% 7 \mathrm{Cdab}$

Moorman, H. (2017). Epipi [photograph]. Retrieved February 13, 2019, From https://www.behance.net/gallery/54936019/Epipi. Copyright 2017 Harry Moorman.

Oberleitner, M., \& Malzone, M. (2018). Diabetes, Type 1. In Gale (Ed.), Gale Encyclopedia of Children's Health: Infancy Through Adolescence. Retrieved from 
http://search.credoreference.com/content/entry/galegchita/diabetes_ type_1/0

O'Brien, M. (2003). Focus groups supporting effective product development. The Design Journal, 6(1), 61-62. doi:10.2752/146069203790219317

Rechenberg, K., Grey, M., \& Sadler, L. (2018). "Anxiety and type 1 diabetes are like cousins": The experience of anxiety symptoms in youth with type 1 diabetes. Research in Nursing \& Health, 41(6), 544-554. doi:10.1002/ nur.21913

Rodríguez Ramírez, E., \& Chan, K. (2016). Smart interactions for home healthcare: A semantic shift. International Journal of Arts and Technology, 9(4). doi:10.1504/IJART.2016.081328

Sanders, E. B.-N., Brandt, E., \& Binder, T. (2010). A Framework for Organizing the Tools and Techniques of Participatory Design. Proceedings of the 11th Biennial Participatory Design Conference, 195-198. doi: $10.1145 / 1900441.1900476$

Sanders, E. B. N., Brandt, E., \& Binder, T. (2010). A framework for organizing the tools and techniques of participatory design. Proceedings of the 11th Biennial Participatory Design Conference, 195-198. doi:10.1145/1900441.1900476

Sanders, E. B. N., \& Stappers, P. J. (2014). Probes, toolkits and prototypes: Three approaches to making in codesigning. CoDesign, 10(1), 5-14. doi:10.1080/1 5710882.2014 .888183

Sanoff, H. (1990). Participatory design: Theory \& techniques. Raleigh, N.C.: Henry Sanoff distributor.

Schabert, J., Browne, J. L., Mosely, K., \& Speight, J. (2013). Social stigma in diabetes: A framework to understand a growing problem for an increasing epidemic. The Patient; Auckland, 6(1), 1-10.

Shinohara, K., \& Wobbrock, J. O. (2011). In the shadow of misperception: Assistive technology use and social interactions. Proceedings of the SIGCHI Conference on Human Factors in Computing Systems, 705-714. doi:10.1145/1978942.1979044

Simonsen, J., \& Robertson, T. (2013). Routledge international handbook of participatory design. Retrieved from http://helicon.vuw. ac.nz/login?url=http://www.VUW.eblib.com/EBLWeb/ patron/?target=patron\&extendedid=P_1047068_0 
Spinuzzi, C. (2005). The methodology of participatory design. Technical Communication; Washington, 52(2), 163-174.

Thrower, S. L., \& Bingley, P. J. (2014). What is type 1 diabetes? Medicine, 42(12), 682-686. doi:10.1016/j. mpmed.2014.09.003

Vaes, K. R. V., Stappers, P. J., Standaert, A., \& Desager, K. (2012). Contending stigma in product design: Using insights from social psychology as a stepping stone for design strategies. Proceedings of the 8th International Conference on Design and Emotion, London, Great Britain. doi:10.13140/2.1.3738.8800

Wang, J. (2015). Temporary blood glucose meter tattoo [Photograph]. Retrieved February 14, 2019, From https://www.flickr.com/photos/jsoe/16054780789/in/album-72157649793949249/

Wertheim, A. H. (2010). Visual conspicuity: A new simple standard, its reliability, validity and applicability. Ergonomics, 53(3), 421-442. doi:10.1080/00140130903483705

Wiebe, D. J., Berg, C. A., Mello, D., \& Kelly, C. S. (2018). Self- and social-regulation in type 1 diabetes management during late adolescence and emerging adulthood. Current Diabetes Reports, 18(5), 23. doi:10.1007/s11892-018-0995-3

Zarki, T. (2017). Hue Inhalor [Photograph]. Retrieved January 29, 2019, From https://www.zarki.net/ work/huin 
C.

141 


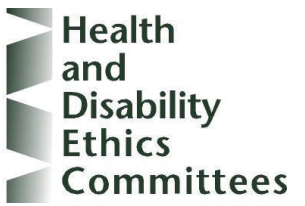

Health and Disability Ethics Committees Ministry of Health 133 Molesworth Street PO Box 5013

Wellington

24 August 2018

Madeleine Hazelton

Victoria University of Wellington

mailto:madeleine.hazelton@vuw.ac.nz

Dear Madeleine Hazelton,

Study title: Designing medical devices for adolescents with type 1 diabetes be designed to match users' preferences for conspicuousness

Thank you for emailing HDEC a completed scope of review form on 14 August 2018. The Secretariat has assessed the information provided in your form and supporting documents against the Standard Operating Procedures.

Your study will not require submission to HDEC as, on the basis of the information you have submitted, it does not appear to be within the scope of HDEC review. This scope is described in section three of the Standard Operating Procedures for Health and Disability Ethics Committees.

Your study meets the student-led research exemption criteria described below. Your scope of review form described an observational research project for the attainment of a Master's degree. Further, as your study is observational we note that:

An observational study requires HDEC review only if the study involves more than minimal risk (that is, potential participants could reasonably be expected to regard the probability and magnitude of possible harms resulting from their participation in the study to be greater than those encountered in those aspects of their everyday life that relate to the study).

For the avoidance of doubt, an observational study always involves more than minimal risk if it involves one or more of the following:

- one or more participants who will not have given informed consent to participate, or

- one or more participants who are vulnerable (that is, who have restricted capability to make independent decisions about their participation in the study), or

- standard treatment being withheld from one or more participants, or

- the storage, preservation or use of human tissue without consent, or

- the disclosure of health information without authorisation.

For the avoidance of doubt a study conducted wholly or principally for the purposes of an educational qualification requires HDEC review only if it:

- is an intervention study, or

- is not conducted at or below a Master's level.

If you consider that our advice on your project being out of scope is in incorrect please contact us as soon as possible giving reasons for this.

This letter does not constitute ethical approval or endorsement for the activity described in your application, but may be used as evidence that HDEC review is not required for it. 
Please note, your locality may have additional ethical review policies, please check with your locality. If your study involves a DHB, you must contact the DHB's research office before you begin. If your study involves a university or polytechnic, you must contact its institutional ethics committee before you begin.

Please don't hesitate to contact us for further information.

Yours sincerely,

Judit Angeli

Assistant Advisor

Health and Disability Ethics Committees

hdecs@moh.govt.nz 


\begin{abstract}
te Whare wänanga o te Ũoróo te tKa a máut
DESIGNING MEDICAL DEVICES FOR ADOLESCENTS WITH TYPE 1 DIABETES TO MATCH USERS' PREFERENCES FOR CONSPICUOUSNESS
\end{abstract}

INFORMATION SHEET FOR PARENTS/CAREGIVERS FOR INTERVIEWS

You are responsible for an adolescent under the age of 16 who are invited to take part in this research. Please read this information before deciding whether to take part. If you decide to participate, thank you. If you decide not to participate, thank you for considering this request.

\title{
Who am I?
}

My name is Maddy Hazelton and I am a master's student in the school of design at Victoria University of Wellington. This research project is work towards my thesis.

\section{What is the aim of the project?}

This project aims to collaborate with adolescents through interviews and participatory design methods to understand their current medical devices and their preferences for future medical devices. I am investigating how we might design medical devices that respond to teenagers' preferences around conspicuousness - for example, can we design medical devices that are really discreet for people who are feeling embarrassed, or don't want to disclose their condition, or alternatively, can we design beautiful devices that draw positive attention and give people an option to talk about diabetes when they choose to do so? In the course of the research, we will produce prototypes of new ideas for medical devices. These will not be fully-functioning medical devices. This research has been approved by the Victoria University of Wellington Human Ethics Committee \#0000026751.

\section{What will happen?}

If the participant agrees to take part, I will interview them at Victoria University Te Aro Campus, 139 Vivian St, Te Aro, Wellington. I will ask questions about their experience with type 1 diabetes, their medical devices and attention. The interview will take 45 minutes to 1 hour. If you would like to you are welcome to accompany your teenager during the research activities. I will audio record the interview with permission and write it up later. The participant can choose not to answer any question or stop the interview at any time, without giving a reason, or to not have the interview recorded. The participant can withdraw from the study by contacting me at any time, no later than two weeks after the transcripts of the interviews have been sent to them. If they withdraw from the research, the information they have provided will be destroyed or returned to them. As a parent/caregiver you are also allowed to be present at the interview. 
What will happen to the information you give?

This research is confidential. This means that the researchers named below will be aware of the participant's identity, but the research data will be combined, and their identity will not be revealed in any reports, presentations, or public documentation

Only my supervisors and I will read the notes or transcript of the interview. The interview transcripts, summaries and any recordings will be kept securely and destroyed on the $1^{\text {st }}$ of July 2020.

\section{What will the project produce?}

The information from my research will be used in my Master's thesis, academic publications or presented at conferences.

\section{What are the rights as a research participant?}

The participant does not have to accept this invitation. If they do decide to participate, have the right to:

- choose not to answer any question;

- ask for the audio recorder to be turned off at any time during the interview

- withdraw from the study no later than two weeks after receiving the interview transcripts;

- ask any questions about the study at any time;

- receive and comment on a copy of their interview transcript;

- receive a summary of my research once it has been completed;

- be able to read any reports of this research.

What are the rights of a parent/caregiver?

- Withdraw the participant from the study no later than two weeks after receiving the interview transcripts;

- ask any questions about the study at any time;

- receive a summary of my thesis once it has been completed;

- be able to read any reports of this research by emailing the researcher to request a copy.

If you have any questions or problems, who can you contact?

If you have any questions, either now or in the future, please feel free to contact either:

Student:

Name: Maddy Hazelton

University email address:

madeleine.hazelton@vuw.ac.nz

\section{Supervisor:}

Name: Gillian McCarthy

Role: Lecturer Interaction Design

School: Design

Phone: 044639548 
Gillian.McCarthy@vuw.ac.nz

\section{Human Ethics Committee information}

If you have any concerns about the ethical conduct of the research you may contact the Victoria University HEC Convenor: Dr Judith Loveridge. Email hec@vuw.ac.nz or telephone +64-4-463 6028 


\section{DESIGNING MEDICAL DEVICES FOR ADOLESCENTS WITH TYPE 1 DIABETES TO MATCH USERS PREFERENCES FOR CONSPICUOUSNESS}

\section{CONSENT TO INTERVIEW}

This consent form will be held for 3 years.

Researcher: Madeleine Hazelton, School of Design, Victoria University of Wellington.

- I have read the Information Sheet and the project has been explained to me. My questions have been answered to my satisfaction. I understand that I can ask further questions at any time.

I understand that:

- I can be present during the interview if the participant requires it.

- $\quad$ the participant may withdraw themselves (or any information they have provided) from this project, without having to give reasons, by e-mailing madeleine.hazelton@vuw.ac.nz no later than two weeks after the transcripts of the first interview have been sent to them.

- The identifiable information I have provided will be destroyed on the $1^{\text {st }}$ of October 2019.

- that any information the participant provides will be kept confidential to the researcher and their supervisor, the published results will not use their name, and that no opinions will be attributed to them in any way that will identify them.

- I understand that the results will be used for a Master's thesis, academic publications or presented at conferences.

- The participant's name will not be used in reports, nor will any information that would identify me.

- $\quad$ I would like to receive a copy of the final report and have added my Yes $\square$ No $\square$ email address below.

Name of participant:

Signature of parent/caregiver: 
Name of parent/caregiver:

Date:

Contact details: 


\section{DESIGNING MEDICAL DEVICES FOR ADOLESCENTS WITH TYPE 1 DIABETES TO MATCH USERS' PREFERENCES FOR CONSPICUOUSNESS}

\section{INFORMATION SHEET FOR PARTICIPANTS FOR INTERVIEWS}

You are invited to take part in this research, please read this information before deciding whether to take part. If you decide to participate, thank you. If you decide not to participate, thank you for considering this request.

\section{Who am I?}

My name is Maddy Hazelton and I am a master's student in the school of design at Victoria University of Wellington. This research project is work towards my thesis.

\section{What am I researching?}

The aim of this project is to understand how type 1 diabetes medical devices could be better in the future. How can we design cooler or more inviting medical devices? To do this, I want to work with teenagers, by asking questions and completing activities, to understand your current medical devices that are used to help manage type 1 diabetes. Together we will come up with some ideas for medical devices, that I will develop further into non-working concepts. This research has been approved by the Victoria University of Wellington Human Ethics Committee \#0000026751.

\section{How can you help?}

You have been invited to participate because you have type 1 diabetes and are between the age of 13-18 years old. Your experiences and knowledge of this topic are valuable to my research. If you agree to take part, I will interview you at Victoria University Te Aro Campus, 139 Vivian St, Te Aro, Wellington. I will ask you questions about your experience with type 1 diabetes, medical devices and attention. The interview will take 45 minutes to 1 hour. I will audio record the interview with your permission and write it up later. You can choose not to answer any question or stop the interview at any time, without giving a reason. I will also meet with you a second time to review the final concepts of medical devices. You can withdraw from the study by contacting me no later than two weeks after the transcripts of the first interview have been sent to you. If you withdraw from the research, the information you provided will be destroyed or returned to you.

\section{What will happen to the information you give?}

This research is confidential. This means that the researchers named below will be aware of your identity, but your identity will not be revealed in any reports, presentations, or public documentation. 
Only my supervisors and I will read the notes or transcript of the interview. The interview transcripts, summaries and any recordings will be kept securely and destroyed on the $1^{\text {st }}$ of July 2020.

\section{What will the project produce?}

The information from my research will be used in my Master's thesis, academic publications or presented at conferences.

\section{If you accept this invitation, what are your rights as a research participant?}

You do not have to accept this invitation if you don't want to. If you do decide to take part, you have the right to:

- choose not to answer any question;

- ask for the recorder to be turned off at any time during the interview

- withdraw from the study no later than two weeks after receiving the interview transcripts;

- ask any questions about the study at any time;

- receive and comment on a copy of your interview transcript;

- receive a summary of my research once it has been completed;

- be able to read any reports of this research

If you have any questions or problems, who can you contact?

If you have any questions, either now or in the future, please feel free to contact either:

\section{Student:}

Name: Maddy Hazelton

University email address:

madeleine.hazelton@vuw.ac.nz

\section{Supervisor:}

Name: Gillian McCarthy

Role: Lecturer Interaction Design

School: Design

Phone: 044639548

Gillian.McCarthy@vuw.ac.nz

\section{Human Ethics Committee information}

If you have any concerns about the ethical conduct of the research you may contact the Victoria University HEC Convenor: Dr Judith Loveridge. Email hec@vuw.ac.nz or telephone +64-4-463 6028. 


\section{DESIGNING MEDICAL DEVICES FOR ADOLESCENTS WITH TYPE 1 DIABETES TO MATCH USERS PREFERENCES FOR CONSPICUOUSNESS}

\section{CONSENT TO INTERVIEW - OVER THE AGE OF 16}

This consent form will be held for 3 years.

Researcher: Madeleine Hazelton, School of Design, Victoria University of Wellington.

- I have read the Information Sheet and the project has been explained to me. My questions have been answered and I understand that I can ask further questions at any time.

I understand that:

- I may withdraw (or any information I have provided) from this project, without having to give reasons, by e-mailing madeleine.hazelton@vuw.ac.nz no later than two weeks after the write up of the first interview has been sent to them.

- I will have an opportunity to check the transcripts of the interview. The identifiable information I have provided will be destroyed on the $1^{\text {st }}$ of October 2019.

- $\quad$ Any information the I provide will only be seen by the researcher and their supervisor, the published results will not use my name, and neither will any information that would identify me.

- $\quad$ The results will be used for a Master's thesis, academic publications or presented at conferences.

- I would like a copy of the recording of my interview $\quad$ Yes $\square \quad$ No $\square$

- I would like to receive a copy of the final report and have added my Yes $\square$ No $\square$ email address below.

- I would like to receive a copy of the write up of the interview $\quad$ Yes $\square \quad$ No $\square$

Name of participant:

Signature of participant: 
APPENDIX

Date:

Contact details:

4 


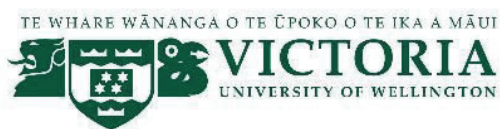

\section{DESIGNING MEDICAL DEVICES FOR ADOLESCENTS WITH TYPE 1 DIABETES TO MATCH USERS PREFERENCES FOR CONSPICUOUSNESS}

\section{ASSENT TO INTERVIEW - UNDER 16 YEARS OF AGE}

This consent form will be held for 3 years.

Researcher: Madeleine Hazelton, School of Design, Victoria University of Wellington.

- I have read the Information Sheet and the project has been explained to me. My questions have been answered and I understand that I can ask further questions at any time.

I understand that:

- I may withdraw (or any information I have provided) from this project, without having to give reasons, by e-mailing madeleine.hazelton@vuw.ac.nz no later than two weeks after the write up of the first interview has been sent to them.

- I will have an opportunity to check the transcripts of the interview. The identifiable information I have provided will be destroyed on the $1^{\text {st }}$ of October 2019.

- that any information the I provide will only be seen by the researcher and their supervisor, the published results will not use my name, and neither will any information that would identify me.

- I understand that the results will be used for a Master's thesis, academic publications or presented at conferences.

- I would like to receive a copy of the final report and have added my Yes $\square$ No $\square$ email address below.

- I would like a copy of the recording of my interview

- I would like to receive a copy of the write up of the interview

Name of participant: 
Signature of participant:

Date:

Contact details: 

PREFERENCES FOR CONSPICUOUSNESS

\author{
FOCUS GROUP RULES FOR PARTICIPANTS
}

- The information shared in this meeting is confidential. You should not discuss the opinions and comments made by other focus group participants with anybody outside this room. We would like you and others to feel comfortable when sharing information.

- You do not need to agree with others, but you should listen respectfully as others share their views.

- We would like to hear a wide range of opinions: please speak up on whether you agree or disagree.

- There are no right or wrong answers, every person's experiences and opinions are important.

- The meeting is audio recorded, therefore, please one person speak at a time.

- Please turn off your phones. 


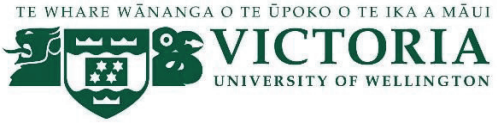

\section{DESIGNING MEDICAL DEVICES FOR ADOLESCENTS WITH TYPE 1 DIABETES TO MATCH USERS' PREFERENCES FOR CONSPICUOUSNESS}

\section{INFORMATION SHEET FOR PARENTS/CAREGIVERS}

You are responsible for an adolescent under the age of 16 who are invited to take part in this research. Please read this information before deciding whether to take part. If you decide to participate, thank you. If you decide not to participate, thank you for considering this request.

\section{Who am I?}

My name is Maddy Hazelton and I am a master's student in the school of design at Victoria University of Wellington. This research project is work towards my thesis.

\section{What is the aim of the project?}

This project aims to collaborate with adolescents, through focus groups, to understand how type 1 diabetes medical devices could be better in the future. I have been investigating how we might design medical devices that respond to teenagers' preferences around conspicuousness - for example, can we design medical devices that are really discreet for people who are feeling embarrassed, or don't want to disclose their condition, or alternatively, can we design beautiful devices that draw positive attention and give people an option to talk about diabetes when they choose to do so? In the course of the research, I have been working alongside teenagers in Wellington to design concepts of medical devices. These will not be fully-functioning medical devices. The focus groups at the Camp in Totara Springs will provide an opportunity for adolescents to give feedback on the concepts of medical devices I have designed. This research has been approved by the Victoria University of Wellington Human Ethics Committee \#0000026751.

\section{What will happen}

If the participant agrees to take part, they will be involved in a focus group at the North Island Family Camp at Totara Springs from the $15^{\text {th }}-17^{\text {th }}$ of March. I will ask them and other participants questions about how type 1 diabetes medical devices can be conspicuous and if they would use a device like the concepts I have designed. The focus group will take 45 minutes to 1 hour. I will audio record the focus group with your permission and write it up later.

The information shared during the focus group is confidential. That means that I will not share your identity with anyone, and the participant should not share the identity of other focus group members either.

You can withdraw from the focus group at any time before the focus group begins. 
You can also withdraw while the focus group it is in progress. However, it will not be possible to withdraw the information you have provided up to that point as it will be part of a discussion with other participants.

\section{What will happen to the information the participant gives?}

This research is confidential. This means that the researchers named below will be aware of your identity, but your identity will not be revealed in any reports, presentations, or public documentation.

Only my supervisors and I will read the notes or transcript of the focus group. The focus group transcripts, summaries and any recordings will be kept securely and destroyed on the $1^{\text {st }}$ of July 2020

\section{What will the project produce?}

The information from my research will be used in my master's thesis, academic publications or presented at conferences.

\section{What are the rights as a research participant?}

You do not have to accept this invitation if you don't want to. If you do decide to participate, you have the right to:

- choose not to answer any question;

- $\quad$ ask for the recorder to be turned off at any time during the focus group;

- withdraw from the focus group while it is taking part however it will not be possible to withdraw the information you have provided up to that point;

- $\quad$ ask any questions about the study at any time;

- $\quad$ read over and comment on the transcripts of the focus group;

- be able to read any reports of this research by emailing the researcher to request a copy.

\section{What are the rights of a parent/caregiver?}

- Withdraw the participant from the study no later than two weeks after receiving the interview transcripts;

- $\quad$ ask any questions about the study at any time;

- $\quad$ receive a summary of my thesis once it has been completed;

- be able to read any reports of this research by emailing the researcher to request a copy.

If you have any questions or problems, who can you contact?

If you have any questions, either now or in the future, please feel free to contact either:

\section{Student:}

Name: Maddy Hazelton

University email address:

madeleine.hazelton@vuw.ac.nz

\section{Supervisor:}

Name: Gillian McCarthy

Role: Lecturer Interaction Design

School: Design

Phone: 044639548

Gillian.McCarthy@vuw.ac.nz 


\section{Human Ethics Committee information}

If you have any concerns about the ethical conduct of the research you may contact the Victoria University HEC Convenor: Dr Judith Loveridge. Email hec@vuw.ac.nz or telephone +64-4-463 6028. 


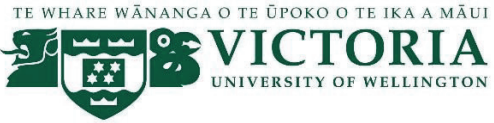

\section{DESIGNING MEDICAL DEVICES FOR ADOLESCENTS WITH TYPE 1 DIABETES TO MATCH USERS' PREFERENCES FOR CONSPICUOUSNESS}

\section{CONSENT TO PARTICIPATE IN FOCUS GROUP}

This consent form will be held for 3 years.

Researcher: Madeleine Hazelton, School of Design, Victoria University of Wellington.

- I have read the Information Sheet and the project has been explained to me. My questions have been answered to my satisfaction. I understand that I can ask further questions at any time.

I understand that:

- The participant can withdraw from the focus group while it is in progress however it will not be possible to withdraw the information they have provided up to that point as it will be part of a discussion with other participants

- The identifiable information the participant provides will be destroyed on the $1^{\text {st }}$ of October 2019.

- $\quad$ Any information that the participant provides will only be seen by the researcher and their supervisor, the published results will not use my name, and neither will any information that would identify me.

- The results will be used for a Master's thesis, academic publications or presented at conferences.

- The participant's name will not be used in reports, nor will any information that would identify them.

- $\quad$ I would like to receive a copy of the final report and have added my Yes $\square$ No $\square$ email address below.

Name of Participant:

Signature of parent/caregiver: 
Name of parent/caregiver:

Date:

Contact details: 

PREFERENCES FOR CONSPICUOUSNESS

\author{
FOCUS GROUP RULES FOR PARTICIPANTS
}

- The information shared at this meeting is confidential. You should not discuss the opinions and comments made by other focus group participants with anybody outside this room. We would like you and others to feel comfortable when sharing information.

- You do not need to agree with others, but you should listen respectfully as others share their views.

- We would like to hear a wide range of opinions: please speak up on whether you agree or disagree.

- There are no right or wrong answers, every person's experiences and opinions are important.

- The meeting is audio recorded, therefore, please one person speak at a time.

- Please turn off your phones. 


\section{DESIGNING MEDICAL DEVICES FOR ADOLESCENTS WITH TYPE 1 DIABETES TO MATCH USERS PREFERENCES FOR CONSPICUOUSNESS}

\section{INFORMATION SHEET FOR PARTICIPANTS}

You are invited to take part in this research about managing type 1 diabetes. Please read this information before deciding whether or not to take part. If you decide to participate, thank you. If you decide not to participate, thank you for considering this request.

\section{Who am I?}

My name is Maddy Hazelton and I am a master's student in the school of design at Victoria University of Wellington. This research project is work towards my thesis.

\section{What is the aim of the project?}

The aim of this project is to understand how type 1 diabetes medical devices could be better in the future. How can we design cooler or more inviting medical devices? To do this, I've been working with some teenagers in Wellington to design some ideas for medical devices, and I'd like to get your feedback on these designs. How could we make them better? This research has been approved by the Victoria University of Wellington Human Ethics Committee $\$ 0000026751$.

\section{How can you help?}

You have been invited to take part because you have type 1 diabetes and are between the age of 13-18 years old. Your personal experiences and knowledge of type 1 diabetes are really valuable. If you agree to take part, you will be involved in a focus group at the North Island Family Camp at Totara Springs from the $15^{\text {th }}-17^{\text {th }}$ of March. I will ask you and the other participants questions about how type 1 diabetes medical devices can draw attention and how we could improve them. The focus group will take 45 minutes to 1 hour. I will audio record the focus group with your permission and write it up later.

The information shared during the focus group is confidential. That means that I will not share your identity with anyone, and you should not share the identity of other focus group members either.

You can withdraw from the focus group at any time before the focus group begins.

You can also withdraw while the focus group it is in progress. However, it will not be possible to withdraw the information you have provided up to that point as it will be part of a discussion with other participants.

\section{What will happen to the information you give?}


This research is confidential. This means that the researchers named below will be aware of your identity, but your identity will not be revealed in any reports, presentations, or public documentation.

Only my supervisors and I will read the notes or transcript of the focus group. The focus group transcripts, summaries and any recordings will be kept securely and destroyed on the $1^{\text {st }}$ of July 2020

\section{What will the project produce?}

The information from my research will be used in my Master's thesis, academic publications or presented at conferences.

\section{If you accept this invitation, what are your rights as a research participant?}

You do not have to accept this invitation if you don't want to. If you do decide to participate, you have the right to:

- $\quad$ choose not to answer any question;

- $\quad$ ask for the recorder to be turned off at any time during the focus group;

- $\quad$ withdraw from the focus group while it is taking part, however, it will not be possible to withdraw the information you have provided up to that point;

- $\quad$ ask any questions about the study at any time;

- $\quad$ read over and comment on the transcripts of the focus group;

- be able to read any reports of this research by emailing the researcher to request a copy.

If you have any questions or problems, who can you contact?

If you have any questions, either now or in the future, please feel free to contact either:

Student:

Name: Maddy Hazelton

University email address:

madeleine.hazelton@vuw.ac.nz

\section{Supervisor:}

Name: Gillian McCarthy

Role: Lecturer Interaction Design

School: Design

Phone: 044639548

Gillian.McCarthy@vuw.ac.nz

\section{Human Ethics Committee information}

If you have any concerns about the ethical conduct of the research you may contact the Victoria University HEC Convenor: Dr Judith Loveridge. Email hec@vuw.ac.nz or telephone +64-4-463 6028. 


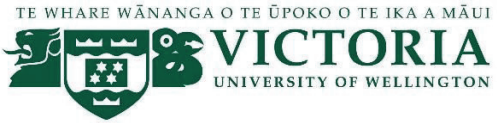

\section{DESIGNING MEDICAL DEVICES FOR ADOLESCENTS WITH TYPE 1 DIABETES TO MATCH USERS' PREFERENCES FOR CONSPICUOUSNESS}

\section{CONSENT TO PARTICIPATE IN FOCUS GROUP - OVER THE AGE OF 16}

This consent form will be held for 3 years.

Researcher: Madeleine Hazelton, School of Design, Victoria University of Wellington.

- I have read the Information Sheet and the project has been explained to me. My questions have been answered to my satisfaction. I understand that I can ask further questions at any time.

- I agree to take part in an audio-recorded focus group

I understand that:

- I acknowledge that I am agreeing to keep the information shared during the focus group confidential. I am aware that after the focus group, I must not communicate the identity of other members to anyone.

- I can withdraw from the focus group while it is in progress however it will not be possible to withdraw the information I have provided up to that point as it will be part of a discussion with other participants

- $\quad$ The identifiable information I have provided will be destroyed on the $1^{\text {st }}$ of October 2019.

- $\quad$ Any information the I provide will only be seen by the researcher and their supervisor, the published results will not use my name, and neither will any information that would identify me.

- The results will be used for a Master's thesis, academic publications or presented to conferences.

- My name will not be used in reports, nor will any information that would identify me.

- I would like a transcript of the focus group:

Yes $\square \quad$ No $\square$

- $\quad$ I would like to receive a copy of the final report and have added my Yes $\square$ No $\square$ email address below.

Signature of participant: 
Name of participant:

Date:

Contact details 


\section{DESIGNING MEDICAL DEVICES FOR ADOLESCENTS WITH TYPE 1 DIABETES TO MATCH USERS PREFERENCES FOR CONSPICUOUSNESS}

\section{ASSENT TO PARTICIPATE IN FOCUS GROUP - UNDER 16 YEARS OF AGE}

This consent form will be held for 3 years.

Researcher: Madeleine Hazelton, School of Design, Victoria University of Wellington.

- I have read the Information Sheet and the project has been explained to me. My questions have been answered to my satisfaction. I understand that I can ask further questions at any time.

- I agree to take part in an audio-recorded focus group

I understand that:

- I acknowledge that I am agreeing to keep the information shared during the focus group confidential. I am aware that after the focus group, I must not communicate the identity of other members to anyone.

- I can withdraw from the focus group while it is in progress however it will not be possible to withdraw the information I have provided up to that point as it will be part of a discussion with other participants

- $\quad$ The identifiable information I have provided will be destroyed on the $1^{\text {st }}$ of October 2019.

- $\quad$ Any information the I provide will only be seen by the researcher and their supervisor, the published results will not use my name, and neither will any information that would identify me.

- The results will be used for a Master's thesis, academic publications or presented at conferences.

- My name will not be used in reports, nor will any information that would identify me.

- I would like a transcript of the focus group:

Yes $\square \quad$ No $\square$

- $\quad$ I would like to receive a copy of the final report and have added my Yes $\square$ No $\square$ email address below.

Signature of participant: 
Name of participant:

Date:

Contact details: 


\section{Appendix C}

\begin{tabular}{|c|c|c|c|c|c|c|c|}
\hline & $\frac{\cdot u}{\underline{n}}$ & 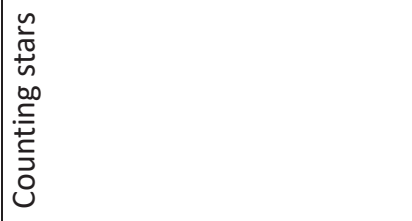 & 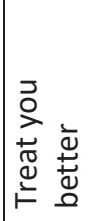 & 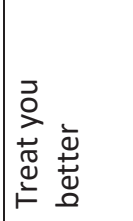 & & 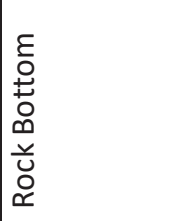 & 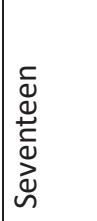 \\
\hline & 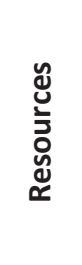 & & 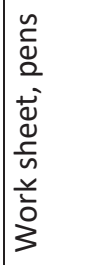 & 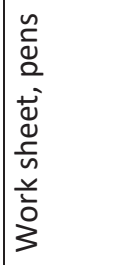 & & 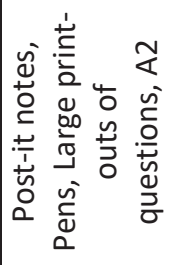 & \\
\hline $\begin{array}{l}\frac{5}{0} \\
\frac{0}{0} \\
\frac{0}{3} \\
\frac{0}{0} \\
\underline{n}\end{array}$ & 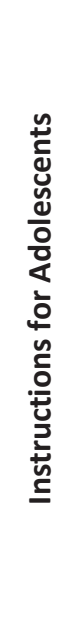 & 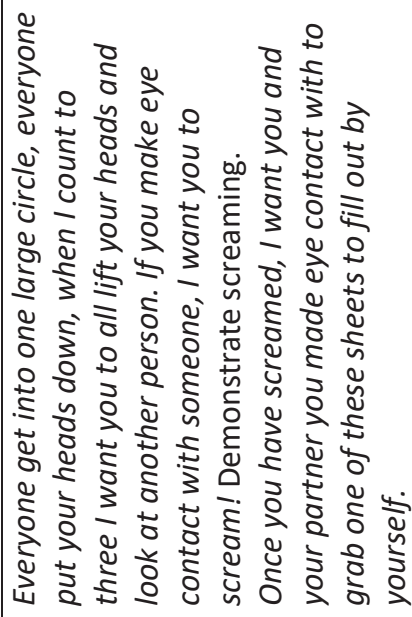 & & 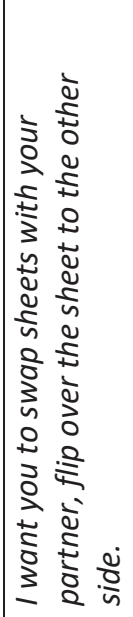 & 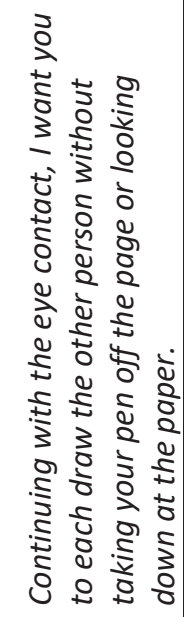 & 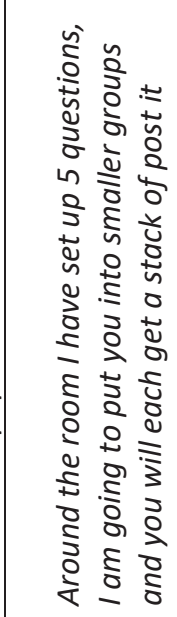 & 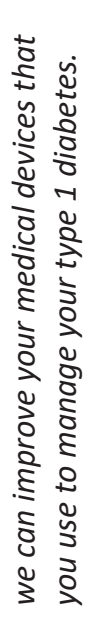 \\
\hline & 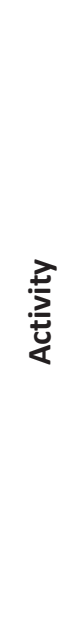 & 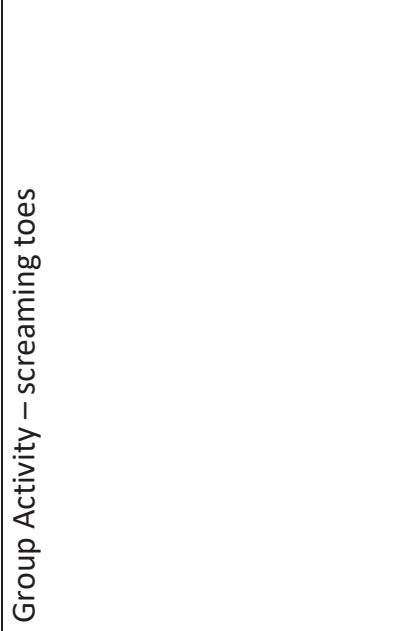 & 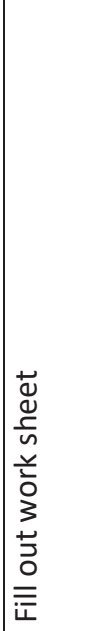 & 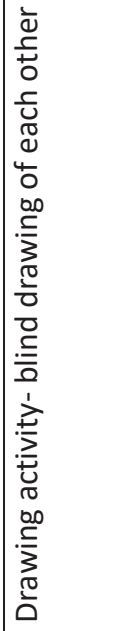 & & 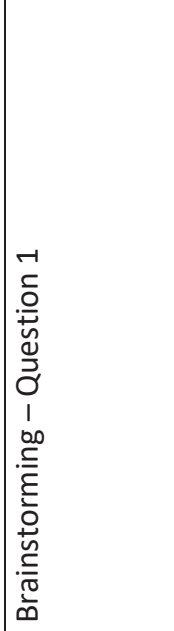 & 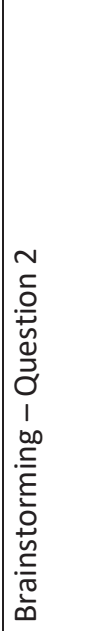 \\
\hline & $\dot{2} \frac{0}{2}$ & $\begin{array}{l}\text { 今a } \\
\text { 인 }\end{array}$ & 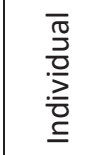 & & $N$ & $\begin{array}{l}\overline{\bar{\sigma}} \\
\text { 总 } \\
\text { 号 } \\
\end{array}$ & 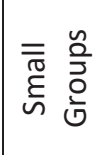 \\
\hline & $\stackrel{\mathscr{\Xi}}{\underline{\xi}}$ & $\stackrel{\vec{f}}{\vec{f}}$ & $\begin{array}{l}\hat{O} \\
\text { ri }\end{array}$ & & & $\begin{array}{l}\stackrel{\infty}{\rightarrow} \\
\dot{m}\end{array}$ & 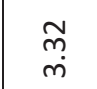 \\
\hline
\end{tabular}




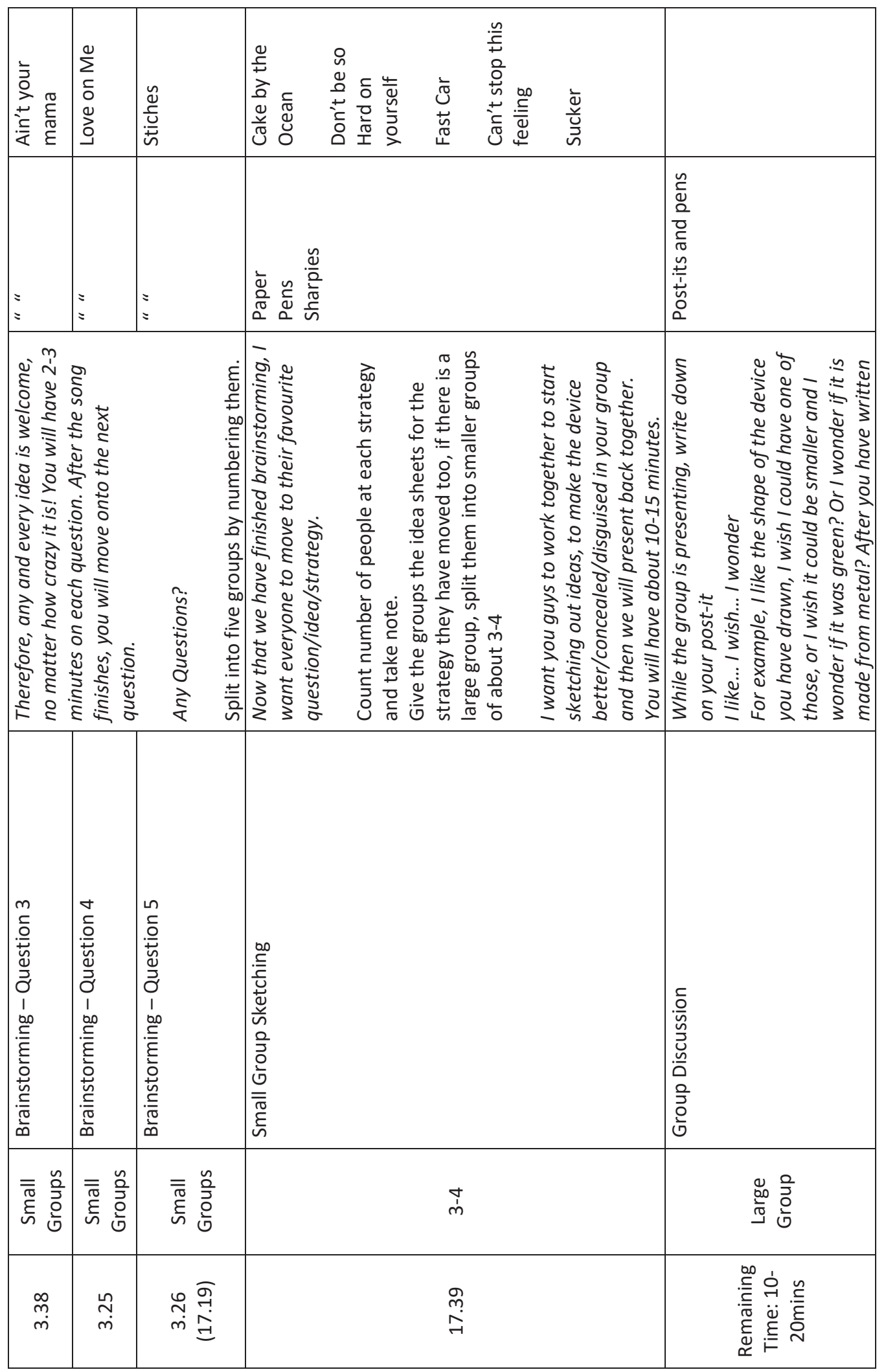




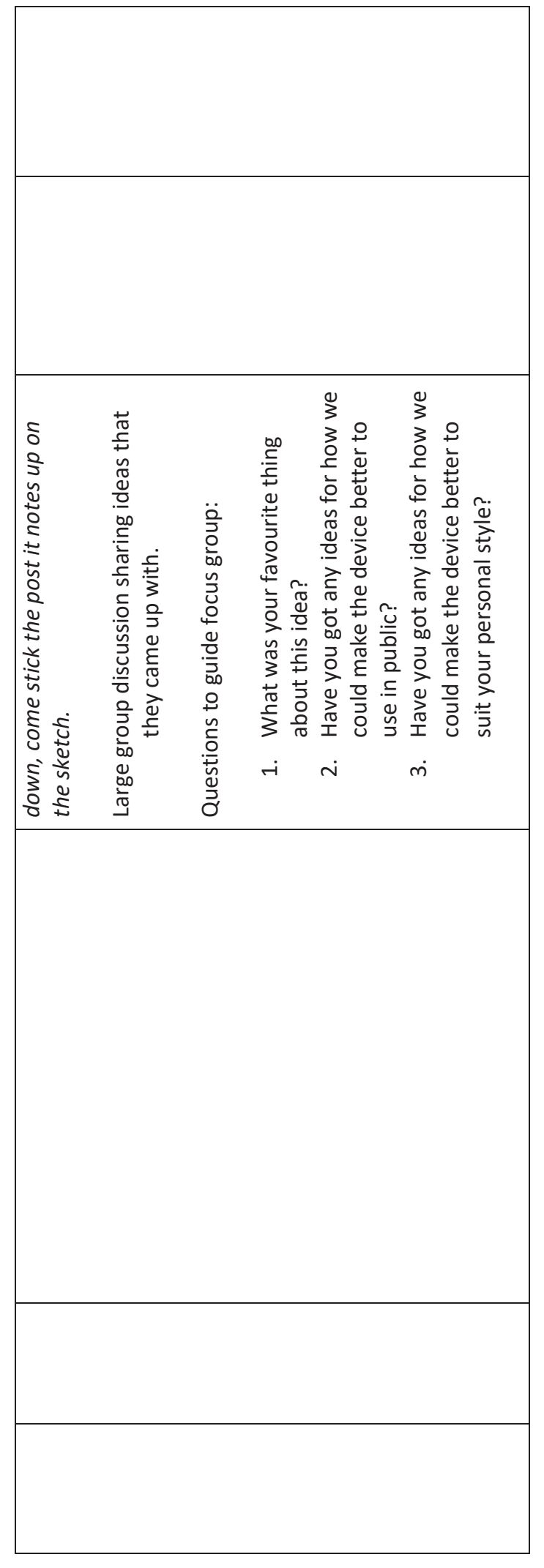

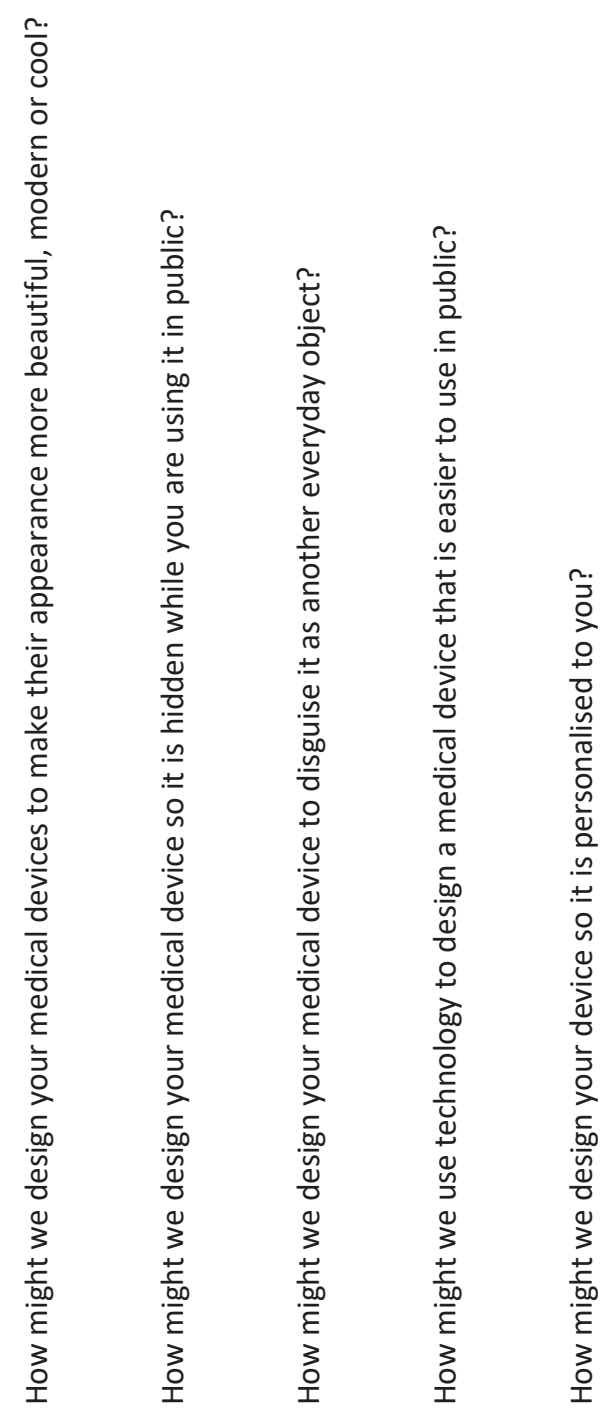


C. 

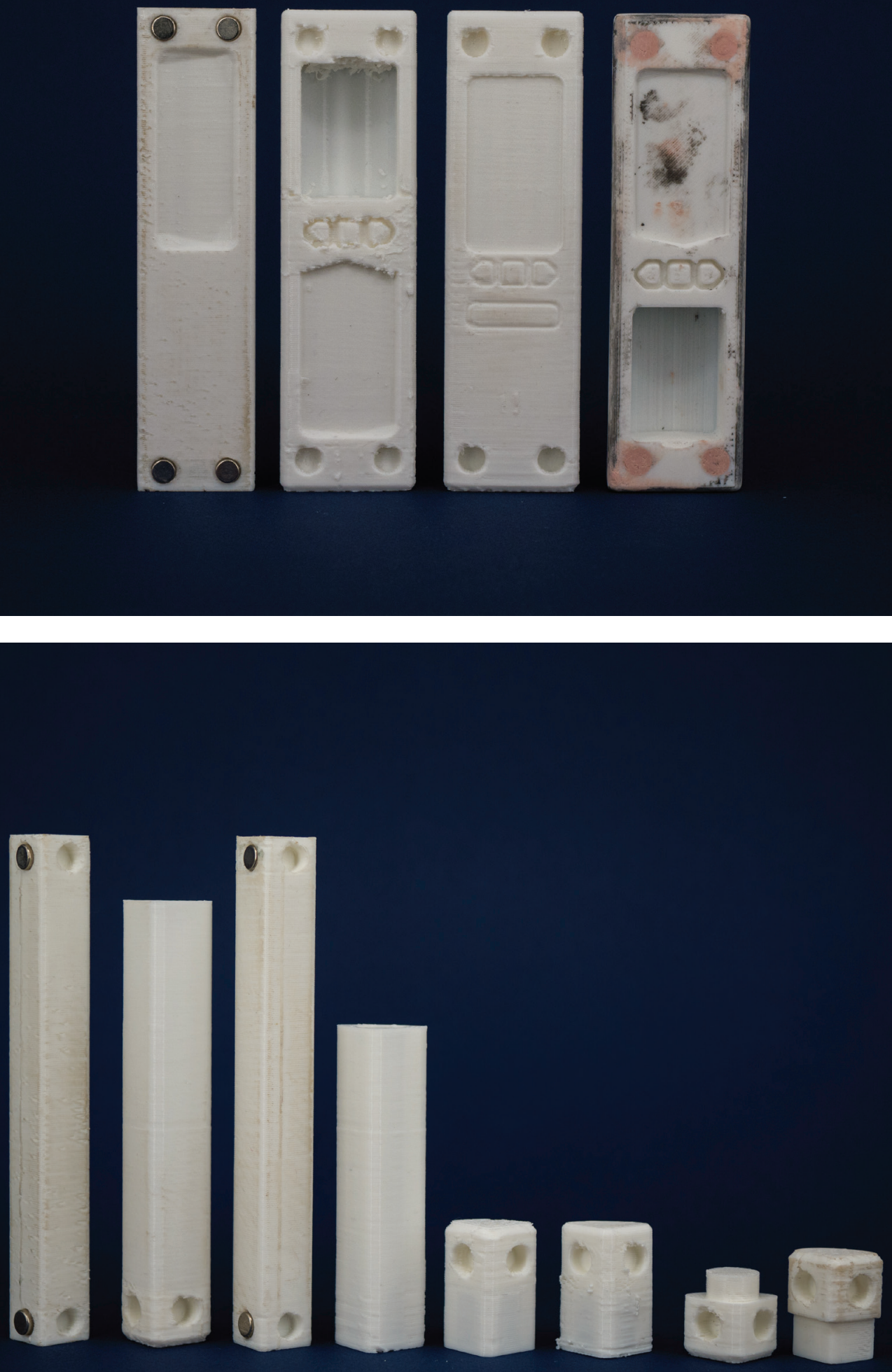

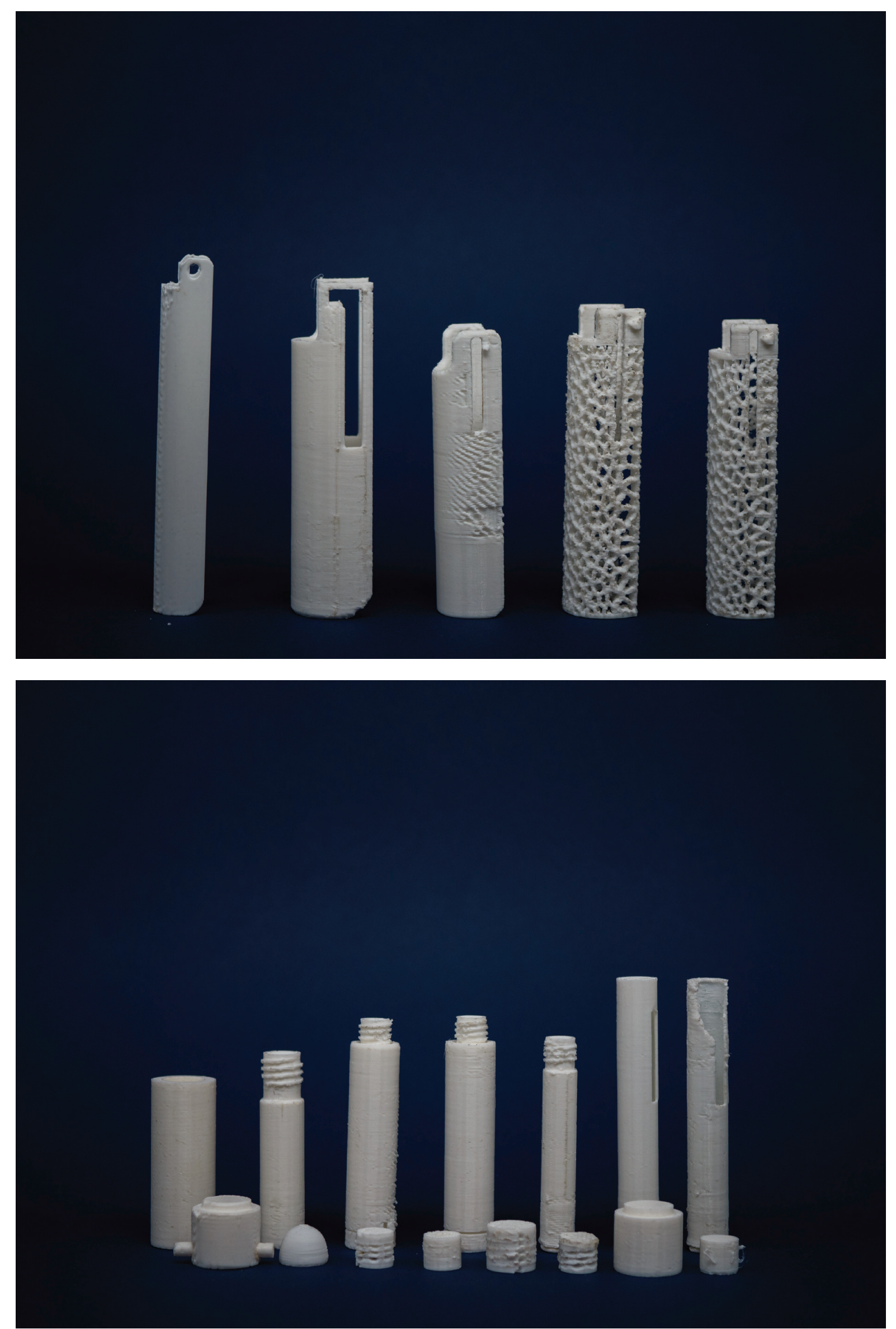